\title{
EVAPOTRANSPIRAÇÃO E TRANSPIRAÇÃO MÁXIMA EM CAFEZAL ADENSADO
}

\author{
FÁBIO RICARDO MARIN
}

Tese apresentada à Escola Superior de Agricultura "Luiz de Queiroz", Universidade de São Paulo, para obtenção do título de Doutor em Agronomia, Área de Concentração: Física do Ambiente Agrícola.

PIR A C I C A B A

Estado de São Paulo - Brasil

Junho - 2003 


\section{EVAPOTRANSPIRAÇÃO E TRANSPIRAÇÃO MÁXIMA EM CAFEZAL ADENSADO}

\section{FÁBIO RICARDO MARIN}

Engenheiro Agrônomo

Orientador: Prof. Dr. LUIZ ROBERTO ANGELOCCI

Tese apresentada à Escola Superior de Agricultura "Luiz de Queiroz", Universidade de São Paulo, para obtenção do título de Doutor em Agronomia, Área de Concentração: Física do Ambiente Agrícola.

P I R A C I C A B A

Estado de São Paulo - Brasil Junho - 2003 
Dados Internacionais de Catalogação na Publicação (CIP) DIVISÃO DE BIBLIOTECA E DOCUMENTAÇÃO - ESALQ/USP

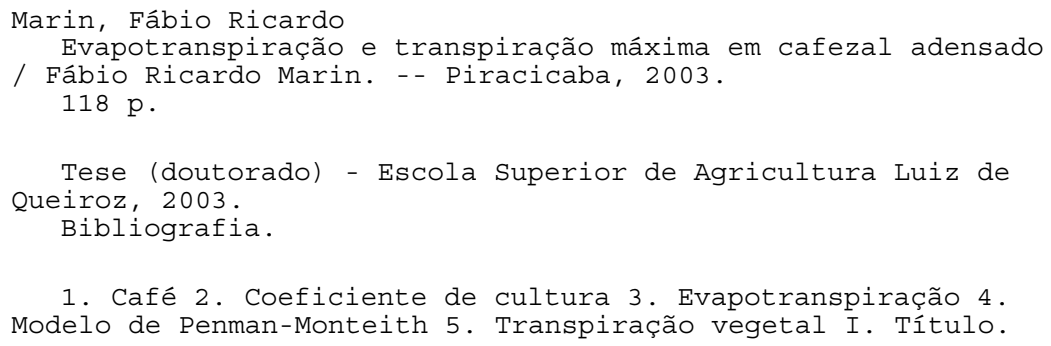

CDD 633.73

"Permitida a cópia total ou parcial deste documento, desde que citada a fonte - O autor" 
Aos meus pais, SÉRGIO e LUIZA,

OFEREÇO

À amada MICHELLE

e aos nossos filhos ANDRÉ E PEDRO,

DEDICO. 


\section{AGRADECIMENTOS}

Ao Professor Luiz Roberto Angelocci, pela orientação e ensinamentos transmitidos, pelo exemplo de conduta pessoal e profissional e pela amizade.

Ao Professor Paulo César Sentelhas, pelo apoio em todos os momentos, pela generosidade e pelos valiosos ensinamentos.

Ao Professor Ricardo Ferraz de Oliveira, pela cessão dos equipamentos para as medidas de campo e pelas demonstrações de confiança e amizade.

Ao Departamento de Produção Vegetal da ESALQ, na pessoa do Professor José Laércio Favarin pelo apoio no experimento de campo.

Ao amigo Evandro Righi pelo apoio durante todas as etapas deste trabalho, sem o qual sua conclusão teria sido muito mais difícil.

Aos amigos Alaílson Santiago, Jesus Ocariz e Héliton Pandorfi pelo apoio durante a fase experimental e pela amizade.

A bibliotecária Maria de Cléofas Faggion Alencar pelo apoio na organização das referências e revisão do texto.

A Escola Superior de Agricultura "Luiz de Queiroz", Universidade de São Paulo, por todas as oportunidades de crescimento pessoal e profissional oferecidas.

Ao Centro Nacional de Pesquisas de Monitoramento por Satélite, da Embrapa, pelo apoio concedido durante a fase de análise dos dados e redação do texto.

À Fundação de Amparo a Pesquisa do Estado de São Paulo, pela concessão da Bolsa de Estudos e pelo suporte financeiro para instalação e condução do experimento.

À minha esposa Michelle, por seu amor, que lhe fez paciente e compreensiva nos momentos mais difíceis, e pelo apoio irrestrito para a realização dessa importante etapa da minha vida.

A Deus, inteligência suprema e causa primária de todas as coisas. 
SUMÁRIO

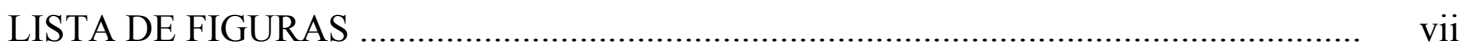

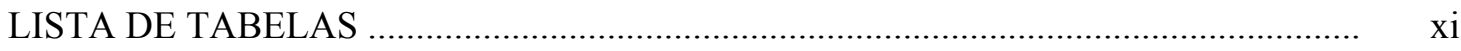

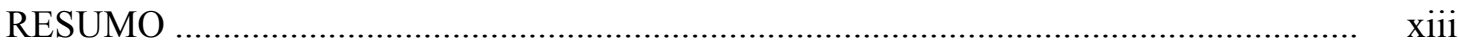

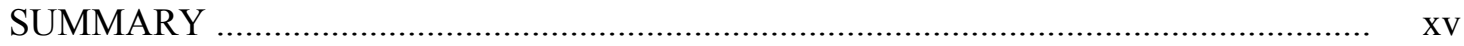

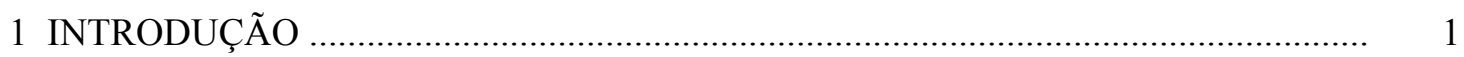

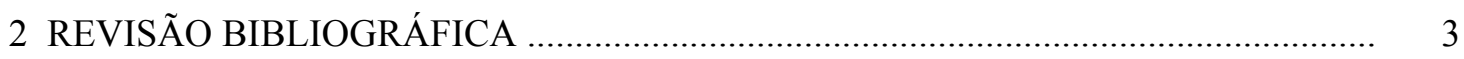

2.1 ASPECTOS ECOFISIOLÓGICOS DA CULTURA DO CAFEEIRO .......................... 3

2.2 EVAPOTRANPIRAÇÃO E TRANSPIRAÇÃO DE CAFEZAIS .................................. 6

2.3 ESTIMATIVA DA TRANSPIRAÇÃO MÁXIMA DE PLANTAS ISOLADAS COM

O MODELO DE PENMAN-MONTEITH ……......................................................... 9

2.4 DETERMINAÇÃO DAS VARIÁVEIS DO MODELO DE PENMAN-MONTEITH

PARA ESTIMATIVA DA TRANSPIRAÇÃO …........................................................ 11

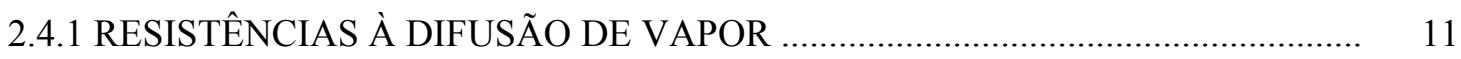

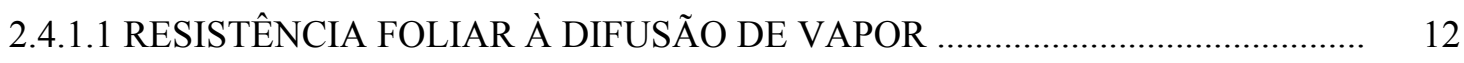

2.4.1.2 RESISTÊNCIA AERODINÂMICA …............................................................... 17

2.4.2 ABSORÇÃO DE ENERGIA RADIANTE PELA FOLHAGEM .............................. 20

2.5 MEDIDAS DE FLUXO DE SEIVA PELO MÉTODO DO BALANÇO DE CALOR . 22

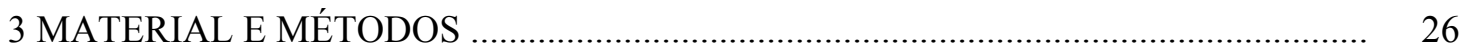

3.1 CARACTERIZAÇÃO DA ÁREA EXPERIMENTAL …........................................... 26

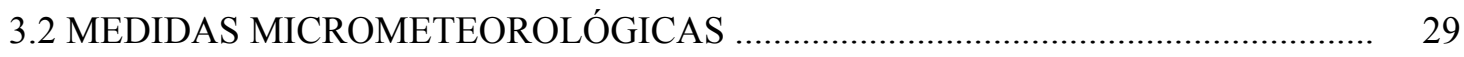

3.3 MEDIDAS DE FLUXO DE SEIVA ....................................................................... 30

3.4 MODELO DE PENMAN-MONTEITH ADAPTADO A PLANTAS ISOLADAS ...... 36

3.4.1 ENERGIA RADIANTE ABSORVIDA PELAS PLANTAS …............................... 37

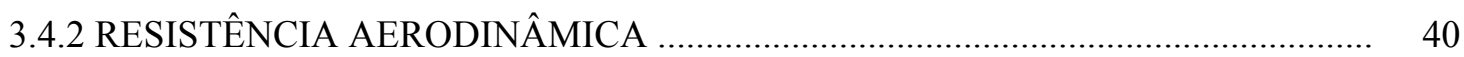

3.4.3 RESISTÊNCIA FOLIAR À DIFUSÃO DE VAPOR ........................................... 42 
3.5 ESTIMATIVA DA EVAPOTRANSPIRAÇÃO DO CAFEZAL PELO MÉTODO DA

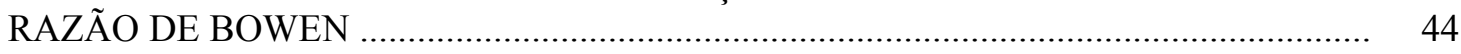

3.6 ESTIMATIVA DA EVAPOTRANSPIRAÇÃO DE REFERÊNCIA ............................. 46

4 RESULTADOS E DISCUSSÃO .............................................................................. 48

4.1 CONDIÇÕES MICROMETEOROLÓGICAS DURANTE A FASE EXPERIMENTAL 48

4.1.1 VELOCIDADE DO VENTO ................................................................................. 48

4.1.2 TEMPERATURA E UMIDADE DO AR .............................................................. 51

4.1.3 ENERGIA RADIANTE E BALANÇO DE RADIAÇÃO ………………………….... 55

4.2 AVALIAÇÃO DAS MEDIDAS DE FLUXO DE SEIVA …………………………..... 59

4.3 ESTIMATIVA DA TRANSPIRAÇÃO MÁXIMA DOS CAFEEIROS PELO

MODELO DE PENMAN-MONTEITH ......................................................................... 71

4.3.1 ANÁLISE E ESTIMATIVA DAS VARIÁVEIS DO MODELO DE PENMAN-

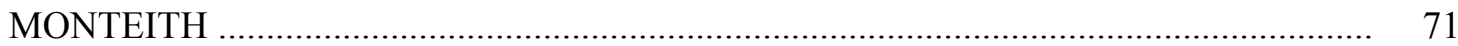

4.3.2 COMPARAÇÃO ENTRE O FLUXO DE SEIVA E A TRANSPIRAÇÃO MÁXIMA ESTIMADA PELO MODELO DE PENMAN-MONTEITH ………............................... 93

4.4 RELAÇÃO ENTRE A TRANSPIRAÇÃO DOS CAFEEIROS E A EVAPOTRANSPIRAÇÃO DE REFERÊNCIA E DO CAFEZAL …………………….... 97

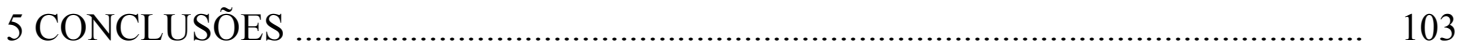

REFERÊNCIAS BIBLIOGRÁFICAS …………………………………………..... 105

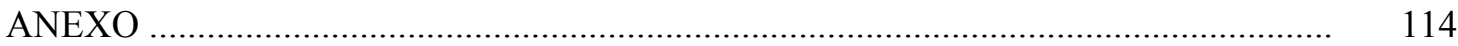




\section{LISTA DE FIGURAS}

1 Esquematização das fases fenológicas em ciclo bianual do cafeeiro arábica, para as condições climáticas do Brasil (extraído de Camargo \& Camargo, 2001)

2 Representação esquemática das resistências à difusão de vapor no caminho de fluxo entre a folha e o ar turbulento .

3 Esquema da associação das resistências à difusão de vapor na folha.

4 Componentes do balanço hídrico no cafezal. C/I é o volume de chuva e/ou irrigação aplicados na área, em L planta ${ }^{-1}$; ETm é a evapotranspiração máxima utilizando coeficiente de cultura igual a unidade, em L planta $^{-1}$; ARM é o armazenamento médio de água no solo, em L planta ${ }^{-1}$.

5 Extrato do balanço hídrico climatológico de Piracicaba, a partir de dados médios do período entre 1917 e 1999 considerando CAD de 100mm.

6 Vista do mastro com os sensores meteorológicos .

7 Representação esquemática da constituição do sensor de fluxo de seiva segundo Baker \& Van Bavel (1987)

8 Esquema de ligação dos sensores comerciais Dynamax, utilizando 4 canais analógicos diferenciais para sua ligação

9 Vista do sensor recoberto com camadas de papel alumínio e sem o cone de papel alumínio (A) e durante a aplicação da cola de silicone da parte superior do sensor (B).

10 Representação esquemática do sistema de medida da energia radiante absorvida pelos cafeeiros

11 Representação esquemática do sistema móvel para medida da energia radiante disponível para quatro cafeeiros no renque

12 Relação entre a área de 50 folhas de um cafeeiro e o produto entre o maior comprimento

(C) e a maior largura (L) de cada uma delas

13 Variação horária da velocidade do vento nas alturas 3,5m e 1,5m, no cafezal, e de $2 \mathrm{~m}$ na estação agrometeorológica da ESALQ, nos dia 244 e 296 de 2002, em Piracicaba, SP

14 Variação das médias diárias de velocidade do vento medida no cafezal em alturas de 1,5m (Café 1,5) e 3,5m (Café 3,5) e na estação agrometeorológica da ESALQ, a $2 \mathrm{~m}$ de altura (Estação), durante o período experimental, em Piracicaba, SP 
15 Correlações entre a velocidade média diária do vento medida na estação agrometeorológica (Vento Estação) e a velocidade do vento medida no cafezal nas alturas de 1,5m (Vento Café 1,5m) e 3,5m (Vento Café 3,5m), em Piracicaba, SP......

16 Correlação entre a velocidade média diária do vento medida no cafezal nas alturas de 1,5m (Vento Café 1,5m) e 3,5m (Vento Café 3,5m), em Piracicaba, SP

17 A) variação horária da temperatura do ar na estação agrometeorológica da ESALQ $\left(\operatorname{Tar}_{\text {esta }}\right)$ e no cafezal, nas alturas de $1,5 \mathrm{~m}(\operatorname{Tar} 1,5 \mathrm{~m})$ e 3,5m (Tar 3,5m); B) variação diária na temperatura média do ar nas duas alturas e na estação

18 Correlações entre a temperatura máxima (A) e mínima (B) medidas nas alturas de $1,5 \mathrm{~m}$ e 3,5m em cafezal, em Piracicaba, SP

19 A) variação horária da pressão atual de vapor para as alturas de 3,5m (ea 3,5m) e 1,5m (ea $1,5 \mathrm{~m}$ ) e na estação agrometeorológica da ESALQ (eaesta), para os dias 244 e 296 de 2002, em Piracicaba, SP. B) variação diária do déficit de pressão de vapor médio diário (DPV) nas três posições ao longo do experimento

20 Variação horária do fluxo de calor no solo medido em três posições do cafezal, ao longo de dois dias de 2002, em Piracicaba, SP. G1 - solo coberto com vegetação rasteira e sombreado pelos cafeeiros; G2 - solo nu sem sombreamento; G3 - solo com cobertura morta

21 Variação horária do saldo de radiação medido no cafezal (Rncafé) e sobre gramado e da radiação solar global para dois dias de 2002, em Piracicaba, SP .

22 Variação dos valores integrados para períodos diários do saldo de radiação medido sobre o cafezal (Rncafé), saldo de radiação medido sobre gramado (Rngrama), na estação agrometeorológica, e da radiação solar global (RG) durante a fase experimental, em Piracicaba, SP .

23 Relação entre os valores de radiação solar global (RG) e saldo de radiação no cafezal (Rncafé) e o saldo de radiação medido sobre gramado (Rngrama), na estação agrometeorológica da ESALQ, em Piracicaba, SP

24 Variação do fluxo de seiva diário de quatro cafeeiros e do saldo de radiação medido sobre do cafezal e integrado para períodos diários (Rncafé)

25 Correlação linear entre os valores de fluxo de seiva dos quatro cafeeiros e o saldo de radiação medido sobre o cafezal (Rncafé) (A) e correlação entre os valores de fluxo de seiva por unidade de área foliar e Rncafé (B)

26 Correlação logarítmica entre os valores médios de fluxo de seiva de quatro plantas (FS) dos quatro cafeeiros e o saldo de radiação medido sobre o cafezal (Rncafé), integrado para o período diário

27 Correlação linear entre os valores de fluxo de seiva (FS) e de saldo de radiação medido sobre o cafezal para as quatro plantas consideradas isoladamente $(\mathrm{P})$

28 Variação do fluxo axial (Qv) e radial (Qr) de energia térmica nos sensores de fluxo de seiva das quatro plantas nos dias 245 e 301

29 Variação horária da diferença de temperatura entre a extremidade superior e inferior (dT) do sensor de fluxo de seiva e do saldo de radiação medido sobre o cafezal (Rncafé) durante três dias, para a planta 1 
30 Variação horária da diferença de temperatura entre a extremidade superior e inferior (dT) do sensor de fluxo de seiva e do saldo de radiação medido sobre o cafezal (Rncafé) durante três dias, para a planta 2 .....

31 Variação horária da diferença de temperatura entre a extremidade superior e inferior (dT) do sensor de fluxo de seiva e do saldo de radiação medido sobre o cafezal (Rncafé) durante três dias, para a planta 3

32 Variação horária da diferença de temperatura entre a extremidade superior e inferior (dT) do sensor de fluxo de seiva e do saldo de radiação medido sobre o cafezal (Rncafé) durante três dias, para a planta 4

33 Variação diurna da resistência foliar estimada com a metodologia proposta e da medida com o porômetro em pomar de lima ácida "Tahiti" em Piracicaba, SP.

34 Variação diurna da condutância foliar estimada com a metodologia proposta e medida com o porômetro em cafeeiro adulto em Piracicaba, SP

35 Relação entre os valores estimados e medidos de condutância foliar (gf) (A) e de resistência foliar à difusão de vapor (rf) (B)

36 Relação entre os valores de resistência aerodinâmica estimada com o modelo de Landsberg \& Powell (1973) e a velocidade do vento a 1,5m, para as quatro plantas estudadas.

37 Relação entre a velocidade do vento medida a $3,5 \mathrm{~m}$ e a resistência aerodinâmica do cafezal estimado pelo método dos perfis logarítmicos

38 Variação diurna da resistência aerodinâmica determinada pelo método de Landsberg \& Powell (ra) da planta $2\left(\mathrm{AF}=13,9 \mathrm{~m}^{2}\right)$, da resistência foliar à difusão de vapor (rf) determinada pela equação (25) e da razão entre elas (rf/ra), para o dia 234 .

39 Relação da área foliar com o coeficiente angular das equações de regressão entre a resistência aerodinâmica estimada com o modelo de Landsberg \& Powell (1973) e a velocidade do vento na altura média das copas dos cafeeiros

40 Variação do desvio do zero nas medidas de saldo de radiação sem a planta no interior do sistema, para intervalos de 10 minutos durante três dias, em Piracicaba, SP

41 Variação horária do desvio do zero nas medidas de saldo de radiação a sem planta no interior do sistema (DRn) e do saldo de radiação medido sobre gramado (Rngrama), em Piracicaba, SP

42 Evolução horária das medidas dos oito saldo-radiômetros do sistema móvel

43 Correlação da energia radiante total absorvida por quatro plantas (A), e da energia radiante absorvida por unidade de área foliar (B) com a irradiância solar global. Dados obtidos em intervalos de 15 minutos

44 Correlação da energia radiante total absorvida por quatro plantas (A), e da energia radiante absorvida por unidade de área foliar (B) com o saldo de radiação medido sobre gramado. Dados obtidos em intervalos de 15 minutos

45 Correlação da energia radiante total absorvida por quatro plantas (A), e da energia radiante absorvida por unidade de área foliar (B) com o saldo de radiação medido sobre o cafezal. Dados obtidos em intervalos de 15 minutos 
46 Variação horária diurna do coeficiente médio de extinção durante 10 dias de medida,

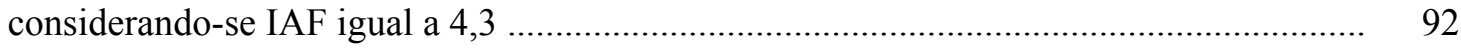

47 Correlação entre os valores de energia radiante absorvida pelas quatro plantas, medido pelo sistema móvel (Rnf) e os valores estimados a partir da adaptação da lei de Beer (Rnfb). Dados medidos a cada 15 minutos

48 Relação entre a transpiração máxima de quatro cafeeiros estimada com o modelo de Penman-Monteith (Transpiração PM) e as medidas de fluxo de seiva (FS) .

49 Correlação entre a transpiração máxima estimada para um cafeeiro hipotético com área foliar igual à soma da área foliar dos quatro cafeeiros e a soma do fluxo de seiva medido nos quatro cafeeiros

50 Relação entre a transpiração dos cafeeiros $\left(T_{\text {total }}\right)$ e a evapotranspiração cafezal ( $\left.E T_{\text {total }}\right)$, considerando toda a área do cafezal, em dois períodos subseqüentes. No segundo período a vegetação intercalar estava presente e ativa

51 Variação da evapotranspiração total do cafezal $\left(\mathrm{ET}_{\text {tota }} \mathrm{l}\right)$ e da transpiração total $\left(\mathrm{T}_{\text {tota }} \mathrm{l}\right)$ ao longo do período experimental

52 Relação entre a transpiração total do cafezal (Ttotal) e a evapotranspiração total (ETtotal) com a evapotranspiração de referência extrapolada para a área total do cafezal $\left(\mathrm{ETo}_{\text {total }}\right)$. 


\section{LISTA DE TABELAS}

1 Diâmetro, perímetro e área da seção reta do caule das plantas na posição de instalação dos sensores de fluxo de seiva, com as especificações do modelo utilizado e da resistência elétrica, nas duas datas de instalação.

2 Valores medidos de área foliar (AF) com analisador de dossel (LAI 2000) e pela contagem e medição das folhas $\left(\mathrm{af}_{\mathrm{m}}{ }^{*} \mathrm{C}^{*} \mathrm{~L}\right)$, índice de área foliar (IAF) e da razão entre $\mathrm{AF}$ e a área da silhueta (p) de quatro cafeeiros. O índice de área foliar foi determinado com base na área projetada de copa sobre o solo.

3 Valores médios diurnos da condutância foliar à difusão de vapor (gf), do desvio padrão (DP) e do coeficiente de variação (CV) para os cinco dias de medida em cafeeiro.

4 Estatística descritiva, com média, desvio padrão e coeficiente de variação (C.V.) da condutância foliar a difusão de vapor (gf) e da transpiração foliar (T) medidas com porômetro, agrupando-se os dados em três níveis de radiação fotossinteticamente ativa (PAR) e duas classes de idade das folhas. 


\title{
EVAPOTRANSPIRAÇÃO E TRANSPIRAÇÃO MÁXIMA EM CAFEZAL ADENSADO
}

\author{
Autor: FÁBIO RICARDO MARIN \\ Orientador: Prof. Dr. LUIZ ROBERTO ANGELOCCI
}

\section{RESUMO}

O cafeeiro arábica é extensamente cultivado em regiões tropicais, sendo cultura de grande importância econômica para o Brasil. Atualmente, ele é cultivado em áreas com deficiência hídrica, para as quais a irrigação suplementar é necessária para aumentar a produtividade e a qualidade da bebida. $\mathrm{O}$ aumento da eficiência da prática irrigacionista exige em primeiro lugar informação sobre o consumo hídrico do cafezal. Tendo em vista a falta de informações sobre esse consumo e, também, o fato de que os plantios adensados têm tido grande avanço no país, o presente estudo foi realizado com a finalidade de determinar a evapotranspiração de um cafezal Mundo Novo Apuatã e sua partição em transpiração dos cafeeiros e evapotranspiração da entrelinha. O cafezal, localizado em Piracicaba/SP, tinha plantio adensado (2500plantas/ha) e era irrigado por gotejamento. A evapotranspiração do cafezal foi determinada pelo método da razão de Bowen, enquanto que a transpiração foi estimada pelo modelo de Penman-Monteith adaptado, sendo este comparado com medidas de fluxo de seiva pelo método do balanço de calor no caule. Nessa confrontação, verificou-se razoável concordância entre a transpiração diária pelo modelo e o fluxo de seiva, havendo discordância em duas da quatro plantas avaliadas, provavelmente devido à forma de determinação da energia radiante absorvida pelas plantas e à relação entre esta e a área foliar dos cafeeiros, bem como aos erros introduzidos pela estimativa da condutância foliar à difusão de vapor. Observou-se que a transpiração dos cafeeiros representou $90 \%$ da evapotranspiração 
do cafezal no período em que a entrelinha da cultura tinha solo sem vegetação viva e $69 \%$ no período subseqüente, quando a entrelinha tinha vegetação desenvolvida. Com a separação da evapotranspiração em seus dois componentes, foi possível determinar que o coeficiente basal foi igual a 0,8 e que o coeficiente evaporativo igual 0,2 , com um coeficiente de cultura global próximo da unidade. 


\title{
EVAPOTRANSPIRATION AND MAXIMUM TRANSPIRATION IN A HIGH DENSITY COFFEE PLANTATION
}

\author{
Author: FÁBIO RICARDO MARIN \\ Adviser: Prof. Dr. LUIZ ROBERTO ANGELOCCI
}

\section{SUMMARY}

Coffee arabica plants are extensively cultivated in tropical regions and it is a crop of great economic importance for Brazil. Currently, it is cultivated in areas with water deficits for which the irrigation is necessary to increase yields and drink quality. To increase irrigation efficiency one needs to know the water consumption of coffee plantation, information that is not easyly get specially in high density coffee plantations. The present study was carried out in order to determine the evapotranspiration of a coffee plantation Novo Mundo Apuatã and its partition in transpiration of coffee plants and interrow evapotranspiration. The coffee plantarion had a high density (2500 plants/ha) and drip irrigation. Evapotranspiration of coffee plantation was determined by Bowen ratio method, while transpiration was obtained by Penman-Monteith model, where this last one was compared with sap flow measures by heat balance method in stem. The comparison showed reasonable agreement between daily transpiration by model and sap flow data, with major disagreement in two of four evaluated plants wich was probably due to technique of determination of radiant energy absorbed by coffee plants. Moreover, the relation between the amount of absorbed radiant energy and leaf area of plants seems to contribute to discrepances between sap flow and estimated transpiration. The leaf resistance also introduced some error in estimated transpiration by Penman-Monteith model. It was verified that coffee plants transpiration represented $90 \%$ of total evapotranspiration of coffee plantation in the period when interrows had no living vegetation. In the subsequent period, 
when vegetation was developed, transpiration decrease to $69 \%$ of total evapotranspiration. Dividing evapotranspiration in its two components, it was determined that basal crop coefficient and evaporative coefficient were equal to 0,8 and 0,2 , respectively, with a global crop coefficient next to unit. 


\section{INTRODUÇÃO}

Desde sua introdução no país, a cultura do café figura como um dos principais suportes da economia agrícola brasileira, atuando como importante fonte de renda do setor rural por seu alto valor agregado, por ser produto de exportação e por possuir elevada demanda no mercado interno.

Atualmente, com sua expansão para regiões que possibilitam a obtenção de bebidas com qualidade superio e rendimentos economicamente mais interessantes, a cafeicultura passa a ser cada vez mais dependente da suplementação hídrica. Essas regiões, em grande parte, são afetadas por condições climáticas que prejudicam o desenvolvimento e a produção do cafeeiro, sobretudo pela ocorrência de deficiência hídrica severa em fases fenológicas críticas da planta, tornando altamente interessante o uso da irrigação. Além disso, mesmo em regiões onde os déficits hídricos são menos severos, o manejo adequado da irrigação vem possibilitando uma melhor condução dos cafezais, garantindo floradas e frutificações vigorosas, reduzindo o estresse fisiológico das plantas e possibilitando a aplicação de insumos via água de irrigação.

Entretanto, para que a aplicação de água seja eficiente, é fundamental o conhecimento adequado da demanda hídrica da cultura, que, por sua vez, é regulada por suas características biológicas e pelo clima da região. Diversos trabalhos de pesquisa têm sido realizados com o intuito de modelá-la com base nos elementos meteorológicos e em parâmetros biométricos, obtendo-se meios práticos e eficientes de determinar o consumo hídrico das plantas a partir de medidas relativamente simples. Esses trabalhos têm alcançado resultados expressivos para culturas anuais, mas no caso de culturas perenes, são ainda incipientes.

No caso de cafezais, estudos dessa natureza são complicados pelas peculiaridades micrometeorológicas introduzidas pela configuração geométrica de plantio, principalmente quanto à interceptação da radiação, ao regime de ventos e ao aproveitamento da água do solo. Adicionalmente, um aspecto que deve ser mencionado em estudos neste tipo de cobertura é a 
partição da evapotranspiração em seus componentes, a transpiração e a evapotranspiração da entrelinha, como base para um manejo mais adequado da irrigação.

A determinação da transpiração dos cafeeiros pode ser feita com medidas de fluxo de seiva, baseadas em métodos de fornecimento de calor no caule, e também a partir de estimativas com modelo de Penman-Monteith. O método do balanço de calor é uma técnica que tem apresentado bons resultados na medida do consumo hídrico de plantas lenhosas, desde que sejam tomadas certas precauções para evitar os erros de medida. Já o modelo de Penman-Monteith pode, teoricamente, ser aplicado para qualquer tipo de vegetação, desde que as suas variáveis de entrada sejam adaptadas especificamente para cada cultura e a escala de interesse. A estimativa da evapotranspiração pode ser feita com o método da razão de Bowen, que permite fornece bons resultados e tem aplicação relativamente simples em comparação com os métodos alternativos.

Além do conhecimento produzido a partir do estudo de cada uma dessas técnicas, relacionando-as com a evapotranspiração de referência pode-se determinar o valor do coeficiente de cultura do cafezal $(\mathrm{Kc})$, uma informação de grande utilidade prática no manejo da irrigação da cultura. Mais recente, o conceito de Kc foi ampliado com vistas a melhorar o manejo da irrigação em culturas com cobertura descontínua do terreno, como ocorre num cafezal, sendo dividido num componente referente à transpiração da cultura (coeficiente basal), e outro referente a evapotranspiração da entrelinha (coeficiente evaporativo).

Levando em conta esses aspectos e a necessidade de informações sobre o consumo hídrico de cafezais, o presente trabalho teve o objetivo de adaptar e verificar o desempenho do modelo de Penman-Monteith para a estimativa da transpiração máxima de cafeeiros em cafezal adensado, comparando seus resultados com medidas de fluxo de seiva, e estudar a evapotranspiração total do cafezal sob duas condições de cobertura do solo da entrelinha, verificando-se a partição dessa evapotranspiração nos seus dois componentes (transpiração dos cafeeiros e evapotranspiração das entrelinhas), determinando-se os valores do coeficiente de cultura basal e o evaporativo. 


\section{REVISÃO BIBLIOGRÁFICA}

\subsection{ASPECTOS ECOFISIOLÓGICOS DA CULTURA DO CAFEEIRO}

As plantações comerciais de café são distribuídas desde o Havaí $\left(20\right.$ a $\left.25^{\circ} \mathrm{N}\right)$, passando por Cuba $\left(22^{\circ} \mathrm{N}\right)$ até o Estado no Paraná (22 a $\left.23^{\circ} \mathrm{S}\right)$. Os cafeeiros são plantas sempre verdes, com folhas formadas ao longo de todo o ano, dependendo das condições de umidade do solo e temperatura do ar (Carr, 2001).

A região de origem da espécie Coffea arábica L. tem temperaturas variando entre $15^{\circ} \mathrm{C}$ e $20^{\circ} \mathrm{C}$ e ambientes sombreados no sub-bosque de florestas dos planaltos da Etiópia, com altitudes entre $1600 \mathrm{~m}$ e $2000 \mathrm{~m}$ e uma única estação de seca que dura cerca de três meses (Carr, 2001). Segundo Cannel (1985), as respostas fisiológicas ao ambiente, especialmente aquelas relacionadas com a água, podem ser mais bem entendidas a partir do conhecimento das condições de origem do café, postulando que as características fotossintéticas dos cafeeiros são típicas de espécies adaptadas à condição de sombra.

As folhas sombreadas são mais eficientes na assimilação de $\mathrm{CO}_{2}$ que as folhas expostas ao sol, devido ao fato da radiação solar em ambientes tropicais atingir facilmente 3 a 5 vezes o limite de saturação luminosa, podendo a temperatura foliar superar de $5^{\circ} \mathrm{C}$ a $20^{\circ} \mathrm{C}$ a faixa de temperatura ótima, o que pode causar danos físicos ao tecido foliar. Os estudos de Nutman (1941), Hernandez et al. (1989) e Marin et al. (2003) reforçaram esta hipótese a partir de medidas de transpiração, mostrando que, mesmo reduzindo-se consideravelmente o total de energia radiante disponível às plantas, a transpiração sofreu redução de cerca de $10 \%$, em comparação com plantas não sombreadas.

Hernandes et al. (1989) estudaram também as respostas da condutância foliar à difusão de vapor em função da umidade do ar e concluíram que a espécie Coffea arabica tem sua regulação estomática fortemente afetada pelo déficit de pressão de vapor do ar. Os autores 
inferem também que a manutenção de lavouras de café sombreadas com baixos níveis de uso de insumos é uma forma sustentável de cultivo, principalmente pela redução expressiva do déficit de pressão de vapor do ar e também pela maior longevidade dos cafezais neste sistema. Jaramillo-Robledo (1994) avaliou as condições micrometeorológicas de um cultivo adensado de café, verificando valores de temperatura de folhas expostas de até $10^{\circ} \mathrm{C}$ acima da temperatura do ar, com valores médios nos horários mais quentes por volta de $2,5^{\circ} \mathrm{C}$. Marur et al. (2001) avaliaram as taxas de assimilação de $\mathrm{CO}_{2}$ em três diferentes espaçamentos de plantio e concluíram que o espaçamento de $2,0 \mathrm{~m}$ por $0,5 \mathrm{~m}$ apresentou maiores taxas fotossintéticas que os espaçamentos de $3,0 \mathrm{~m}$ por $0,3 \mathrm{~m}$ e $1,5 \mathrm{~m}$ por $0,7 \mathrm{~m}$, com maior produção de biomassa que os demais.

Uma característica ecofisiológica muito interessante do café arábica é o fato dele necessitar de dois anos para a conclusão de seu ciclo reprodutivo. Uma importante contribuição para a definição e esquematização das fases fenológicas do cafeeiro, levando em conta esse aspecto, é o trabalho de Camargo \& Camargo (2001), com a proposição de um método de previsão do ciclo fenológico das variedades Catuaí e Mundo Novo, baseado na evapotranspiração potencial acumulada em determinadas fases de seu ciclo (Figura 1). Vale destacar que o método para estimativa da evapotranspiração utilizado pelos autores foi o de Thornthwaite (1948) e, isso implica no fato de que, ainda que de forma indireta, essa escala fenológica é baseada na soma térmica das plantas, algo próximo do conceito de graus-dia. Uma constatação interessante dos autores foi que a maturação das gemas e a florada principal ocorrem quando a evapotranspiração potencial acumulada desde o mês de abril atinge os $350 \mathrm{~mm}$, de modo que, para as condições do planalto paulista, o florescimento dos cafezais ocorre entre setembro e início de outubro. 


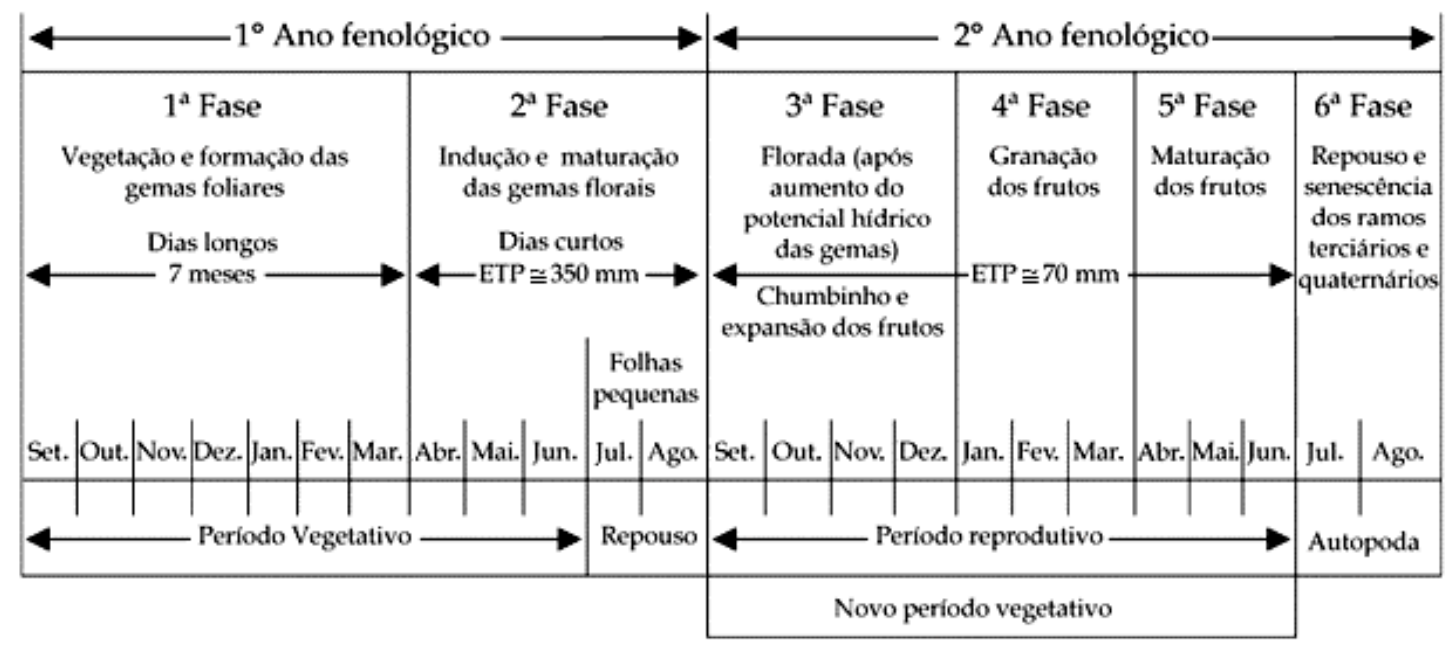

Figura 1 - Esquematização das fases fenológicas em ciclo bianual do cafeeiro arábica, para as condições climáticas do Brasil (extraído de Camargo \& Camargo, 2001).

Os estudos sobre o consumo hídrico de cafeeiros têm grande aplicação na agricultura por subsidiar tecnicamente a irrigação. No Estado de São Paulo, e nas regiões cultivadas com café nos estados de Minas Gerais, Bahia e Espírito Santo, principais produtores nacionais, é comum a ocorrência de deficiências hídricas em fases em que a cultura é sensível e, ainda mais comum, é a ocorrência de veranicos em fases importantíssimas do ciclo reprodutivo da planta (Matiello, 1991). Por isso, são também freqüentes as quebras de safras devidas à ausência de suplementação hídrica nessas ocasiões, levando a prejuízos econômicos e ocasionando algum estresse fisiológico da planta (Boyer, 1969). Por outro lado, o efeito positivo da irrigação sobre o crescimento vegetativo e a produção do cafeeiro, bem como sua qualidade, é bem documentado na literatura, podendo-se utilizá-la ainda como uma técnica condicionante do florescimento e, portanto, da época de colheita (Camargo \& Pereira, 1994).

Um aspecto importante a se considerar em estudos envolvendo cafezais é a forma como as plantas são agrupadas, formando contínuos vegetados conhecidos como renques, principalmente nos plantios modernos com espaçamentos reduzidos (plantios adensados), e áreas com solo e vegetação de entrelinha exposto. Essa peculiaridade possibilita tanto enfocar esses renques de forma isolada do restante da cobertura, estudando individualmente sua relação com os elementos micrometeorológicos, como estudar a partição da evapotranspiração em evaporação e transpiração. Esta é uma informação fundamental para o manejo da irrigação, especialmente quando métodos de aplicação localizada de água são utilizados. 
Rena \& Maestri (1987) fizeram algumas considerações sobre as implicações do adensamento dos cafezais, já que esta não era uma prática comumente utilizada até os anos 80 . Os autores propõem que populações de 5000 plantas ha ${ }^{-1}$ estariam próximas do ideal, especialmente para cultivos de pequeno porte em solos de baixa fertilidade. Sobre o consumo hídrico desse sistema de plantio, os autores inferem que não seria esperado um agravamento do estresse hídrico das plantas, devido a adaptação das plantas à maior competição intra-específica. Essa adaptação está ligada tanto ao aprofundamento das raízes em busca de água e nutrientes, como também à redução da temperatura foliar e do solo. Pode-se incluir nessa análise a diminuição da rugosidade do cultivo adensado em relação ao convencional como um fator para a minimização das trocas gasosas entre as plantas e a atmosfera, reduzindo, portanto os valores de déficit de pressão de vapor do ar. Além disso, deve-se considerar as diferenças de área foliar entre os dois sistemas, o que leva a concluir que o adensamento gera uma elevação no consumo de água por unidade de área de terreno, a despeito das alterações micrometeorológicas, sem que isso implique em estresse por deficiência hídrica nesse sistema de cultivo.

\subsection{EVAPOTRANPIRAÇÃO E TRANSPIRAÇÃO DE CAFEZAIS}

As medidas de transpiração em cafeeiros foram iniciadas na África, por Nutman (1941), que estudou as relações ecofisiológicas de cafeeiros a partir da década de 30 (Nutman, 1933a, 1933b, 1934, 1937). Em seu trabalho sobre transpiração, ele utilizou um engenhoso equipamento para medida e registro contínuo da transpiração a intervalos de 5 minutos, além da temperatura do ar, déficit de saturação de vapor e radiação solar global, demonstrando que a taxa de transpiração dos cafeeiros é influenciada principalmente pela radiação solar e pelo déficit de saturação de vapor.

No Brasil, um trabalho de grande importância nessa linha foi o de Franco \& Inforzato (1950), que mediram a transpiração de cafeeiros cultivados em vasos, estabelecendo comparações com o volume de chuva precipitado, no intuito de aplicar o conhecimento obtido à prática da irrigação. Os dados obtidos no estudo são muito próximos daqueles medidos por Nutman (1941), com taxas de transpiração variando de 0,45 a $0,65 \mathrm{~L} \mathrm{~m}^{-2}$ de folha nos dois trabalhos. Nesse sentido, é interessante destacar que tanto Gutiérrez \& Meinzer (1994a) como Marin et al. (2003), utilizando o método do balanço de calor para a medida do fluxo de seiva, 
encontraram valores oscilando entre 0,30 e $0,50 \mathrm{~L} \mathrm{~m}^{-2}$ de folha, que são próximos daqueles obtidos por Nutman (1941) e Franco \& Inforzato (1950) há mais de 50 anos.

No trabalho de Nutman (1941), foram publicados dados de radiação solar global medidos simultaneamente às determinações de transpiração, permitindo o estabelecimento da razão entre a taxa de transpiração e a energia radiante. A razão entre transpiração por unidade de área foliar e a irradiância solar global foi igual a $0,018 \mathrm{~L} \mathrm{MJ}^{-1}$. Analisando-se os dados de Gutiérrez \& Meinzer (1994) com esse mesmo enfoque, obtém-se um valor para essa razão de $0,035 \mathrm{~L} \mathrm{MJ}^{-1}$ para plantas com área foliar variando de $3,7 \mathrm{~m}^{2}$ até $15,5 \mathrm{~m}^{2}$. Já com os dados de Marin et al. (2003), obtém-se valores entre $0,04 \mathrm{~L} \mathrm{MJ}^{-1}$, para dias com elevada incidência de radiação solar, até $0,11 \mathrm{~L} \mathrm{MJ}^{-1}$, para dias com nebulosidade e baixos valores de saldo de radiação.

Um dos principais métodos micrometeorológicos para determinação da evapotranspiração em culturas é o método da razão de Bowen (MRB) e por isso, faz-se um breve apanhado sobre suas características e principais aplicações. O uso do MRB para a estimativa da evapotranspiração teve início com o método da razão de Bowen (Bowen, 1926), seguindo os estudos de Schmidt (1915). Sua aplicação na agrometeorologia vai de desde a determinação do balanço energético em áreas ou culturas de interesse (Prueger et al., 1998), passando pela determinação da perda de água (Malek et al., 1990) e de coeficientes de cultura (Malek \& Bingham, 1993) até o estudo de relações hídricas em plantas (Grantz \& Meinzer, 1991).

O histórico dos principais estudos envolvidos no desenvolvimento do método foi abordado por Villa Nova (1973), que prestou valiosa contribuição para essa linha de pesquisa, especialmente quanto à metodologia e equipamentos utilizados. Um dos pressupostos básicos para o emprego do método da razão de Bowen (MRB) é considerar igual à unidade a razão entre os coeficientes de difusividade turbulenta de calor sensível $(\mathrm{Kh})$ e de calor latente $(\mathrm{Ke})$, o que permite simplificar a determinação da razão de Bowen e os fluxos de calor latente e sensível da superfície, utilizando apenas medidas de um perfil de temperatura do bulbo seco e bulbo úmido. Atualmente, são bem conhecidas as limitações e as vantagens do MRB e é extensa a relação de trabalhos realizados com o intuito de avaliá-lo, especialmente para culturas anuais (Tanner, 1960; Fuchs \& Tanner, 1970; Angus \& Watts, 1984; Heilman \& Brittin, 1989; Grantz \& Meinzer, 1990; Steduto \& Hsiao, 1998).

Em seu trabalho, Daamen et al. (1999) deu uma importante contribuição ao estudo da evapotranspiração em culturas com cobertura esparsa do terreno. Esses autores estudaram os fluxos de água e energia em pomar de citros irrigado na Nova Zelândia, medindo a 
evapotranspiração em duas alturas do pomar, visando a determinar a contribuição da entrelinha e das árvores para a evapotranspiração total da área. Além disso, os autores verificaram boa correlação entre a os fluxos medidos a oito metros de altura e a soma dos componentes da evapotranspiração, obtidos com medidas de fluxo de seiva pelo método do balanço de calor, referente a transpiração dos limoeiros, e com o MRB medido abaixo do nível médio das copas, referente à evapotranspiração da entrelinha. Nesse trabalho, os autores também comparam o MRB com o método da correlação de turbilhões, verificando diferenças expressivas entre os métodos nas medidas feitas acima da copa dos limoeiros, e atribuindo isso à interferência de quebra-ventos circundando o pomar.

Esse tipo de interferência também foi avaliada por Pereira et al. (2003) em pomar de lima ácida 'Tahiti', especialmente, nas estimativas fornecidas pelo método aerodinâmico. Os autores verificam que o MRB não é tão sensível às diferentes alturas de medidas dos gradientes de temperatura e pressão de vapor e que o método aerodinâmico, nas condições do experimento, teve seu desempenho prejudicado quando foram incluídas correções para o estado de estabilidade atmosférica.

Para cafezais, um trabalho de grande importância foi o de Gutiérrez \& Meinzer (1994a), realizado no Havaí com a variedade Catuaí e utilizando o MRB para a determinação da evapotranspiração. Estudando cafezais com diferentes áreas foliares os autores relacionaram a evapotranspiração da cultura com o fluxo de seiva dos cafeeiros, verificando que há uma relação linear direta entre a evapotranspiração do cafezal e o índice de área foliar (IAF), quando este variou de 1,5 a 7,5. Os valores de Kc encontrados ficaram entre 0,59 na área com IAF de 1,5 e 0,81 para cafezal com IAF de 5,3.

No trabalho, os autores comparam a evapotranspiração com os valores convertidos de fluxo de seiva, na unidade de $\mathrm{mm} \mathrm{d}^{-1}$, dividindo-os pela área foliar da planta e multiplicando o resultado pelo IAF. Pela variação dos valores de IAF publicados, deduz-se que os mesmos foram calculados com base na área projetada da copa, indicando que a conversão poderia ser feita apenas pela divisão da taxa de transpiração pela área projetada da copa. Esse método de conversão de unidade não parece ser o mais indicado por uniformizar as unidades sem antes igualar as escalas de trabalho. Como o fluxo de seiva é medido de forma individualizada e, muitas vezes, em uma única planta, a técnica utilizada pelos autores admite que a transpiração de uma única planta pode representar toda a população do cafezal e ser comparada com a medida da evapotranspiração, referente a toda a área do cafezal, ponderando a taxa de evapotranspiração ocorrida em cada unidade de área do cafezal. É evidente que essa premissa não é adequada e que 
a transformação dos dados de fluxo de seiva por esse método não permite compará-los com valores de evapotranspiração determinados pelo MRB, por exemplo.

Nesse tipo de comparação faz-se necessário ponderar a relação da(s) planta(s) em que se mede o fluxo de seiva com as demais na área, antes de converter as unidades, de modo que se possa extrapolar dados individualizados para toda a população. Com isso, tem-se tanto a evapotranspiração como o fluxo de seiva transformado sendo representativos de uma mesma escala, ou seja, de toda a área cultivada.

Marin et al. (2002b) em estudo em pomar de lima ácida 'Tahiti' fizeram estudo semelhante ao de Gutiérrez \& Meinzer (1994b), adotando, porém, outro método para conversão de unidades e comparação dos dados. Como as medidas de fluxo de seiva foram feitas em duas árvores de lima ácida 'Tahiti', utilizou-se o valor médio das taxas de transpiração por unidade de área foliar das duas plantas, multiplicando esse valor pela área foliar média do pomar, obtido a partir de medidas em 12 plantas. Feito isso, multiplicou-se pelo número de plantas do pomar, obtendo-se o volume total transpirado pelo pomar por dia. $\mathrm{Na}$ verdade, a unidade final de trabalho é de pouca importância nessa comparação, sendo essencial, na verdade, o procedimento de extrapolação dos dados envolvendo valores médios de área foliar da população de plantas. Os resultados de Marin (2000), seguindo a abordagem de Gutierrez \& Meinzer (1994b), mostraramse incoerentes com as condições de contorno do experimento, indicando que o precedimento utilizado por Marin et al. (2002b) é mais adequado para a conversão da escala de trabalho e transformação de unidades para a comparação entre a evapotranspiração de toda área e a transpiração das plantas de interesse econômico.

\subsection{ESTIMATIVA DA TRANSPIRAÇÃO MÁXIMA DE PLANTAS ISOLADAS COM O MODELO DE PENMAN-MONTEITH}

A modelagem da transpiração de plantas isoladas tem sido alvo de diversos estudos, principalmente após a ampliação do uso de sistemas de irrigação localizada, como a microaspersão e o gotejamento, pois nesse caso o interesse é repor a água perdida pela vegetação de interesse econômico, minimizando ou evitando a aplicação da água nas entrelinhas. $\mathrm{O}$ clássico modelo da grande folha ("big leaf model") ou de Penman-Monteith (modelo P-M) (Monteith, 1965) tem sido adaptado para estimativa da transpiração de plantas isoladas a partir de Buttler (1976). 
Thorpe (1978a) utilizou o modelo P-M adaptado para estimar a transpiração de macieiras de um pomar em renque. Caspari et al. (1993) encontraram boa concordância na escala horária entre a transpiração estimada pelo modelo P-M e o fluxo de seiva determinado pelo método do pulso de calor, com plantas cultivadas sob bom suprimento hídrico, mas o modelo não apresentou desempenho similar para plantas com deficiência hídrica, principalmente nos horários iniciais e finais do período diurno. Green \& McNaughton (1997) utilizaram o modelo em ameixeira, separando a transpiração das folhas à sombra e ao sol. A comparação com o fluxo de seiva determinado pelo método de pulso de calor mostrou a potencialidade do modelo nas escalas horária e diária.

Angelocci (1996) utilizou o modelo para a estimativa da transpiração máxima de macieiras em pomares com bom suprimento hídrico no solo, encontrando boa relação com o fluxo de seiva diário determinado pelo método de balanço de calor. Zhang et al. (1997) utilizaram o modelo de Penman-Monteith para estimativa da transpiração máxima de Pyrus serotina ("Asian pears") e compararam seus resultados com medidas de fluxo de seiva pelo método do balanço de calor encontrando um bom nível d e ajuste entre ambos. Um aspecto interessante deste trabalho foi tanto o uso de dados de medições porométricas no modelo, quanto a estimativa de rf a partir da inversão da equação de Penman-Monteith.

Daamen et al. (1999) encontraram resultados razoáveis ao estimarem a transpiração de árvores isoladas de limão, na Nova Zelândia, com o método de P-M, tendo observado superestimativa de $29 \%$, em média, em relação ao fluxo de seiva integrado para períodos de 24 horas. Segundo os autores, esse desvio deveu-se principalmente à forma adotada para determinação da resistência foliar à difusão de vapor (rf), proveniente de medições porométricas realizadas por volta das 12 horas em um dos seis dias avaliados, utilizando-se esse valor médio como constante para todos os dias de medida. Marin et al. (2002a) fizeram uso do modelo em lima ácida 'Tahiti', avaliando-se o modelo P-M em duas épocas do ano, na escala diária. Foram encontradas boas correlações entre a transpiração estimada e o fluxo de seiva determinado pelo método de balanço de calor (Sakuratani, 1981; Baker \& Van Bavel, 1987), especialmente para os dados obtidos no verão. 


\subsection{DETERMINAÇÃO DAS VARIÁVEIS DO MODELO DE PENMAN-MONTEITH PARA ESTIMATIVA DA TRANSPIRAÇÃO}

O modelo P-M utiliza quatro variáveis básicas, conforme discutir-se-á no item 3.4, para a determinação da densidade de fluxo transpiratório (fluxo por unidade de área foliar): o saldo de radiação da copa (por unidade de área foliar), duas resistências à difusão de vapor (resistência foliar e resistência aerodinâmica) e o déficit de pressão de vapor do ar. Dessas variáveis, as resistências difusivas e o saldo de radiação da copa são as que apresentam maiores dificuldades de determinação, havendo na literatura procedimentos diversos para tal.

\subsubsection{RESISTÊNCIAS À DIFUSÃO DE VAPOR}

A resistência à difusão de vapor é uma variável associada à estrutura do caminho de fluxo e das características do próprio fluxo, que indica o grau de dificuldade imposto pelo meio ao transporte de vapor. Pela lei de Fick, pode-se descrever a difusão molecular de gases pela folha pela seguinte equação:

$$
J_{v a}=D_{v a} \frac{\Delta C_{v a}}{\Delta x}
$$

em que $\mathrm{J}_{\mathrm{va}}$ é a densidade de fluxo de vapor, expresso em unidades de massa por unidade de área foliar e de tempo, $\mathrm{D}_{\mathrm{va}}$ é o coeficiente de difusão de vapor d'água no ar e $\Delta \mathrm{C}_{\mathrm{va}} / \Delta \mathrm{x}$ é o gradiente efetivo de concentração de vapor entre as extremidades do caminho de fluxo. Essa equação pode, no entanto, ser expressa em termos de resistência (rf) ou condutância $\left(g_{f}\right)$ do meio à difusão de vapor d'água:

$$
J_{v a}=\frac{1}{r_{v a}} \Delta C_{v a}
$$

$\mathrm{ou}$

$$
J_{v a}=g_{v a} \Delta C_{v a}
$$

sendo

$$
r_{v a}=\frac{1}{g_{v a}}
$$

e 


$$
g_{v a}=\frac{D_{v a}}{\Delta x}
$$

sendo que rf é expresso em s m${ }^{-1}$, no Sistema Internacional de Unidades.

A literatura mostra, entretanto, outras unidades para expressar a resistência, como é o caso da unidade $\mathrm{m}^{2} \mathrm{~s} \mathrm{~mol}^{-1}$ quando se trabalha com o gradiente de fração molar de vapor ao longo do caminho de fluxo como força motriz, tornando os valores de resistência menos dependentes da temperatura e independentes da pressão atmosférica, permitindo assim, melhor comparação de dados obtidos em diferentes locais.

O caminho de difusão desde os sítios de evaporação até o ar turbulento normalmente é considerado como composto de duas grandes resistências, a foliar e a aerodinâmica, associadas em série como mostra a Figura 2.

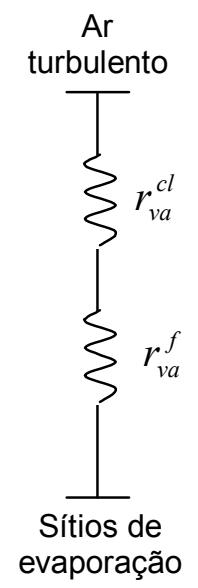

Figura 2 - Representação esquemática das resistências à difusão de vapor no caminho de fluxo entre a folha e o ar turbulento. $r_{v a}^{f}$ é a resistência foliar; $r_{v a}^{c l}$ é a resistência da camada-limite da folha.

\subsubsection{RESISTÊNCIA FOLIAR À DIFUSÃO DE VAPOR}

A resistência foliar à difusão de vapor (rf) possui três componentes, a saber: a resistência dos espaços intercelulares de ar, a da cutícula e a dos estômatos, associados em série conforme o esquema da Figura 3. 


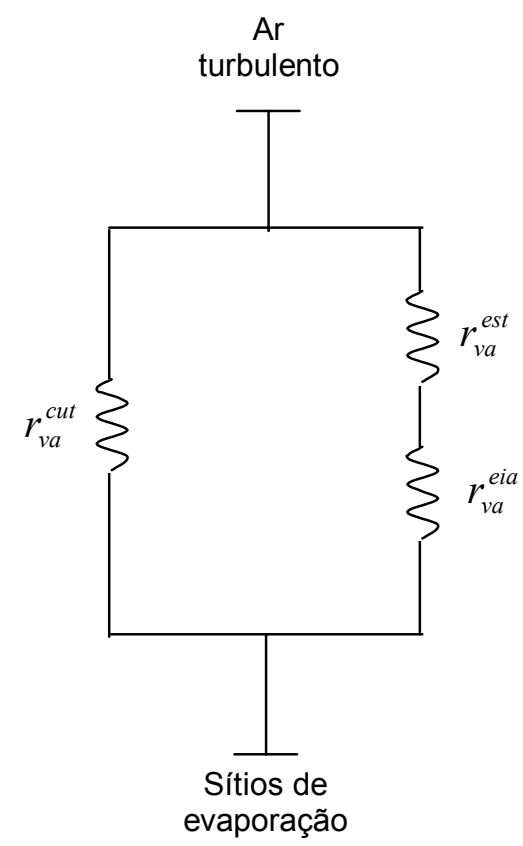

Figura 3 - Esquema da associação das resistências à difusão de vapor na folha. $r_{v a}^{e s t}$ é a resistência estomática à difusão de vapor; $r_{v a}^{e i a}$ é a resistência dos espaços intercelulares de ar; ${ }^{c u t}$ é a resistência cuticular.

A resistência dos espaços intercelulares de ar pode ser obtida pela determinação do comprimento efetivo do caminho do vapor d'água dos sítios de evaporação até a cavidade subestomática. Embora esses espaços tenham forma irregular e dimensões diferentes entre as espécies, pode-se adotar um comprimento efetivo variável entre $100 \mu \mathrm{m}$ e $1 \mathrm{~mm}$, levando a valores de resistência dessa componente com magnitude entre 4 e $40 \mathrm{~s} \mathrm{~m}^{-1}$, a $20{ }^{\circ} \mathrm{C}$ (Nobel, 1999; Angelocci, 2002). A resistência da cutícula pode ser estimada apenas a partir de medidas, e para plantas cultivadas têm-se valores variando entre $2500 \mathrm{~s} \mathrm{~m}^{-1}$ e $10000 \mathrm{~s} \mathrm{~m}^{-1}$ (Nobel, 1999). Já a resistência estomática é mais complicada para ser calculada, devido às particularidades do caminho de fluxo do aparato estomático, constituído pelas células guarda, pela cavidade subestomática, pelas células subsidiárias e pelo poro estomático.

O poro estomático, cuja área é definida pelo grau de abertura das células-guarda, é responsável pela saída de vapor d'água e a entrada de $\mathrm{CO}_{2}$. Dessa forma, mesmo com as células epidérmicas ocupando uma fração muito maior da área da folha que os poros estomáticos $(95 \%$ a 99,5\% da área), a cutícula cerosa que as cobre reduz significativamente a perda de água de suas paredes celulares para o ar turbulento, reduzindo a transpiração cuticular (Nobel, 1999). A perda 
de água pela via cuticular, portanto, adquire importância relativa apenas quando os poros estomáticos estão fechados (Jones, 1992).

O mecanismo de regulação estomática é afetado pelos fatores ambientais, como vento, radiação solar, déficit de pressão de vapor, temperatura etc., e o entendimento desse relacionamento tem sido questão de difícil solução, principalmente pela forte interação entre esses fatores. Aparentemente, a resposta mais consistente e documentada é a relação entre a variação da abertura estomática com os aspectos quali-quantitativos da radiação (Jones, 1992).

A máxima abertura é usualmente atingida quando os níveis de radiação solar estão por volta de 1/4 da irradiância solar máxima, ou seja, com valores próximos de $200 \mathrm{~W} \mathrm{~m}^{-2}$, sendo esse valor variável com a espécie e com a condição ambiental (Jones, 1992). Por exemplo, estômatos de folhas adaptadas à sombra abrem-se sob níveis sensivelmente menores de radiação que aqueles encontrados para folhas adaptadas à luz (Warrit et al., 1980). Segundo Jones (1992), a resposta de estômatos de citros aumenta com a radiação fotossinteticamente ativa, até atingir saturação, por volta de $500 \mu \mathrm{mol} \mathrm{m} \mathrm{m}^{-2} \mathrm{~s}^{-1}$ que corresponde a aproximadamente $25 \%$ da radiação solar máxima. Para Mansfield et al. (1990), as respostas estomáticas para radiação e $\mathrm{CO}_{2}$ devem ser consideradas conjuntamente, porque ambas contribuem substancialmente no ciclo diário da abertura e fechamento do poro estomático, e pela dificuldade na determinação da contribuição relativa de cada um desses fatores.

Para Jones (1992), embora parte da resposta estomática à luz possa ser indiretamente atribuída à diminuição na concentração de $\mathrm{CO}_{2}$ que ocorre com a iluminação, há forte evidência para uma resposta direta da luz envolvendo dois fotorreceptores independentes. Embora na maioria das plantas os estômatos abram-se sob iluminação e se fechem no escuro, nas plantas com metabolismo ácido das crassuláceas (CAM) no ciclo fotossintético, adaptadas à ambientes mais secos, o comportamento é inverso, com o máximo da abertura estomática ocorrendo nas primeiras horas do período noturno.

$\mathrm{O}$ estômato responde também à variação da fração molar de $\mathrm{CO}_{2}$ nos espaços intercelulares, de forma que quando essa fração molar decresce, o estômato tende a se abrir, com a sensibilidade sendo extremamente dependente do ambiente e da espécie (Meidner \& Mansfield, 1968). O estômato responde ao $\mathrm{CO}_{2}$ tanto sob luz quanto no escuro, de forma que a resposta não depende somente da fotossíntese. Contudo, Wong et al. (1979) constataram que a concentração interna de $\mathrm{CO}_{2}$ é mantida praticamente constante (em aproximadamente $130 \mathrm{vpm}$ em espécies $C_{3}$ e 230 vpm em espécies $C_{4}$ ) sob uma larga faixa de condições e taxas fotossintéticas. 
Os estômatos são também sensíveis ao potencial da água da folha, com uma clara tendência de fechamento do ostíolo com o decréscimo do potencial. O fechamento pode ocorrer em diferentes condições de conteúdo de água no tecido foliar, sendo que essa relação pode ser modificada pela exposição da folha a um fator de estresse (Jones, 1992). Recentemente, passouse a considerar que o movimento estomático é também dependente de outros fatores indiretos, denominados de mensageiros químicos (Naor, 1998), originários da raiz em resposta à deficiência hídrica no solo.

Quanto à influência da umidade do ar na regulação estomática, sua atuação é mais bem compreendida pela análise do déficit de pressão de vapor (DPV) entre a folha e o ar. Com a elevação do DPV, ocorre o fechamento do poro estomático devido à defasagem entre o fluxo de água para as células-guarda e a demanda atmosférica. É importante destacar que tais aumentos na resistência estomática devido ao incremento no déficit de saturação de vapor do ar, na maior parte dos casos não são suficientes para reduzir a transpiração sob condições não limitantes de água no solo, como demonstrado experimentalmente para citros (Meyer \& Green, 1981; Hall et al., 1975) e macadâmia (Lloyd, 1991). Segundo Jones (1992), a magnitude dessa resposta varia com a espécie, com o estádio fenológico e com o potencial da água da folha, havendo respostas mais pronunciadas sob altas temperaturas ou em plantas estressadas.

O efeito da temperatura na regulação estomática é ainda contraditório, mas, em linhas gerais, pode-se estabelecer que a área do poro estomático tende a aumentar com a temperatura. Kramer \& Boyer (1995) afirmam que o estômato pode aclimatar-se a condições de baixas temperaturas; Hall et al. (1975) verificaram uma leve diminuição da resistência com o aumento da temperatura entre $20^{\circ} \mathrm{C}$ e $30^{\circ} \mathrm{C}$ e Khairi \& Hall (1976) observaram um decréscimo da resistência quando a temperatura superava $30^{\circ} \mathrm{C}$.

Apesar do avanço significativo das técnicas de medida da resistência foliar à difusão de vapor nas últimas três décadas, principalmente da porometria, a determinação "in situ" de rf é complicada por uma série de fatores (variação temporal e variabilidade espacial de rf, problemas de alteração da abertura estomática na câmara porométrica etc.), ficando restrita à pesquisa científica.

Para fins de aplicação prática é interessante tentar-se modelar a resposta estomática aos fatores do ambiente e à condição hídrica da planta, como uma forma de estimar rf. No entanto, a modelagem é dificultada pelo entendimento parcial dos mecanismos de regulação estomática e de sua resposta aos fatores ambientais. A modelagem físico-matemática tem sido empregada segundo a proposta de Jarvis (1976), em conseqüência da qual modelos não lineares têm sido 
utilizados, como em citros (Syverstsen \& Lloyd, 1994), macadâmia (Lloyd, 1991), lichia (Batten et al., 1992) e milho (Yu et al., 1998).

Thorpe et al. (1980) desenvolveram um modelo de estimativa de rf para macieira a partir da proposta de Jarvis (1976), que considera como variáveis de entrada o déficit de saturação entre o ar e a folha e a radiação fotossinteticamente ativa. Normalmente esses modelos são obtidos a partir de estudos em ambientes controlados.

Para Jones (1992), a aplicação em condições de campo de informações obtidas em ambientes controlados para propósitos de modelagem é complicada por vários fatores, a saber: i) interações entre as respostas (ou seja, qualquer resposta depende do nível dos outros fatores); ii) variabilidade do ambiente natural; iii) o tempo de resposta do estômato é freqüentemente da mesma ordem de grandeza ou mais longo que aquele de mudanças no ambiente; iv) em espécies com folhas anfiestomáticas, os estômatos na superfície adaxial tendem a ter respostas mais eficientes que os da superfície abaxial; e v) o ritmo endógeno tende a afetar a abertura estomática independentemente das condições ambientais. Apesar dos problemas, o modelo proposto por Thorpe et al. (1990) para macieira tem sido empregado na modelagem da transpiração dessa espécie pelo modelo P-M (Green \& McNaughton; Angelocci, 1996).

Como esses trabalhos de modelagem lançam mão de condições controladas para a avaliação da resposta individual de cada uma das variáveis climáticas, tem-se comumente uma grande dificuldade em se utilizar tais modelos em condições de campo e com finalidades práticas. Nos trabalhos de Green \& McNaughton (1997), o modelo de Thorpe et al. (1980) foi utilizado considerando-se folhas ao sol e à sombra, numa tentativa de aproximar-se da realidade de campo, onde são encontrados nas copas de árvores condições diferentes de exposição das folhas à radiação solar.

Marin \& Angelocci (1999) avaliaram um modelo proposto por Syverstsen \& Lloyd (1994) para a espécie Citrus paradisi para estimativa da rf para árvores de lima ácida 'Tahiti' em condições de campo, tendo observado um desempenho ruim do modelo nessa espécie. Mesmo utilizando dados médios horários com a intenção de reduzir a variabilidade das medidas, o modelo mostrou-se ineficiente para estimativa da $\mathrm{rf}$ em condições de campo. Além desse modelo, Marin (1998) avaliou também a proposta de Thorpe et al. (1980) para as mesmas condições, obtendo resultados inconsistentes quando comparados com a porometria.

Tendo em vista tais dificuldades e a necessidade de um método de estimativa da resistência estomática em função de variáveis de simples medida, Marin et al. (2001a) propuseram um modelo para estimativa de rf em função do déficit de pressão de vapor do ar, 
saldo de radiação e velocidade do vento, além de um fator de ponderação obtido a partir da razão entre o fluxo de calor latente e o saldo de radiação, com valor entre 0,7 e 0,8 para culturas irrigadas. Esse modelo foi derivado do enfoque de Monteith (1965) para o modelo da grande folha e mostrou-se relativamente eficiente em comparação com dados médios de rf medidos em árvores adultas de lima ácida 'Tahiti'. Sua aplicação no modelo de Penman-Monteith para estimativa da transpiração máxima de árvores de lima ácida 'Tahiti' (Marin et al., 2002a) e para a evapotranspiração de gramado (Marin et al., 2002c) forneceu resultados coerentes de transpiração diária, quando comparada com o fluxo de seiva ou com medidas de lisímetros.

\subsubsection{RESISTÊNCIA AERODINÂMICA}

Como uma resistência difusiva, a resistência aerodinâmica (ra) pode ser entendida como o tempo decorrido para que uma unidade de volume de ar troque momento, vapor d'água, calor sensível ou $\mathrm{CO}_{2}$ com uma unidade de área de superfície (Monteith, 1965).

A determinação da resistência aerodinâmica, como sinônimo de resistência da camadalimite, apresenta certa dificuldade, principalmente pelas imprecisões na escala de trabalho e no sistema de interesse. Nesse sentido, deve-se levar em conta o sistema de interesse para cada situação, seja ele uma comunidade vegetal, a copa de uma árvore, a folhagem de um ramo ou mesmo uma única folha. Para uma comunidade vegetal, nas situações em que a taxa de variação vertical da temperatura é próxima do gradiente adiabático seco, pode-se admitir que a velocidade do vento varia de forma logarítmica com a altura de medida (Monteith, 1965). A partir dessa premissa e de medições do perfil adiabático do vento dentro da camada limite de uma vegetação homogênea, Penman \& Long (1960) propuseram a proporcionalidade (6) e, aplicando-a na equação geral do fluxo-gradiente, deduziram a equação (7) para estimativa da resistência aerodinâmica de uma cobertura vegetal (ra):

$$
u \propto \ln \left[\frac{(z-d)}{z_{o}}\right]
$$

$$
r a=\frac{\ln \left[\frac{(z-d)}{z_{o}}\right]^{2}}{u k^{2}}
$$


em que: u é a velocidade do vento; $\mathrm{z}$ é a altura de medida de u; d é o deslocamento do plano zero, sempre menor que a altura (h) da cultura; e $z_{o}$ é o comprimento da rugosidade da superfície, dependente das propriedades aerodinâmicas da superfície entre d e h; e k é a constante de Von Karman.

Segundo Campbell \& Norman (1998), o conceito de d pode ser entendido considerandose que numa superfície homogênea e totalmente lisa, a transferência de momento ocorre na altura d' $=0$. Para uma cultura, a transferência de momento ocorre dentro da sua folhagem, mas uma única superfície posicionada numa determinada altura abaixo do topo do dossel pode ser imaginada como a posição onde se dá essa transferência. Se z, na equação (7), fosse medido a partir deste ponto, não seria necessário a inclusão de $\mathrm{d}$, mas, como normalmente se faz a medida de $\mathrm{z}$ a partir da superfície do solo, d é utilizado para manter a coerência físico-matemática da equação.

Sobre $z_{0}$, Campbell \& Norman (1998) afirmam que até mesmo um entendimento intuitivo de seu significado é difícil. Apesar de ter unidade de comprimento, $\mathrm{z}_{\mathrm{o}}$ não pode ser interpretado como uma distância mensurável. Ele é, na verdade, uma representação do arrasto aerodinâmico e da superfície de fricção na camada de ar que interage com a superfície. Sua determinação é feita empiricamente a partir da medida da velocidade do vento em vários pontos acima da superfície da vegetação e plotando $\ln (\mathrm{z}-\mathrm{d})$ contra $\mathrm{u}(\mathrm{z})$. Uma linha de tendência pode então ser extrapolada até $\mathrm{u}=0$, obtendo-se o valor de $\ln \left(\mathrm{z}_{0}-\mathrm{d}\right)$ no eixo das abscissas.

Para superfícies uniformemente vegetadas, os valores de $\mathrm{d}$ e $\mathrm{z}_{\mathrm{o}}$ podem ser determinados, de forma aproximada, a partir da altura do dossel. Esse método é, no entanto, utilizado para aplicações em que se pode admitir os valores de $\mathrm{d}$ e $\mathrm{z}_{\mathrm{o}}$ como constantes, o que não ocorre de fato. Eles são, na verdade, muito dependentes da altura da cultura, da cobertura do solo, da estrutura da folha e da copa e da velocidade do vento (Perrier, 1982; Shaw \& Pereira, 1982; Massman, 1992; Marin et al., 2002c).

Monteith (1965), analisando ra para diferentes tipos de escoamento atmosférico, constatou que os valores de ra em fluxo turbulento são uma ordem de magnitude menor que aqueles verificados em escoamento laminar. Diante disso, pode-se aceitar que os processos de trocas entre uma superfície vegetada e a atmosfera são governados principalmente pelas trocas turbulentas. Nessas condições, o trabalho de Rider (1954) apontou para o fato de que os perfis de vento e pressão de vapor para superfícies extensas e uniformes têm o mesmo formato, inferindose a partir daí que os valores do coeficiente de difusão de vapor e de momento são similares. 
Acima de uma superfície, a forma do perfil de vento é determinada pela taxa de transporte vertical de momento (Landsberg \& James, 1971). Se essa superfície for o topo da copa de uma planta, o momento é transferido de cima para baixo, com as folhas exercendo uma resistência ao fluxo de ar e extraindo momento da camada de ar que passa sobre elas. O efeito que elas exercem sobre o perfil depende da densidade de folhas e de suas propriedades para a absorção de momento, definidas pelo coeficiente de arrasto $\left(C_{d}\right)$, característico da folhagem (Landsberg \& James, 1971). Um trabalho que merece destaque nessa linha é o de Brenner \& Jarvis (1995), que desenvolveram um método para a determinação de ra para folhas isoladas. Nesse método, os autores utilizaram uma folha aquecida com forma similar a do milheto para a determinação de ra, relacionando-a com a velocidade do vento.

Apesar desse trabalho ser de grande utilidade prática, dada sua aplicabilidade em condições de campo, ele não leva em conta a interferência mútua entre as folhas. Esse aspecto é especialmente importante quando se pretende aplicar o conceito de ra para plantas isoladas, devido às modificações nas condições de contorno e a inadequação das premissas admitidas para superfícies homogêneas. Dessa forma, enfoques diferenciados foram propostos para estudo de ra na escala de uma planta, resultando em uma linha específica de pesquisa.

Landsberg \& Thom (1971) mediram a transferência de momento e vapor em uma espécie de pinus, e detectaram um aumento de ra à medida que a densidade de folhas aumentava. Segundo Landsberg \& Powell (1973), como as folhas são submetidas a uma mútua interferência aerodinâmica, a troca de qualquer propriedade entre a superfície da folha e o ar deve ser afetada por essa interferência, tornando-se menos eficiente à medida que aumenta a área foliar num dado volume.

Diante dessa evidência, Landsberg \& Powell (1973) realizaram um estudo de interesse teórico e com grandes aplicações práticas, por permitir a quantificação de ra para copas de plantas isoladas e com interferência mútua. Isso foi de grande importância para os estudos de transpiração de plantas isoladas, já que a partir deste ponto passou-se a contar com uma metodologia desenvolvida exatamente para a escala de interesse. Diversos trabalhos envolvendo a modelagem da transpiração máxima de plantas isoladas (Thorpe, 1978a; Caspari et al., 1993; , Angelocci, 1996; Zhang et al., 1997; Green et al., 1997; Marin, 2000) utilizaram o modelo de Landsberg \& Powell (1973) e, dada sua importância para este trabalho, faz-se a seguir um resumo das premissas e proposições desse modelo.

Trabalhando com mudas de macieiras de diferentes densidades foliares e também com uma planta modelo, construída com caule e ramos de cobre e folhas de alumínio envolvidas com 
papel de filtro umedecido, Landsberg \& Powell (1973) realizaram uma série de experimentos buscando modelar a influência da densidade foliar no coeficiente de arrasto da planta. Nesses estudos, definiram a densidade da planta $(\sigma)$ como a soma da área das folhas e dos ramos, dividida pela área projetada da copa sobre o solo. Com isso, os autores notaram que a força de arrasto para plantas com interferência aerodinâmica mútua é maior que aquela encontrada para plantas sem interferência, o que os levou a propor um fator de interferência (p), aplicado tanto para o transporte de momento como de vapor. O valor de p é dado pela razão entre o coeficiente de arrasto de folhas isoladas e o coeficiente de arrasto de folhas com interferência mútua, que, por sua vez, seria função de $\sigma$ e da velocidade do vento.

$\mathrm{Na}$ prática, esse fator representa a limitação para os processos de troca das propriedades atmosféricas com a superfície foliar devido à ação da interferência mútua das folhas. Essa característica torna esses processos dependentes da densidade foliar e diretamente proporcional à razão entre a área de silhueta da planta e a área projetada da copa.

Baseando-se na equação básica para ra proposta por Monteith (1965), Landsberg \& Powell (1973) derivaram uma equação aplicável para plantas com copas isoladas e folhagem adensada. Vale ressaltar que a aplicabilidade do estudo desses autores para outras culturas é apenas presumida, pois são poucos os trabalhos que avaliaram o modelo para outras espécies, devido à dificuldade para a realização de estudos deste tipo e do aparato experimental necessário. Um trabalho que merece menção foi o de Oliveira (1994), que avaliou o modelo de Landsberg \& Powell (1973) para três espécies, verificando que pequenas modificações poderiam ser feitas na equação original para ajustá-la às espécies estudadas. Vale destacar que para velocidades de vento superiores a $3 \mathrm{~m} \mathrm{~s}^{-1}$ não foram verificadas modificações significativas na proposição original.

\subsubsection{ABSORÇÃO DE ENERGIA RADIANTE PELA FOLHAGEM}

Nos estudos com o objetivo de estimar a transpiração de árvores isoladas, faz-se imprescindível à quantificação da energia radiante absorvida pela folhagem de uma planta e sua expressão por unidade de área foliar (Rnf). Tem-se tentado usar modelos físico-matemáticos que envolvem a geometria e as características da folhagem juntamente com a geometria de radiação para estimar a absorção de radiação solar, como base para a determinação do saldo de radiação de plantios em renques. 
Dentre os modelos, podem ser citados os Palmer (1977) e de Charles-Edwards \& Thorpe (1976). Esses dois últimos autores propuseram e validaram um modelo de interceptação de radiação direta e difusa por renques de macieira, com uso de geometria elipsóide, irradiância solar direta e difusa, densidade de área foliar e distância do caminho percorrido pela radiação na copa. Riou et al. (1989) utilizaram um modelo que utiliza uma representação geométrica das árvores, a "porosidade" da folhagem, a posição do sol e o albedo do solo e das folhas. O trabalho foi validado em videira e em macieiras e, a partir da medida da radiação interceptada e do uso de saldo de radiação acima da copaos autores estimaram o saldo de radiação nos renques de duas culturas.

Para testar modelos desse tipo, é importante ter-se procedimentos de medida. Thorpe (1978a) deu início a uma série de estudos objetivando a quantificação de Rnf, utilizando para tanto um conjunto de 8 saldo-radiômetros lineares dispostos ao redor de um renque de macieiras. McNaughton et al. (1992), com objetivos semelhantes, aprimorou o instrumental utilizado para tais medidas, construindo um sistema metálico giratório ("whirligig") para uma planta isolada, no qual foram fixados oito saldo-radiômetros, obtendo-se com isso uma excelente amostragem espaço-temporal. Esse mesmo sistema foi utilizado por Green (1993) e Green \& McNaughton (1997) em nogueira e por Angelocci et al. (2000) em lima ácida 'Tahiti'.

Pereira et al. (2001), analisando os dados de Green (1993) e Angelocci et al. (2000), obtidos em ameixeira e lima ácida 'Tahiti', respectivamente, estabeleceram uma relação entre o saldo de radiação medido em gramado (Rng) e Rnf, aplicável para as duas espécies. Neste trabalho, os autores propuseram a seguinte relação $\mathrm{Rnf}=0,32 \mathrm{Rng}$. Vale destacar que as plantas tinham áreas foliares variando entre $26,4 \mathrm{~m}^{2}$ e $40 \mathrm{~m}^{2}$ e, a despeito disso, a relação proposta apresentou um bom ajuste aos dados medidos na escala diária. No entanto, aplicando-a aos dados de McNaughton et al. (1992) obteve-se estimativas inconsistentes para a espécie Robinia pseudoacacia.

Outras abordagens foram também empregadas para a determinação de Rnf. Angelocci (1996), baseado nos trabalhos de Riou et al. (1989), Landsberg et al. (1973), Buttler (1976) e Thorpe (1978a), valeu-se de relações entre o saldo de radiação do pomar e a radiação solar global para a determinação de Rnf. Daamen et al. (1999), estudando os fluxos de massa e energia em pomar irrigado na Nova Zelândia, estimaram Rnf a partir de medidas do saldo de radiação acima e abaixo do nível das copas das árvores, posicionando os saldo-radiômetros nas linhas de plantio, e assumido que a energia disponível às plantas era dada pela diferença entre eles. 
Marin (2000), baseado no trabalho de Ricthie (1972), utilizou um método relativamente simples para estimativa de Rnf em lima ácida 'Tahiti', considerando que a extinção de radiação pela copa pode ser descrita pela lei de Beer. Pode-se antever que haja alguma limitação na aplicação dessa lei, pois ela contempla um meio homogêneo e isotrópico atravessado por radiação monocromática. No entanto, os dados experimentais obtidos em lima ácida 'Tahiti' indicaram a viabilidade dessa abordagem, com erros aceitáveis para modelagem em condições de campo.

\subsection{MEDIDAS DE FLUXO DE SEIVA PELO MÉTODO DO BALANÇO DE CALOR}

Os primeiros relatos de medidas diretas de fluxo de seiva em plantas foram feitos por Huber (1932) (apud Marshall, 1958), utilizando o método hoje conhecido como pulso de calor. Outra forma para quantificação do fluxo de seiva em lenhosas foi proposta por Granier (1985, 1987) propôs uma forma para quantificação do fluxo seiva em plantas lenhosas, utilizando a diferença de temperatura entre duas sondas inseridas no caule, sendo uma delas aquecida com fornecimento constante de calor ao caule. Devido a sua constituição, esse método ficou conhecido como método da sonda de dissipação térmica ou, simplesmente, método de Granier.

Cermak et al. (1973) propôs a primeira versão do atualmente denominado método do balanço de calor (MBC), que se constitui basicamente na aplicação contínua de calor à taxa constante em um segmento do caule, quantificando-se as perdas por condução axial e radial e a variação da energia térmica armazenada no caule. Dessa forma, o fluxo de calor transportado pela seiva é determinado a partir da diferença entre essas perdas e a potência aplicada. A partir dessa quantidade de calor transportada convectivamente é possível determinar o fluxo de seiva. Esses autores utilizaram um sistema de variação do aporte de energia aplicado ao sensor de acordo com a taxa de transpiração da planta, o que, evidentemente, exige um aparato eletrônico relativamente complexo para a realização de medidas no campo.

Atualmente, esse método segue a forma proposta por Sakuratani (1981) e Baker \& Van Bavel (1987), que difundiram sua utilização por torná-lo mais simples e de menor custo. A principal modificação proposta por esses autores foi a aplicação de uma potência elétrica constante sobre a jaqueta de dissipação térmica do sensor, o que diminui as exigências eletrônicas para realização das medidas, tornando necessária apenas uma fonte de corrente contínua para alimentação dos sensores de fluxo. 
Esses autores, no entanto, propuseram formas distintas para construção de sensores com as mesmas finalidades. Enquanto Sakuratani (1981) descreve a construção de sensores que utilizam um maior número de canais analógicos para seu monitoramento, Baker \& Van Bavel (1987), através de um tratamento matemático relativamente simples, conseguiram reduzir o número de canais necessários para a medida do fluxo de seiva. Essa redução, contudo, limita a avaliação do desempenho dos sensores, sendo o método de Sakuratani (1981) mais adequado para as ocasiões em que se pretende avaliar a qualidade dos dados obtidos de forma mais detalhada.

O MBC destaca-se perante os outros métodos por apresentar algumas características interessantes, dentre elas: é um método absoluto que dispensa procedimentos de calibração; exige equipamentos de simples construção e de baixo custo. Sua utilização, no entanto, exige que certos cuidados sejam tomados de modo a minimizar erros de medida, sendo os principais: assegurar bom contato entre o corpo do sensor e o caule (Weibel \& de Vos, 1994); realizar boa amostragem dos gradientes axiais de temperatura, nos casos em que há acentuada variabilidade radial no tronco na condução de água (Steinberg et al., 1990a); computar a variação do armazenamento de calor no volume de tronco amostrado, especialmente nos caules de grande porte (Valancogne \& Nasr, 1993). Um aspecto importante a ser levado em conta é que o desempenho do método depende da estrutura anatômica de caule (Baker \& Nieber, 1989), bastante variável entre as espécies. Por isso, é recomendável que ele seja testado em espécies onde tal procedimento ainda não ocorreu.

De acordo com os interesses dos grupos de pesquisas que utilizam o MBC, adota-se um ou outro procedimento com maior freqüência. Segundo os trabalhos de Valancogne \& Nasr (1993), Dayau (s.d.) e Angelocci \& Valancogne (1993), percebe-se que os pesquisadores do "Institut National de la Recherche Agronomique" (INRA, França) trabalham com o MBC na forma proposta por Sakuratani (1981). Já nos Estados Unidos, nota-se que a variante de Baker \& Van Bavel (1987) é comumente empregada, talvez devido à criação da única empresa de expressão mundial que comercializa este tipo de produto.

A despeito das restrições ao uso dos sensores comerciais em pesquisas científicas, a praticidade e a robustez desse tipo de sensor têm sido o grande atrativo para sua divulgação no meio científico. Alguns trabalhos foram feitos com o objetivo de avaliar seu desempenho em condições de campo e para situações em que se necessite de medidas acuradas do fluxo de seiva. Herzog et al. (1997) trabalhando com plantas de pequeno diâmetro, realizaram uma comparação entre duas formas de suplementação de energia térmica ao sensor: a variável, com aquecimento 
interno do caule (Cermak et al., 1973), e a constante, com aquecimento externo de caules de pequeno diâmetro (Sakuratani, 1981), obtendo bons resultados com esta última, desde que uma área relativamente grande do caule seja isolada termicamente, e não somente a área do sensor propriamente dito.

Um trabalho de grande importância prática nessa linha foi conduzido por Gutiérrez et al. (1994), com vistas a avaliar o desempenho dos sensores comerciais em condições de casa de vegetação e de campo em cafeeiro. Os autores confirmaram as verificações de Baker \& Nieber (1989) e de Shackel et al. (1992) que, sob condições ambientais severas, como em ambientes com temperaturas elevadas e expostos à radiação solar direta, os sensores comerciais apresentavam distorções nas medidas de fluxo de seiva. Entretanto, tais erros foram atribuídos à medida do aquecimento da seiva durante sua passagem pelo sensor, o que foi corrigido pela colocação de uma proteção adjacente ao corpo do sensor, com a finalidade principal de evitar a incidência de radiação direta sobre ele, mas que permitisse também a circulação do ar e a manutenção do equilíbrio térmico do sensor com o ambiente. Um outro aspecto de grande interesse indicado nesse trabalho é o fato de que, quando instalados em plantas com elevada área foliar e, portanto, com sombreimento do sensor nos horários mais quentes do dia, os erros de medida são expressivamente minimizados.

No mesmo trabalho, os autores propuseram e utilizaram uma forma prática para monitoramento dos erros de medida causados pelo ambiente. Para tanto, eles instalaram um sensor de forma idêntica aos utilizados para a coleta dos dados experimentais, mantendo-o, porém, sem a alimentação elétrica. Assim, era possível quantificar a influência ambiental sobre os sensores através do cômputo dos erros de medida para diversas condições micrometeorológicas. Em um dos dias de medida, os autores verificaram que a resposta dos sensores sem a proteção exterior apresentou desvios expressivos em relação a sensores adequadamente instalados.

Para a avaliação dos resultados, os autores compararam os valores de transpiração obtidos pelo MBC em plantas de coco e café com pesagens em balanças eletrônicas, verificando que o desempenho dos sensores, depois de tomadas as precauções acima listadas, esteve muito próximo do ideal, com uma leve tendência de superestimativa nas plantas de coco e uma pequena tendência de subestimativa nas plantas de café.

Shackel et al. (1992) apontaram algumas fontes de erros de medida com os sensores comerciais, fazendo com que o fabricante (Van Bavel, 1999) respondesse apontando os seguintes equívocos no procedimento de medida daqueles autores: o sensor havia sido instalado 
numa posição muito próxima à superfície do solo, prática não recomendada pelo fabricante; as avaliações de Shackel et al. (1992) foram feitas com um único sensor instalado em uma planta com diâmetro de caule fora das especificações do sensor e; os sensores não foram protegidos contra os efeitos térmicos ambientais, conforme recomendado posteriormente por Gutiérrez et al. (1994).

Em plantas lenhosas, desde que evitadas tais fontes de erro, o MBC tem se mostrado eficiente na determinação do fluxo de seiva e, cujos valores integrados para períodos maiores ou iguais a $24 \mathrm{~h}$, representam bem a transpiração diária desde que as condições de disponibilidade hídrica no solo sejam ideais. O método foi alvo de diversos estudos realizados com o intuito de avaliar suas medidas em relação com àquelas obtidas com lisímetros ou com modelos climatológicos indicando que o desempenho do método é coerente quando tomadas as precauções contra os possíveis erros de medida (Steinberg et al., 1990b; Cienciacala et al., 1992; Devitt et al., 1993; Trejo-Chandia et al., 1997, Herzog et al., 1997; Gutiérrez et al., 1994). 


\section{MATERIAL E MÉTODOS}

\subsection{CARACTERIZAÇÃO DA ÁREA EXPERIMENTAL}

O trabalho foi desenvolvido em área experimental do Departamento de Produção Vegetal, Escola Superior de Agricultura “Luiz de Queiroz”, Universidade de São Paulo (USP), situada no município de Piracicaba, SP, nas seguintes coordenadas geográficas: 2242’30’' Sul; 47³0'00' Oeste; e a 546m de altitude.

A área experimental é constituída de um cafezal com 5 anos de idade, com 812 plantas, da variedade Mundo Novo Apuatã, plantado em espaçamento de 2,5 m X 1,0 m em solo classificado como Terra Roxa Estruturada. Ao sul, havia um cafezal em fase de crescimento com aproximadamente um ano de idade e cerca de $0,8 \mathrm{~m}$ de altura e, a norte, uma área de pastagem e construções zootécnicas para engorda de gado em sistema de confinamento.

A disposição geométrica das plantas constitui um sistema de renques com direção de aproximadamente 15 graus a partir do norte para noroeste. A altura média das plantas do cafezal era de $2,5 \mathrm{~m}$ e as copas tinham diâmetro médio de aproximadamente 1,6m. A área foi irrigada por sistema de gotejamento. Em um dos lados do cafezal, separado por um carreador, encontravamse pastagens e os outros três lados eram ocupados por um cafezal em crescimento (na época do experimento com cerca de um ano após o plantio e altura média de $0,8 \mathrm{~m}$ ), com cerca de 3,2 ha. No cafezal, foram escolhidas, no renque central da área, quatro árvores saudáveis, vigorosas e representativas da população quanto ao porte e à altura, para a realização de todas as medidas necessárias.

$\mathrm{Na}$ falta de medida direta de água no solo, para a verificação das condições de disponibilidade hídrica no solo, elaborou-se o balanço hídrico de cultura na escala de uma planta para período o diário para o período compreendido entre os meses de agosto e novembro de 2002, especificamente entre os dias 234 e 305. Para esse cálculo, estimou-se a evapotranspiração 
máxima (ETm) de uma planta hipotética a partir da evapotranspiração de referência (ETo) (Allen et al. 1998), dividida pelo índice de área foliar médio $\left(\mathrm{IAF}_{\mathrm{m}}\right)$ do cafezal e multiplicado por 14 $\mathrm{m}^{2}$, valor correspondente à área foliar da maior planta e indicativo do maior consumo hídrico dentre as plantas amostradas (equação 8):

$$
E T m=\frac{E T o}{I A F_{m}} A F
$$

A capacidade de água disponível (CAD) do solo foi determinada a partir dos valores de umidade volumétrica do solo na capacidade de campo $\left(\theta_{\mathrm{CC}}\right)$ e no ponto de murcha permanente $\left(\theta_{\mathrm{PMP}}\right)$. Os valores de $\theta_{\mathrm{CC}}$ e $\theta_{\mathrm{PMP}}$ foram determinados por Pauletto (1986) na mesma área onde se encontra atualmente o cafezal, e considerados iguais a 0,45 e $0,30 \mathrm{~cm}^{3} \mathrm{~cm}^{-3}$, respectivamente. Utilizou-se, também, o valor da profundidade efetiva do sistema radicular (z), igual a $0,80 \mathrm{~m}$, determinada a partir da abertura de um perfil de solo próximo a uma planta com porte similar às avaliadas neste estudo. Para a uniformização de unidades, foi utilizada na determinação da CAD $\mathrm{o}$ valor da área efetiva ocupada pelo sistema radicular da planta $\left(\mathrm{A}_{\mathrm{EF}}\right)$, considerada igual a 1,25 $\mathrm{m}^{2}$. Com isso obteve-se um valor de CAD expresso em $\mathrm{L}_{\text {planta }}{ }^{-1}$, e equivalente a $150 \mathrm{~L}_{\text {planta }}{ }^{-1}$ aplicando-se os valores citados na equação (9).

$$
C A D=\left(\theta_{C C}-\theta_{P M P}\right) z A_{E F}
$$

A Figura 4 apresenta a variação do armazenamento de água no solo durante o período experimental, com os níveis de umidade mantidos sempre acima de 50\% da capacidade máxima de retenção. Deve-se considerar que o valor da ETm pode ter sido superestimado, já que considerou-se similaridade entre a taxa de transpiração por unidade de área foliar do cafeeiro e de um gramado. Além disso, a área foliar adotada foi a da maior planta, o que levou à estimativa de valores mais elevados de ETm e de menor nível de armazenamento de água no solo em relação as demais plantas. Dessa forma, pode-se assumir que as condições de disponibilidade hídrica do solo durante o experimento não causaram deficiência hídrica no solo. 


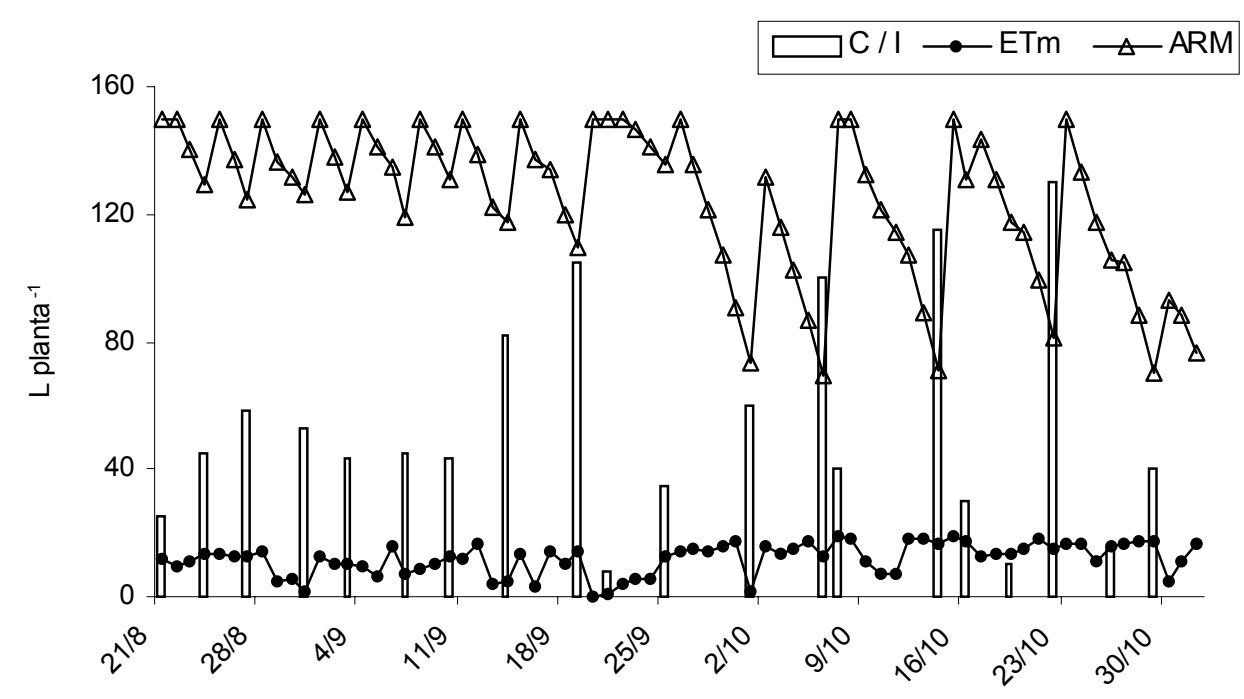

Figura 4 - Componentes do balanço hídrico no cafezal. C/I é o volume de chuva e/ou irrigação aplicados na área, em L planta $^{-1}$; ETm é a evapotranspiração máxima utilizando coeficiente de cultura igual a unidade, em L planta ${ }^{-1}$; ARM é o armazenamento médio de água no solo, em L planta ${ }^{-1}$.

A região de Piracicaba tem clima caracterizado como subtropical úmido, de acordo com a classificação de Köppen, com verão chuvoso e seca de inverno, com as temperaturas médias mensais variando de $24,8{ }^{\circ} \mathrm{C}$ no verão a $17,1^{\circ} \mathrm{C}$ no inverno, sendo a média anual igual a $21,4{ }^{\circ} \mathrm{C}$. As chuvas são da ordem de $1278 \mathrm{~mm}$ anuais, sendo cerca de $1000 \mathrm{~mm}$ de outubro a março, e 278 $\mathrm{mm}$ de abril a setembro. A Figura 5 mostra o extrato do balanço hídrico normal, evidenciando os períodos de deficiência e de excedente hídrico. Em termos médios, o excedente hídrico total ao longo no ano é de $259 \mathrm{~mm}$ e a deficiência é de $70 \mathrm{~mm}$. 


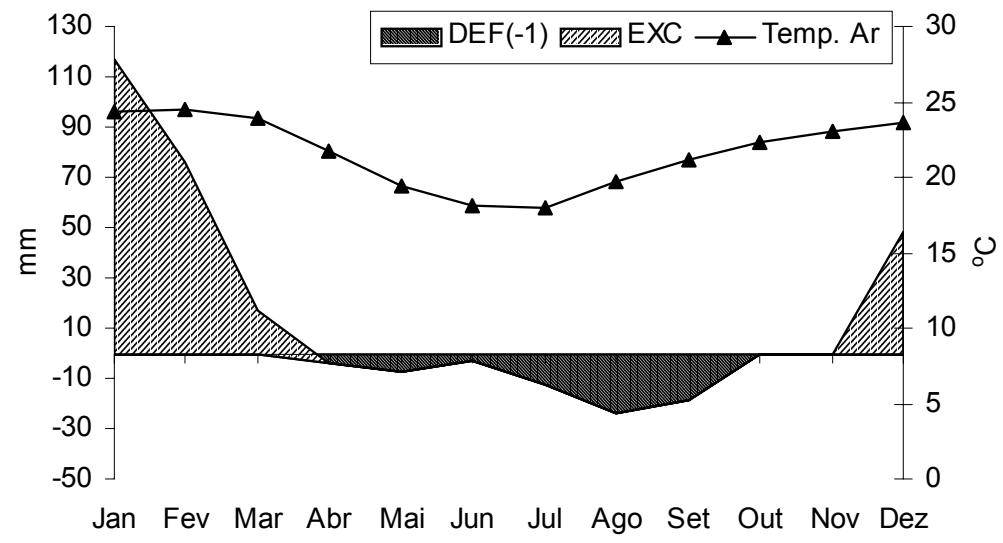

Figura 5 - Extrato do balanço hídrico climatológico de Piracicaba, a partir de dados médios do período entre 1917 e 1999 e considerando CAD de 100mm.

\subsection{MEDIDAS MICROMETEOROLÓGICAS}

Os sensores para as medidas micrometeorológicas do cafezal foram instalados em um mastro de $4 \mathrm{~m}$ de altura, posicionado no centro da área experimental (Figura 6), com os sinais elétricos coletados em um sistema automático de aquisição de dados (CR7, Campbell Scientific, Logan, Utah, EUA). O programa do sistema automático de aquisição é apresentado no Anexo 1.

Nas alturas de $1,5 \mathrm{~m}$ e $3,5 \mathrm{~m}$ foram instalados psicrômetros ventilados de termopar construídos no Departamento de Ciências Exatas da ESALQ, conforme Marin et al. (2001d), em conjunto com dois anemômetros de canecas, um a altura de 1,5m (O14A, Met-One Instruments, Grants Pass, Oregon, EUA) e outro à altura de 3,5m (03001 Wind Sentry Wind Set, R.M. Young, Traverse City, Michigan, EUA). Essas alturas de instalação dos sensores foram determinadas por estarem a $1 \mathrm{~m}$ acima e $1 \mathrm{~m}$ abaixo da altura média dos cafeeiros, de aproximadamente 2,5m. Essa disposição foi adotada com base nos estudos de Pereira et al. (2003) em lima ácida 'Tahiti', que recomendaram a medida dos gradientes de pressão atual de vapor e velocidade do vento em posições proporcionais a essas.

A $4 \mathrm{~m}$ de altura foi instalado um saldo-radiômetro (NR Lite, Kipp \& Zonen, Delft, Holanda) acoplado a um tubo de ferro de $3 \mathrm{~m}$ de comprimento, projetando-o distante do mastro e permitindo que sua visada ficasse entre a entrelinha e o renque, favorecendo uma boa amostragem do cafezal. No solo, foram instaladas 3 placas de fluxo de calor (HFT3, Rebs, 
Seattle, Washington, EUA), sendo uma instalada entre duas plantas, na linha de plantio da cultura, outra na entrelinha de plantio e, a última, no limite de projeção das copas das plantas, numa posição intermediária entre as demais. Para efeito de cálculo, foi considerado como fluxo de calor do solo representativo do cafezal o valor médio das 3 placas.

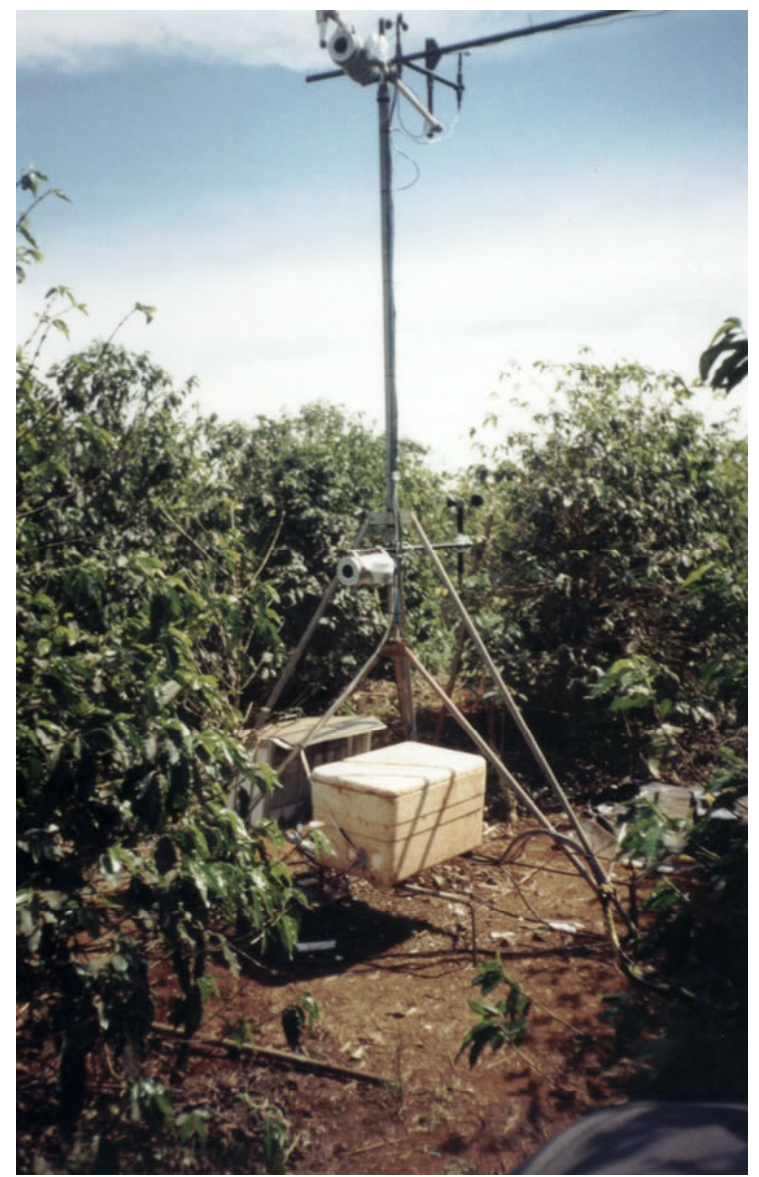

Figura 6 - Vista do mastro com os sensores meteorológicos.

\subsection{MEDIDAS DE FLUXO DE SEIVA}

A medida do fluxo de seiva dos cafeeiros foi feita pelo método do balanço de calor no caule, com sensores comerciais (SGB50 e SGB35, Dynamax, Houston, Texas, EUA), que seguem o modelo proposto por Baker \& Van Bavel (1987). Como constituição básica, esses sensores possuem uma jaqueta térmica para dissipação de calor, um fluxímetro de termopilha para quantificação do fluxo radial e de junções de termopar de cobre-constantan 
convenientemente dispostas para medir o fluxo de calor axial por condução no caule (Figura 7). A Tabela 1 apresenta as dimensões dos caules das plantas com medida de fluxo de seiva e as especificações dos sensores utilizados.

Tabela 1. Diâmetro, perímetro e área da seção reta do caule das plantas na posição de instalação dos sensores de fluxo de seiva, com as especificações do modelo utilizado e da resistência elétrica, nas duas datas de instalação.

\begin{tabular}{ccccccc}
\hline $\begin{array}{c}\text { Data da } \\
\text { medida }\end{array}$ & Planta & $\begin{array}{c}\text { Perímetro } \\
\text { médio }(\mathrm{cm})\end{array}$ & $\begin{array}{c}\text { Diâmetro médio } \\
(\mathrm{cm})\end{array}$ & $\begin{array}{c}\text { Área média } \\
\left(\mathrm{cm}^{2}\right)\end{array}$ & $\begin{array}{c}\text { Sensor } \\
\text { Modelo }\end{array}$ & $\begin{array}{c}\text { Resistência } \\
(\text { Ohms })\end{array}$ \\
\hline $21 / 08 / 2002$ & 1 & 17,6 & 5,6182 & 24,7902 & SGB50 & 26,2 \\
& 2 & 17,3 & 5,5226 & 23,9546 & SGB50 & 24,0 \\
& 3 & 19,2 & 6,3185 & 29,3354 & SGB50 & 24,0 \\
$8 / 10 / 2002$ & 4 & 14,1 & 4,4881 & 15,8208 & SGB35 & 41,3 \\
& 1 & 17,3 & 5,5173 & 23,9086 & SGB50 & 26,2 \\
& 2 & 17,4 & 5,5386 & 24,0928 & SGB50 & 27,1 \\
& 3 & 19,1 & 6,1009 & 29,2337 & SGB50 & 26,2 \\
& 4 & 14,0 & 4,4563 & 15,5971 & SGB35 & 40,4 \\
\hline
\end{tabular}

A equação (10) foi utilizada para determinação do fluxo volumétrico de água na seção reta do caule na região de instalação do sensor e, para seu uso, determinou-se o fluxo radial (Qr) e o axial (Qa).

$$
F S=\frac{P-Q a-Q r}{d T c p}
$$

em que: P é a potência aplicada (W); Qa é o fluxo em watts de energia dissipada axialmente, dado pela soma dos fluxos axiais superior (Qs) e inferior (Qi); Qr é o fluxo de energia dissipada radialmente; dT é a diferença de temperatura entre a extremidade superior e inferior do sensor (representa o aquecimento da seiva no volume amostrado pelo calor fornecido) e cp é o calor específico da água $\left(4,18610^{-3} \mathrm{~J} \mathrm{~kg}^{-1}{ }^{\circ} \mathrm{C}^{-1}\right)$. 


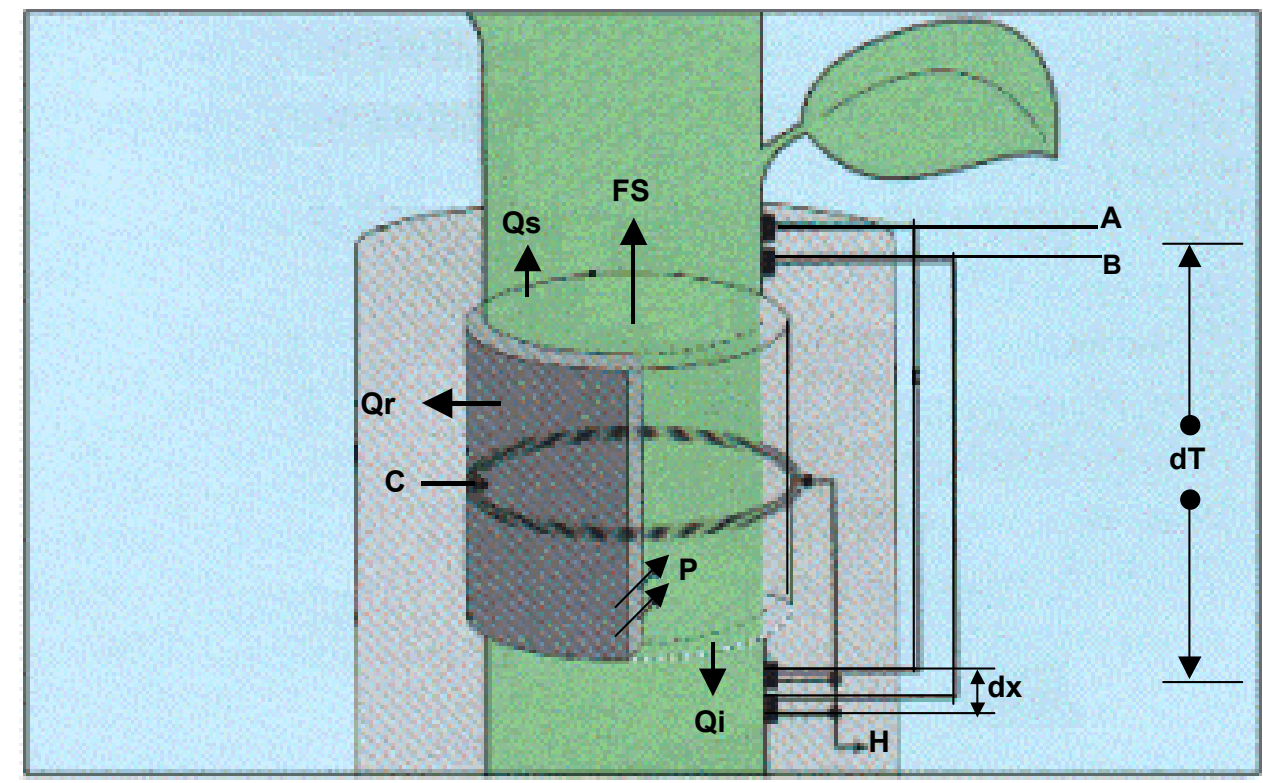

Figura 7 - Representação esquemática da constituição do sensor de fluxo de seiva segundo Baker \& Van Bavel (1987).

Os fluxos axiais ascendente e descendente no caule a partir do volume amostrado (Qa) foram determinados pela medida do gradiente de temperatura entre o par de junções de termopares instaladas imediatamente acima e abaixo da jaqueta dissipadora de calor (equação 11). Nos sensores Dynamax esses fluxos são calculados conjuntamente, estimando-se um valor total para as perdas axiais do sensor. A Figura 8 apresenta o esquema de ligação dos sensores Dynamax no sistema automático de aquisição de dados, destacando o número de canais utilizados para as medidas dos gradientes de temperatura.

$$
Q a=\frac{K t A(B H-A H)}{d x C_{S}}
$$

em que: Qa é a soma dos fluxos axiais inferior e superior (W); Kt é a condutividade térmica do caule, adotando-se $0,42 \mathrm{~W} \mathrm{~m}^{-1} \mathrm{~K}^{-1}$ para caules lenhosos, $0,54 \mathrm{~W} \mathrm{~m}^{-1} \mathrm{~K}^{-1}$ para caules de plantas herbáceas e $0,28 \mathrm{~W} \mathrm{~m}^{-1} \mathrm{~K}^{-1}$ para caules com espaços aéreos; $\mathrm{AH}$ e $\mathrm{BH}$ são as diferenças de voltagem proporcionais ao gradiente de temperatura entre duas junções de termopares instalados à jusante e a montante da jaqueta térmica do sensor; $\mathrm{dx}$ é a distância entre as junções de termopares para as medidas de $\mathrm{BH}$ e $\mathrm{AH}$; e, $\mathrm{C}_{\mathrm{s}}$ é o valor do coeficiente Seebeck para os termopares de cobre-constantan (aproximadamente igual a $38 \mu \mathrm{V}^{\circ} \mathrm{C}^{-1}$ ).

Em sistemas de aquisição que dispõem de algorítmos para conversão das medidas de tensão elétrica entre junções de termopar em valores de temperatura, o coeficiente $C_{s}$ da equação 
11 não é utilizado, tornando mais precisa a determinação de Qa. Os sinais elétricos provenientes dos sensores foram medidos e armazenados por um sistema automático de aquisição de dados (CR7, Campbell Scientific, Logan, Utah, EUA), que contava com o programa descrito no Anexo 1, e que contava com um polinômio de sexto grau que relacionava as medidas de $\mathrm{AH}$ e $\mathrm{BH}$ com as diferenças de temperatura entre as junções.

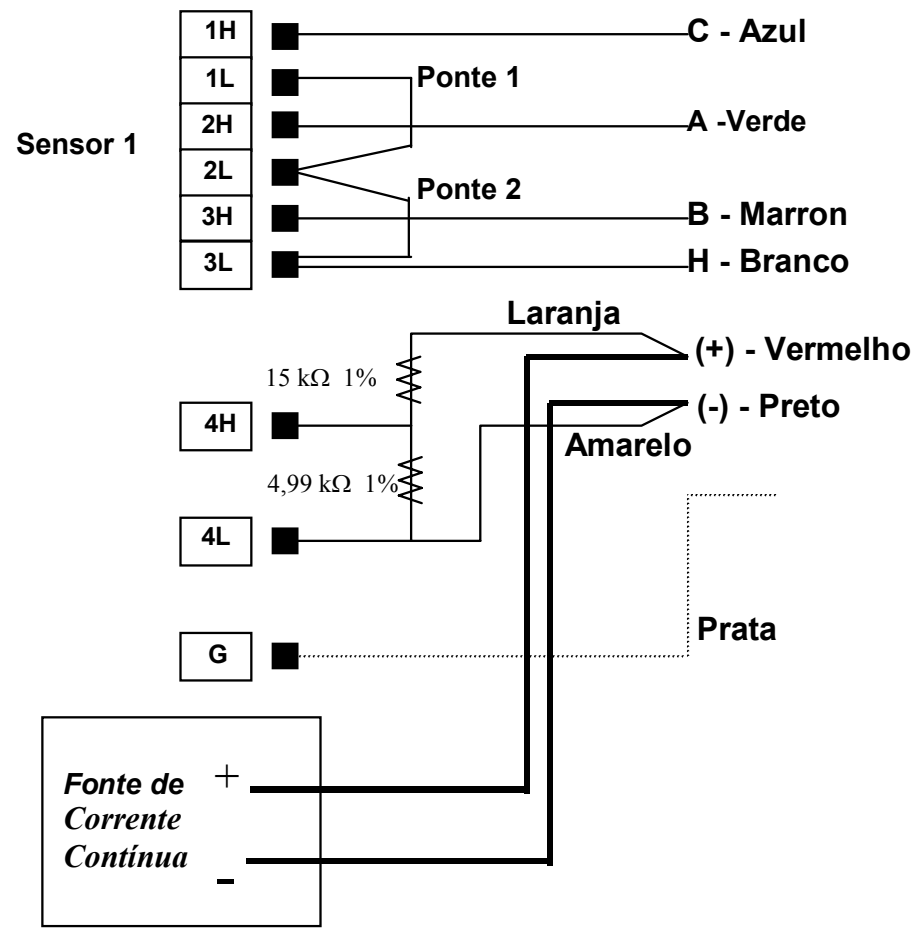

Figura 8 - Esquema de ligação dos sensores comerciais Dynamax, utilizando 4 canais analógicos diferenciais para sua ligação, indicando a ordem de ligação dos fios e seus padrões de cores.

A determinação de $\mathrm{Kr}$ foi feita tomando-se dados obtidos durante a madrugada, quando se presume que o fluxo de seiva é nulo ou desprezível sob condições de boa disponibilidade hídrica do solo, calculando-se Qr como termo residual da equação (10) e Kr a partir da equação (12). Embora Valancogne \& Nasr (1993) tenham sugerido que seja considerado o valor mínimo da madrugada como representativo de $\mathrm{Kr}$, no presente trabalho seguiu-se a recomendação de Gutiérrez et al. (1994), adotando-se como valor representativo de Kr para cada dia de medida a média dos valores obtidos a cada 15 minutos entre as 3:00 e 5:00 da madrugada.

$$
K r=\frac{Q a-P}{T i-T e}
$$


em que Qa é o fluxo de calor axial (W); P é a potência aplicada (W) e; Ti-Te é a diferença de temperatura entre a face interna e a externa do fluxímetro de termpar do sensor $\left({ }^{\circ} \mathrm{C}\right)$.

Como forma de avaliação dos resultados obtidos com os sensores, o fabricante sugere a aplicação de dois filtros aos dados de fluxo de seiva, sendo um deles utilizado em condições de altas taxas de transpiração e outro nas condições de reduzida ascensão de água pelo caule. $\mathrm{O}$ filtro para baixas taxas de transpiração é empregado nos momentos em que o valor de dT aproxima-se de zero, o que ocorre quando há um aquecimento do caule pelo sensor devido ao baixo fluxo de água. Com isso, mesmo havendo uma expressiva redução do valor de Qf, os valores de dT tendem para zero e isso leva a ocorrência de taxas de transpiração excessivamente altas e, portanto, irreais. A aplicação deste filtro foi feita utilizando-se o seguinte algoritmo:

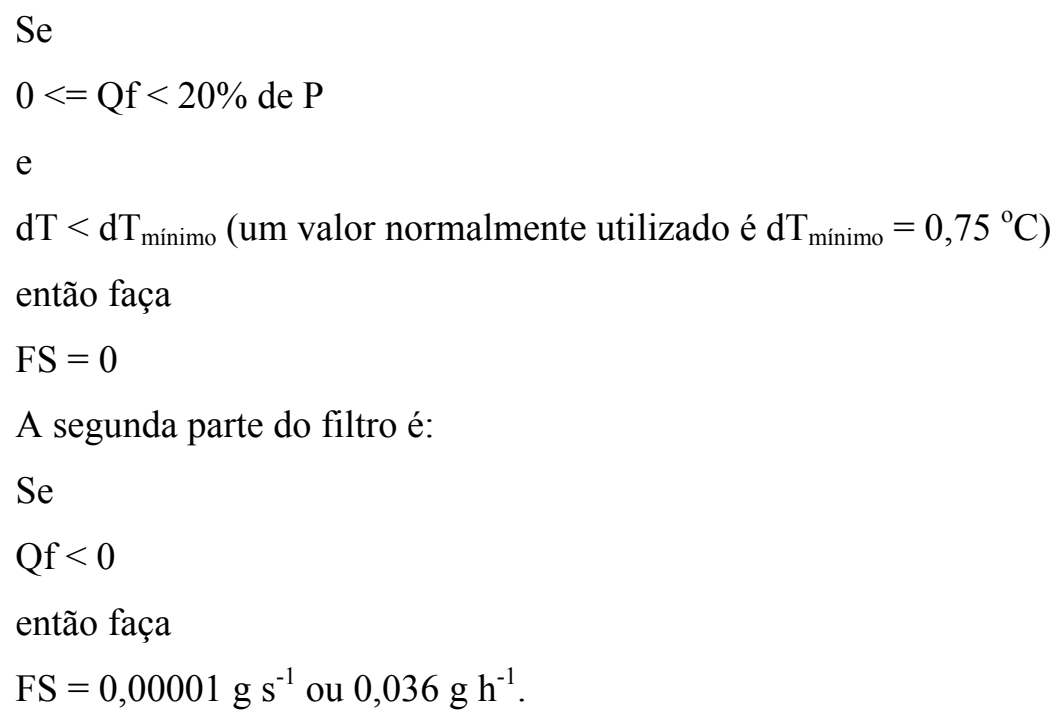

O filtro para altas taxas de transpiração também leva em conta a relação hiperbólica entre a taxa de fluxo e o valor de dT. Considerando-se que o máximo fluxo é obtido com o mínimo valor de dT, a limitação prática de valores de fluxos de seiva elevados é determinada a partir da análise de sensibilidade do sensor. Os erros normalmente verificados nos momentos de fluxos elevados estão relacionados com valores excessivamente baixos de dT, sendo possível minimizar esse tipo de erro aplicando-se um filtro aos dados que imponha um valor máximo de fluxo de seiva. Esse filtro pode ser determinado a partir da velocidade máxima de ascensão de seiva e da área da seção reta do caule. A velocidade máxima $\left(\mathrm{V}_{\max }\right)$ de ascensão normalmente utilizada nesse procedimento é de $0,042 \mathrm{~cm} \mathrm{~s}^{-1}$ que multiplicada pela área média da seção 
transversal do caule (A) fornece o valor máximo de fluxo $\left(\mathrm{FS}_{\max }\right)$, como apresentado no algoritmo a seguir:

$$
\begin{aligned}
& \mathrm{FS}_{\text {max }}=\mathrm{V}_{\text {max }} \mathrm{A} \\
& \mathrm{Se} \\
& \mathrm{FS}>\mathrm{FS}_{\text {max }} \\
& \text { então faça } \\
& \mathrm{FS}=\mathrm{FS}_{\text {max }}
\end{aligned}
$$

Para que fosse assegurada a qualidade das medidas, recobriu-se o sensor com quatro camadas de papel aluminizado de modo a melhorar o isolamento térmico do sensor (Figura 9A) e, para evitar a entrada de água da chuva na parte superior, utilizou-se uma camada de cola de silicone para vedar os espaços entre as folhas de papel alumínio e os ramos, minimizando os efeitos prejudiciais da umidade sobre os sensores e sobre o caule das árvores (Figura 9B). Além disso, fez-se uma proteção adicional sobre os sensores, valendo-se de uma estrutura em forma de cone e revestida de papel alumínio, de modo que a parte mais estreita do cone ficasse justaposta à extremidade superior do sensor.

De acordo com Gutiérrez et al. (1994), esse procedimento resultou num expressivo ganho de qualidade das medidas de fluxo de seiva com os sensores comerciais. Além disso, para evitar o efeito negativo da água sobre o desempenho dos sensores, o caule das plantas foi recoberto por um filme plástico liso e, sob este, aplicou-se uma camada de pasta com elevada condutividade térmica e baixa condutividade elétrica (G4 eletrical insulating compound, Dow Corning, Houston, Texas, EUA), melhorando o contato do sensor com o caule e reduzindo o efeito das irregularidades do tronco sobre as medidas.

A alimentação dos sensores foi feita com uma fonte de corrente contínua (PS-3002D, Dawer, São Paulo, SP), fornecendo uma voltagem de entrada de aproximadamente 6,0 volts, o que é equivalente a uma potência dissipada entre $1,0 \mathrm{~W}$ e $1,5 \mathrm{~W}$, dependendo da resistência elétrica da jaqueta térmica do sensor. 


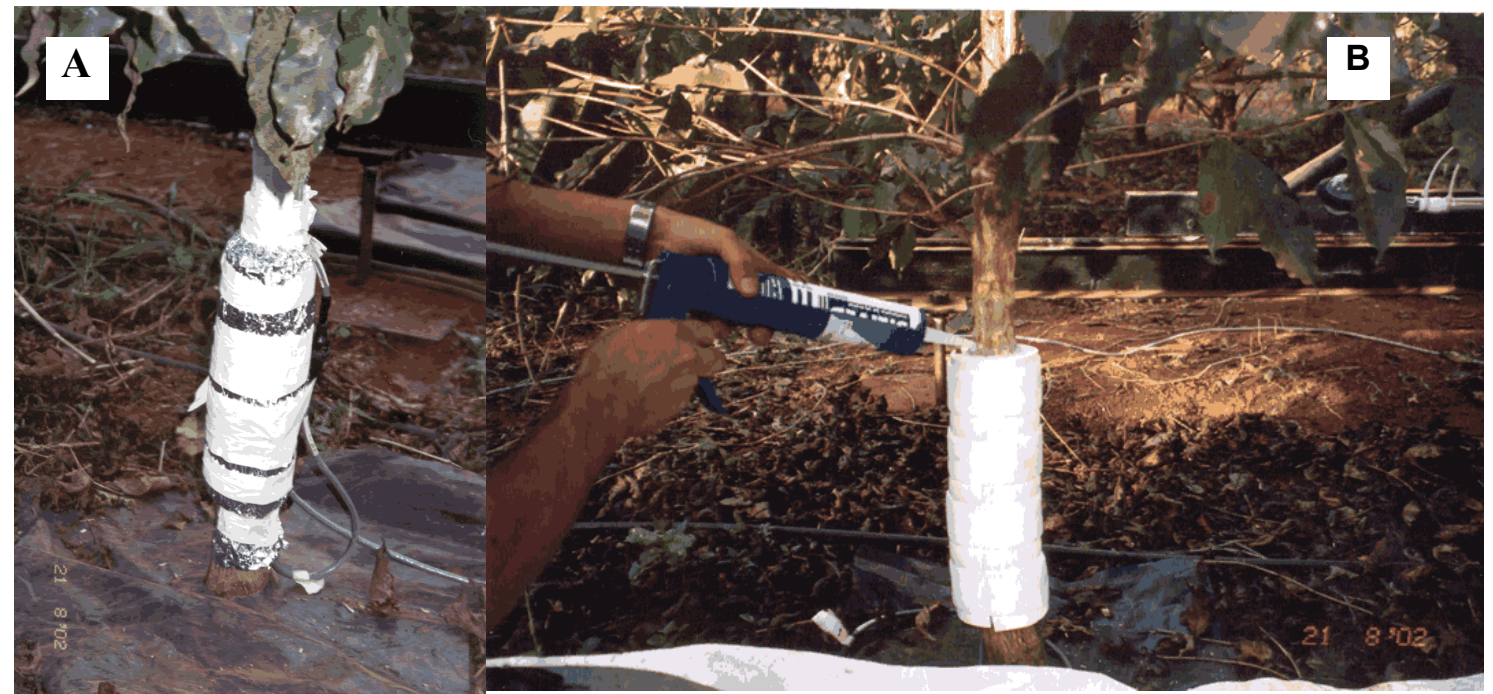

Figura 9 - Vista do sensor recoberto com camadas de papel alumínio e sem o cone de papel alumínio (A) e durante a aplicação da cola de silicone da parte superior do sensor (B).

\subsection{MODELO DE PENMAN-MONTEITH ADAPTADO A PLANTAS ISOLADAS}

A estimativa da transpiração máxima dos cafeeiros foi feita empregando-se o modelo de Penman-Monteith (Monteith, 1965) adaptado para folhas hipoestomáticas, conforme apresentado na equação (13) para intervalo de tempo de 15 minutos. Os dados estimados pelo modelo foram integrados para períodos de 24 horas, considerando-se os valores de Rnf iguais a zero durante o período noturno, obtendo-se assim a transpiração das plantas pelo termo aerodinâmico da equação. A título de comparação, o modelo também foi utilizado somente para dados do período diurno, considerando-se nula a transpiração no período noturno.

$$
T=A F \frac{s R n_{f}+900 \rho c p \frac{\Delta e}{r a}}{\lambda\left[s+\gamma\left(2+\frac{r c}{r a}\right)\right]}
$$

em que T é a transpiração máxima $\left(\mathrm{kg}\right.$ árvore $\left.{ }^{-1} 15 \mathrm{~min}^{-1}\right)$; $\mathrm{AF}$ é a área foliar da árvore $\left(\mathrm{m}^{2}\right) ; \mathrm{Rn}_{\mathrm{f}}$ é o saldo de radiação efetivo da copa ( $\mathrm{MJ} \mathrm{m}^{-2}$ de folha $\left.15 \mathrm{~min}^{-1}\right)$ (item 3.4.1); ra é a resistência aerodinâmica à difusão de vapor $\left(\mathrm{s} \mathrm{m}^{-1}\right)$ (item 3.4.2); rf é a resistência da cobertura à difusão de vapor $\left(\mathrm{s} \mathrm{m}^{-1}\right)$; $\rho$ é a densidade de ar $\left(\mathrm{kg} \mathrm{m}^{-3}\right)$ (item 3.4.3); cp é o calor específico do ar seco 
$\left(\mathrm{J} \mathrm{kg}^{-1} \mathrm{~K}^{-1}\right)$; $\lambda$ é o calor latente de vaporização da água $\left(\mathrm{MJ} \mathrm{kg}^{-1}\right) ; \gamma$ é o coeficiente psicrométrico $\left(\mathrm{kPa}^{\mathrm{O}} \mathrm{C}^{-1}\right) ; \Delta$ e é o déficit de pressão de vapor do $\operatorname{ar}(\mathrm{kPa})$.

\subsubsection{ENERGIA RADIANTE ABSORVIDA PELAS PLANTAS}

A Figura 10 ilustra o sistema móvel de medida da energia radiante na copa por oito saldo-radiômetros (Q7.1, REBS, Logan, Utah, EUA). Os saldo-radiômetros foram instalados a intervalos de $45^{\circ} \mathrm{em}$ um arco circular de alumínio posicionado em torno do renque e deslocandose na direção deste à velocidade aproximada de $12,8 \mathrm{~m} \mathrm{~min}^{-1}$, apoiado sobre um suporte tracionado por corrente com 4,28m de comprimento e acionado por um motor elétrico de $0,75 \mathrm{hp}$ com redutor de velocidade. O sistema descrevia um caminho de ida e volta a cada 40 segundos, permitido por um mecanismo de inversão da rotação do motor acionado por um sistema de fotocélulas, acopladas a uma central eletrônica de comando numa extremidade e, na outra, por um dispositivo de rosca sem fim que acionava um relê de contato. O sistema amostrava integralmente a copa de quatro cafeeiros.

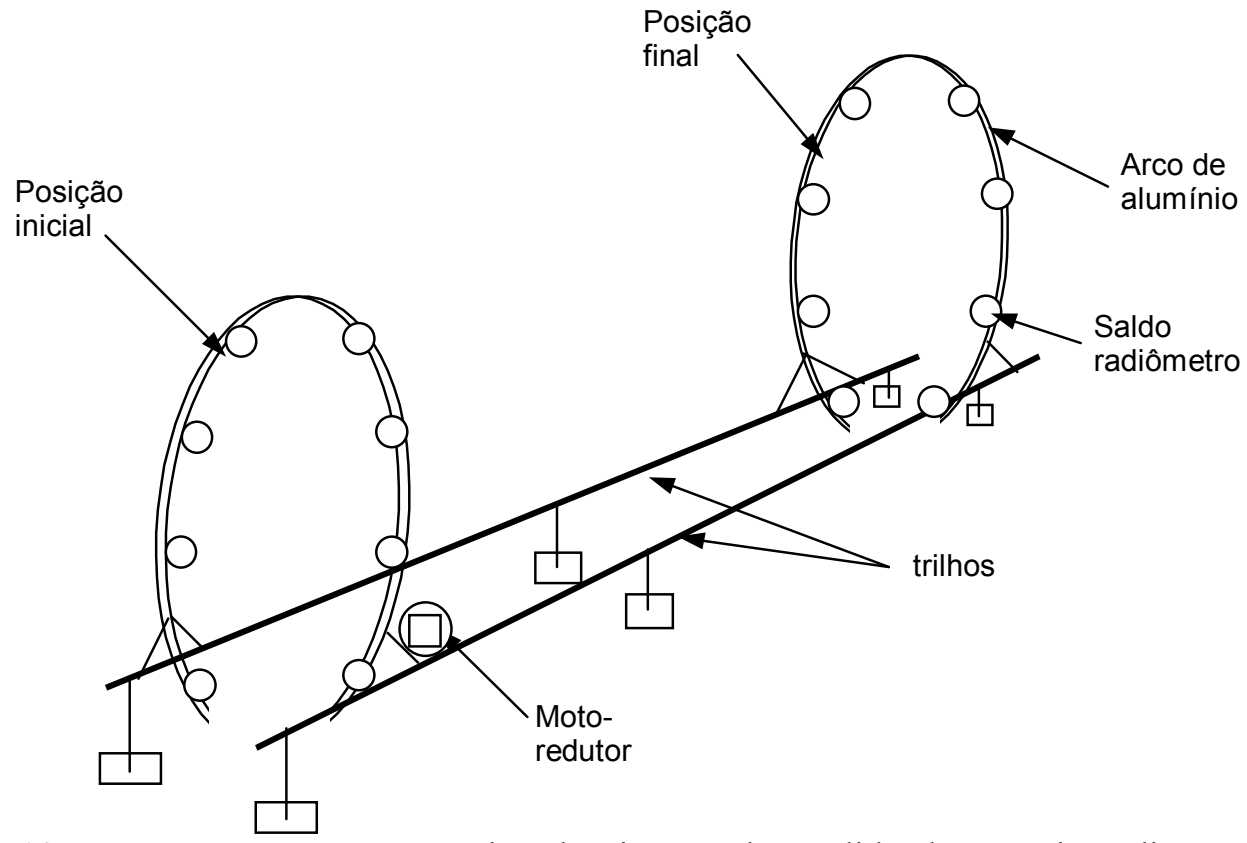

Figura 10 - Representação esquemática do sistema de medida da energia radiante absorvida pelos cafeeiros. 
Os saldo-radiômetros foram posicionados no arco de maneira que suas placas sensoras tangenciassem uma superfície curvilínea hipotética em torno da copa das árvores, de modo que o deslocamento dos sensores na linha do renque gerava uma geometria cilíndrica de medida.

O valor do saldo de radiação total para o renque foi obtido pela integração das medidas dos oito saldo-radiômetros, considerando-se que cada um deles varria áreas equivalentes que, somadas, compondo a área representada pela superfície lateral do cilindro de medida (excetuando-se a área plana das duas bases). Desse modo, a energia radiante absorvida pelas plantas amostradas pelo sistema móvel de medida da radiação (SMR) foi calculado com as equações (14) e (15).

$$
\begin{aligned}
& R n p=\left(\frac{1}{8} \sum_{i=1}^{8} R n_{i}\right) d_{h} 2 R \pi \\
& R n f=\frac{\left(\frac{1}{8} \sum_{i=1}^{8} R n_{i}\right) d_{h} 2 R \pi}{A F}
\end{aligned}
$$

em que: $\mathrm{Rn}_{\mathrm{i}}$ é a medida de saldo de radiação de cada um dos oito saldo-radiômetros; $\mathrm{d}_{\mathrm{h}}$ é a distância horizontal percorrida pelo sistema $(4,28 \mathrm{~m})$ e; R é o raio do arco de fixação dos saldoradiômetros $(1,15 \mathrm{~m})$.

Os valores obtidos com o SMR foram comparados com medidas horizontais de saldo de radiação feitas sobre gramado e sobre o cafezal e, também, com a radiação solar global, estabelecendo-se relações entre elas. As comparações com medidas sobre gramado foram facilitadas pelo fato da área experimental distanciar-se apenas $150 \mathrm{~m}$ da Estação Agrometeorológica do Departamento de Ciência Exatas da ESALQ.

A parte inferior do SMR foi pintada de preto para reduzir a reflexão da radiação solar incidente e reduzir os erros de medida de Rnp, procedimento adotado após medidas realizadas sobre gramado, nas quais constatou-se que o componente de erro devido à reflexão da radiação solar era considerável. O alinhamento dos saldo-radiômetros foi feito de modo que as placas dos oito sensores focalizassem o centro geométrico do arco de alumínio do SMR, já que sua instalação no arco foi feita de forma eqüidistante. Para tanto, alinhou-se as partes sensoras dos saldo radiômetros utilizando um fio fino flexível esticado entre sensores opostos (Figura 11) e ajustando um ângulo reto entre o fio e a superfície sensora por meio de um esquadro. 


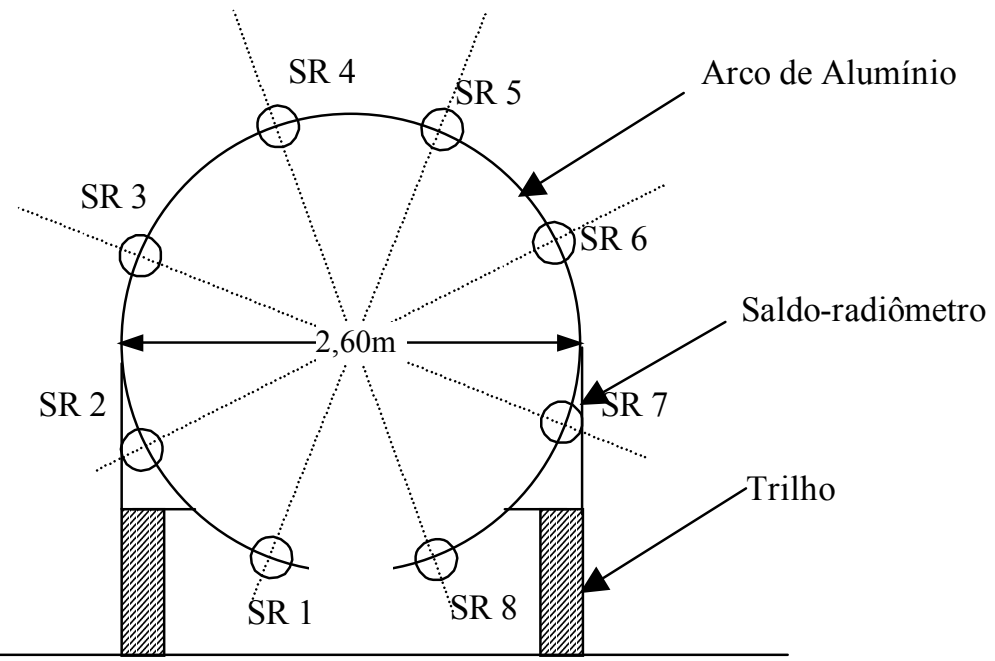

Figura 11 - Representação esquemática do sistema móvel para medida da energia radiante disponível para quatro cafeeiros no renque.

Antes de o SMR ter sido instalado no cafezal, fez-se uma seqüência de medidas sobre superfície gramada, sem plantas no centro do cilindro sensor. Nesse procedimento, admitiu-se a hipótese de que não havendo qualquer corpo no interior do cilindro, o saldo de radiação medido deveria tender a zero. $\mathrm{O}$ teste foi realizado durante o período diurno de três dias, com medidas a cada segundo e médias a cada 10 minutos dos oito sensores. Para o cálculo dos desvios em relação ao zero (DRn) no procedimento de aferição utilizou-se a mesma equação para a determinação de Rnp, já que os valores diferentes de zero obtidos quando o SMR encontrava-se sobre gramado e sem plantas no centro do cilindro-sensor representaram o erro associado às medidas de Rnp.

A energia absorvida por unidade de área foliar foi determinada, também, a partir de medidas do saldo de radiação sob os renques, subtraindo-se o seu valor daquele medido acima do cafezal, conforme a metodologia utilizada por Daamen et al. (1999). Os valores de saldo de radiação utilizados neste procedimento foram obtidos a partir dos saldo-radiômetros instalados no SMR, sendo que o saldo de radiação acima da copa foi considerado igual a média dos sensores 4 e 5 (Figura 11) e, abaixo, pelo sensores instalados na parte inferior do sistema (1 e 8 , Figura 11).

Determinou-se o coeficiente de extinção do cafeeiro e, utilizando-se o enfoque proposto por Ritchie (1972), baseado na lei de Beer, estimou-se o valor da energia radiante absorvida pelas plantas (doravante denominada de Rnfb, para diferenciá-la dos valores determinados com o 
SMR) a partir de medidas de saldo de radiação feitas acima do cafezal, empregando-se a equação (16).

$$
R n f b=\frac{R n_{a c}\left(1-e^{-k I A F}\right)}{I A F}
$$

em que: Rnfb é o saldo de radiação expresso por unidade de área foliar ( $\mathrm{W} \mathrm{m}^{-2}$ folha); $\mathrm{Rn}_{\mathrm{ac}}$ é o saldo de radiação acima do cafezal $\left(\mathrm{W} \mathrm{m}^{-2}\right), \mathrm{k}$ é o coeficiente de extinção (adimensional); IAF é o índice de área foliar com base na área projetada da copa (adimensional).

\subsubsection{RESISTÊNCIA AERODINÂMICA}

De acordo com os estudos realizados em túneis de vento por Landsberg \& Powell (1973) a resistência aerodinâmica de uma planta isolada, ou mesmo de um conjunto de plantas é função da velocidade do vento, da razão entre a área frontal (ou silhueta) e a área foliar, bem como de uma dimensão característica das folhas. A equação original de Landsberg \& Powell (1973) foi adaptada e apresentada na forma da equação (17) por Landsberg \& Jones (1981).

$$
r a=58 p^{0,56}\left(\frac{\delta}{u}\right)^{0,5}
$$

em que p é uma medida da razão entre a área foliar e a área frontal de cada árvore na direção predominante do vento; $u$ é a velocidade do vento medida na altura média das copas conforme a recomendação de Landsberg \& Jones (1981); $\delta$ é uma dimensão característica (m) das folhas e considerada igual a raiz quadrada da área média das folhas da árvore ( $\mathrm{af}_{\mathrm{m}}$ ) (Angelocci, 1996). A Tabela 3 apresenta os valores do fator p para as árvores estudadas.

$\mathrm{O}$ valor de $\mathrm{af}_{\mathrm{m}}$ foi determinado por ocasião da medida da área foliar das plantas estudadas, fazendo-se a contagem de todas as folhas de uma das plantas e medindo-se o maior comprimento (C) e a maior largura (L) de aproximadamente $10 \%$ delas, obtendo-se assim valor médio pela seguinte relação:

$$
a f_{m}=C L \phi
$$

em que $\phi$ é o fator de ponderação de forma da folha, determinado por Marin et al. (2003) para as plantas do cafezal estudado. Esse fator foi determinado medindo-se a área de 50 folhas de uma planta com um medidor eletrônico de área foliar (LI3100, Li-Cor, Lincoln, NE, EUA). A área de cada folha foi relacionada, então, ao produto $C *$ L através de análise de regressão (Figura 12), obtendo-se um valor de $\phi=0,703 \mathrm{~cm}^{2}$, com $\mathrm{R}^{2}=0,986$. A área foliar total (AF) das plantas foi 
obtida multiplicando o valor de af $\mathrm{m}_{\mathrm{m}}$ pelo número de folhas de cada árvore, variando entre 2686, na planta 4 , e 5150 na planta 2.

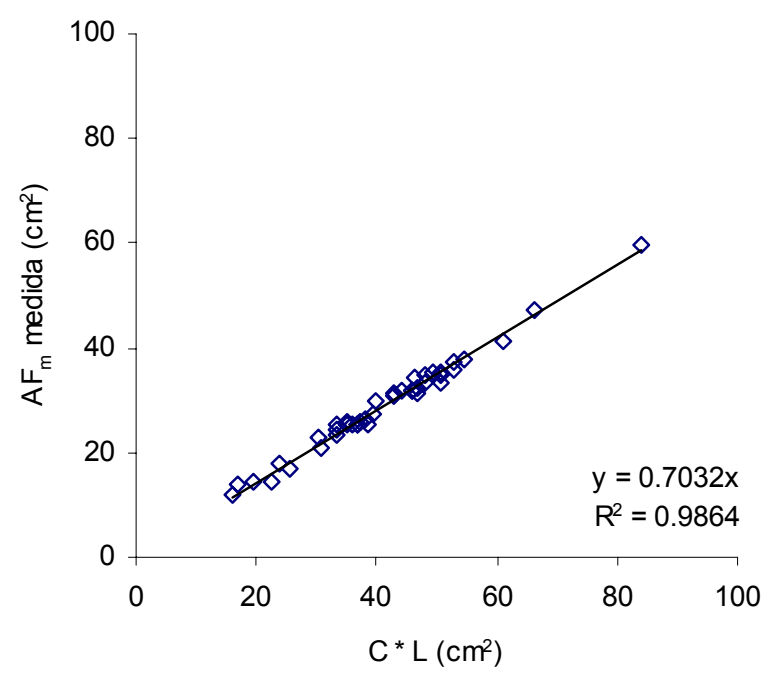

Figura 12 - Relação entre a área de 50 folhas de um cafeeiro e o produto entre o maior comprimento (C) e a maior largura (L) de cada uma delas.

Foi utilizada uma segunda forma para determinação da área foliar das plantas, com um medidor portátil de área foliar (LAI-2000 Canopy Analyser, Li-Cor, Lincoln, NE, EUA), atentando-se para suas restrições no que se refere às medidas de AF e IAF em plantas isoladas. Foram considerados como referência os valores de AF obtidos através da média aritmética entre os dois métodos. A Tabela 2 mostra os valores de área foliar, índice de área foliar e área da silhueta das quatro árvores amostradas.

A velocidade do vento foi medida a $1,5 \mathrm{~m}$ acima do solo de acordo com o descrito no item 3.2. Foi feita a medida, também, da velocidade do vento a $3,5 \mathrm{~m}$ de altura, visando a caracterização das propriedades aerodinâmicas da vegetação e a estimativa da resistência aerodinâmica do cafezal com a equação (7), apresentada no item 2.3.1.2. Os valores assim estimados foram comparados com a determinação de ra feitas com o modelo de Landsberg \& Powell (1973). Os valores de d e zo foram determinados a partir de relações com a altura média dos cafeeiros $(\mathrm{h})$, considerando-se zo igual a $10 \%$ de $\mathrm{h}(2,5 \mathrm{~m})$ e d igual a $65 \%$ de $\mathrm{h}$ (Cowan, 1968). 
Tabela 2. Valores medidos de área foliar (AF) com analisador de dossel (LAI 2000) e pela contagem e medição das folhas $\left(\mathrm{af}_{\mathrm{m}}{ }^{*} \mathrm{C} * \mathrm{~L}\right)$, índice de área foliar (IAF) e da razão entre $\mathrm{AF}$ e a área da silhueta (p) de quatro cafeeiros. O índice de área foliar foi determinado com base na área projetada de copa sobre o solo.

\begin{tabular}{ccccccccccccc}
\hline Método & & Planta 1 & & \multicolumn{3}{r}{ Planta 2 } & & Planta 3 & \multicolumn{3}{c}{ Planta 4 } \\
& $\mathrm{AF}\left(\mathrm{m}^{2}\right)$ & $\mathrm{IAF}$ & $\mathrm{p}$ & $\mathrm{AF}\left(\mathrm{m}^{2}\right)$ & $\mathrm{IAF}$ & $\mathrm{p}$ & $\mathrm{AF}\left(\mathrm{m}^{2}\right)$ & $\mathrm{IAF}$ & $\mathrm{p}$ & $\mathrm{AF}\left(\mathrm{m}^{2}\right)$ & $\mathrm{IAF}$ & $\mathrm{p}$ \\
\hline LAI 2000 & 9,1 & & & 13,8 & & & 11,6 & & 6,1 & \\
$\mathrm{af}_{\mathrm{m}}{ }^{*} \mathrm{C}{ }^{*} \mathrm{~L}$ & 9,6 & & & 14,0 & & & 11,1 & & & 5,9 & & \\
Média & 9,3 & 3,6 & 3,2 & 13,9 & 4,5 & 4,2 & 11,4 & 3,4 & 3,1 & 6,0 & 2,4 & 2,0 \\
\hline
\end{tabular}

\subsubsection{RESISTÊNCIA FOLIAR À DIFUSÃO DE VAPOR}

Tanto a medida quanto a modelagem dessa variável são complicadas devido às características inerentes ao processo biofísico de regulação estomática, além da altíssima variabilidade espacial da resistência de cobertura numa mesma árvore (Angelocci et al., 1998). Diante disso, com base nas ponderações feitas por Alves \& Pereira (2000) a respeito do enfoque com que deve ser encarada a rf, utilizou-se uma forma alternativa para sua estimativa, em acordo com as formulações propostas por Pereira et al. (1999).

Essa proposição baseia-se no enfoque utilizado por Monteith (1965) na descrição do "modelo da grande folha" ("big-leaf model"), o qual assume que a cobertura vegetal atua como se fosse uma única grande folha, com um determinado valor de Rnf e rf (Marin et al., 2001a). Pode-se descrever o balanço de energia dessa cobertura com a equação (19):

$$
R n f=H+\lambda E
$$

em que Rnf é o saldo de radiação efetivo da cobertura vegetal, ( $\mathrm{W} \mathrm{m}^{-2}$ de folha), H é a densidade de fluxo de calor sensível entre a vegetação e a atmosfera ( $\mathrm{W} \mathrm{m}^{-2}$ de folha), dado pela equação (20); $\lambda E$ é a densidade de fluxo de calor latente proveniente da copa ( $\mathrm{W} \mathrm{m}^{-2}$ de folha), dado pela equação (21).

$$
H=\frac{\rho c p\left(T_{f}-T_{a r}\right)}{r a}
$$




$$
\lambda E=\frac{\rho c p\left(e_{f}-e_{a r}\right)}{\gamma(r c+2 r a)}
$$

em que $\mathrm{T}_{\mathrm{f}}$ é a temperatura da "grande folha" $\left({ }^{\circ} \mathrm{C}\right)$; Tar a temperatura do ar $\left({ }^{\circ} \mathrm{C}\right) ; \mathrm{e}_{\mathrm{f}}$ a pressão atual de vapor da cavidade estomática $(\mathrm{kPa})$, considerada igual à pressão de saturação de vapor à temperatura da folha; $e_{a r}$ é a pressão atual de vapor do ar turbulento $(\mathrm{kPa}) ; \gamma$ é a coeficiente psicrométrico $\left(\mathrm{kPa}^{\circ} \mathrm{C}^{-1}\right)$; rf é a resistência à difusão de vapor da "grande folha" $\left(\mathrm{s} \mathrm{m}^{-1}\right)$.

Substituindo-se as equações (20) e (21) na equação (19), tem-se:

$$
R n_{f}=\frac{\rho c p\left(T_{f}-T_{a r}\right)}{r a}+\frac{\rho c p\left(e_{f}-e_{a r}\right)}{\gamma(r f+2 r a)}
$$

Num dado dossel vegetativo, sabe-se que as folhas estão submetidas cada qual a uma condição diferenciada, tanto radiativa quanto aerodinâmica. Essa variabilidade, portanto, afeta diferenciadamente cada extrato do dossel, e até mesmo cada uma das folhas, daí serem freqüentes os relatos experimentais de variabilidade espacial altíssima em medidas foliares, sobretudo no que diz respeito à sua temperatura. No entanto, numa condição em que não haja restrição hídrica, existem evidências de que a temperatura média das folhas do dossel seja próxima da temperatura do ar devido ao processo transpiratório, no qual há perda de energia na forma de calor latente.

Admitindo-se como verdadeira essa premissa, a equação (22) resume-se à equação (23), de modo que, evidenciando-se rf, obtém-se a equação (24):

$$
\begin{aligned}
& R n_{f}=\frac{\rho c p \Delta e}{\gamma(r f+2 r a)} \\
& r f=\frac{\rho c p \Delta e}{\lambda R n_{f}}-2 r a
\end{aligned}
$$

A partir da equação (24) deduz-se que a desconsideração do fluxo de calor sensível (H) é uma limitação do modelo. Uma forma para minimização desse erro é subtrair do valor de $\mathrm{Rn}_{\mathrm{ef}} \mathrm{a}$ fração convertida em calor sensível e, assim, tornar as estimativas mais realistas. Os estudos realizados com o método da razão de Bowen (item 3.5.1) indicaram que $\mathrm{H}$ representou, em média, 30\% do saldo de radiação do cafezal durante a fase experimental do trabalho, entre agosto e novembro, no período das 8:00 as 17:00. Portanto, a equação de estimativa de rf pode ser corrigida para uso no período diurno, considerando assim a fração de energia convertida em $\mathrm{H}:$ 


$$
r f=\frac{\rho c p \Delta e}{\gamma 0,70 R n_{f}}-2 r a
$$

A equação (25) fornece, portanto, uma estimativa de rf, para culturas sem restrição hídrica, a partir de variáveis meteorológicas e da resistência aerodinâmica. Para sua avaliação, comparou-se os valores estimados por ela com os valores obtidos com um porômetro de equilíbrio dinâmico (LI 1600 steady state porometer, LI-COR, Lincoln, Nebraska, USA) ao longo de cinco dias. Em cada dia, foram realizadas sete seqüências de medida, a intervalos médios de 1 hora, amostrando-se 20 folhas em cada seqüência. Essas 20 medidas foram feitas subdividindo-se a planta em três extratos e em duas faces, uma voltada para o norte e outra para o sul. Como o lado do renque voltado para o norte possuía maior quantidade de folhas, tomou-se 12 medidas desse lado e 8 no lado voltado para o sul. Considerou-se a média das 20 medidas como representativas de $\mathrm{rf}$ da planta.

A estimativa de rf com a equação (25) foi feita utilizando-se os sensores descritos no item 3.2, sendo que ra foi determinada pela equação de Landsberg \& Powell (1973) com a velocidade do vento medida a $1,5 \mathrm{~m}$; Rnf foi determinada a partir das relações entre as medidas feitas com o SMR e os dados de radiação solar global, para intervalos de 15 minutos. Durante o período noturno, quando a equação 25 fornecia valores negativos, considerou-se rf igual a 10000 $\mathrm{s} \mathrm{m}^{-1}$ com o intuito de simular a resistência da cutícula foliar ao caminho de fluxo do vapor (Nobel, 1999), importante quando os estômatos fecham-se.

\subsection{ESTIMATIVA DA EVAPOTRANSPIRAÇÃO DO CAFEZAL PELO MÉTODO DA RAZÃO DE BOWEN}

O método da razão de Bowen (MRB) é baseado numa relação que leva em conta os gradientes de temperatura do bulbo úmido e do bulbo seco, medidos em duas alturas conhecidas, e um fator de ponderação $\mathrm{W}$, dependente da temperatura do ar e do coeficiente psicrométrico. A determinação da razão de Bowen $(\beta)$ foi feita da seguinte forma (Pereira et al., 1997):

$$
\beta=\left[\frac{\Delta T u}{(1-W) \Delta T s}-1\right]^{-1}
$$

em que $\Delta \mathrm{Tu}$ é a diferença de temperatura do bulbo úmido entre as alturas de medida; e $\Delta \mathrm{Ts}$ é a diferença de temperatura do bulbo seco entre as alturas de medida. $\mathrm{O}$ valor de $\mathrm{W}$ foi calculado a 
partir das equações propostas por Wilson \& Rouse (1972) e Viswanadhan et al. (1991) (apud Pereira et al.,1997):

$$
\begin{gathered}
W=0,407+0,0145 \mathrm{Tu}, \text { para } 0<\mathrm{Tu}<16{ }^{\circ} \mathrm{C} \\
W=0,483+0,01 \mathrm{Tu}, \text { para } 16,1<\mathrm{Tu}<32{ }^{\circ} \mathrm{C}
\end{gathered}
$$

em que Tu é a temperatura média do bulbo úmido entre as alturas de medida.

Os fluxos de calor latente (LE) e sensível (H) foram calculados com as seguintes equações:

$$
\begin{aligned}
& L E=\frac{R n-G}{(1+\beta)} \\
& H=L E \beta
\end{aligned}
$$

Conforme sugerido por Perez et al. (1999), nas situações em que $\beta<-0,75$, o fluxo de calor latente foi considerado igual à energia disponível (Rn-G), ou seja, desprezou-se o fluxo de calor sensível. Esse procedimento foi adotado devido ao fato dessa condição conduzir à estimativas irreais dos fluxos energéticos, já que os valores de $\beta$ perdem seu significado físico. Além disso, valores de $\beta$ próximos de -1 ocorreram durante o nascer e o pôr-do-sol, quando as direções dos gradientes de temperatura e pressão de vapor são opostas, e também durante a ocorrência de precipitações. Dessa forma, desprezou-se os dias chuva e considerou-se que a evapotranspiração igual a zero nos períodos de inversão do gradiente de pressão de vapor. Os valores foram calculados para intervalos de 15 minutos e somados para obtenção dos totais diários e diurnos. As verificações relativas aos valores de $\beta$ foram feitas para cada passo de tempo, através de rotinas de computador.

Para comparação dos dados de evapotranspiração estimados pelo MRB com o fluxo de seiva, tomou-se por base o trabalho de Marin et al. (2002b) por ter apresentado bons resultados em pomar de lima ácida 'Tahiti'. Os autores converteram os dados de transpiração utilizando-se a área foliar das plantas em que se mediu o fluxo de seiva, obtendo-se a transpiração por unidade de área foliar $\left(\mathrm{T}_{\text {folha }}\right)$. A partir de medidas de $\mathrm{AF}$ de várias plantas do pomar, obteve-se a $\mathrm{AF}$ média da população de plantas que, multiplicada pelo número de plantas do pomar, forneceu o volume total de água transpirado, como mostra a equação (26). Os valores de evapotranspiração foram extrapolados a partir da área total do pomar, sendo os fluxos comparados na unidade de $\mathrm{m}^{3} \mathrm{~d}^{-1}$. No presente trabalho, admitiu-se que a média aritmética de AF dos quatro cafeeiros nos quais se mediu a transpiração como representativas do cafezal. A evapotranspiração estimada 
pelo método da razão de Bowen teve sua unidade convertida pela multiplicação dos valores obtidos em $\mathrm{mm} \mathrm{d}^{-1}$ por $2500 \mathrm{~m}^{2}$, área total do cafezal.

$$
T_{\text {total }}=\frac{T_{\text {folha }} A F_{\text {med }} N_{p l}}{1000}
$$

em que $\mathrm{T}_{\text {total }}$ é a transpiração total do cafezal $\left(\mathrm{m}^{3} \mathrm{~d}^{-1}\right) ; \mathrm{T}_{\text {folha }}$ é a transpiração média das quatro plantas, expressa por unidade de área foliar $\left(\mathrm{L} \mathrm{m}^{-2}\right.$ folha $\left.\mathrm{d}^{-1}\right) ; \mathrm{AF}_{\mathrm{med}}$ é a área foliar média das plantas do cafezal, determinada a partir da média aritmética das quatro plantas utilizadas na medida de fluxo de seiva $\left(9,975 \mathrm{~m}^{2}\right.$ ) (Tabela 2); $\mathrm{N}_{\mathrm{pl}}$ é o número de plantas do cafezal (812). $\mathrm{O}$ valor 1000 foi utilizado no denominador da equação para expressão dos valores de $\mathrm{T}_{\text {total }} \mathrm{em} \mathrm{m}^{3}$.

\subsection{ESTIMATIVA DA EVAPOTRANSPIRAÇÃO DE REFERÊNCIA}

Para estimativa da evapotranspiração de referência (ETo) na forma parametrizada pela FAO (Allen et al., 1998) utilizou-se dados da Estação Agrometeorológica Automática do Departamento de Ciências Exatas, da ESALQ, USP. O sistema de aquisição de dados (CR10X, Campbell Scientific, Logan, Utah, EUA) foi programado para realizar medidas a cada segundo e médias a cada 15 minutos. A medida do saldo de radiação foi feita na altura de $1 \mathrm{~m}$ da superfície do solo, sobre gramado, utilizando-se um saldo radiômetro ((NR Lite, Kipp \& Zonen, Delft, Holanda). A temperatura foi medida com termistor e a umidade relativa do ar com sensor capacitivo (HTM45C, Vaisala, Helsinki, Finlândia) posicionado a 2m de altura, em mini-abrigo multiplacas. A velocidade do vento foi medida com um anemômetro de canecas posicionado a $2 \mathrm{~m}$ de altura e com velocidade de partida de $0,2 \mathrm{~m} \mathrm{~s}^{-1}$ (Wind Sentry, R.M. Young, Logan, Utah, USA).

A equação de Penman-Monteith parametrizada para estimativa da evapotranspiração de referência utilizada foi:

$$
E T o=\frac{s(R n+G)}{\left(s+\gamma^{*}\right) \lambda}+\frac{900 \rho c p \Delta e}{\lambda r a\left(s+\gamma^{*}\right)}
$$

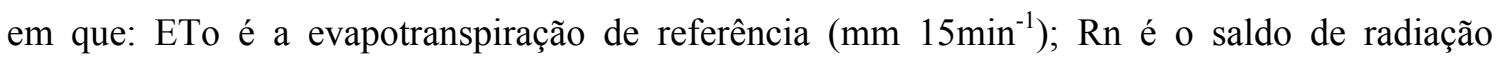
$\left(\mathrm{MJ} \mathrm{m}^{-2} 15 \mathrm{~min}^{-1}\right)$; G é o fluxo de calor no solo $\left(\mathrm{MJ} \mathrm{m}^{-2} 15 \mathrm{~min}^{-1}\right)$, considerado como negativo durante o período diurno; $\rho$ é a densidade do ar $\left(\mathrm{kg} \mathrm{m}^{-3}\right)$; cp é o calor específico do $\operatorname{ar}\left(\mathrm{J} \mathrm{kg}^{-1} \mathrm{k}^{-1}\right)$; $\Delta$ e é o déficit de pressão de vapor do ar $(\mathrm{kPa})$, dado por: 


$$
\Delta e=e_{s}-e_{a}
$$

sendo $e_{\mathrm{a}}$ a pressão atual de vapor do ar $(\mathrm{kPa})$ e $\mathrm{e}_{\mathrm{s}}$ a pressão de vapor de saturação $(\mathrm{kPa})$, determinadas a cada 15 minutos com as equações (32) e (33):

$$
\begin{gathered}
e_{a}=\frac{e_{s} U R}{100} \\
e_{s}=0,6110^{\frac{(7,5 T)}{(237,3+T)}}
\end{gathered}
$$

s é a declividade da curva de pressão de vapor, determinada pela seguinte expressão:

$$
s=\frac{4098 e_{s}}{(T+237,3)^{2}}
$$

sendo $\mathrm{T}$ a temperatura do ar, $\left({ }^{\circ} \mathrm{C}\right) ; \gamma^{*}$ é a coeficiente psicrométrico modificada $\left(\mathrm{kPa}^{\mathrm{O}} \mathrm{C}^{-1}\right)$, dada por

$$
\gamma^{*}=\gamma\left(1+0,33 U_{2}\right)
$$

sendo $\mathrm{U}_{2}$ a velocidade do vento medida a $2 \mathrm{~m}$ e $\gamma$ o coeficiente psicrométrico $\left(0,066 \mathrm{kPa}^{\mathrm{O}} \mathrm{C}^{-1}\right)$; ra é a resistência aerodinâmica $\left(\mathrm{s} \mathrm{m}^{-1}\right)$, obtida pela relação:

$$
r a=\frac{208}{U_{2}}
$$

A conversão de unidades da ETo para comparação com os dados de fluxo de seiva, também convertidos, foi feita com o mesmo procedimento utilizado para os dados de evapotranspiração com o MRB, multiplicando-se as estimativas de ETo pela área total do cafezal. 


\section{RESULTADOS E DISCUSSÃO}

\subsection{CONDIÇÕES MICROMETEOROLÓGICAS DURANTE A FASE EXPERIMENTAL}

Com o objetivo de descrever e caracterizar as condições meteorológicas durante a fase experimental, analisa-se nesta seção as principais variáveis meteorológicas monitoradas no experimento. Faz-se também uma comparação entre as medidas obtidas no cafezal com as medidas da estação agrometeorológica da ESALQ, buscando com isso, além da análise comparativa entre os ambientes, fornecer relações para estimativa dos elementos na cultura a partir de dados oriundos de estações meteorológicas.

\subsubsection{VELOCIDADE DO VENTO}

A Figura 13 ilustra a variação horária da velocidade do vento no cafezal, nas alturas de $1,5 \mathrm{~m}$ e 3,5m e também na estação agrometeorológica, na altura de 2,0 m, para os dias 244 e 296, de 2002. Esses dias foram selecionados para exemplificar a forma de variação da velocidade do vento nessas três posições e por apresentarem uma variabilidade temporal relativamente alta ao longo das 24horas. Para o dia 244, a velocidade média diária do vento variou de $1,9 \mathrm{~m} \mathrm{~s}^{-1}$ na altura de $3,5 \mathrm{~m}$ e $0,7 \mathrm{~m} \mathrm{~s}^{-1}$, a $1,5 \mathrm{~m}$, no cafezal. Já no dia 296, a velocidade média na estação foi de $2,9 \mathrm{~m} \mathrm{~s}^{-1}$ e a $3,5 \mathrm{~m}$, no cafezal, igual a $2,3 \mathrm{~m} \mathrm{~s}^{-1}$.

$\mathrm{Na}$ escala horária a velocidade do vento apresentou uma tendência de variação aleatória nesses dois dias, com as velocidades medidas nas três posições alternando-se ao longo dos períodos., Pelas médias diárias, porém, verifica-se que a tendência de variação torna-se relativamente uniforme em comparação com as medidas obtidas na estação e na altura de $3,5 \mathrm{~m}$, no cafezal (Figura 14). 


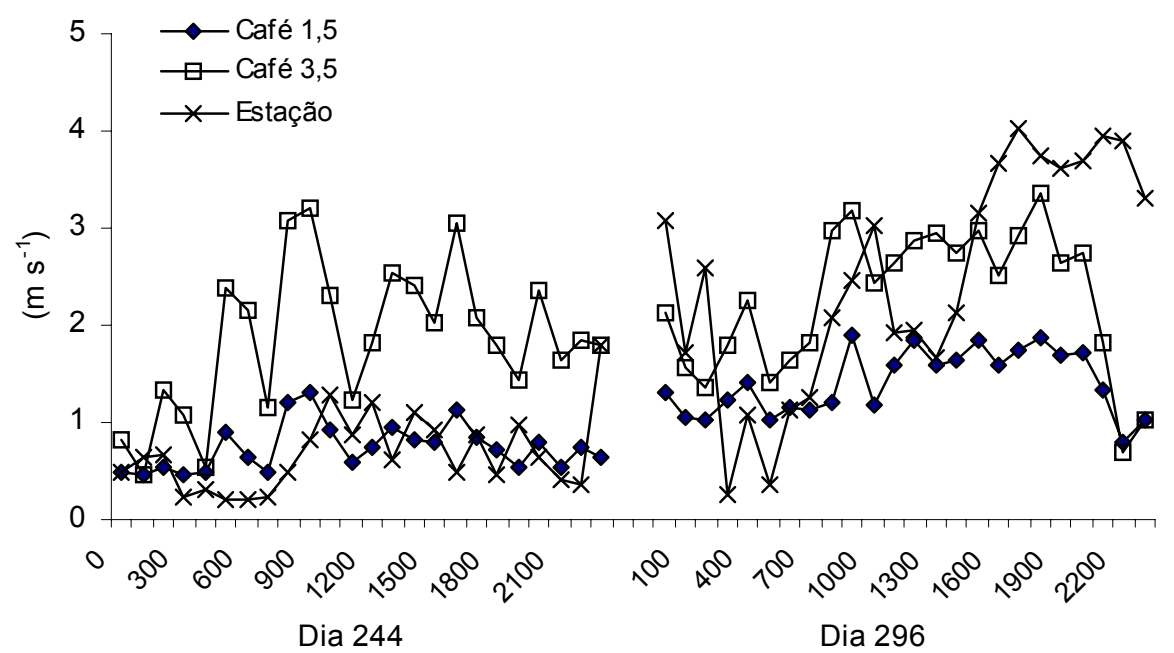

Figura 13 - Variação horária da velocidade do vento nas alturas 3,5m e 1,5m, no cafezal, e de $2 \mathrm{~m}$ na estação agrometeorológica da ESALQ, nos dia 244 e 296 de 2002, em Piracicaba, SP.

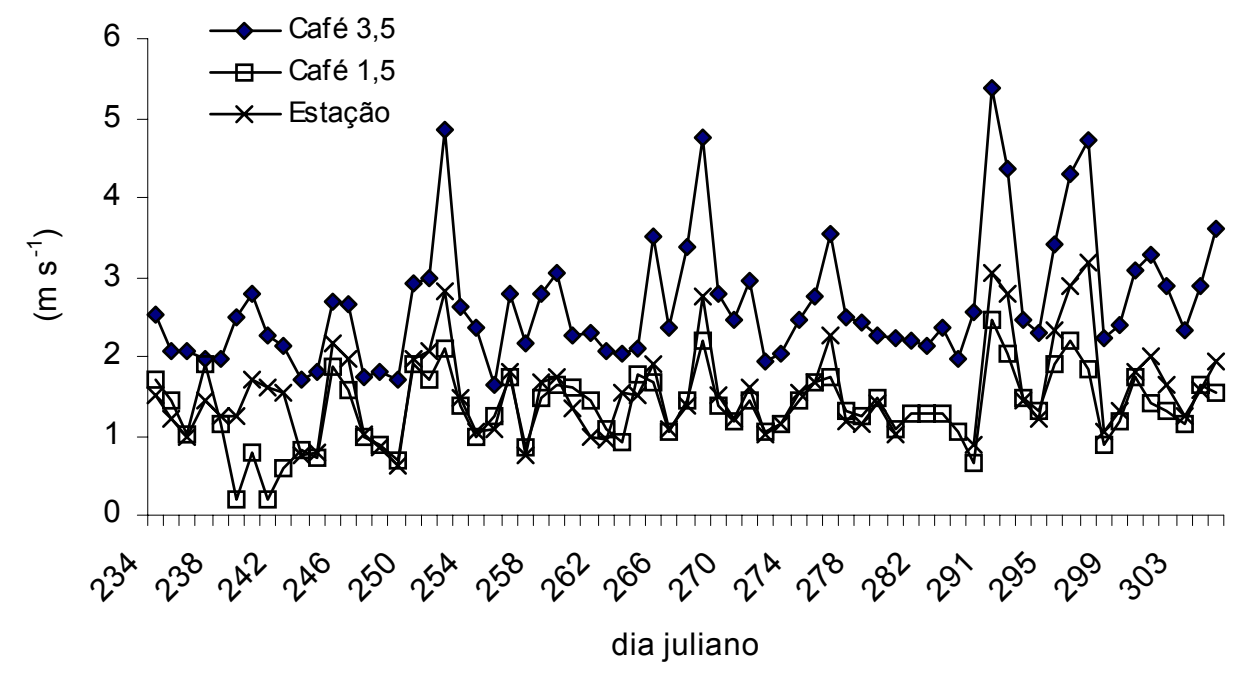

Figura 14 - Variação das médias diárias de velocidade do vento medida no cafezal em alturas de 1,5m (Café 1,5) e 3,5m (Café 3,5) e na estação agrometeorológica da ESALQ, a $2 \mathrm{~m}$ de altura (Estação), durante o período experimental, em Piracicaba, SP.

Para avaliar quantitativamente essas relações, fez-se a análise de regressão linear entre as medidas no cafezal e na estação, verificando-se um bom nível de ajuste dos dados e a 
existência de correlação significativa ao nível de $5 \%$ de probabilidade para as duas análises da Figura 15. Na Figura 15A, pelo valor do coeficiente de determinação $\left(R^{2}=0,81\right)$ vê-se que a dispersão dos dados foi relativamente baixa e, pelo o coeficiente angular da equação $(b=0,58)$, infere-se que a velocidade do vento na altura de $3,5 \mathrm{~m}$ no cafezal foi cerca de $72 \%$ maior que na estação. Como se esperava, a velocidade do vento a 3,5m foi maior que a medida nas outras duas posições e o valor medido abaixo no nível médio dos cafeeiros foi o que apresentou as menores velocidades médias de vento.

O ajuste entre os dados da estação e a 1,5m, no cafezal, não foi tão bom quanto ao obtido na outra comparação, especialmente para valores mais baixos de velocidade do vento (Figura 15B), com $\mathrm{R}^{2}=0,54$ e $\mathrm{b}=1,12$, sendo a velocidade do vento a $2 \mathrm{~m}$ acima do gramado foi cerca de $12 \%$ maior que a medida a $1,5 \mathrm{~m}$. Na Figura 16 apresenta-se a análise de regressão linear entre as medidas realizadas no cafezal, verificando-se um decréscimo ainda maior no nível de ajuste entre os dados $\left(\mathrm{R}^{2}=0,35\right)$, especialmente para valores inferiores a $1 \mathrm{~m} \mathrm{~s}^{-1}$ na altura de $1,5 \mathrm{~m}$.

Jaramillo-Robledo (1994) observou que a velocidade do vento a $3 \mathrm{~m}$ de altura, em cafezal adulto, variou entre $0,8 \mathrm{~m} \mathrm{~s}^{-1}$ e $2,5 \mathrm{~m} \mathrm{~s}^{-1}$ e, a $2 \mathrm{~m}$ de altura, não passou de $0,7 \mathrm{~m} \mathrm{~s}^{-1}$, cerca de três vezes menor. A comparação com o cafezal estudado neste trabalho, no entanto, fica prejudicada porque o autor não menciona altura média dos cafeeiros onde foram realizadas essas medidas.
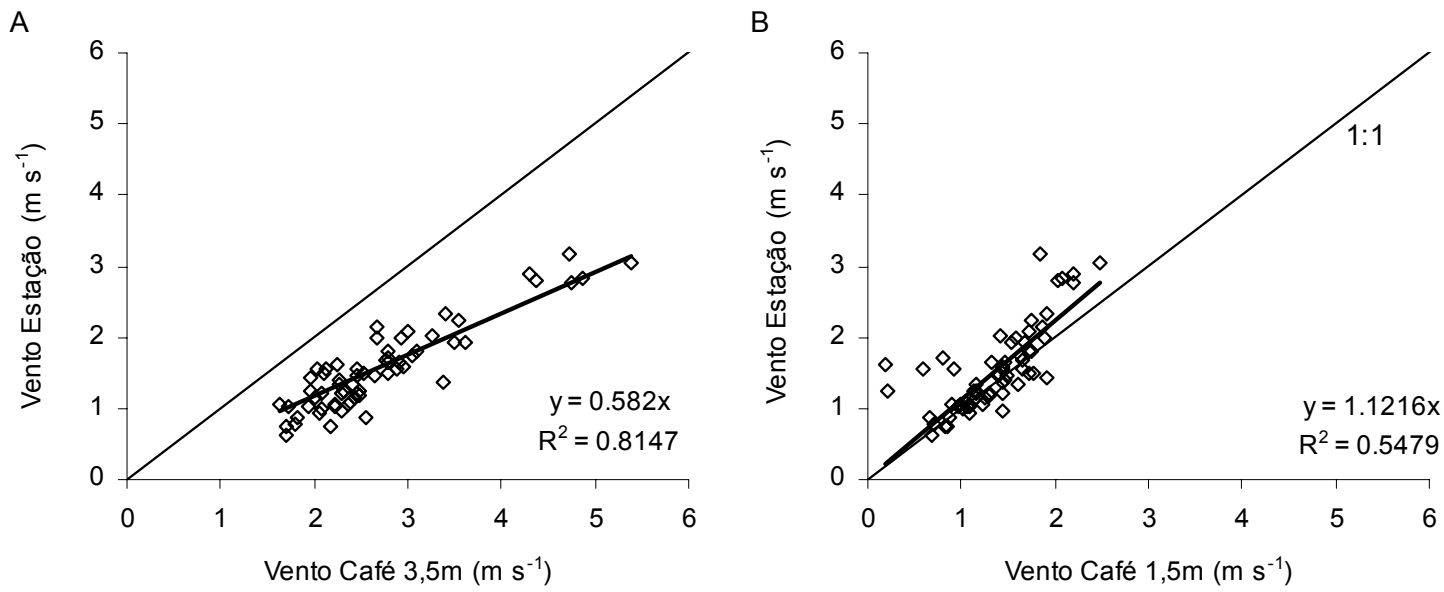

Figura 15 - Correlações entre a velocidade média diária do vento medida na estação agrometeorológica (Vento Estação) e a velocidade do vento medida no cafezal nas alturas de 1,5m (Vento Café 1,5m) e 3,5m (Vento Café 3,5m), em Piracicaba, SP. 


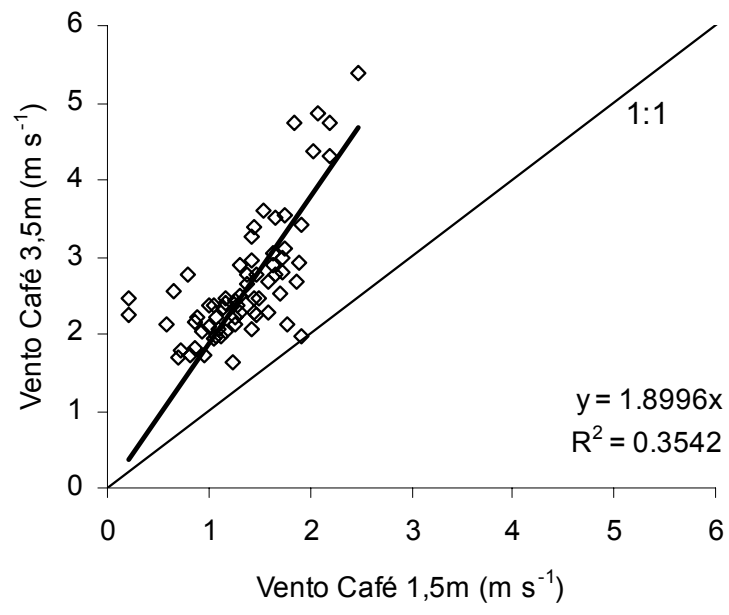

Figura 16 - Correlação entre a velocidade média diária do vento medida no cafezal nas alturas de 1,5m (Vento Café 1,5m) e 3,5m (Vento Café 3,5m), em Piracicaba, SP.

\subsubsection{TEMPERATURA E UMIDADE DO AR}

Comparando as medidas de Tar do cafezal com os valores obtidos na estação (Figura 17A) ao longo dos dias 244 e 296, percebe-se que a temperatura do ar na estação, entre as 14:00 e 24:00, esteve abaixo daquela medida no cafezal e que os valores obtidos na altura de $1,5 \mathrm{~m}$ foram maiores que os medidos a 3,5m, no dia 244. No dia 296, essa tendência se inverteu, com Tar medido a 3,5m sendo maior que os demais. Comparando-se as curvas apresentadas na Figura 17 com as da Figura 13, pode-se inferir que as diferenças da temperatura do ar nas diferentes alturas podem ser relacionadas com a velocidade do vento, já que no dia 244 , quando a temperatura a $1,5 \mathrm{~m}$, no período diurno, foi cerca de $0,7^{\circ} \mathrm{C}$ superior a obtida a $3,5 \mathrm{~m}$, a velocidade do vento a $3,5 \mathrm{~m}$ foi cerca de 2,5 vezes maior que a velocidade a $1,5 \mathrm{~m}$, no mesmo período. Já no dia 296, a velocidade do vento mais elevada nas duas alturas favoreceu as trocas turbulentas entre a atmosfera e a vegetação, reduzindo o gradiente vertical de temperatura no cafezal.

A partir dos valores diários da temperatura do ar (Tar) medida nas duas alturas no cafezal, obteve-se um valor médio igual a $22,6^{\circ} \mathrm{C}$, oscilando entre $13,4^{\circ} \mathrm{C}$ e $28,6^{\circ} \mathrm{C}$. Na estação agrometeorológica, no mesmo período, o valor médio de Tar foi igual a $22,1^{\circ} \mathrm{C}$, variando entre $13,1^{\circ} \mathrm{C}$ e $28,6^{\circ} \mathrm{C}$. Na Figura $17 \mathrm{~B}$ nota-se a proximidade entre os valores médios diários de temperatura do ar nas três posições com grande variação ao longo do período de medidas, devido a passagem de sistemas frontais sobre a região, causando chuvas e queda na temperatura. 

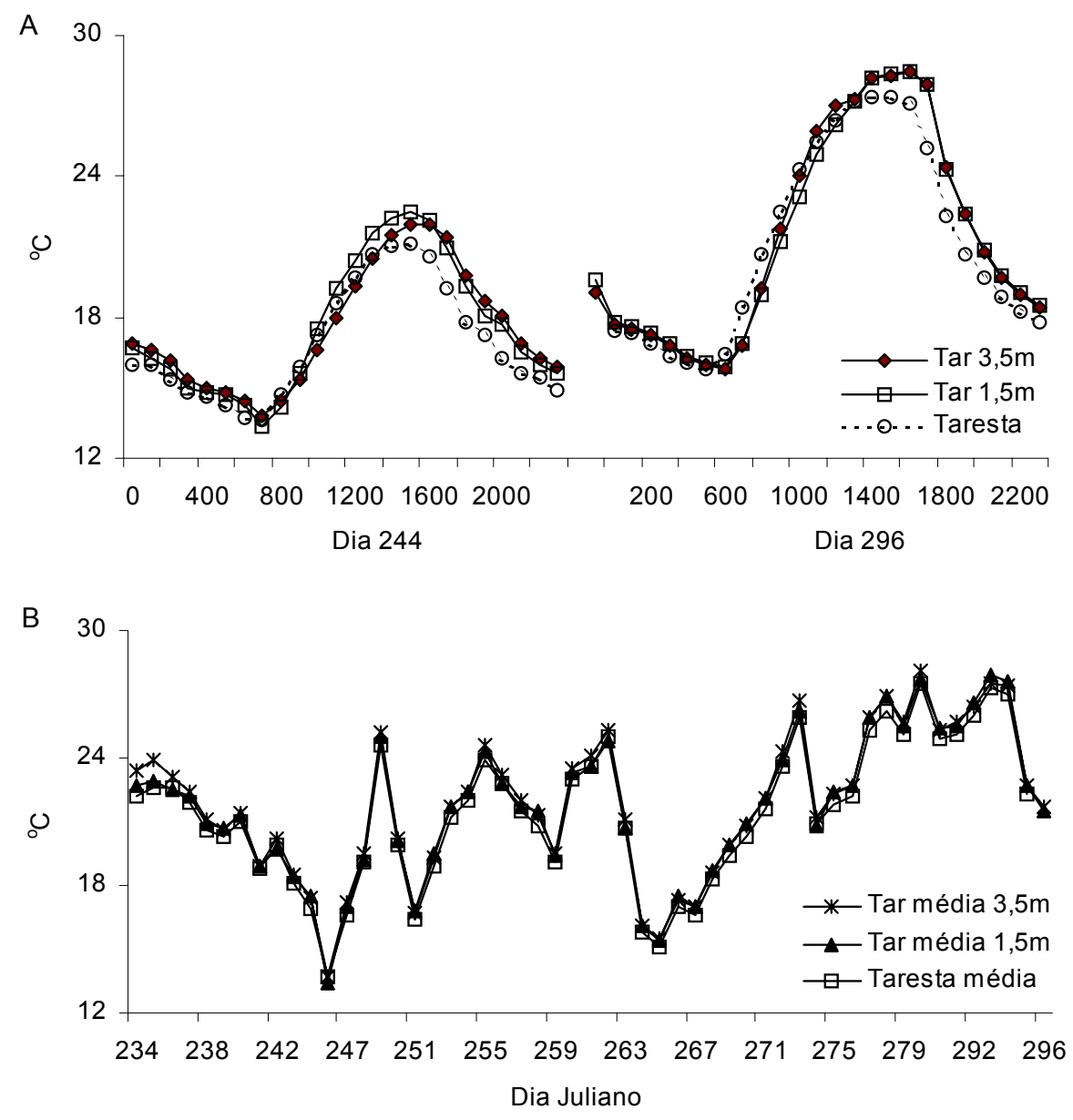

Figura 17 - A - variação horária da temperatura do ar na estação agrometeorológica da ESALQ ( Tar $_{\text {esta }}$ ) e no cafezal, nas alturas de 1,5m (Tar 1,5m) e 3,5m (Tar 3,5m); B - variação diária na temperatura média do ar nas duas alturas e na estação.

A Figura 18 apresenta as relações entre as temperaturas máximas e mínimas diárias obtidas nas duas alturas, no cafezal, com os valores de $\mathrm{R}^{2}$ próximos da unidade e indicando a existência de uma diferença praticamente constante entre os dados, representada pelos coeficientes lineares (a) das equações de regressão. Desses valores pode-se admitir que a diferença média de Tar entre as alturas nos períodos diurno foi igual a $0,59^{\circ} \mathrm{C}$ (Figura 16A) e no período noturno igual a $0,70^{\circ} \mathrm{C}$ (Figura $16 \mathrm{~B}$ ). Tomando-se os valores de todo período de medidas, tem-se que, para as máximas, a diferença média entre as alturas foi igual a $1,1^{\circ} \mathrm{C}$, enquanto que para as mínimas essa diferença foi igual a $0,4^{\circ} \mathrm{C}$. A tendência de valores positivos de a para a máxima e negativos para a mínima são consistentes com a estratificação da temperatura no período diurno e no período noturno, respectivamente. 

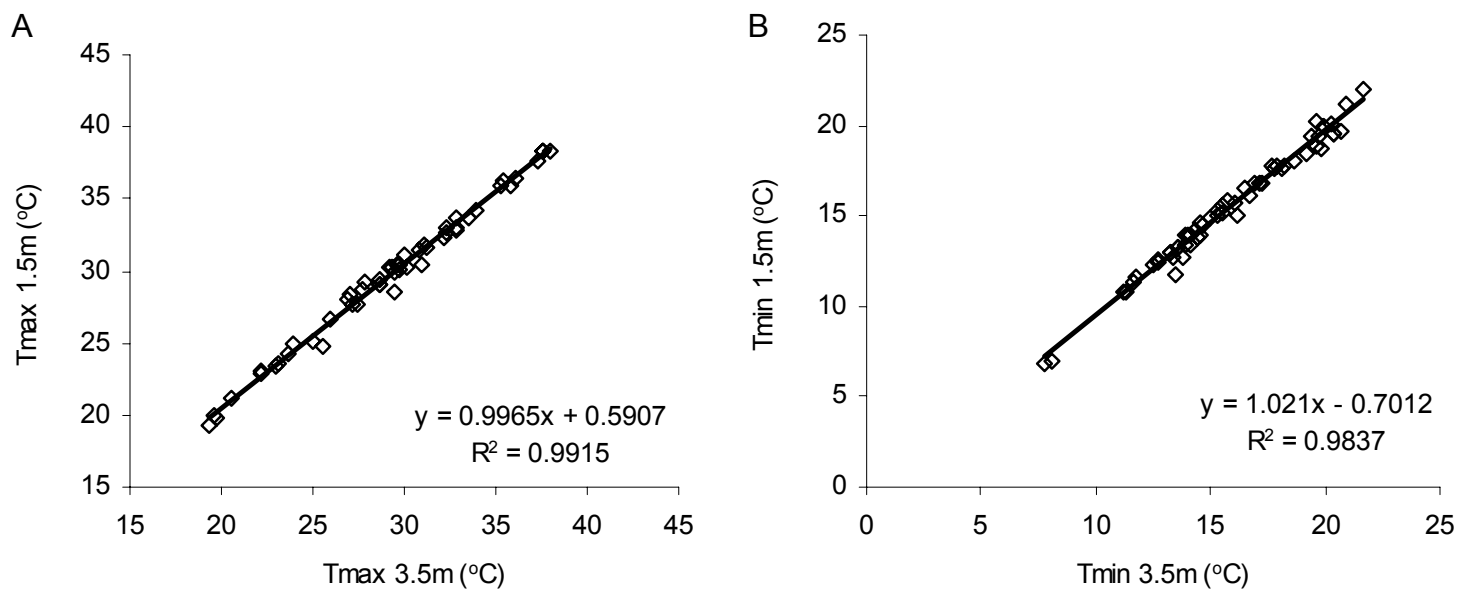

Figura 18 - Correlações entre a temperatura máxima (A) e mínima (B) medidas nas alturas de 1,5m e 3,5m em cafezal, em Piracicaba, SP.

A Figura 19A apresenta a variação da pressão atual de vapor (ea) nas duas alturas do cafezal e também na estação agrometeorológica, notando-se tendências inversas de variação ao longo dos dias amostrados. Enquanto no dia 244 houve tendência de redução na pressão de vapor, no dia 296 tem-se uma elevação de ea nos horários mais quentes, semelhante ao encontrado por Landsberg et al. (1973) e Angelocci (1996) em pomar de macieiras, com elevação considerável de ea por volta das $12 \mathrm{~h}$ e redução proporcional no início da noite. Valendo-se da mesma análise feita pelos autores, esse efeito está associado à abertura estomática, que começa a declinar de forma mais acentuada somente após as 14:00 (item 4.3.1.1) e do maior valor do déficit de saturação do ar no período das 12:00 as 14:00, de modo que a evapotranspiração aumenta, com conseqüente incremento da quantidade de vapor d'água na atmosfera.

Já a redução de ea ao longo do dia 244 está relacionada com a entrada de uma massa de ar frio e seco precedida por um sistema frontal que atuava sobre a região, fenômeno de ocorrência normal nessa época do ano no Estado de São Paulo. Avaliando-se a variação diária da temperatura do ar no mesmo dia (Figura 17A), nota-se que a temperatura máxima não ultrapassou $25^{\circ} \mathrm{C}$, enquanto que no dia 296 , a máxima esteve próxima de $30^{\circ} \mathrm{C}$. Na Figura 21 , verifica-se que os dois dias tiveram níveis de radiação solar semelhantes, reforçando a hipótese de que as variações de ea no dia 244 foram causadas pela ação de uma massa de ar polar seca, contribuindo para a diminuição da quantidade de vapor d'água próximo à superfície. Por outro lado, a tendência de diminuição de ea do interior do cafezal para o nível acima dele é esperado 
pela estratificação do perfil de vapor d'água, com tendência de se aproximarem os valores de ea entre os dois pontos de medida durante a madrugada (Geiger, 1980). Na Figura 19B vê-se que o déficit de pressão de vapor do ar (DPV) apresentou diferenças sistemáticas entre os três pontos de medida, sendo que na maior parte dos dias analisados a altura de $3,5 \mathrm{~m}$ no cafezal teve os maiores valores de DPV, com média de $0,905 \mathrm{kPa}$. Na estação meteorológica, ocorreram os menores valores de DPV ao longo do experimento, variando entre 1,974 $\mathrm{kPa}$ e 0,103 $\mathrm{kPa}$, devendo-se ressaltar que o sensor de umidade do ar da estação é diferente dos usados no cafezal.
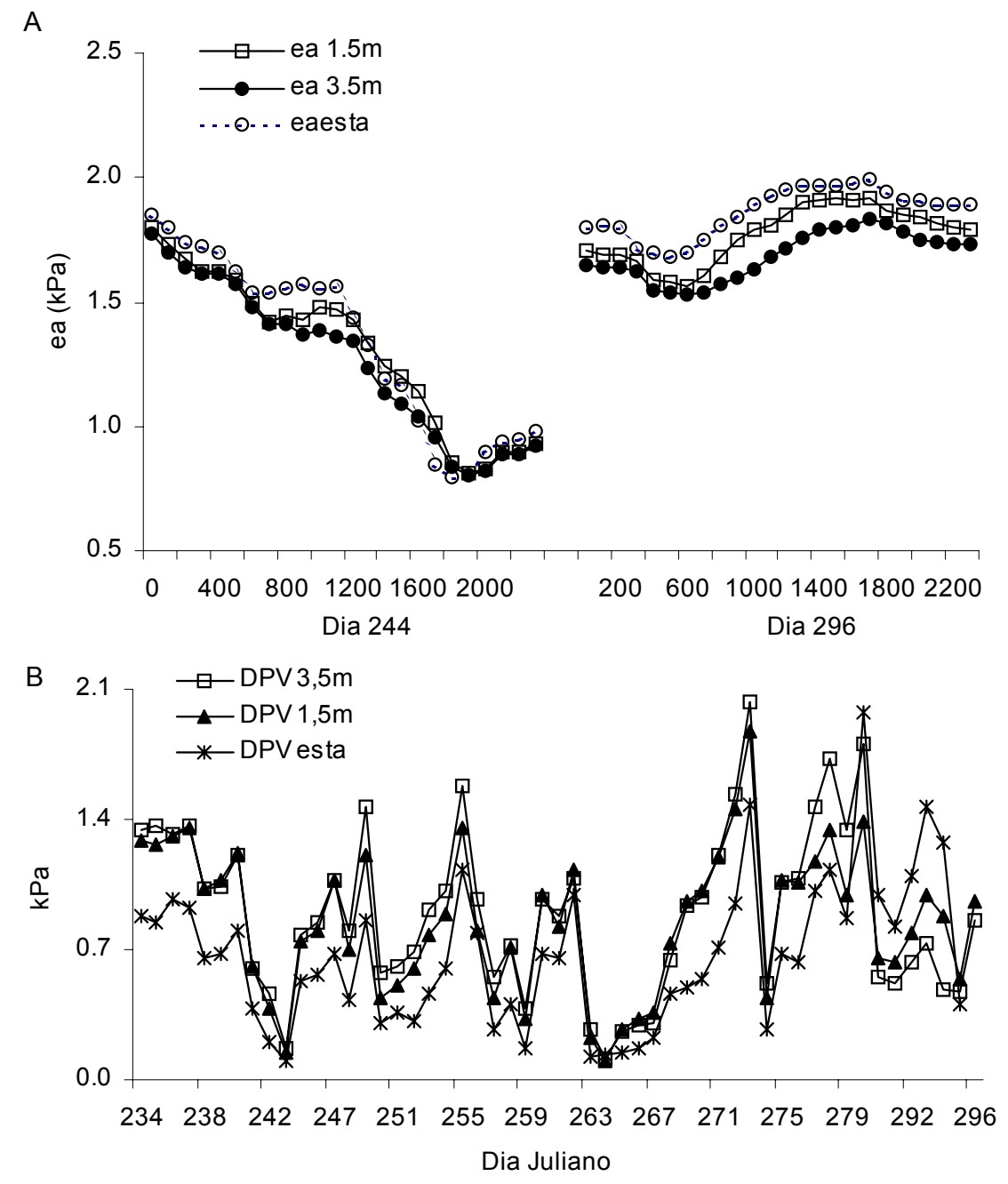

Figura 19 - A - variação horária da pressão atual de vapor para as alturas de 3,5m (ea 3,5m) e 1,5m (ea 1,5m) e na estação agrometeorológica da ESALQ (eaesta), para os dias 244 e 296 de 2002, em Piracicaba, SP. B - variação diária do déficit de pressão de vapor médio diário (DPV) nas três posições ao longo do experimento 


\subsubsection{ENERGIA RADIANTE E BALANÇO DE RADIAÇÃO}

O fluxo de calor no solo foi medido por placas de fluxo instaladas em profundidades similares e em diferentes posições no cafezal. As curvas apresentadas para os dias 244 e 296 indicaram que a condução da energia térmica no solo foi diferente entre as posições, com a placa G2, inserida em região de solo exposto sem cobertura morta ou vegetação, apresentando a maior amplitude de variação entre os três pontos de medida (Figura 20). Além disso, pela defasagem entre as curvas, verifica-se que, nas outras duas placas sensoras, a cobertura da vegetação rasteira e a sombra dos cafeeiros restringiram o fluxo de calor no solo nesses pontos, resultando inclusive na menor amplitude das curvas G1 e G3 (Figura 20). Tomando-se os dados médios das três placas, tem-se que o de fluxo de calor no solo representou cerca de $5 \%$ da energia radiante disponível no ambiente para o período diário e cerca de $9 \%$ para o período diurno.

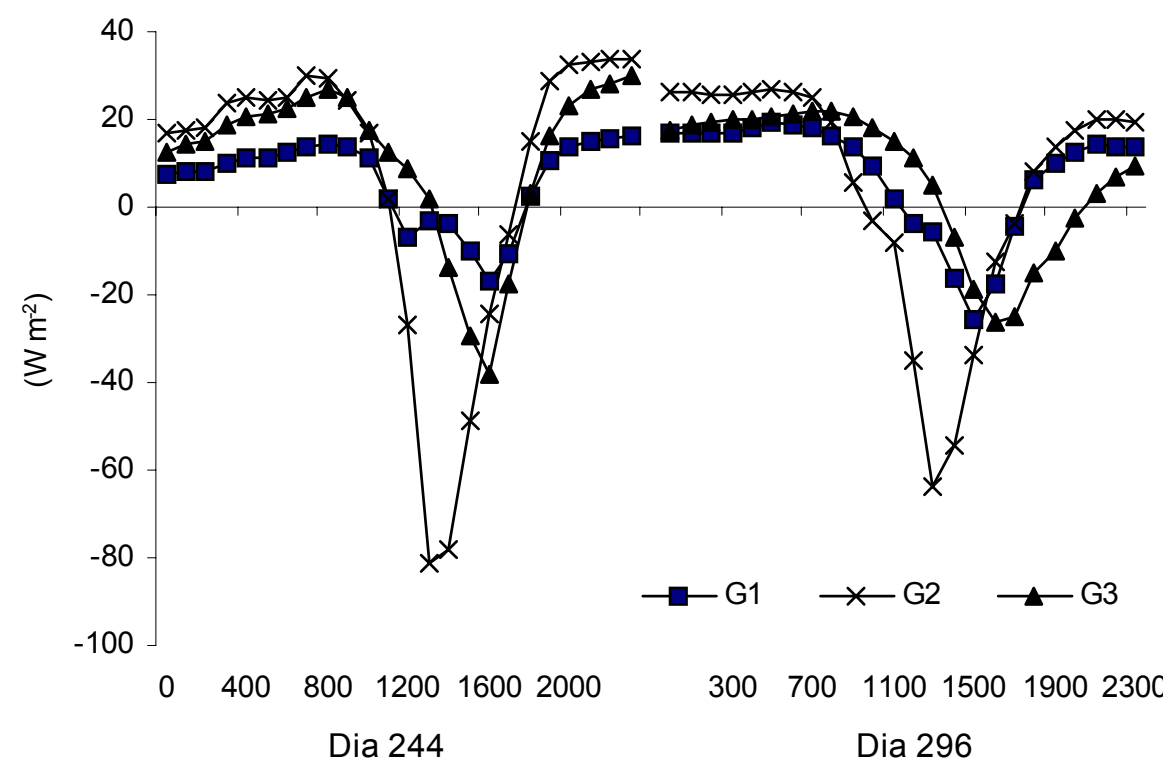

Figura 20 - Variação horária do fluxo de calor no solo medido em três posições do cafezal, ao longo de dois dias de 2002, em Piracicaba, SP. G1 - solo coberto com vegetação rasteira e sombreado pelos cafeeiros; G2 - solo nu sem sombreamento; G3 - solo com cobertura morta.

A Figura 21 mostra a variação da radiação solar global $(\mathrm{RG})$ e do saldo de radiação medido acima do cafezal (Rncafé) ao longo dos dias 244 e 296. Nota-se pelas curvas que ambos 
tiveram céu limpo, mas diferentes condições de temperatura, umidade do ar e regime de ventos, como já discutido. $\mathrm{O}$ valor médio de $\mathrm{RG}$ foi igual a $453 \mathrm{~W} \mathrm{~m}^{-2}$ e os valores médios de Rncafé foram de $267 \mathrm{~W} \mathrm{~m}^{-2}$ para o período diurno e de $118 \mathrm{~W} \mathrm{~m}^{-2}$ para os dados diários.

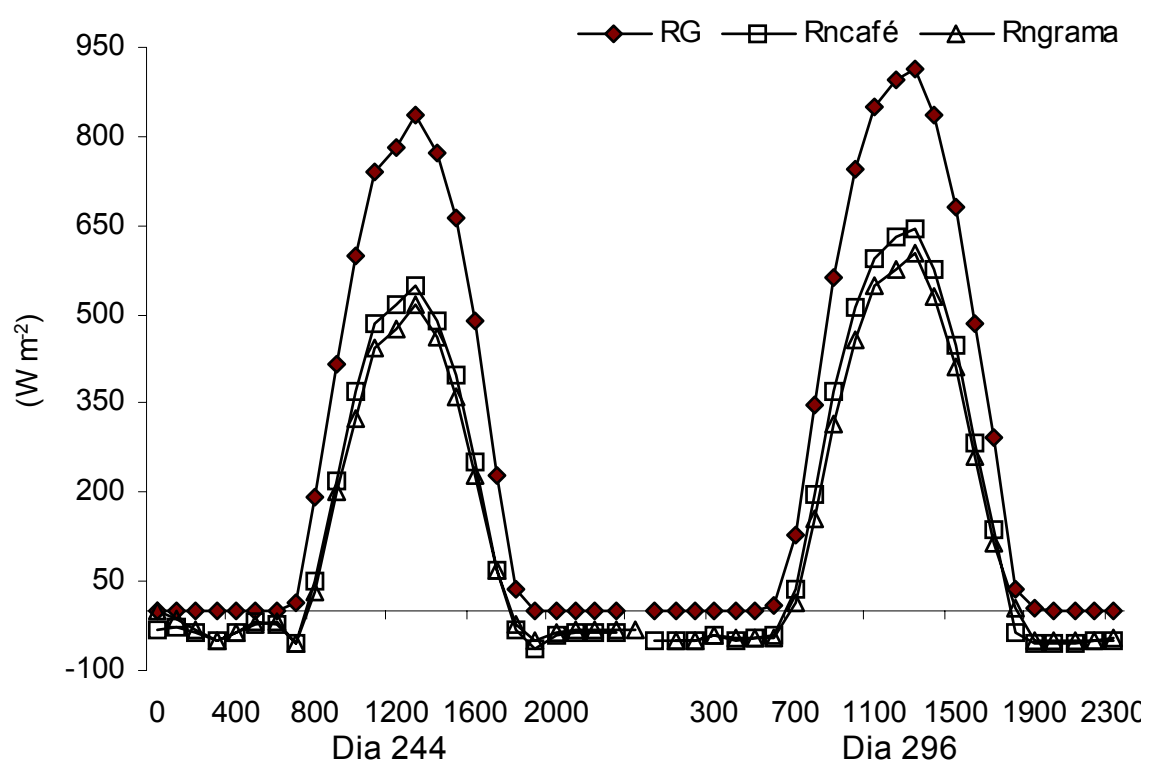

Figura 21 - Variação horária do saldo de radiação medido no cafezal (Rncafé) e sobre gramado e da radiação solar global para dois dias de 2002, em Piracicaba, SP.

A Figura 22 mostra a variação dos valores integrados diários de RG, Rncafé e do saldo de radiação medido sobre gramado (Rngrama) para toda a fase experimental do trabalho, podendo-se notar a ampla faixa de variação desses elementos ao longo do período de medidas. Os valores de RG variaram entre 4,1 $\mathrm{MJ} \mathrm{m}^{-2} \mathrm{~d}^{-1} \mathrm{e} 24,8 \mathrm{MJ} \mathrm{m}^{-2} \mathrm{~d}^{-1}$, com média de $17,4 \mathrm{MJ} \mathrm{m}^{-2} \mathrm{~d}^{-1}$, enquanto que os valores de Rngrama tiveram variação entre $0,7 \mathrm{MJ} \mathrm{m}^{-2} \mathrm{~d}^{-1}$ e $12,9 \mathrm{MJ} \mathrm{m}^{-2} \mathrm{~d}^{-1}$, com média de $8,2 \mathrm{MJ} \mathrm{m}^{-2} \mathrm{~d}^{-1}$. 


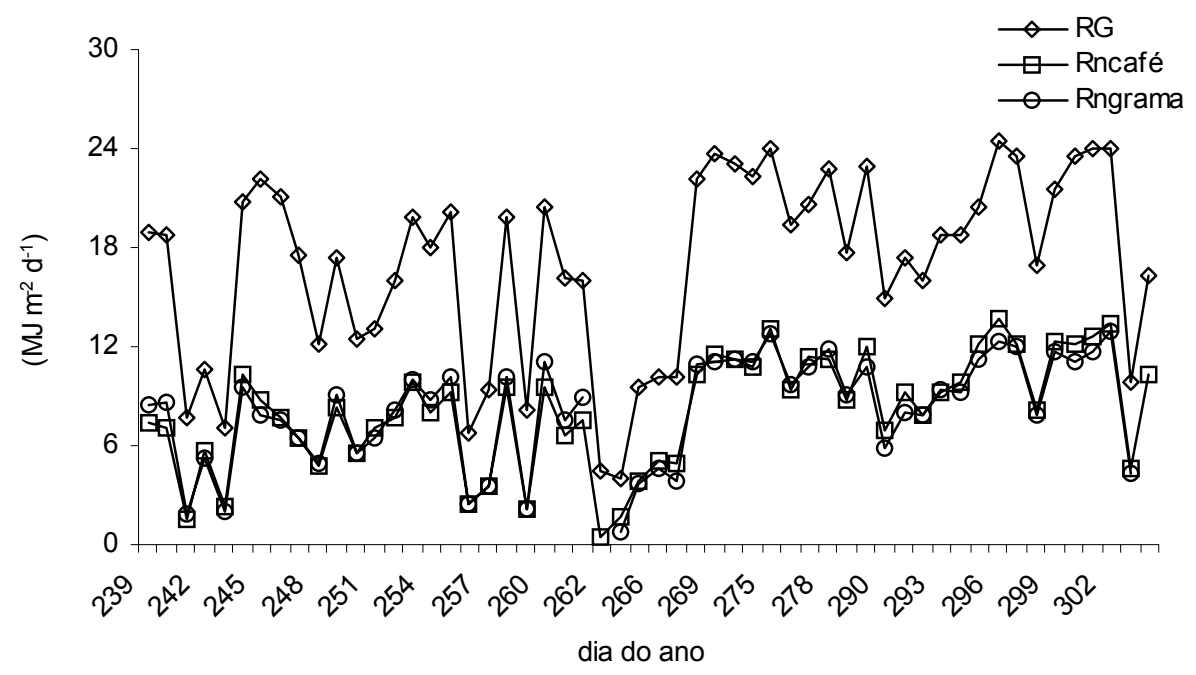

Figura 22 - Variação dos valores integrados para períodos diários do saldo de radiação medido sobre o cafezal (Rncafé), saldo de radiação medido sobre gramado (Rngrama), na estação agrometeorológica, e da radiação solar global (RG) durante a fase experimental, em Piracicaba, SP.

Uma informação de grande utilidade relacionada com o balanço de radiação de culturas é a relação entre o saldo de radiação da cultura e RG, por permitir a estimativa dos valores de saldo de radiação a partir de medidas mais simples. A Figura 23A mostra essa relação para os dados obtidos no cafezal, indicando que Rncafé representou 49\% de RG. É importante destacar que, apesar de ser de fácil aplicação, essa relação não pode ser extrapolada para qualquer cafezal, mas apenas para aqueles cultivados em espaçamentos semelhantes ao utilizado neste estudo, de mesmo porte, para a mesma época do ano e mesma condição de cobertura do solo.

Pode-se, no entanto, comparar esse valor com os dados obtidos em outras coberturas vegetais. Em lima ácida 'Tahiti', Marin et al., 2001b encontraram que a razão entre Rn medido sobre o pomar e RG variou entre 0,59 e 0,69 entre a primavera e o inverno, respectivamente. Pereira et al. (1998) propuseram um único valor anual para a razão entre Rngrama e RG em Piracicaba, igual a 0,57 e Sentelhas \& Nascimento (2001) aprofundaram essas análises estudando separadamente cada mês do ano e encontrando que Rngrama/RG variou de 0,595, em fevereiro, a 0,500, em julho, destacando como causa principal a variação sazonal das propriedades óticas do gramado, aumentando o balanço de ondas curtas e reduzindo os valores absolutos de Rngrama nos meses mais secos do ano. Angelocci (1996) trabalhando com pomar de macieiras irrigado por gotejamento e com vegetação na entrelinha com espaçamento de $4,7 \mathrm{~m}$ 
por 1,6m, na França, verificou uma variação na relação Rnpomar/RG entre 0,65 e 0,67 entre os meses de julho e agosto. Jaramillo-Robledo (1994) encontrou a relação Rncafé/RG, para um cafezal cultivado com uma população de 10000 plantas $\mathrm{a}^{-1}$, igual a 0,744 , indicando que a população de plantas e a cobertura vegetal da entrelinha tem influência na determinação dessa relação.

Pela Figura 23B vê-se que, durante a primavera, a relação Rngrama/RG aproximou-se da relação entre Rncafé e Rngrama, já que os valores de saldo de radiação medidos nos dois ambientes ficaram muito próximos, com $b=1,006$. Assim, levando-se em conta que durante o período de medidas o gramado passava por um período de deficiência hídrica relativamente acentuada, pode-se aventar como causa provável para a diminuição do valor da relação Rncafé/RG em relação ao de Jaramillo-Robledo (1994) a presença de matéria seca na entrelinha do cafezal durante boa parte do período de medidas, acarretando em aumento do albedo global do cafezal e diminuição do balanço de ondas curtas.

Tomando-se os dados obtidos a cada 15 minutos e fazendo relações como as apresentadas na Figura 23, verificou-se que a razão entre Rncafé e RG foi igual a 0,62 com $\mathrm{R}^{2}$ $=0,976$, utilizando-se apenas dados do período diurno. A relação entre Rngrama e RG caiu para 0,56 com $\mathrm{R}^{2}=0,74$ e a equação de regressão de ambas as análises mostraram-se siginificaivas ao nível de $1 \%$ de probabilidade. A relação entre Rngrama e Rncafé foi relativamente próxima daquela verificada na Figura 23B, sendo igual a 0,92 com $\mathrm{R}^{2}=0,72$. 
A

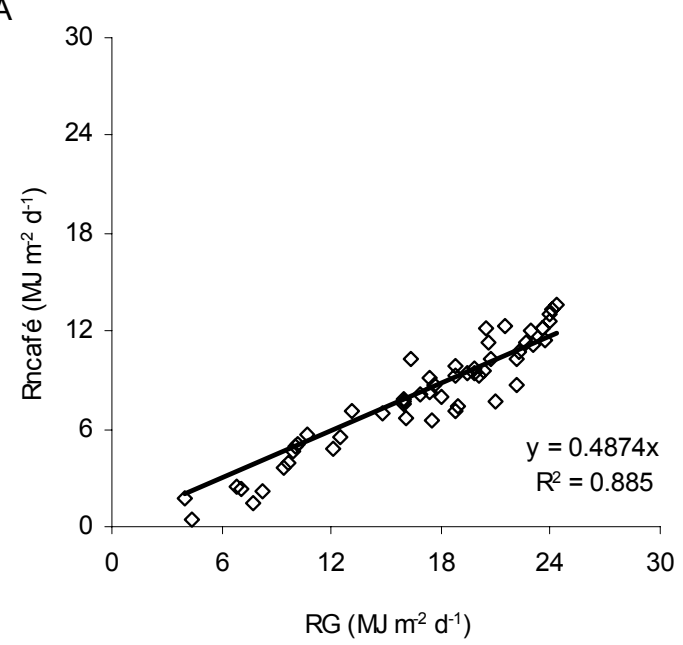

B

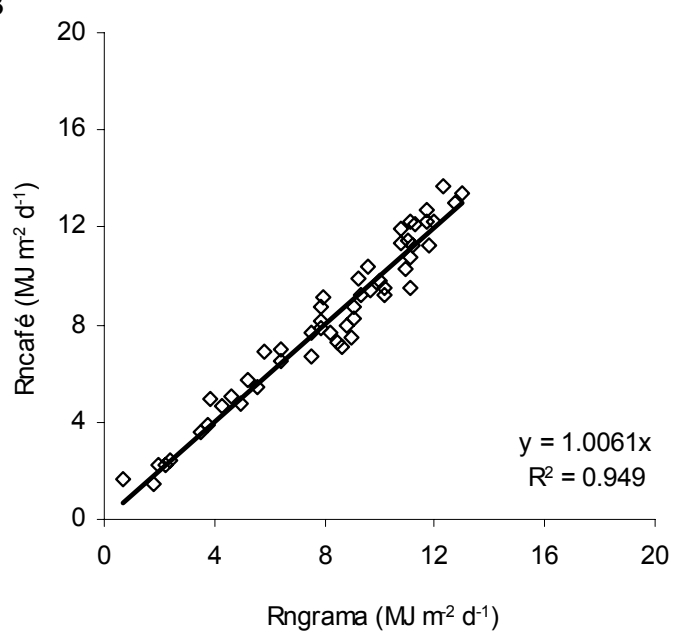

Figura 23 - Relação entre os valores de radiação solar global (RG) e saldo de radiação no cafezal (Rncafé) e o saldo de radiação medido sobre gramado (Rngrama), na estação agrometeorológica da ESALQ, em Piracicaba, SP.

\subsection{AVALIAÇÃO DAS MEDIDAS DE FLUXO DE SEIVA}

A qualidade das medidas de fluxo de seiva obtidas pelo método do balanço de calor é difícil de ser avaliada em condições de campo, a não ser pelo uso de lisímetros, já que não há outros métodos de medida direta da transpiração de árvores que forneçam resultados mais confiáveis. No cafezal estudado, dois lisímetros para cafeeiros adultos foram instalados logo após o término da fase experimental deste trabalho, apresentando também diversos problemas operacionais e impedindo uma avaliação, mesmo que indireta, das medidas de fluxo de seiva. Assim, a possibilidade de que possam ter ocorrido problemas com as medidas de fluxo de seiva não pode ser descartada, mas cuidou-se para as fontes de erro normalmente verificadas nos sensores fossem minimizadas (Baker \& Nieber, 1989; Valancogne \& Nasr, 1993; Gutiérrez et al., 1994).

Apesar de não levar a uma conclusão, fez-se a comparação dos valores obtidos de fluxo de seiva para as quatro plantas com suas respectivas áreas foliares e com o saldo de radiação medido sobre o cafezal, indicativo da taxa de evapotranspiração da cultura. Fez-se, também, a análise da variação diária dos fluxos de calor componentes do método do balanço de calor baseando-se na teoria sobre o método. 
Os valores de fluxo de seiva apresentaram uma grande variabilidade temporal e entre as quatro plantas ao longo do experimento, com valores variando de $0,93 \mathrm{~L} \mathrm{~d}^{-1}$, para a planta 4 $\left(\mathrm{AF}=6,0 \mathrm{~m}^{2}\right)$ no dia 264 , até $13,89 \mathrm{~L} \mathrm{~d}^{-1}$, para a planta $2(\mathrm{AF}=13,9 \mathrm{~m} 2)$ no dia 237 . O desvio padrão em relação à média variou entre $2,25 \mathrm{~L} \mathrm{~d}^{-1}$, para a planta 4 , e $3,16 \mathrm{~L} \mathrm{~d}^{-1}$, para planta 3 . Com os valores expressos por unidade de área foliar, tem-se que a planta 4 apresentou as maiores taxas de transpiração específica dentre as avaliadas, com média de $1,15 \mathrm{~L} \mathrm{~m}^{-2}$ de folha $\mathrm{d}^{-}$ 1. Já a planta 2 teve taxa de transpiração média de $0,59 \mathrm{~L} \mathrm{~m}^{-2}$ de folha $\mathrm{d}^{-1} \mathrm{e}$ as plantas 1 e 3 tiveram taxas em torno de $0,75 \mathrm{~L} \mathrm{~m}^{-2}$ de folha $\mathrm{d}^{-1}$.

A Figura 24 mostra a variação do fluxo de seiva diário por árvore em conjunto com os dados de saldo de radiação do cafezal. Em diversos dias, os fluxos diários não puderam ser integrados devido a problemas em alguns momentos do período, especialmente pela falta de energia elétrica para alimentação da jaqueta térmica dos sensores. Em alguns desses dias, os períodos de falta de energia foram relativamente curtos, mas optou-se por não incluir esses dados nas análises, pois o tempo necessário para o sensor equilibrar-se termicamente com o fluxo de seiva no caule é de difícil determinação. Em geral, houve tendência dos valores diários de fluxo de seiva acompanharem a variação de Rncafé, apresentando, no entanto, uma amplitude de variação menor, tanto nos dias de elevada disponibilidade de energia, como naquele com baixos valores de saldo de radiação. 


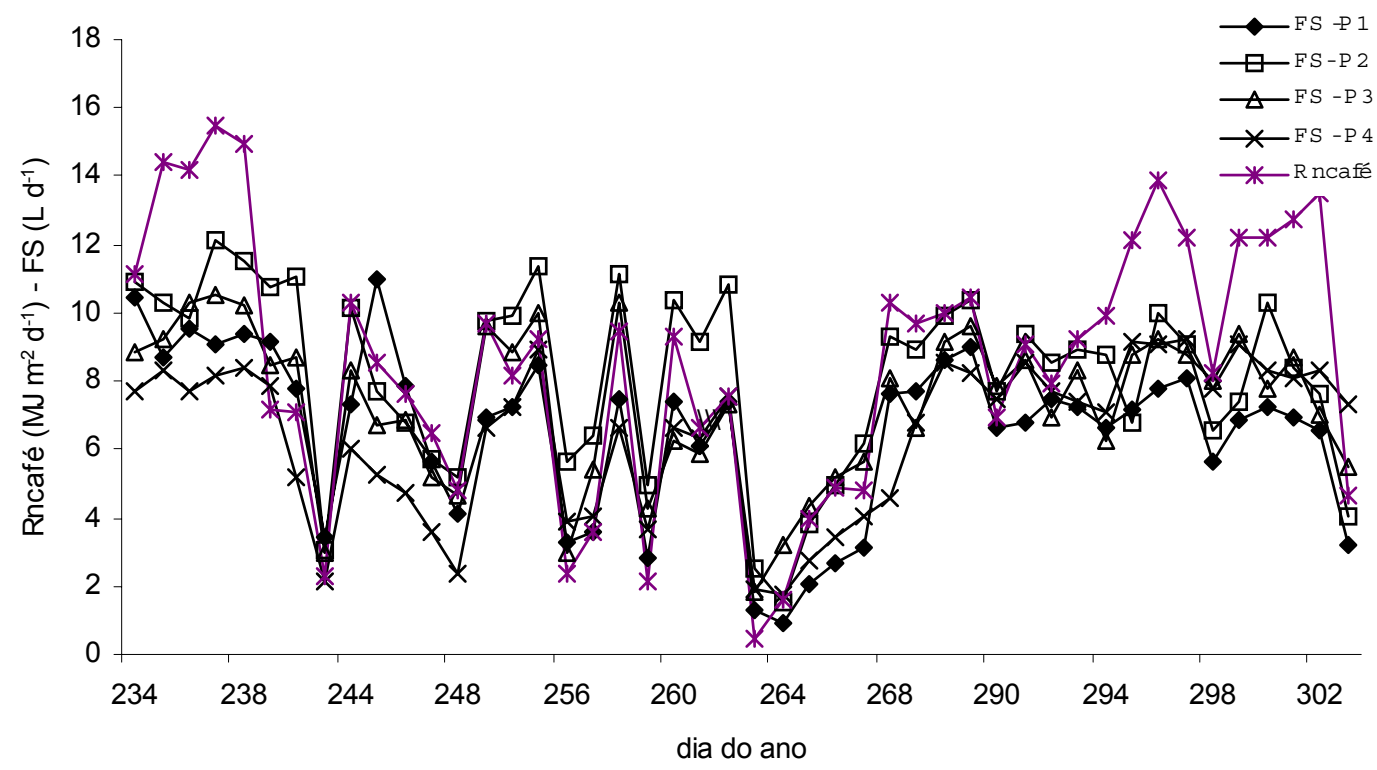

Figura 24 - Variação do fluxo de seiva diário de quatro cafeeiros e do saldo de radiação medido sobre do cafezal e integrado para períodos diários (Rncafé).

Com o objetivo de tornar comparativo os dados de fluxo obtidos nas quatro plantas, os dados diários foram relacionados com os valores de Rncafé (Figura 25A). Mesmo com uma dispersão relativamente elevada dos dados, pelo valor de $b=0,78$ deduz-se que cada litro de água transpirada pelas folhas consumiu, aproximadamente, $1,28 \mathrm{MJ} \mathrm{m}^{-2} \mathrm{~d}^{-1}$ de energia radiante disponível no ambiente.

Isso, no entanto, não se verifica quando os valores de fluxo de seiva superam os $10 \mathrm{~L} \mathrm{~d}^{-1}$, havendo uma tendência de estabilização da transpiração com o aumento de Rncafé. Essa característica é normalmente encontrada em plantas com boa capacidade de regulação estomática da perda de água e sistema radicular relativamente pequeno, como é o caso dos cafeeiros, levando a uma defasagem entre o suprimento hídrico por parte das raízes e a demanda por água da parte da planta. Para compensação dessa defasagem e minimização do desequilíbrio hídrico da planta, é acionado o mecanismo de regulação da perda d'água pelo fechamento estomático. Assim, acima de um determinado valor de energia radiante esse sistema de controle da perda de água é acionado e a sua relação com a transpiração deixa de ser linear.

Outra característica ecofisiológica interessante pode ser depreendida na Figura 25B, onde os dados de fluxo de seiva foram convertidos em taxa de transpiração por unidade de área foliar. As maiores taxas são verificadas na planta 4 , que tinha a menor área foliar dentre as 
amostradas e, na planta com a maior área foliar observa-se as menores taxas de transpiração. Esse aspecto indica que além da regulação estomática da perda de água das folhas, o autosombreamento devido à elevada área foliar limita a captação de energia radiante pelas plantas e, por conseguinte, reduz a taxa de transpiração das plantas de maior porte, como ocorreu com a planta 2 (Figura 25B). Essa característica reitera as considerações sobre relação assintótica entre FS e Rncafé da Figura 25A.
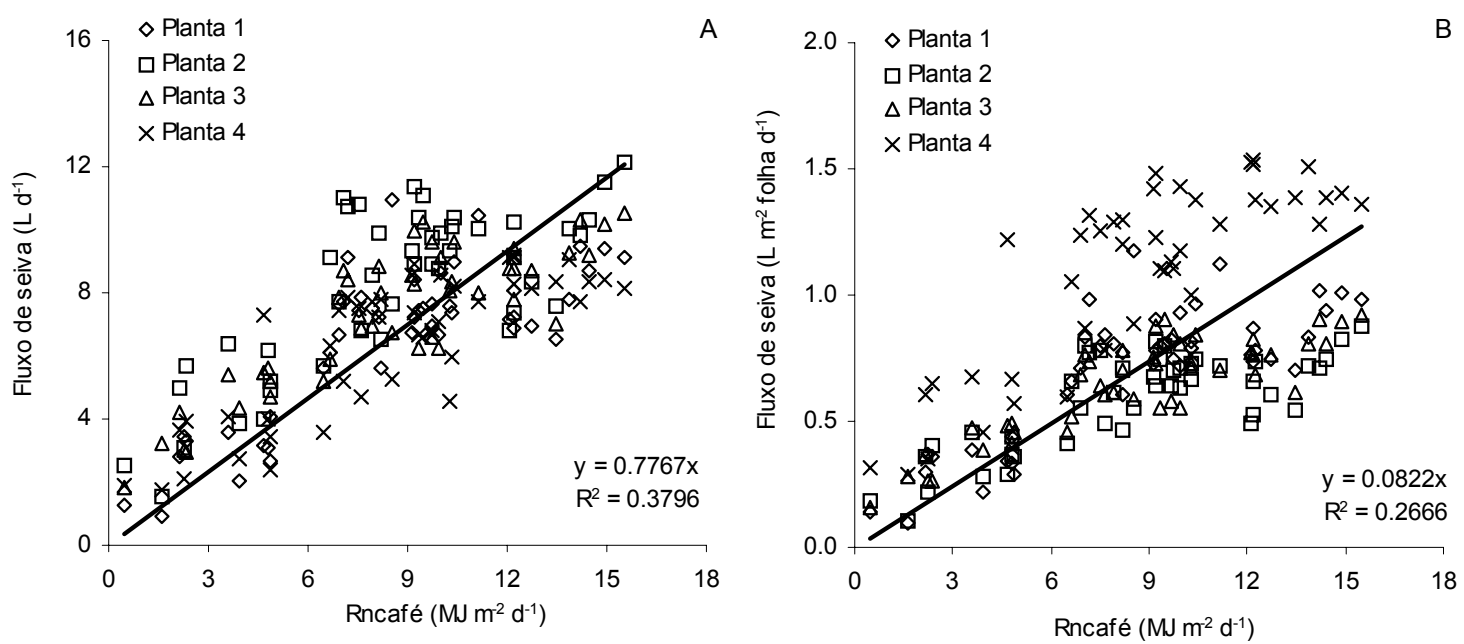

Figura 25 - Correlação linear entre os valores de fluxo de seiva dos quatro cafeeiros e o saldo de radiação medido sobre o cafezal (Rncafé) (A) e correlação entre os valores de fluxo de seiva por unidade de área foliar e Rncafé (B).

A elevação do nível de ajuste entre a energia radiante disponível e o fluxo de seiva com uso da equação logarítmica, apresentada na Figura 26, a partir de $8 \mathrm{~L} \mathrm{~d}^{-1}$ ilustra esse mecanismo de regulação da perda de água dos cafeeiros em condições de elevada demanda hídrica. A elevação dos valores de $\mathrm{R}^{2}$ de 0,38 para 0,85 indicam uma melhor adaptação das variáveis analisadas a funções com tendências assintótica, em detrimento de relações lineares. 


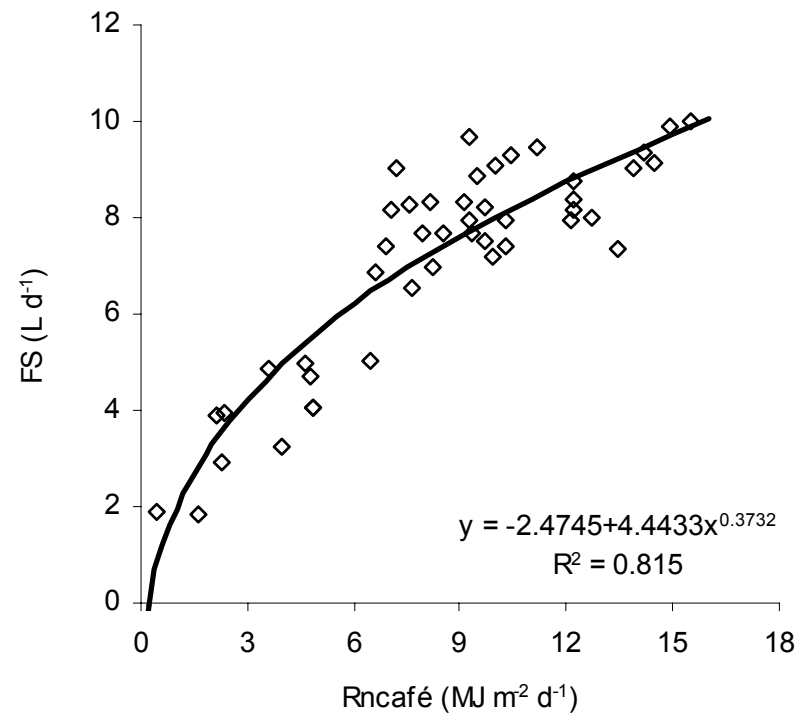

Figura 26 - Correlação logarítmica entre os valores médios de fluxo de seiva de quatro plantas (FS) dos quatro cafeeiros e o saldo de radiação medido sobre o cafezal (Rncafé), integrado para o período diário.

A Figura 27 apresenta as análises de regressão linear entre os dados de Rncafé e fluxo de seiva, separadamente, para os quatro cafeeiros. Para todas as plantas, as regressões foram significativas ao nível de 1\% de probabilidade, evidenciando a relação causal entre a energia radiante e a transpiração das plantas. Os testes estatísticos para os coeficientes lineares, para as quatro plantas, não foram significativos ao nível de $5 \%$ de probabilidade, permitindo que as análises fossem feitas forçando-se a passagem da equação da reta da equação pela origem.

Comparando-se os valores de b assim obtidos e a área foliar das plantas, verifica-se a ausência de uma relação clara entre as plantas, especialmente quando se compara as plantas 2 e 3 e as plantas 1 e 4 . Essa relação contrasta com o que seria esperado, tendo em vista a importância da densidade da folhagem sobre a captação de energia e, conseqüentemente, a transpiração das plantas, permitindo inferir que a planta com menor área foliar (planta 4) apresenta uma fração menor de folhas sombreadas e, a despeito da menor área foliar, transpira em taxas proporcionais as verificadas na planta 1 (Figura 27). 

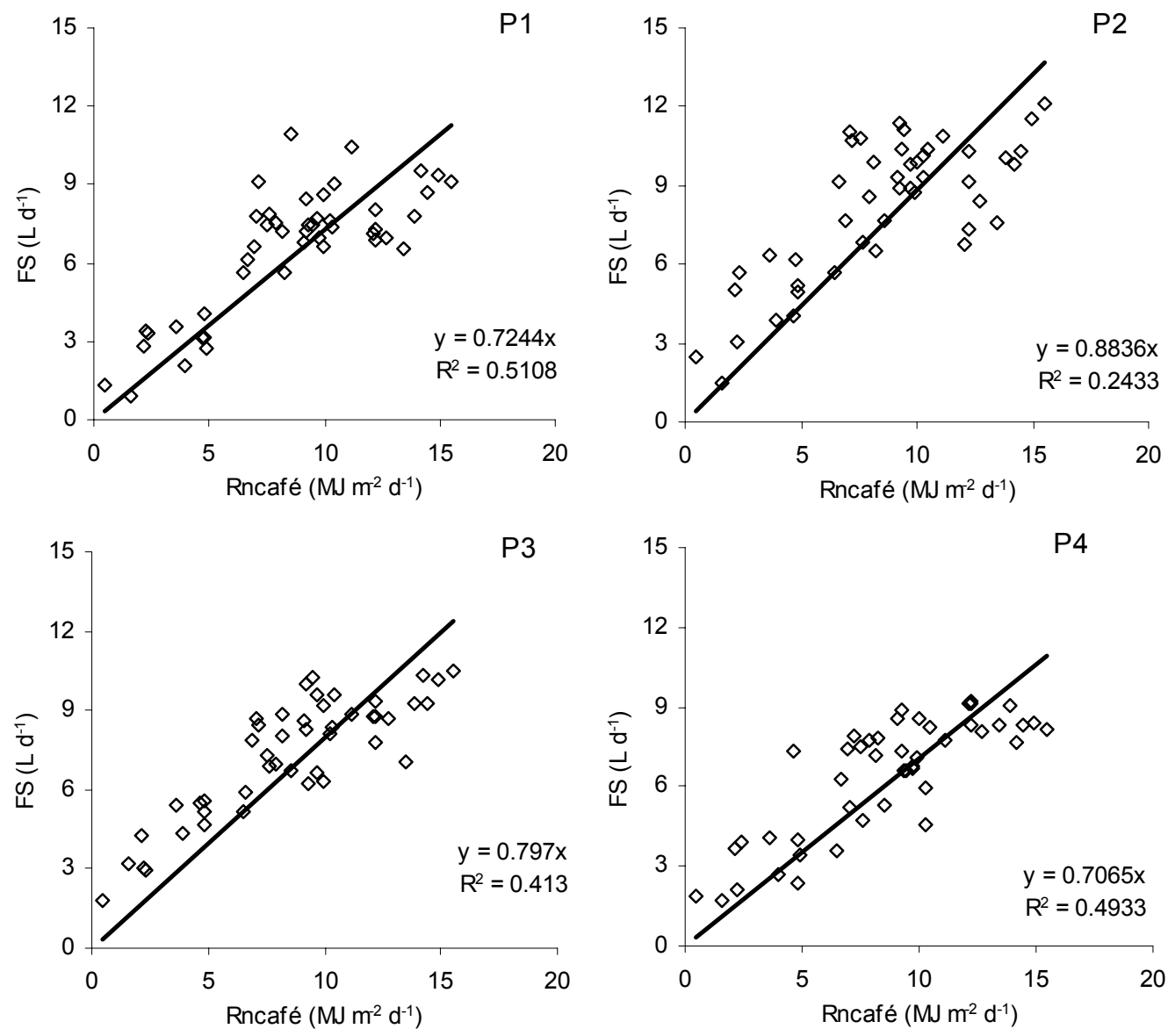

Figura 27 - Correlação linear entre os valores de fluxo de seiva (FS) e de saldo de radiação medido sobre o cafezal para as quatro plantas consideradas isoladamente $(\mathrm{P})$.

Uma segunda forma de análise dos dados de fluxo de seiva pelo método do balanço de calor é avaliar as curvas diárias dos fluxos que compõem o balanço de calor no caule. A experiência mostra que medidas subseqüentes com grande instabilidade denotam problemas com os sensores, que podem ser devidos à presença de quantidade elevada de água sobre as junções de termopares do sensor, à problemas com o sistema de fiação dos sensores ou mesmo pela presença de algum campo de corrente alternada que possa prejudicar o desempenho do sistema de coleta de dados. Assim, um primeiro critério para seleção dos dados de fluxo de seiva pelo MBC é a estabilidade temporal dos dados nos períodos em que não há variação ambiental.

Na Figura 28 são mostradas as curvas de variação temporal dos fluxos axiais (Qv) e do fluxo radial (Qr) para as quatro plantas em dois dias distintos, ilustrando a referida estabilidade 
esperada em sensores com bom funcionamento e variação relativamente modulada ao longo do dia, inclusive nos horários de alterações ambientais com efeito sobre a transpiração das plantas.

As curvas de Qr, componente com o maior grau de empirismo dentre todos do MBC. A necessidade de determinação de um valor diário do coeficiente de difusividade radial de calor do sensor (Ksh) é algo incerto e sujeito a várias críticas. A forma utilizada neste trabalho foi baseada no trabalho de Gutiérrez et al. (1994) que indicou bom funcionamento do método em cafeeiros, consistintindo na tomada do valor médio do Ksh entre as 3:00 e 5:00 da madrugada, para cada dia de medida. Valancogne \& Nasr (1993) propõem que seja adotada o valor mínimo de Ksh encontrado ao longo de todo o período de medidas. Se por um lado, essa última proposta parece ser mais coerente fisicamente, já que o valor mínimo de Ksh é indicativo de bom suprimento hídrico da planta e taxa de transpiração noturna igual ou muito próxima a zero, a sugestão de Gutiérrez et al. (1994) é recomendada por evitar que um erro na determinação de um valor único resulte em erros sistemáticos e expressivos nos dados de fluxo de seiva.

As curvas de Qv mostram-se coerentes com a variação da transpiração de um planta bem suprida hidricamente, elevando-se o seu valor durante a noite devido ao grande aquecimento interno do segmento de caule envolvido pelo sensor e entrando em fase descendente após o amanhecer do dia, com o horário de ocorrência do valor mínimo diário, dependendo das características de instalação do sensor e da taxa de fluxo diária. Nos dois dias analisados, podese considerar coerentes as curvas de Qr, sendo razoável concluir que não ocorreram problemas graves com as medidas e os conseqüentes efeitos sobre a resposta dos sensores.

A adoção de um valor de Ksh para cada dia permite inferir que eventuais erros sejam diluídos ao longo dos dias e, mais importante, que se possa analisar a variação diária de Ksh ao longo da seqüência de medidas. Apesar de ser admissível que ocorram diferenças entre os valores de Ksh, elas não podem ser exageradas entre dias subseqüentes e, assim ocorrendo, temse um indicador de problemas nos valores de fluxo de seiva, sendo, portanto, um segundo modo para avaliação dos dados obtidos a campo.

As curvas diárias de Qr e Qv observados mostram o padrão considerado como o mais adequado por Dayau (s/d) para sensores instalados em plantas com suprimento hídrico suficiente para atender as suas necessidades. A maior importância relativa dos fluxos de Qr em relação a Qv observada em todas as plantas e a forma das curvas ao longo dos dois dias indicam um desempenho dentro dos padrões normais de funcionamento dos sensores. 

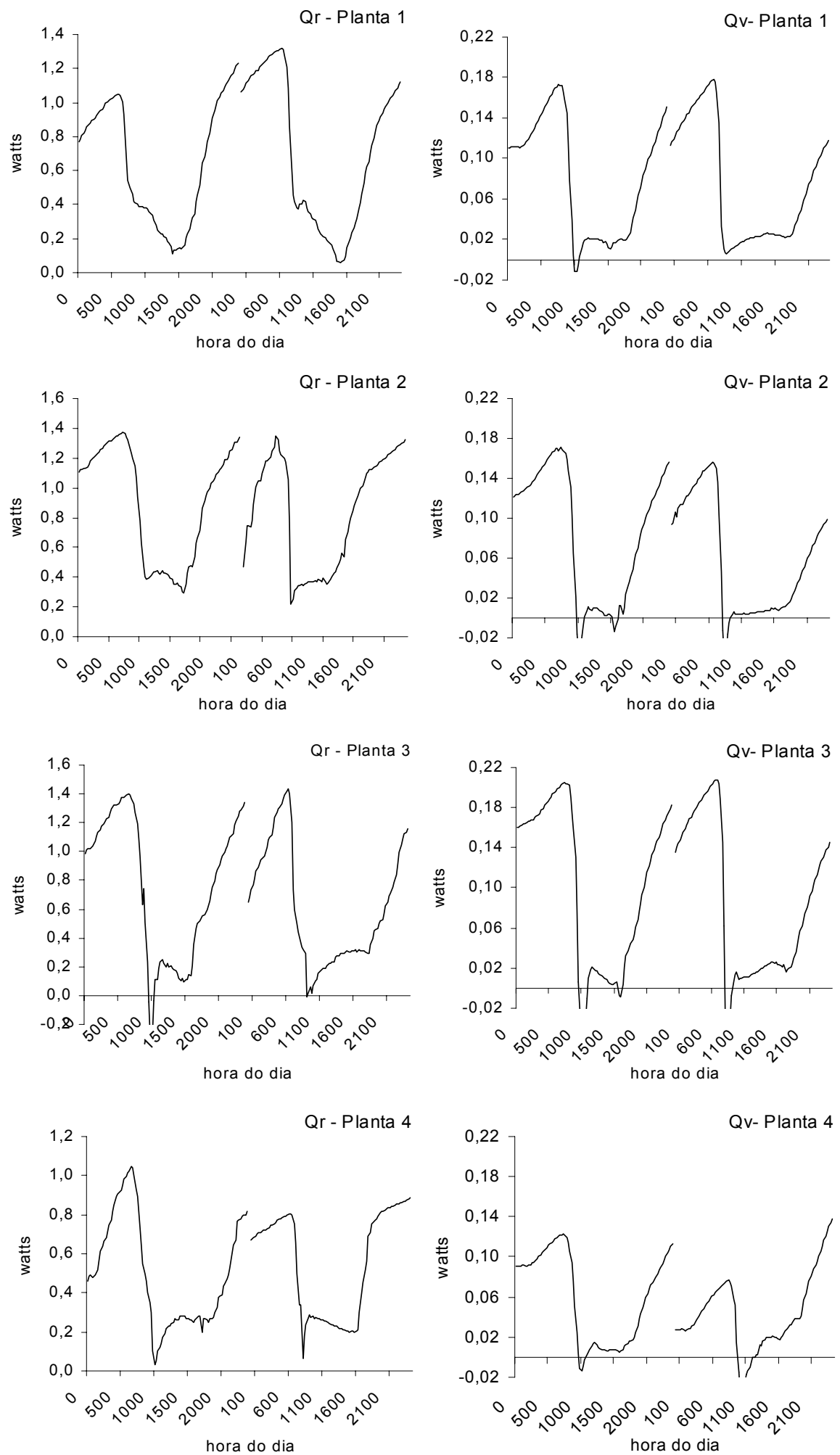

Figura 28 - Variação do fluxo axial (Qv) e radial (Qr) de energia térmica nos sensores de fluxo de seiva das quatro plantas nos dias 245 e 301. 
Uma outra forma de avaliação das medidas de fluxo de seiva pelo método do balanço de calor no caule é pelo formato das curvas diárias da diferença de temperatura entre a extremidade superior e inferior do sensor (dT). As Figuras 29 a 32 apresentam as curvas de dT ao longo de três dias, sendo que nos dias 245 e 301 os sensores foram mantidos em seu funcionamento normal, com aquecimento da jaqueta térmica. No dia 282, apesar de ter sido instalado do mesmo modo que nos demais, o fornecimento de energia para aquecimento da jaqueta térmica foi suspenso a partir das 18:00 do dia anterior. Essa prática foi utilizada por Gutiérrez et al. (1994) para a avaliação do desempenho de sensores comerciais em cafeeiros, sendo de grande utilidade para analisar a influência das condições ambientais sobre as medidas e se o modo de instalação do sensor propiciou isolamento térmico adequado e suficiente para garantir uma boa qualidade das medidas.

As curvas de dT nos dias 245 e 301 são indicadoras de sensores funcionando normalmente, tomando-se por base as variações nos valores de dT na transição entre os períodos diurno e noturno. Em condições normais de operação, os valores de dT medidos durante a noite devem ficar entre 5 e $7^{\circ} \mathrm{C}$, indicando bom isolamento térmico (Dayau, s/d; Van Bavel, 1999). No período entre as 7:00 e 9:00, dependendo da espécie e do porte da planta, espera-se um grande pico de $\mathrm{dT}$, que pode atingir até $12{ }^{\circ} \mathrm{C}$, devido ao início da ascensão da seiva do caule, que estando mais fria ocasiona essa grande diferença entre as extremidades do sensor. Sobre os resultados finais de fluxo, esse pico normalmente não ocasiona erros, já que os demais fluxos indicam ascensão nula. A queda subseqüente dos valores de dT é que normalmente provoca erros de medida, porque os valores de FS são inversamente proporcionais a ele. Assim, o filtro para valores elevados de FS descrito em MATERIAL E MÉTODOS é importante nesse momento para minimizar esse tipo de erro.

Durante o período diurno, desde que mantidas as condições ambientais que influenciam a transpiração das plantas, o que se espera é uma certa estabilização dos valores de dT até os horários nos quais há queda na disponibilidade de radiação solar, quando eles tendem a se elevar até os patamares verificados durante a madrugada.

As curvas referentes ao dia 282 das quatro plantas indicam que os sensores foram isolados adequadamente, já que os valores de dT nesse dia ficaram entre 0,5 e $-0,5^{\circ} \mathrm{C}$, faixa considerada adequada por Gutiérrez et al. (1994). Os valores acima de 0,5 ${ }^{\circ} \mathrm{C}$ encontrados nos horários anteriores as 22:00 nas Figuras 29 a 32 devem-se ao desequilíbrio térmico dos sensores com o ambiente, já que foram alimentados pela fonte de corrente contínua até as 18:00. 
Portanto, embora não tenham sido feitos testes comparativos de medidas pelo método de balanço de calor com medidas de fluxo de seiva ou de transpiração por outros métodos, com base nas comparações de fluxo de seiva do Rncafé e na análise dos fluxos de calor que ocorrem no balanço térmico do caule, bem como com base no desempenho do método em cafeeiros realizados por outros autores (Gutiérrez et al., 1994), é possível admitir que os dados de fluxo de seiva obtidos são confiáveis e podem ser considerados como representativos da transpiração de cada uma das plantas amostradas.
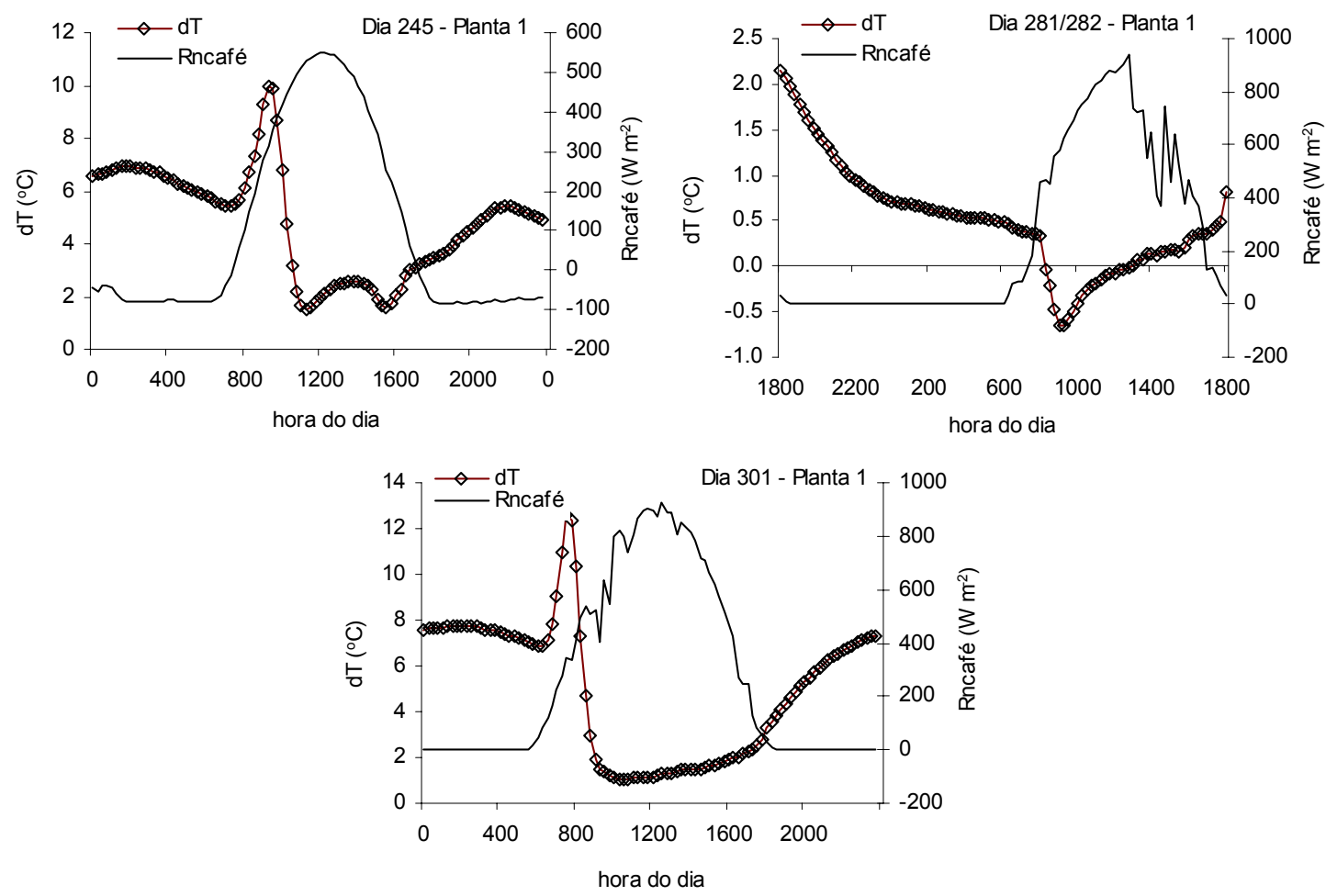

Figura 29 - Variação horária da diferença de temperatura entre a extremidade superior e inferior (dT) do sensor de fluxo de seiva e do saldo de radiação medido sobre o cafezal (Rncafé) durante três dias, para a planta 1 . 

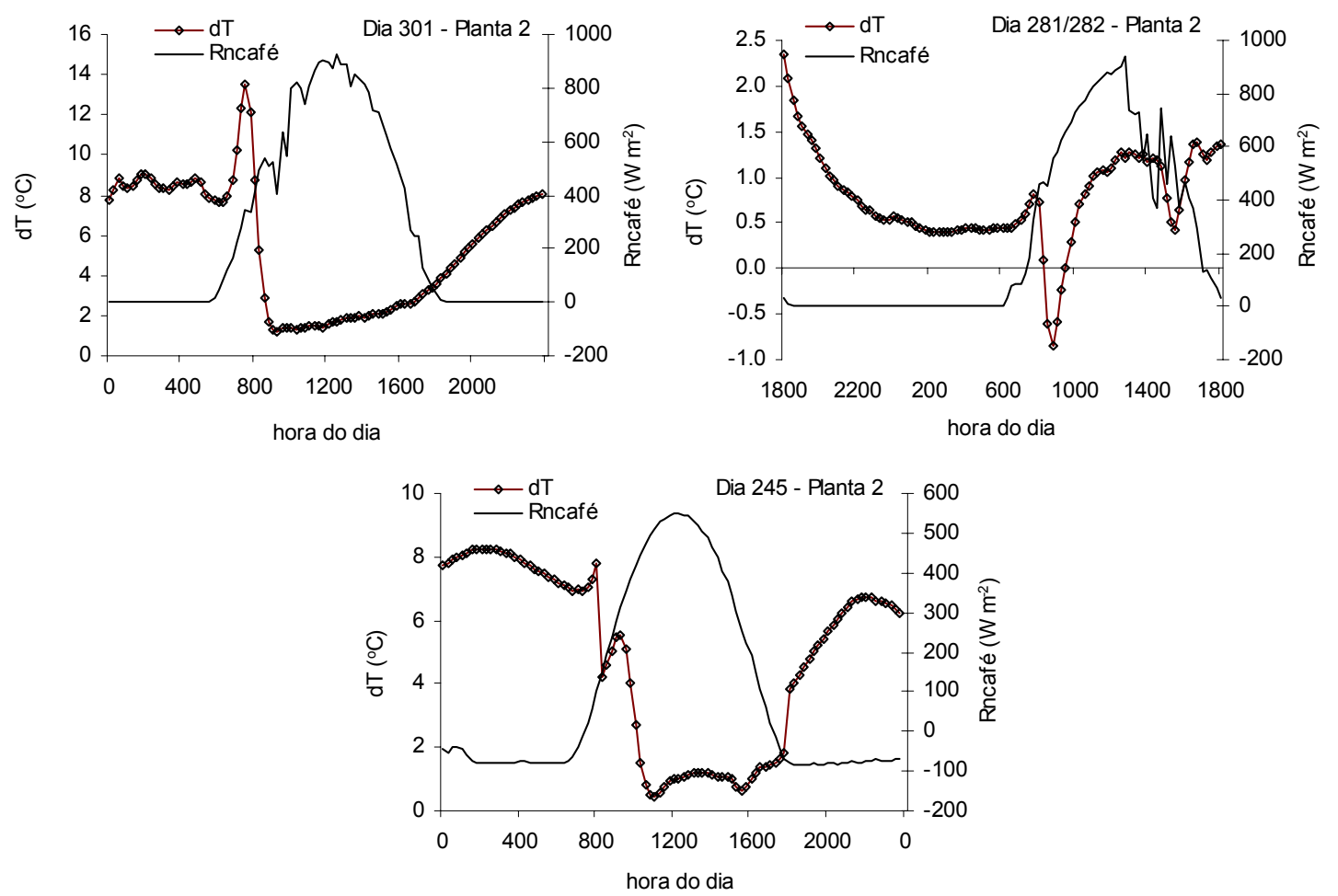

Figura 30 - Variação horária da diferença de temperatura entre a extremidade superior e inferior (dT) do sensor de fluxo de seiva e do saldo de radiação medido sobre o cafezal (Rncafé) durante três dias, para a planta 2. 

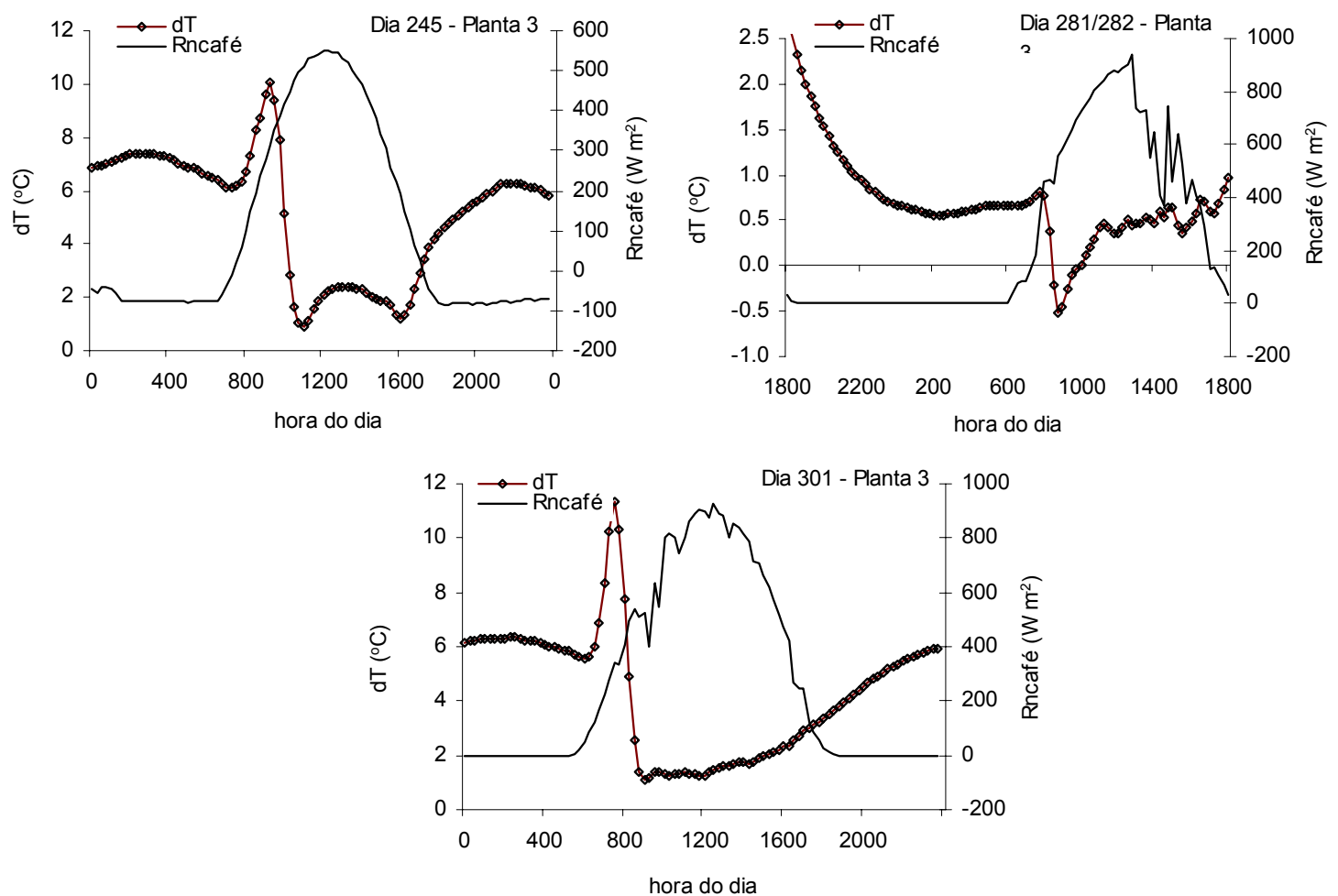

Figura 31 - Variação horária da diferença de temperatura entre a extremidade superior e inferior (dT) do sensor de fluxo de seiva e do saldo de radiação medido sobre o cafezal (Rncafé) durante três dias, para a planta 3. 

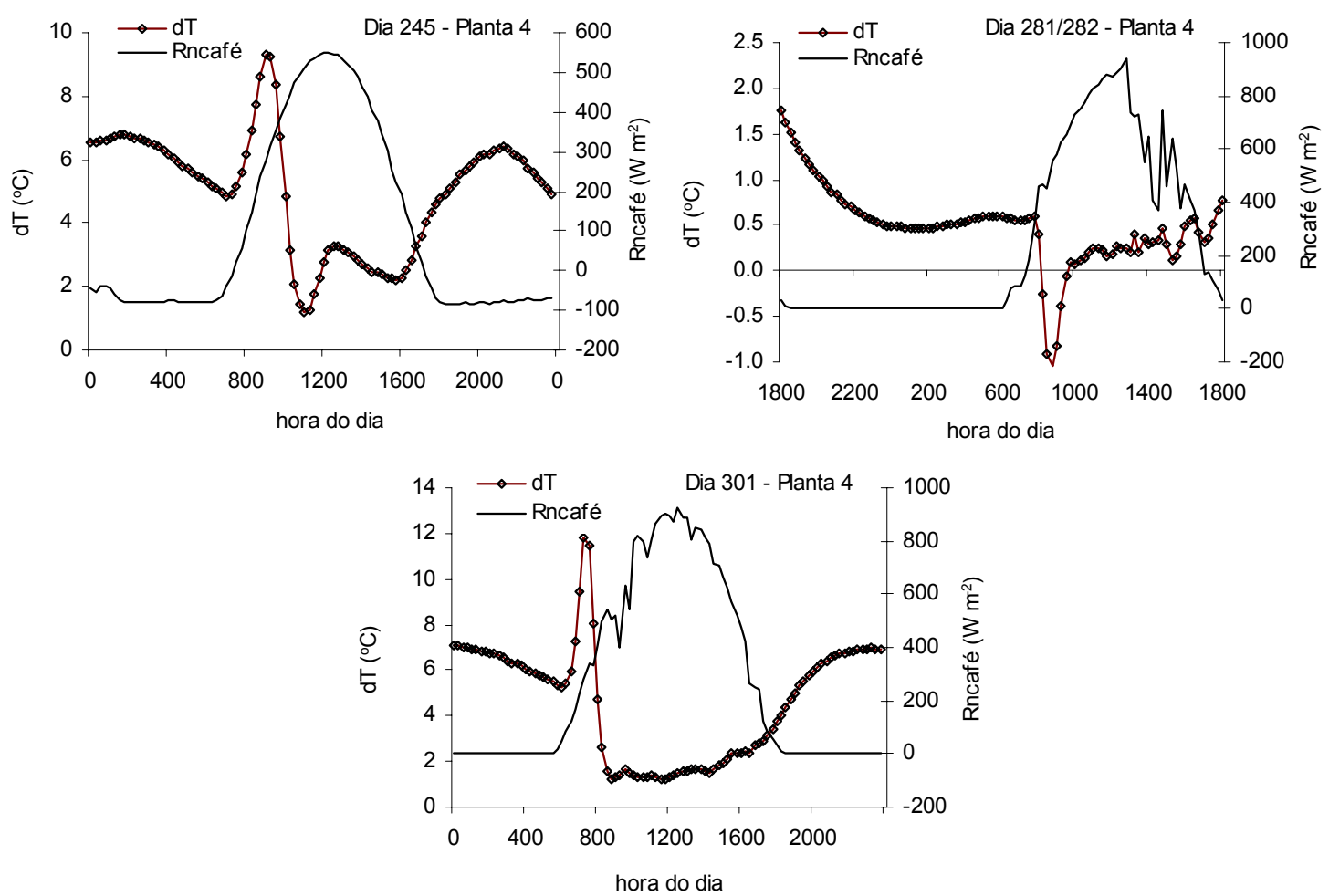

Figura 32 - Variação horária da diferença de temperatura entre a extremidade superior e inferior (dT) do sensor de fluxo de seiva e do saldo de radiação medido sobre o cafezal (Rncafé) durante três dias, para a planta 4.

\subsection{ESTIMATIVA DA TRANSPIRAÇÃO MÁXIMA DOS CAFEEIROS PELO MODELO DE PENMAN-MONTEITH}

\subsubsection{ANÁLISE E ESTIMATIVA DAS VARIÁVEIS DO MODELO DE PENMAN- MONTEITH}

\subsubsection{Resistência foliar à difusão de vapor}

Ao longo dos cinco dias de medida de $\mathrm{rf}$ (ou do seu inverso, gf) por porometria foram amostradas 680 folhas de uma planta irrigada continuamente durante a fase experimental. Esses dados foram obtidos em seqüências de medida com 20 folhas cada uma, em intervalos de uma 
hora. A média geral dos valores de gf foi igual a $1,19 \mathrm{~mm} \mathrm{~s}^{-1}\left(\mathrm{rf}=840 \mathrm{~s} \mathrm{~m}^{-1}\right)$, com desvio padrão de $0,69 \mathrm{~mm} \mathrm{~s}^{-1}$. A Tabela 3 mostra as médias diurnas de gf, com as medidas de dispersão, verificando-se que o coeficiente de variação ficou entre $41 \%$ e 94\%, para os dias 267 e 297 , indicando as dificuldades associadas à modelagem de rf, tanto pelos problemas originários da medição com a técnica porométrica, como também pela dificuldade de amostragem representativa de folhas de toda a planta. Além disso, essa variabilidade é comumente encontrada em medidas de rf no campo, principalmente em árvores, em conseqüência das diferentes condições de exposição das folhas à radiação solar e ao vento, das condições fisiológicas internas das folhas e da oscilação temporal da abertura estomática.

Tabela 3. Valores médios diurnos da condutância foliar à difusão de vapor (gf), do desvio padrão (DP) e do coeficiente de variação (CV) para os cinco dias de medida em cafeeiro.

\begin{tabular}{cccc}
\hline Dia & $\begin{array}{c}\text { gf médio } \\
\mathrm{mm} \mathrm{s}^{-1}\end{array}$ & $\begin{array}{c}\text { DP médio } \\
\mathrm{mm} \mathrm{s}^{-1}\end{array}$ & CV \\
\hline 254 & 1,36 & 0,75 & $65 \%$ \\
267 & 1,30 & 0,52 & $41 \%$ \\
289 & 0,92 & 0,78 & $90 \%$ \\
295 & 1,13 & 0,62 & $53 \%$ \\
297 & 0,90 & 0,79 & $94 \%$ \\
\hline
\end{tabular}

A Tabela 4 apresenta a estatística descritiva para dados agrupados quanto à intensidade de radiação fotossinteticamente ativa (PAR) incidente na folha (medida com o sensor quântico acoplado ao porômetro) e quanto à idade das folhas. $\mathrm{O}$ valor médio de gf das folhas novas foi igual a $1,34 \mathrm{~mm} \mathrm{~s}^{-1}$, com desvio padrão de $0,78 \mathrm{~mm} \mathrm{~s}^{-1}$, enquanto que para as folhas velhas a média foi de $1,73 \mathrm{~mm} \mathrm{~s}^{-1}$, com desvio de $0,85 \mathrm{~mm} \mathrm{~s}^{-1}$. O teste $\mathrm{F}$ para os dois conjuntos de dados não revelou diferença estatística entre eles, o que está relacionado com a elevada variância associada às médias. Isso, por sua vez, indica que a influência ambiental, especialmente da temperatura da folha, radiação solar e déficit de pressão de vapor são mais importantes que as características morfológicas das folhas determinadas pela sua idade. A transpiração, medida pelo porômetro, teve média de $2,04 \mu \mathrm{g} \mathrm{cm}^{-2} \mathrm{~s}^{-1}$, com desvio padrão de $2,05 \mu \mathrm{g} \mathrm{cm}^{-2} \mathrm{~s}^{-1}$.

Na Tabela 4, destaca-se também um decréscimo nos valores de gf com o aumento dos níveis de PAR, variando entre $1,49 \mathrm{~mm} \mathrm{~s}^{-1}$ para folhas com PAR menor que $500 \mu \mathrm{mol} \mathrm{m}^{-2} \mathrm{~s}^{-1}$ até $1,16 \mathrm{~mm} \mathrm{~s}^{-1}$, para folhas com PAR maior que $1000 \mu \mathrm{mol} \mathrm{m} \mathrm{m}^{-2} \mathrm{~s}^{-1}$, o que representa uma variação de cerca de $23 \%$ entre os dois extremos. Contrário a essa tendência, nota-se que o desvio padrão aumentou com PAR, elevando também os valores do coeficiente de variação. 
Tabela 4. Estatística descritiva, com média, desvio padrão e coeficiente de variação (C.V.) da condutância foliar a difusão de vapor (gf) e da transpiração foliar (T) medidas com porômetro, agrupando-se os dados em três níveis de radiação fotossinteticamente ativa (PAR) e duas classes de idade das folhas.

\begin{tabular}{|c|c|c|c|c|c|}
\hline & Classe & Variável & Média & D. Padrão & C.V. \\
\hline \multirow{6}{*}{$\begin{array}{c}\text { PAR } \\
\left(\mu \mathrm{mol} \mathrm{m}{ }^{-2} \mathrm{~s}^{-1}\right)\end{array}$} & \multirow{2}{*}{ menor que 500} & $\operatorname{gf}\left(\mathrm{mm} \mathrm{s}^{-1}\right)$ & 1,49 & 0,77 & $52 \%$ \\
\hline & & $\mathrm{T}\left(\mu \mathrm{g} \mathrm{cm}{ }^{-2} \mathrm{~s}^{-1}\right)$ & 2,13 & 1,71 & $80 \%$ \\
\hline & \multirow{2}{*}{ entre 500 e 1000} & $\operatorname{gf}\left(\mathrm{mm} \mathrm{s}^{-1}\right)$ & 1,21 & 0,93 & $77 \%$ \\
\hline & & $\mathrm{T}\left(\mu \mathrm{g} \mathrm{cm}^{-2} \mathrm{~s}^{-} 1\right)$ & 1,93 & 1,66 & $86 \%$ \\
\hline & \multirow{2}{*}{ maior que 1000} & $\operatorname{gf}\left(\mathrm{mm} \mathrm{s}^{-1}\right)$ & 1,16 & 0,96 & $83 \%$ \\
\hline & & $\mathrm{T}\left(\mu \mathrm{g} \mathrm{cm}{ }^{-2} \mathrm{~s}^{-1}\right)$ & 2,42 & 2,86 & $118 \%$ \\
\hline \multirow{4}{*}{ IDADE } & \multirow{2}{*}{ Folhas novas } & $\operatorname{gf}\left(\mathrm{mm} \mathrm{s}^{-1}\right)$ & 1,73 & 0,85 & $49 \%$ \\
\hline & & $\mathrm{T}\left(\mu \mathrm{g} \mathrm{cm}{ }^{-2} \mathrm{~s}^{-1}\right)$ & 2,52 & 1,90 & $75 \%$ \\
\hline & \multirow{2}{*}{ Folhas velhas } & $\mathrm{gf}\left(\mathrm{mm} \mathrm{s}^{-1}\right)$ & 1,34 & 0,78 & $58 \%$ \\
\hline & & $\mathrm{T}\left(\mu \mathrm{g} \mathrm{cm}^{-2} \mathrm{~s}^{-1}\right)$ & 2,07 & 1,62 & $78 \%$ \\
\hline
\end{tabular}

O teste $\mathrm{F}$ para $5 \%$ de probabilidade comparando-se as médias dos três níveis de PAR revelou diferenças significativa entre os dados de gf obtidos para folhas com PAR menor que $500 \mu \mathrm{mol} \mathrm{m} \mathrm{m}^{-2} \mathrm{~s}^{-1}$ e folhas com PAR entre $500 \mu \mathrm{mol} \mathrm{m} \mathrm{m}^{-2} \mathrm{~s}^{-1}$ e $1000 . \mu \mathrm{mol} \mathrm{m} \mathrm{m}^{-2} \mathrm{~s}^{-1}$. Isso também ocorreu quando se comparou dados obtidos de gf de folhas com PAR menor que $500 \mu \mathrm{mol} \mathrm{m} \mathrm{m}^{-2}$ ${ }^{1}$ e PAR maior que $1000 \mu \mathrm{mol} \mathrm{m} \mathrm{m}^{-2} \mathrm{~s}^{-1}$. Entretanto, não houve diferença significativa entre os dados de folhas com PAR entre 500 e $1000 \mu \mathrm{mol} \mathrm{m}^{-2} \mathrm{~s}^{-1}$ e folhas com PAR maior que $1000 \mu \mathrm{mol}$ $\mathrm{m}^{-2} \mathrm{~s}^{-1}$. Esse fato parece estar relacionado com a elevada variabilidade das medidas, especialmente para folhas ensolaradas, que possuem uma grande variabilidade temporal. Nessas folhas, verificou-se uma tendência de redução de gf ao longo do dia, com valores no início do dia maiores que das folhas sombreadas.

Butler (1977) verificou tendência de diminuição de gf com aumento da irradiância solar das folhas em Coffea canephora, encontrando valores de gf entre 0,4 e $0,5 \mathrm{~mm} \mathrm{~s}^{-1}$ para as expostas ao sol e gf entre 1,0 e $1,5 \mathrm{~mm} \mathrm{~s}^{-1}$ para as sombreadas. Interessante informação desse trabalho é que nos dias de céu nublado, todas as folhas da planta apresentaram gf relativamente maior, em torno dos $2,0 \mathrm{~mm} \mathrm{~s}^{-1}$. O autor relata, também, que em dias precedidos por chuvas expressivas, a diminuição de gf nas folhas ensolaradas não foi verificada como nos demais dias. 
Esses dados permitem confirmar que o efeito das altas temperaturas foliares e, indiretamente, do déficit de pressão entre o tecido foliar e a atmosfera, exercem um papel de suma importância na regulação estomática de cafeeiros, por serem as folhas muito sensíveis às condições ambientais que afetam as suas relações hídricas. A queda de gf nas folhas ensolaradas é o indício dessa dependência, sendo esse efeito devido muito mais à elevação da temperatura da folha acima da temperatura do ar do que à radiação propriamente dita. Nos trabalhos de Fanjul et al. (1985) e Barros et al. (1997) essas considerações são também observadas.

Comparando-se as Figuras 33 e 34, que mostram a variação de rf e gf ao longo de vários dias, pode-se notar que a relação entre os valores medidos e estimados de gf é pior que a verificada para rf, devido à inversão da tendência de variação das medidas e estimativas em alguns horários dos dias, principalmente para gf. Os dados de rf, por se tratar do inverso dos valores de gf, apresentam uma amplitude de variação de cerca de duas ordens de grandeza ao longo de um dia, enquanto que os valores de gf, no máximo, quintuplicam de valor ao longo do período diurno. É evidente que sob o ponto de vista estatístico, a maior amplitude de variação dos dados de rf contribuiu para a elevação dos níveis de ajuste dos dados, visualizado pelo valor de $\mathrm{R}^{2}=0,58$ na regressão com $\mathrm{rf}$, comparativamente maior que o obtido para gf $\left(\mathrm{R}^{2}=0,29\right)$ (Figura 35). Nota-se, também, que o ajuste é melhorado nos horários inicial e final do período diurno ocorreram, também, diferenças expressivas entre os valores estimados e medidos (Figura 33).

Através das barras verticais apresentadas nas curvas referentes aos dados medidos de gf (Figura 33), tem-se o desvio padrão associado a cada valor de média, dando idéia da elevada variabilidade dos dados porométricos. Além disso, percebe-se que não há uma tendência clara de variação do desvio padrão de gf, havendo dias com maior variabilidade nos horários iniciais, e outros nos horários intermediários do período. 

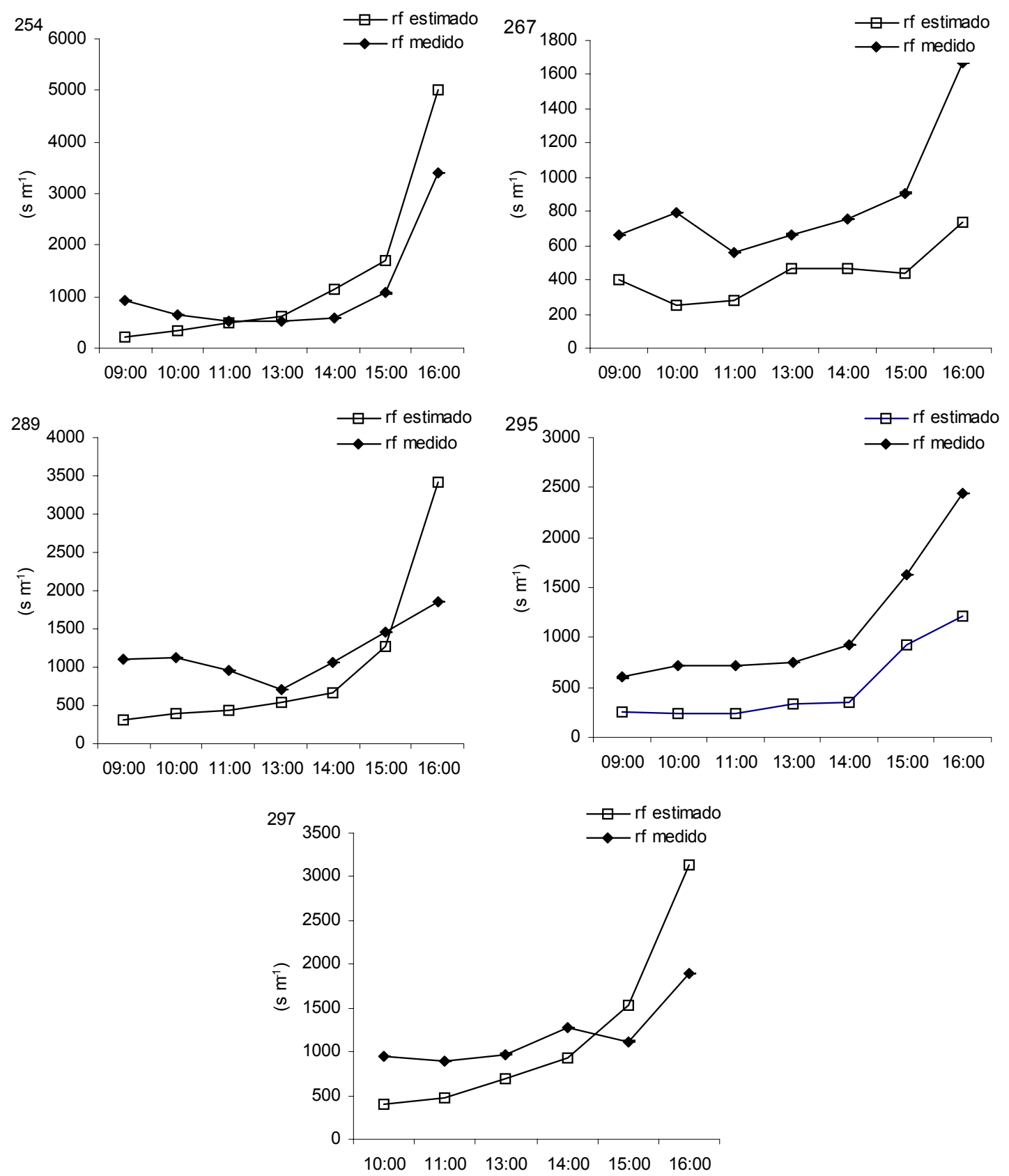

Figura 33 - Variação diurna da resistência foliar estimada com a metodologia proposta e da medida com o porômetro em pomar de lima ácida "Tahiti" em Piracicaba, SP. 

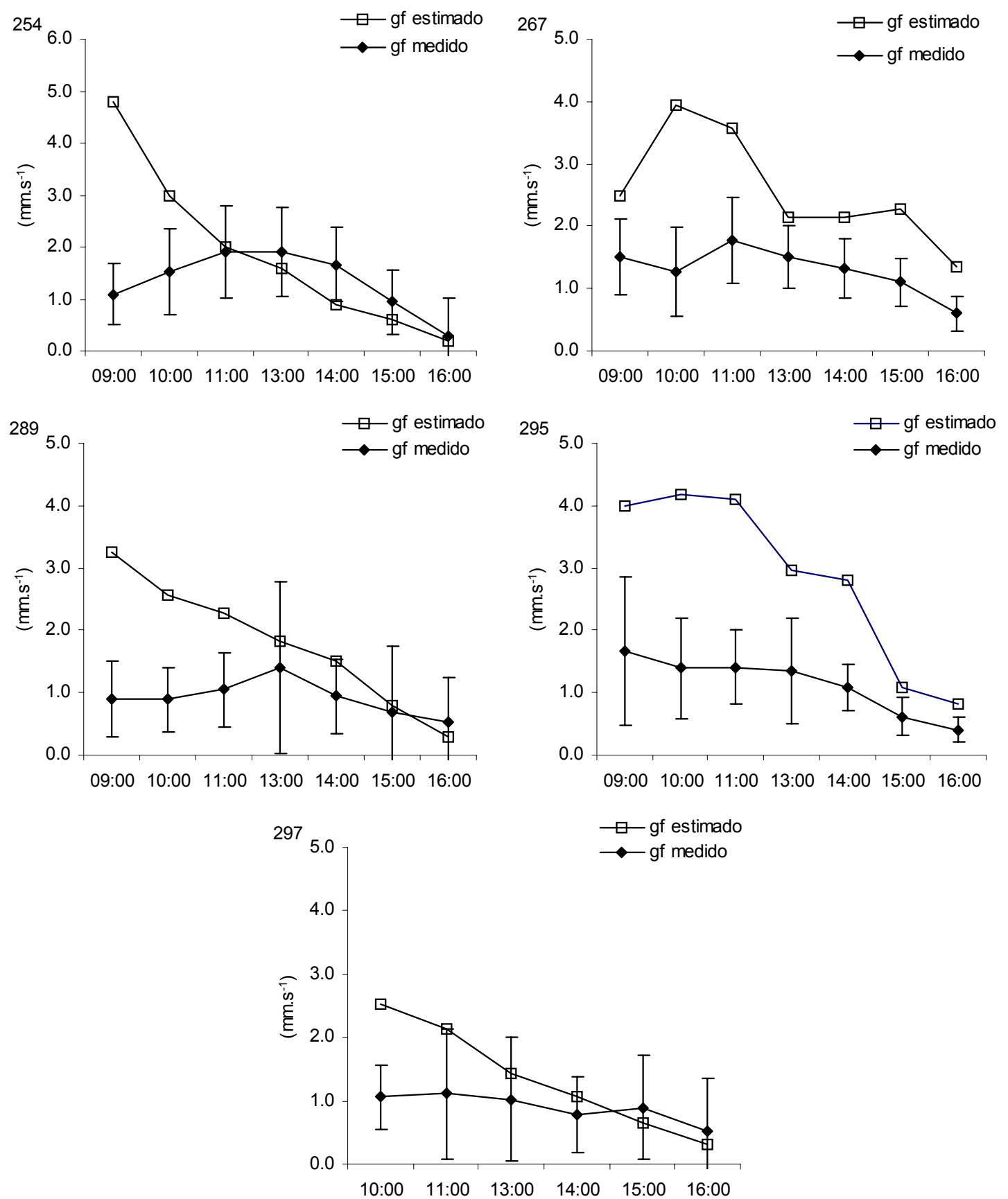

Figura 34 - Variação diurna da condutância foliar estimada com a metodologia proposta e medida com o porômetro em cafeeiro adulto em Piracicaba, SP.

Comparados com o de outras espécies arbóreas, os valores máximos encontrados de gf são menores do que os observados em macieiras (Green \& McNaughton, 1992) e lima ácida Tahiti (Angelocci et al. 1998). No caso da lima ácida foi observda uma variação acentuada de rf 
ao longo do ano, sendo que no período de inverno e primavera em Piracicaba, os valores subiram caíram para níveis próximos a $500 \mathrm{~s} \mathrm{~m}^{-1}$ no mesmo pomar irrigado. No caso do cafeeiro, faltam informações de literatura sobre uma possível variação sazonal, devendo-se ressaltar que nesses dias de medida o déficit de saturação de vapor e a temperatura do ar foram elevados (Figura 19B e 17B), indicando que os níveis de rf obtidos podem estar acima daqueles obtidos durante o verão e o outono.

$\mathrm{Na}$ Figura 35, são apresentadas as correlações entre os valores estimados e medidos de condutância e de ressitência foliar à difusão de vapor. A análise estatística com dados de gf é mais coerente pelo fato de gf apresentar distribuição normal, ao contrário do que se verifica com rf (Campbell \& Norman, 1998). As duas análises de regressão (gf e rf), foram significativas ao nível de $1 \%$ de probabilidade e forçou-se as retas da equação a passar pelos zero porque a análise estatística com o teste $\mathrm{T}$ para o intercepto não foi significativa ao nível 5\%. Assim, pelos valores do coeficiente angular (b) das duas regressões, pode-se perceber que utilizando dados de rf, estimativas mostraram-se estatisticamente mais próximas dos dados medidos, com $b=0,96$, o que representa uma tendência de subestimativa de cerca de 4\%. A elevada dispersão dos dados verificada nessa análise de regressão, no entanto, levanta a possibilidade de que rf pode introduzir erros nas estimativas de transpiração dos cafeeiros com o modelo P-M, já que o modelo apresenta uma alta sensibilidade os valores de $\mathrm{rf}$, chegando a resultar em erros na estimativa de $\mathrm{T}$ de até $30 \%$ quando os erros associados a rf são próximos de 50\% (Angelocci, 1996). Entretanto, considerando-se que a maior parte da dispersão observada ocorreu com valores obtidos nas primeiras horas do período matinal, quando a transpiração está em fase de crescimento, o erro introduzido na estimativa do valor diário pelo modelo P-M pode ser pacialmente reduzido. 

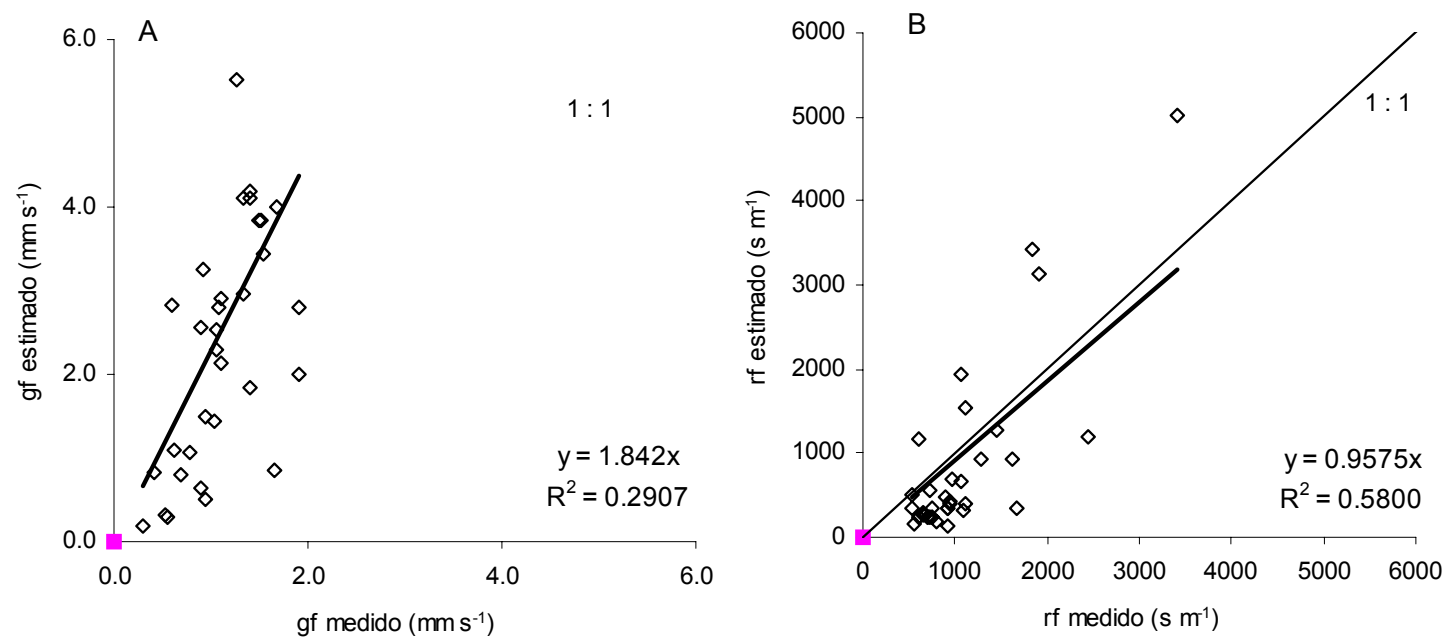

Figura 35 - Relação entre os valores estimados e medidos de condutância foliar (gf) (A) e de resistência foliar à difusão de vapor (rf) (B).

A modelagem de gf feita por Yu et al. (1998) e Stewart (1988) para milho e pinus, por exemplo, adaptando o modelo de Jarvis (1976) para dados foliares, resultou em estimativas com excelente correlação com medidas porométricas, o que normalmente não se verificou para essa modelagem com plantas isoladas de grande porte como em macieiras (Angelocci, 1996) e para lima ácida 'Tahiti' (Marin, 1998) utilizando-se o modelo de Thorpe et al. (1980). Neste último caso, as melhores correlações foram obtidas agrupando-se medidas de 30 folhas, a intervalos de uma hora. A modelagem de gf com a metodologia utilizada neste trabalho foi utilizada para dados de lima ácida 'Tahiti' com resultados coerentes em comparação com dados porométricos médios (Marin et al., 2001a).

As dificuldades impostas para o estudo de rf, que são devidas tanto ao desenvolvimento de um modelo sensível às variáveis reguladoras do movimento estomático e prático para aplicação em condições de campo, quanto à variabilidade dos dados de rf medidos com porômetro, tornam difícil a aferição de modelos com dados independentes. Além da variabilidade associada às medidas porométricas, deve-se considerar que um importante problema nessa comparação é a diferença de escala entre os dados fornecidos pelo modelo, considerando uma planta, e as medidas porométricas, provenientes de uma folha, o que sempre implica em incertezas no procedimento de validação dos dados estimados. Vale citar, também, que a metodologia para as medições porométricas é responsável em grande parte pela dificuldade na aferição de modelos, já que a forma de coleta e registro dos dados e o tempo necessário para isso limitam o número de amostras realizadas numa planta. 
Outro aspecto a ser considerado é que o número ideal de folhas amostradas para determinação de gf deve ser bem maior do que o utilizado neste trabalho. O número permitido de medidas com porômetros é uma fração muito pequena do total de folhas do cafeeiro adulto avaliado, que tinha cerca de 4800 folhas durante a época de medidas. A partir desse valor podese estabelecer que o número de amostras necessárias para representar essa população é igual a 94 folhas, se for admitido um intervalo de confiança de $10 \%$ a $5 \%$ de probabilidade. Reduzindo-se o intervalo de confiança para 5\% (também para 5\% de probabilidade), o tamanho da amostra passaria para 356 folhas. No processo inverso, tomando-se a amostra real utilizada, igual a 20 folhas, pode-se calcular que o valor do intervalo de confiança dos valores medidos com o porômetro é de $22 \%$, valor esse relativamente elevado.

\subsubsection{Resistência aerodinâmica}

A Figura 36 mostra a relação entre a resistência aerodinâmica estimada com o modelo de Landsberg \& Powell (1973) e a velocidade do vento para as plantas amostradas, enquanto que a Figura 37 mostra a relação entre ra estimada a partir do perfil logarítmico e a velocidade do vento. As estimativas da resistência aerodinâmica com o modelo de Landsberg \& Powell (1973) variaram entre $23,5 \mathrm{~s} \mathrm{~m}^{-1}$, com desvio padrão de $4,5 \mathrm{~s} \mathrm{~m}^{-1}$ para a planta $4\left(\mathrm{AF}=6,0 \mathrm{~m}^{2}\right)$, e $37,5 \mathrm{~s}$ $\mathrm{m}^{-1}$, com desvio padrão de $7,1 \mathrm{~s} \mathrm{~m}^{-1}$, para a planta $2\left(\mathrm{AF}=13,9 \mathrm{~m}^{2}\right)$. Por esses dados e pela análise de Figura 36 percebe-se que a amplitude de variação de ra ao longo do período de medida, foi cerca de 2 vezes, sendo relativamente pequena se comparada com rf. Esse desempenho é devido, em parte, à reduzida variabilidade da velocidade do vento na altura de $1,5 \mathrm{~m} \mathrm{~s}^{-1} \mathrm{e}$, também, ao fato do modelo de Landsberg \& Powell (1973) ter sensibilidade relativamente baixa para a velocidade do vento quando comparada com a estimativa de ra pelos perfis logarítmicos (Figuras 36 e 37). Além disso, a característica principal do modelo de considerar a interferência mútua entre as folhas afeta a sua camada limite e reduz a amplitude de variação da ra. Com isso, o modelo fornece valores relativamente maiores de ra quando a velocidade do vento é alta e valores mais baixos que o método do perfil logarítmico quando a velocidade vento é reduzida. 

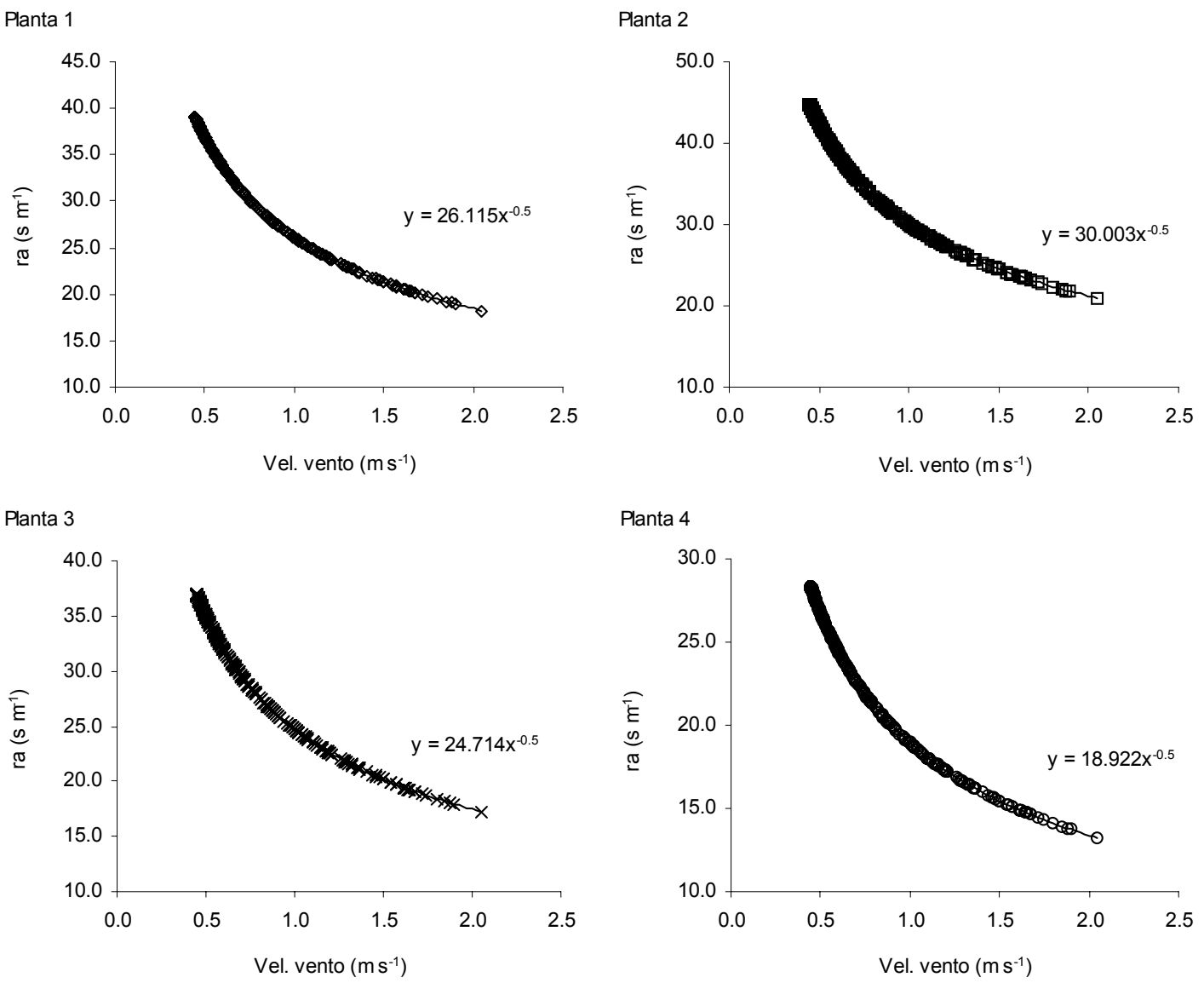

Figura 36 - Relação entre os valores de resistência aerodinâmica estimada com o modelo de Landsberg \& Powell (1973) e a velocidade do vento a 1,5m, para as quatro plantas estudadas. 


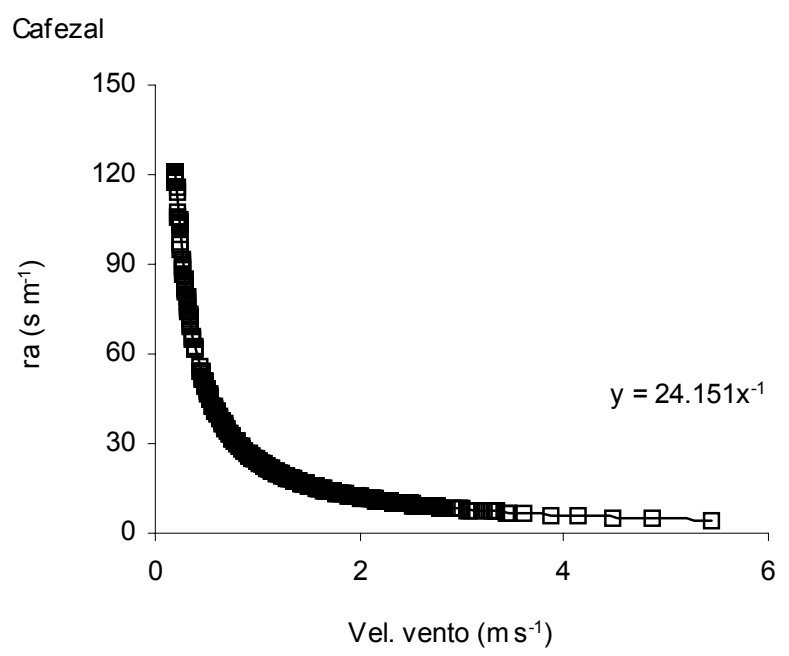

Figura 37 - Relação entre a velocidade do vento medida a 3,5m e a resistência aerodinâmica do cafezal estimado pelo método dos perfis logarítmicos.

É interessante ressaltar que esses valores de ra obtidos com o modelo de Landsberg \& Powell (1973) estão próximos dos encontrados por Kalma (1970), citado por Kalma \& Fuchs (1976), em pomar de laranjeiras recobrindo mais de $80 \%$ da área de solo, indicando que os valores de ra mantêm-se estáveis entre $40 \mathrm{~s} \mathrm{~m}^{-1}$ e $50 \mathrm{~s} \mathrm{~m}^{-1}$ para pomares com cobertura de solo entre $35 \%$ e $80 \%$ da área total. Em pomar de lima ácida 'Tahiti', para árvores de grande porte e ocupando cerca de $35 \%$ da área total do pomar, os valores de ra variaram entre $40 \mathrm{~s} \mathrm{~m}^{-1} \mathrm{e}$ $45 \mathrm{~s} \mathrm{~m}^{-1}$ (Marin, 2000) também muito próximos dos encontrados para os cafeeiros. Vale destacar que os valores de ra foram de uma ordem de grandeza menor que os de rf, validando a constatação de Kalma \& Fuchs (1976), exemplificada pela curva de variação da razão entre rf e ra para o dia 234, mostrada na Figura 38. Em pomar de macieiras, Angelocci (1996) encontrou valores médios de ra para plantas cultivadas em renque em torno de $50 \mathrm{~s} \mathrm{~m}^{-1}$, concordando com os demais trabalhos. 


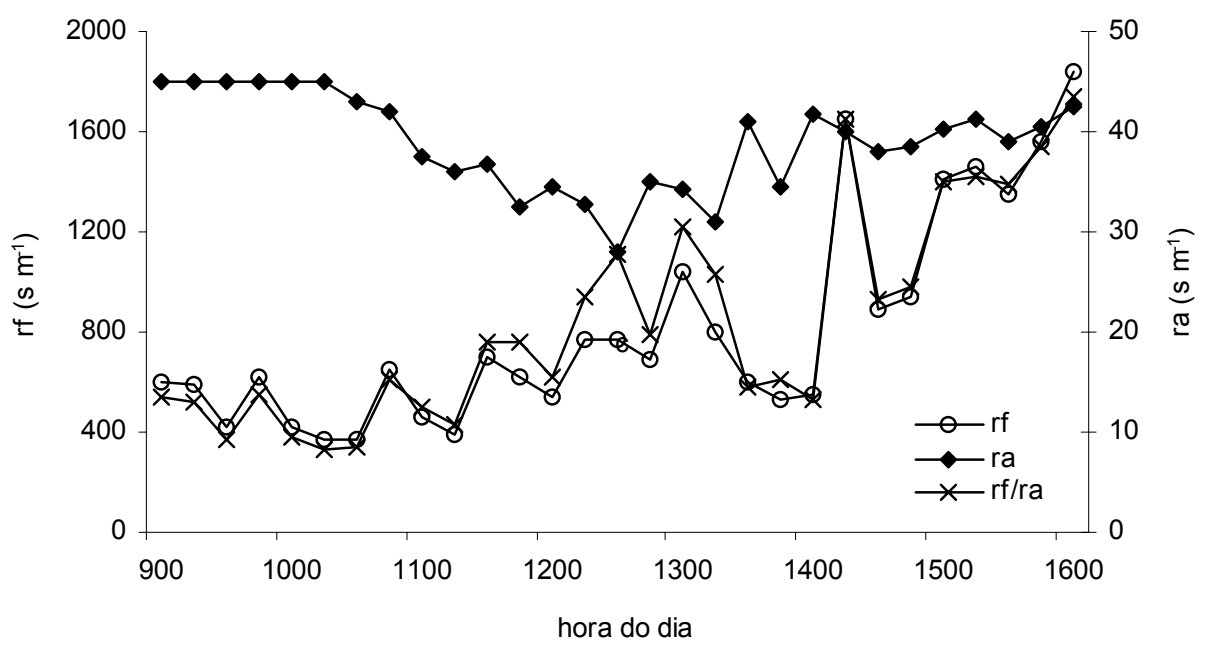

Figura 38 - Variação diurna da resistência aerodinâmica determinada pelo método de Landsberg \& Powell (ra) da planta $2\left(\mathrm{AF}=13,9 \mathrm{~m}^{2}\right)$, da resistência foliar à difusão de vapor (rf) determinada pela equação (25) e da razão entre elas (rf/ra), para o dia 234.

Pode-se perceber que a variação do coeficiente angular das equações da Figura 36 tem relação com a área foliar das plantas, o que remete à possibilidade de estimativa da resistência aerodinâmica do cafezal a partir de variáveis biométricas e do arranjo das plantas na área. A Figura 39 mostra o bom nível de ajuste da correlação linear entre os coeficientes angulares das curvas de ajuste entre ra e a velocidade do vento da Figura 36, e a área foliar das plantas estudadas, possibilitando a estimativa de ra, para o cafezal estudado, a partir apenas da medida da área foliar das plantas e da velocidade do vento na altura média das copas. Nesse caso, ter-seia uma simplificação da equação de Landsberg \& Powell (1973), resultando na equação (39):

$$
r a=\frac{1,263 A F+12,139}{\sqrt{u}}
$$

em que ra é a resistência aerodinâmica para plantas com proteção mútua, adaptada do modelo de Landsberg \& Powell (1973); AF é a área folia dos cafeeiros e u é a velocidade do vento medido na altura média da copa, em $\mathrm{m} \mathrm{s}^{-1}$. 


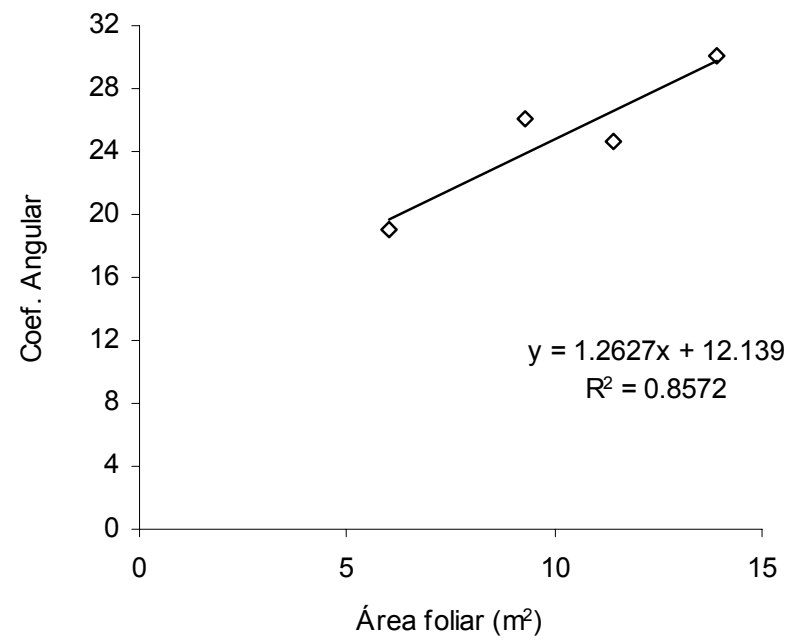

Figura 39 - Relação da área foliar com o coeficiente angular das equações de regressão entre a resistência aerodinâmica estimada com o modelo de Landsberg \& Powell (1973) e a velocidade do vento na altura média das copas dos cafeeiros.

Deve-se considerar que o modelo de Landsberg \& Jones (1981) foi originariamente desenvolvido para uma árvore isolada, considerando-se o efeito da mútua interferência das folhas. Embora sua aplicação para culturas em renque seja comum (Caspari et al., 1993; Green, 1993, Angelocci, 1996; Green \& McNaughton, 1997), deve-se considerar que as condições de contorno do experimento de Landsberg \& Powell (1973) diferiam das encontradas nos cafeeiros amostrados, especialmente devido à disposição em renque das plantas. A interação mútua entre as folhas considerada no referido modelo não considera que as plantas sejam agrupadas, já que o estudo foi realizado com plantas com diversas densidades de folhagem, porém com análises individuais. Assim, admitindo-se a diferença entre as condições do experimento e dos cafeeiros estudados, pode-se inferir que os valores reais de ra das plantas no cafezal sejam maiores que as determinadas pelo modelo de Landsberg \& Powell (1973), já que a interação mútua entre as folhas tem efeito de elevação da ra da camada limite foliar, o que, por sua vez, resulta em maiores valores de ra para toda a copa da planta.

Apesar da relativa simplicidade na determinação de ra para os cafeeiros, a determinação de valores corretos de ra não é fácil (Raupach \& Finnigan, 1988). Apesar dos erros na determinação de ra serem menos problemáticos quando comparados com os da determinação de rf, pelo fato do modelo de Penman-Monteith ser menos sensível a ra, a ausência de métodos independentes para aferição das estimativas de ra para plantas isoladas é um problema. Oliveira 
(1994) mostra que o modelo de Landsberg \& Powell, quando aplicado para três espécies diferentes, necessitou de pequenas adaptações para sua adequação em relação aos valores determinados em túnel de vento e considerados como referência. Atualmente, no Brasil, a principal dificuldade em se determinar de forma mais segura os valores de ra para plantas isoladas é a falta de instrumental e de túneis de vento para medidas do transporte de massa e energia na escala de uma planta.

Comparando a disponibilidade de recursos necessários para as medidas acessórias nos estudos de ra, em relação àquelas disponíveis no experimento de Landsberg \& Powell (1973), poder-se-ia avançar com relativa facilidade o conhecimento sobre ra. Os sistemas de aquisição de dados totalmente programáveis, as balanças eletrônicas com altíssima precisão e com possibilidade de medida contínua se acopladas a microcomputadores, a viabilidade de medidas de temperatura com elevada resolução na escala de uma folha e, as medidas de transpiração por meio de sensores de fluxo de seiva, são exemplos dos recursos que poderiam ser empregados nesse tipo de estudo de forma simples, destacando-se, porém, a ausência de laboratórios de aerodinâmica voltados para estudos em plantas.

\subsubsection{Energia radiante absorvida pelas plantas}

\subsection{Aferição do sistema de medida da energia radiante absorvida pelas plantas}

A aferição do sistema de medida da energia radiante absorvida pela linha de cafeeiros é dificultada pelo fato de não existir um método independente para comparação. Contudo, alguns procedimentos de verificação podem ser adotados como, por exemplo, analisar se as aposições dos sensores estão bem ajustadas, a partir da medida do balanço de energia sem estar a planta instalada no interior do cilindro sensor. Nessa situação, teoricamente, o saldo de radiação deve ser nulo, pois há compensação dos fluxos de entrada e saída nos saldo-radiômetros posicionados em posição oposta. Assim, a medida do desvio do balanço nulo que ocorre quando a planta não está presente no interior do sistema, dá uma idéia dos erros introduzidos pelo próprio sistema. Além de incorreções no posicionamento dos sensores, reflexões causadas pela corrosão e as variações nas superfícies próximas ao sensor quando ele se movimenta, também são fontes de erro que promovem o denominado "desvio do balanço nulo de radiação" ou simplesmente desvio do nulo (DRn). 
A Figura 40 apresenta a variação diária de DRn quando o sistema foi acionado sem o cafeeiro, movimentando-se sobre um gramado, com valores de DRn calculados para intervalos de 10 minutos. Nota-se a ocorrência de dois picos de desvio, sendo um deles negativo, chegando a $40 \mathrm{~W} \mathrm{~m}^{-2}$ por volta das 7:00 e outro positivo, próximo de $100 \mathrm{~W} \mathrm{~m}^{-2}$ as 8:00 ao longo dos três dias. Na parte do período diurno os valores de DRn foram de, aproximadamente, $10 \mathrm{~W} \mathrm{~m}^{-2}$, com inversão do desvio no início da noite, quando os DRn atingiu um valor máximo de $-20 \mathrm{~W} \mathrm{~m}^{-2}$, tendendo para zero durante a maior parte da madrugada. $\mathrm{O}$ valor médio de $\mathrm{DRn}$ ao longo dos três dias foi igual a $5,6 \mathrm{~W} \mathrm{~m}^{-2}$, com desvio padrão de $80,1 \mathrm{~W} \mathrm{~m}^{-2}$, causado pelo padrão de variação de DRn entre os períodos diurno e noturno, especialmente pelos dois picos de variação do desvio erros elevados nos horários iniciais da manhã.

A Figura 41 apresenta a variação de DRn para intervalos de uma hora, permitindo a comparação com dados de Rngrama nos mesmo horários, onde se identifica o mesmo padrão de variação apresentado na Figura 40 nos horários iniciais da manhã. No entanto, ao se relacionar o erro com os valores de Rngrama verifica-se que a integração dos desvios ao longo do dia leva a valores de $0,2 \mathrm{MJ} \mathrm{m}^{-2} \mathrm{~d}^{-1}$, representando até $4 \%$ da energia radiante total disponível na horizontal, com variações que chegam aos $18 \%$ nos momentos de pico. Levando em conta que os desvios são decorrentes da posição do feixe solar direto em relação à estrutura do SMR, de possíveis reflexões no sistema e da posição dos sensores, ele deve ser menor ainda quando se trabalha com o sistema no cafezal, já que a folhagem diminui a incidência de radiação solar direta sobre a parte fixa do sistema de medida. McNaughton et al. (1992) verificaram desvios do nulo inferiores a 5\% ao meio dia e consideraram satisfatórias as medidas realizadas com essa margem de erro.

Assim, considerou-se a margem de erro introduzida pelo SMR, verificado durante o procedimento de aferição, suficientemente pequena para as medidas no cafezal, tendo em vista os objetivos de uso dos dados. No entanto, vale destacar que esses desvios do nulo somente mostraram-se desprezíveis após a pintura da estrutura em cor preta, visto que as medidas a esse procedimento apresentaram desvios do nulo muito superiores aos descritos, devido à reflexão de irradiância solar direta pela própria estrutura. 


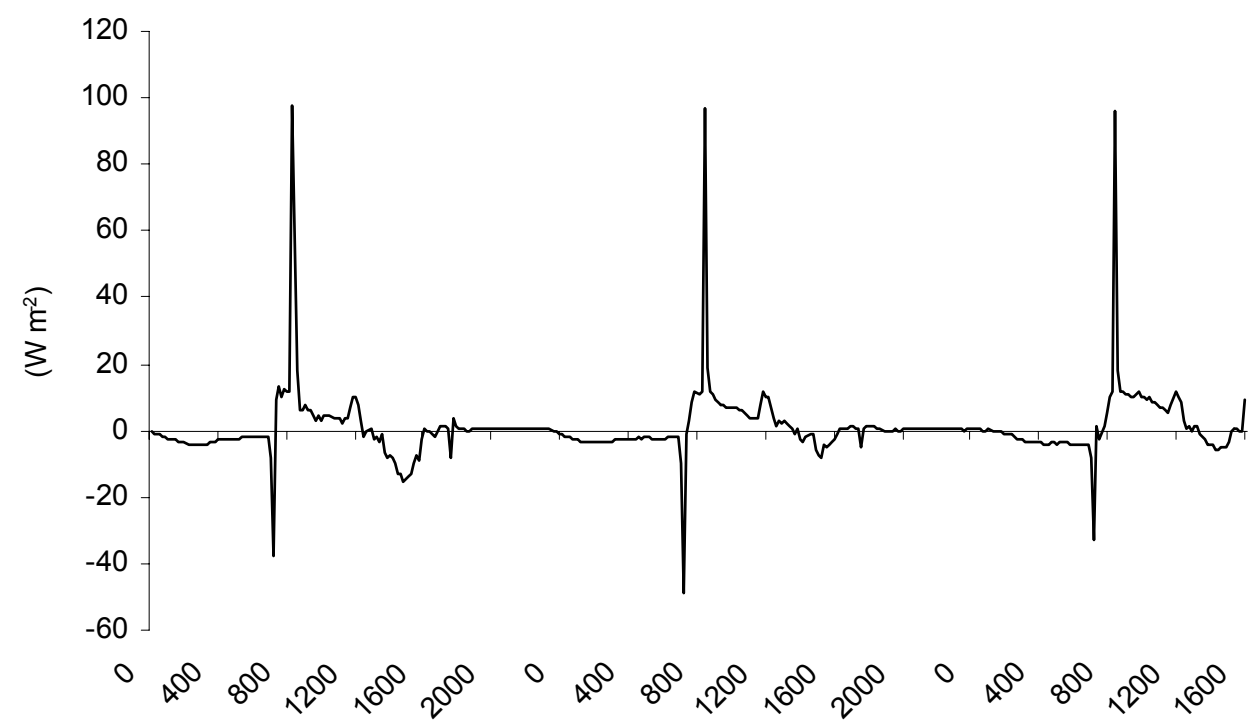

Figura 40 - Variação do desvio do zero nas medidas de saldo de radiação sem a planta no interior do sistema, para intervalos de 10 minutos durante três dias, em Piracicaba, SP.

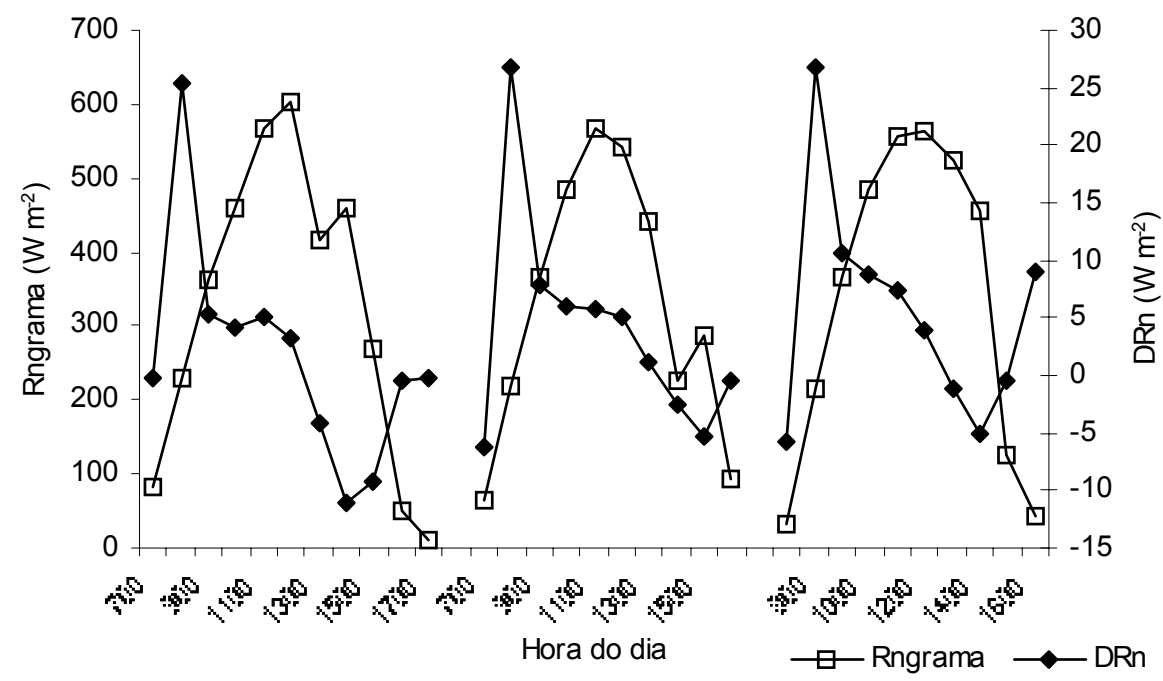

Figura 41 - Variação horária do desvio do zero nas medidas de saldo de radiação a sem planta no interior do sistema (DRn) e do saldo de radiação medido sobre gramado (Rngrama), em Piracicaba, SP. 


\subsection{Medidas de energia radiante absorvida pelos cafeeiros}

O sistema móvel foi instalado no cafezal de modo que sua distância de deslocamento permitiu a medida completa de Rnp da copa de quatro cafeeiros. A Figura 42 apresenta as curvas de variação dos oito saldo-radiômetros ao longo de dez dias. As medidas foram obtidas em diferentes condições de tempo, desde dias com céu nublado durante todo o período, como no dia 256, até dias de céu descoberto e elevada incidência de radiação, como no dia 284. A partir da

equação (13) determinou-se que a diferença de Rnp entre esses dois dias foi de 21,3 $\mathrm{MJ}^{-1}$, variando entre $7,7 \mathrm{M} \mathrm{J} \mathrm{d}^{-1}$ e 29,0 $\mathrm{MJ} \mathrm{d}^{-1}$.

Pode-se observar a disposição do renque em relação ao deslocamento aparente do sol resultou numa simetria temporal das curvas de medida entre os saldo-radiômetros posicionados em cada um dos lados do renque. Um exemplo disso pode ser verificado a partir do formato das curvas dos saldo-radiômetros $4(\mathrm{Rn} 4)$ e $5(\mathrm{Rn} 5)$ no dia 296. Outro aspecto interessante é depreendido das curvas dos sensores $1(\mathrm{Rn} 1)$ e $8(\mathrm{Rn} 8)$, posicionados praticamente sob a copa dos cafeeiros, que apresentaram valores próximos de zero durante todos os dias de medidas e indicando a reduzida quantidade de energia disponível abaixo da copa das plantas.

O SMR utilizado neste trabalho mostrou um desempenho mecanicamente adequado para medidas de longo termo, permitindo medidas por vários dias seguidos, como também foi constatado por McNaughton et al. (1992), que chegaram a realizar medidas contínuas por mais de duas semanas. O único ponto do SMR que necessitou de ajustes diários foi a corrente de tração, que tinha um nível ideal de tensão de modo a não causar desgaste no sistema de transmissão quando muito esticada e, também, não permitir o deslocamento em falso do sistema quando havia folga excessiva da corrente. 

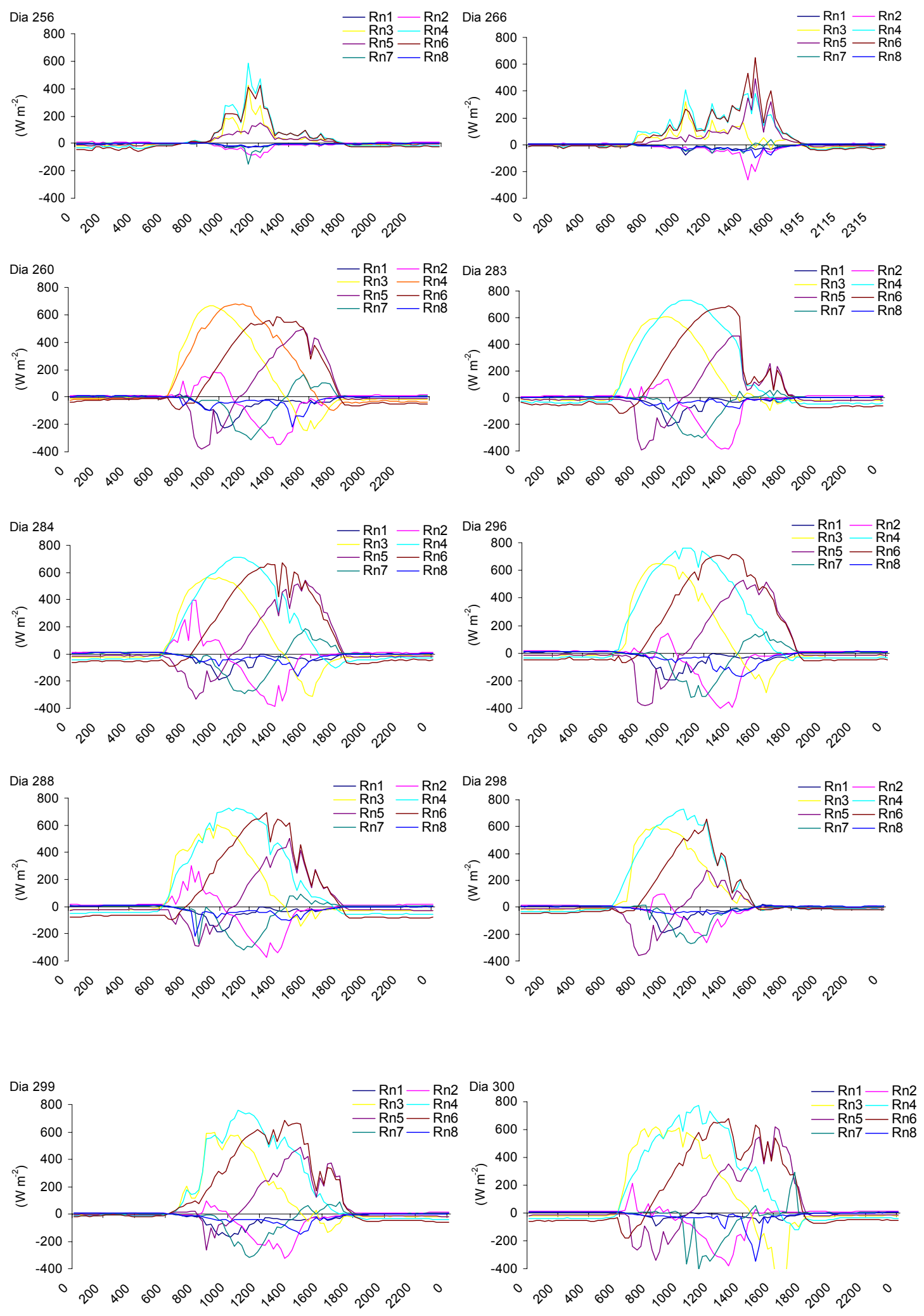

Figura 42 - Evolução horária das medidas dos oito saldo-radiômetros do sistema móvel. 
Com vistas a facilitar a determinação de Rnp e Rnf a partir de medidas de simples realização, verificou-se a relação entre os valores estimados com as equações (13) e (14) e as variáveis Rg, Rngrama e Rncafé. A Figura 43A apresenta a correlação entre Rnp e Rg, na unidade de $\mathrm{W} \mathrm{m}^{-2}$ e intervalos de 15 minutos, indicando a boa correlação obtida, com a equação de regressão significativa ao nível de $1 \%$ de probabilidade e com $\mathrm{R}^{2}=0,960$, indicativo da reduzida dispersão entre as variáveis.
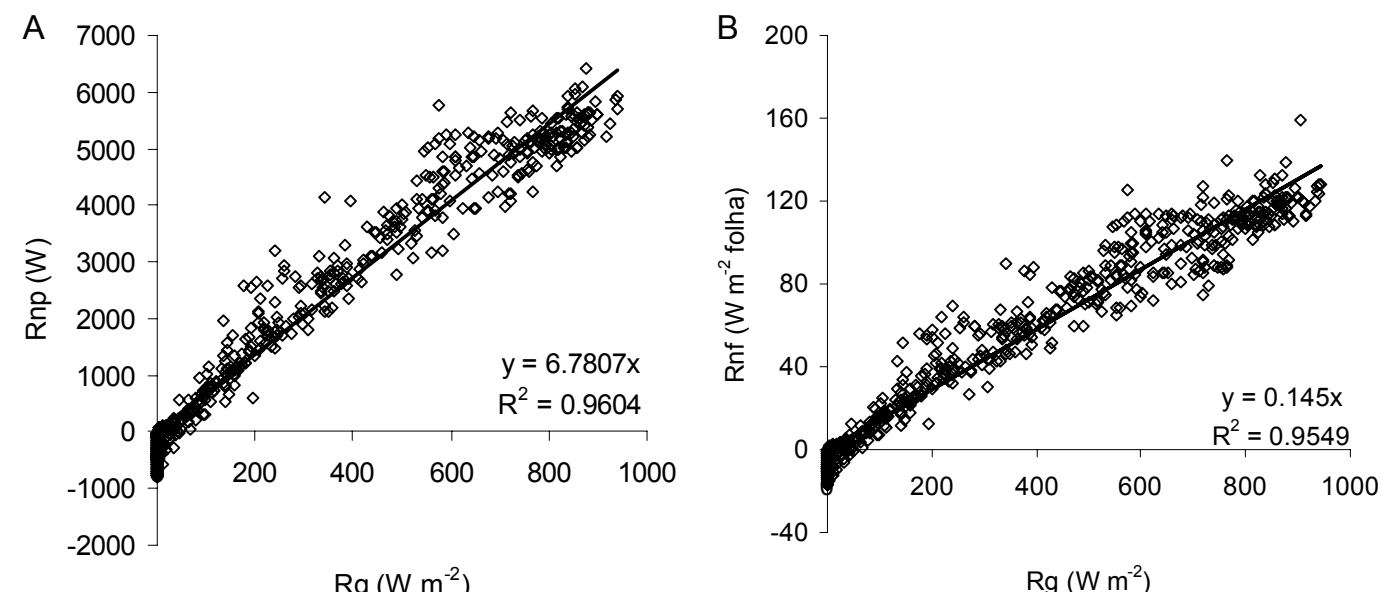

$\mathrm{Rg}\left(\mathrm{W} \mathrm{m}^{-2}\right)$

$\mathrm{Rg}\left(\mathrm{W} \mathrm{m}^{-2}\right)$

Figura 43 - Correlação da energia radiante total absorvida por quatro plantas (A), e da energia radiante absorvida por unidade de área foliar (B) com a irradiância solar global. Dados obtidos em intervalos de 15 minutos.

Nas Figuras 44 e 45, utilizou-se o saldo de radiação medido sobre gramado e sobre o cafezal como variáveis independentes nas regressões. Os padrões de variação são muito próximos dos verificados para a correlação com $\mathrm{Rg}$, destacando-se apenas o aumento considerável dos níveis de dispersão dos dados, sem comprometer, no entanto, a significância da análise de regressão.

Na Figura 44B verifica-se que uma unidade de área de gramado capta cerca de quatro vezes mais energia que uma unidade de área foliar dos cafeeiros. Entretanto, se considerado que o gramado tem índice de área foliar próximo de 2,88 , como normalmente se utiliza em estudos de evapotranspiração de referência, vê-se que a capacidade de absorção de energia se aproxima para os dois tipos de vegetação. Seguindo o mesmo enfoque, na Figura 44A, observa-se que o total de energia absorvido pelos quatro cafeeiros é cerca de 8 vezes maior que o absorvido por uma unidade de área de gramado, sendo necessário considerar que os valores de Rnp referem-se 
ao total absorvido pelas quatro plantas. Análises semelhantes feitas por Angelocci et al. (1999) utilizando plantas de lima ácida 'Tahiti' com $\mathrm{AF}=40 \mathrm{~m}^{2}$ em comparação com gramado, verificaram que as plantas cítricas captaram cerca de 12 vezes mais energia radiante que $1 \mathrm{~m}^{2}$ de gramado. Assim, considerando-se que a AF somada dos quatro cafeeiros resulta no mesmo valor das árvores de lima ácida estudada por Angelocci et al. (1999), vê-se que essa apresenta uma capacidade de absorção de energia radiante cerca de 50\% maior que os cafeeiros, por unidade de área foliar.

A principal causa dessa diferença pode ser atribuída à forma de cultivo das plantas associado a diferenças na estrutura de copa das duas espécies. Enquanto os cafeeiros utilizados são cultivados em renque e com espaçamentos reduzidos, o pomar de lima ácida 'Tahiti' possuía plantas de grande porte e praticamente "isoladas" uma das outras quanto à interação com a radiação solar, devido ao grande espaçamento de implantação do pomar. Assim, a capacidade de absorção de radiação de ondas curtas dos cafeeiros é favorecida nos horários de maior elevação solar, enquanto que os cítricos captam essa energia radiante com grande eficiência desde o início da manhã até o final da tarde, já que a copa dessas plantas tinha formato aproximadamente semiesférico.
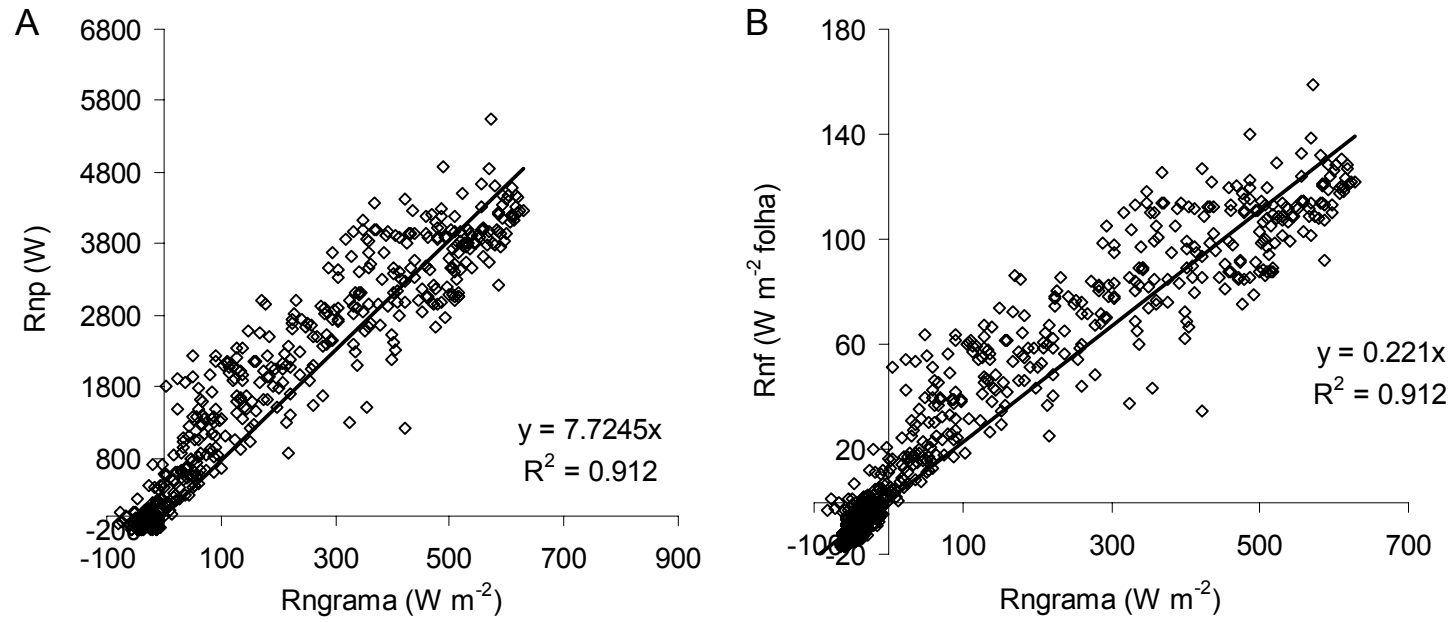

Figura 44 - Correlação da energia radiante total absorvida por quatro plantas (A), e da energia radiante absorvida por unidade de área foliar (B) com o saldo de radiação medido sobre gramado. Dados obtidos em intervalos de 15 minutos. 

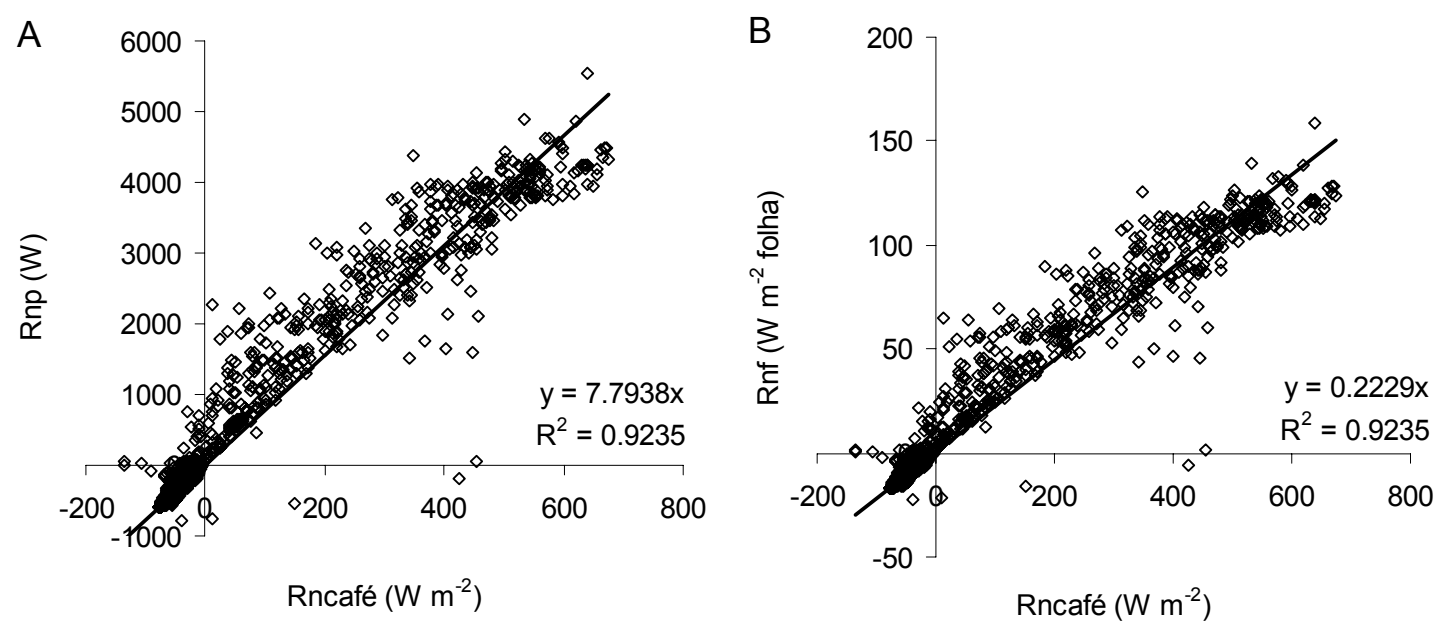

Figura 45 - Correlação da energia radiante total absorvida por quatro plantas (A), e da energia radiante absorvida por unidade de área foliar (B) com o saldo de radiação medido sobre o cafezal. Dados obtidos em intervalos de 15 minutos.

Os resultados mostrados indicam a possibilidade de se estimar o saldo de radiação das plantas de um renque de cafezal na escala de 15 minutos e, em conseqüência, em períodos maiores, a partir de RG, Rngrama e Rncafé. Devido ao fato do saldo de radiação na copa depender de fatores como densiddade de folhagem, direção dos renques, espaçamento entre plantas e geometria da copa, as relações encontradas são aplicáveis ao cafezal estudado ou em condições próximas ao do estudo quanto a essas variáveis.

\subsection{Comparação das medidas de energia radiante absorvida pelas plantas com as estimativas a partir da lei de Beer.}

A estimativa da energia radiante absorvida pelo renque de plantas baseada na lei de Beer (Rnfb) (equação 15) e nos estudos de Ritchie (1972) e Marin (2000), necessita dos valores do coeficiente de extinção $(\mathrm{k})$ para o saldo de radiação na copa dos cafeeiros, obtidos a partir de medidas feitas por saldo radiômetros instalados acima e abaixo do renque de cafeeiros amostrados. A Figura 46 apresenta a curva de variação de k ao longo de 11 dias de medida, determinado a partir da resolução da equação (15) tendo k como incógnita e considerando um índice de área foliar (IAF) médio para as quatro plantas de 4,3. O valor médio de $\mathrm{k}$ foi igual a 0,49, com desvio padrão de 0,15 e variação entre o valor máximo de 0,95 e o mínimo de 0,20. 
Esse valor médio é expressivamente menor que os encontrados por Jaramillo-Robledo (1994) e Castillo (1993) (apud Jaramillo-Robledo, 1994), entre 0,66 e 0,74, para radiação solar global, pelo fato dos valores de $\mathrm{k}$ obtidos neste trabalho serem específicos para o saldo de radiação. Trata-se, portanto, de um coeficiente de extinção referente a radiação tanto de ondas longas como de ondas curtas, algo difícil de ser entendido intuitivamente. Contudo, considerando-o como um coeficiente de absorção de energia radiante, tem-se um conceito de compreensão mais fácil

O baixo valor de $\mathrm{k}$ obtido é explicado, em parte, pela redução no aporte de energia acima da copa devido à reflexão de uma fração da radiação de ondas curtas, associado com elevação no montante de radiação abaixo na copa devido, principalmente, ao componente de ondas longas. $\mathrm{O}$ fato de se ter redução na energia radiante que atinge o topo da copa e elevação da energia radiante transmitida abaixo dela resulta em valores de $\mathrm{k}$ relativamente menores que os encontrados para RG.

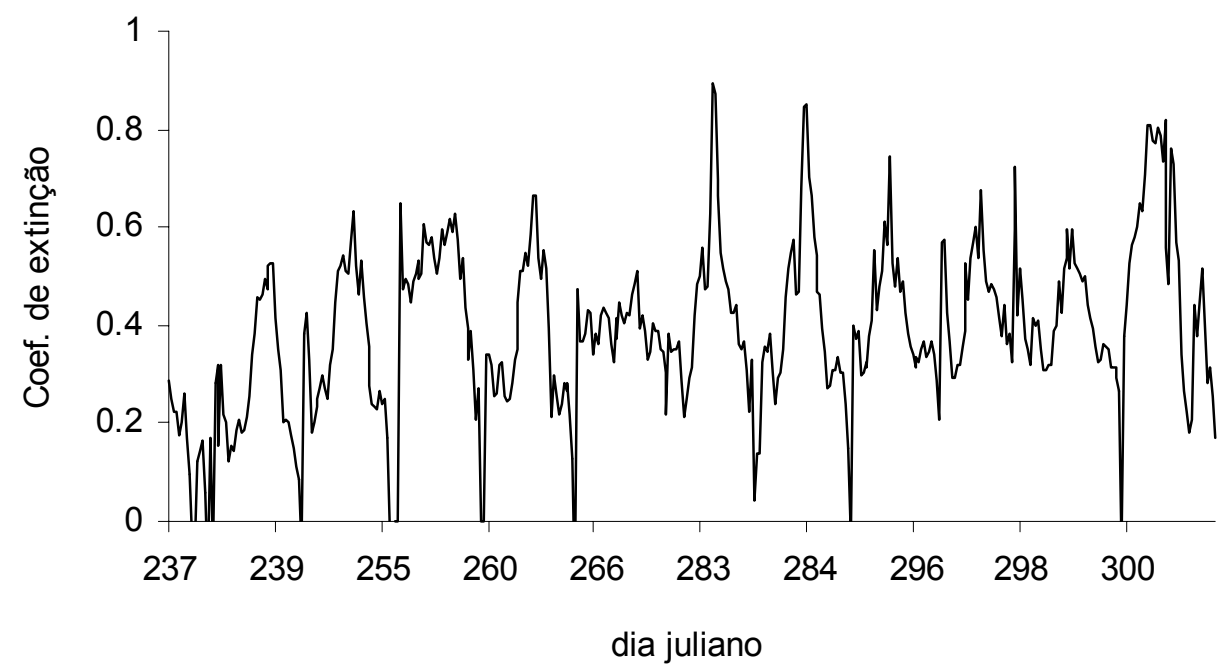

Figura 46 - Variação horária diurna do coeficiente médio de extinção durante 10 dias de medida, considerando-se IAF igual a 4,3.

A correlação entre os valores de Rnfb e os valores determinados com o SMR (Rnf) é apresentada na Figura 47, notando-se o elevado nível de ajuste na análise de regressão linear, que foi significativa ao nível de $1 \%$. Forçando-se a passagem da reta da equação pela origem dos eixos, tem-se o valor de b representando o desvio em relação à linha 1:1, indicando uma tendência de subestimativa pela equação (15) de, aproximadamente, $9 \%$ em relação aos dados de 
Rnf. Essas informações são interessantes quando se considera a dificuldade para a determinação de Rnf em condições de campo, indicando a viabilidade de se estimar Rnf a partir apenas de medidas de saldo de radiação e dos valores do coeficiente de extinção e IAF da vegetação.

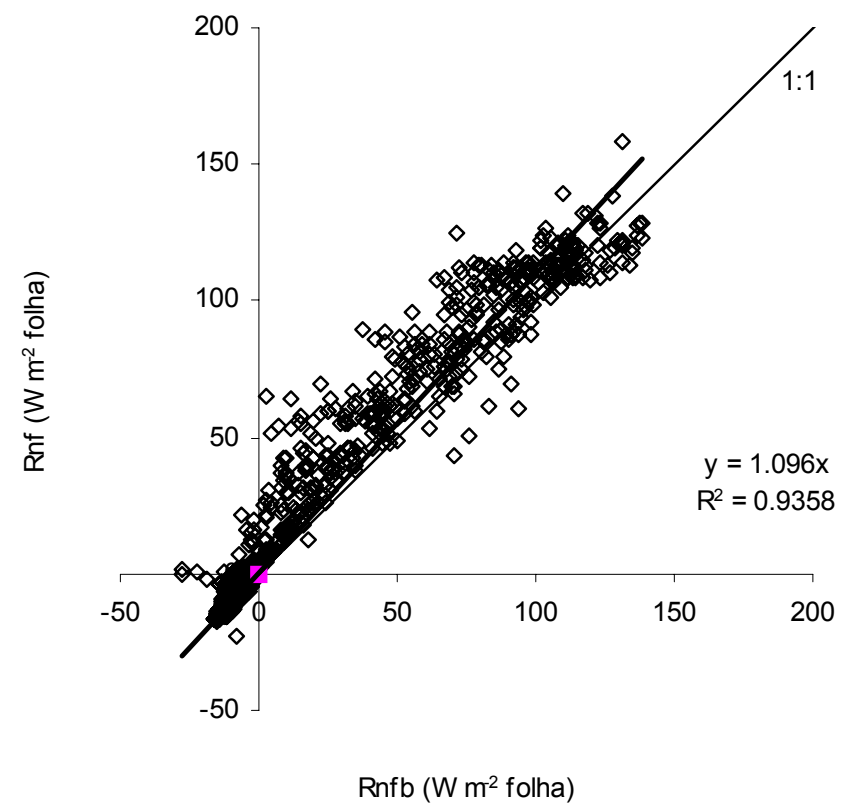

Figura 47 - Correlação entre os valores de energia radiante absorvida pelas quatro plantas, medido pelo sistema móvel (Rnf) e os valores estimados a partir da adaptação da lei de Beer (Rnfb). Dados medidos a cada 15 minutos.

\subsubsection{COMPARAÇÃO ENTRE O FLUXO DE SEIVA E A TRANSPIRAÇÃO MÁXIMA ESTIMADA PELO MODELO DE PENMAN-MONTEITH}

A transpiração máxima é aquela que ocorre em uma planta sem restrição hídrica. É considerada igual aos valores medidos de fluxo de seiva quando estes são integrados para períodos de 24 horas, tendo-se assumido que a condição de boa disponibilidade hídrica ocorreu no cafezal na época das medidas. Na Figura 48 são apresentadas as correlações entre os totais diários de transpiração máxima estimada para cada planta com o modelo de Penman-Monteith, utilizando-se o modelo de Landsberg \& Powell (1973) para a estimativa de ra, a proposta de Marin et al. (2001a), adaptada para cafeeiros na estimativa de rf, e a Rnf estimada a partir da radiação solar global, com a equação da Figura 38B e considerada igual a zero durante a noite. 
Na planta $2\left(\mathrm{AF}=13,9 \mathrm{~m}^{2}\right)$ e na planta $4\left(\mathrm{AF}=6,0 \mathrm{~m}^{2}\right)$ não houve boa concordância dos valores estimados com os medidos sendo que, para a primeira, as estimativas foram cerca de $56 \%$ maior que o fluxo de seiva e, na planta 4 as estimativas foram aproximadamente $30 \%$ menores, enquanto que nas outras duas plantas a concordância foi melhor. $\mathrm{O}$ valor $\mathrm{R}^{2}$ variou entre 0,41 e 0,57 para as quatro plantas e as análises estatísticas com o teste $\mathrm{F}$ indicaram que todas as regressões foram significativas ao nível de $1 \%$ de probabilidade. As análises de significância com o teste $t$, para os coeficientes lineares das equações, não foram significativo ao nível de $1 \%$ de probabilidade para nenhum dos casos, daí se ter forçado a passagem pela origem nas equações. A estimativa de $\mathrm{T}$ somente para dados do período diurno $(\mathrm{Rnf}>0)$ resultou em diferença menor que $2 \%$ em relação aos dados diários.
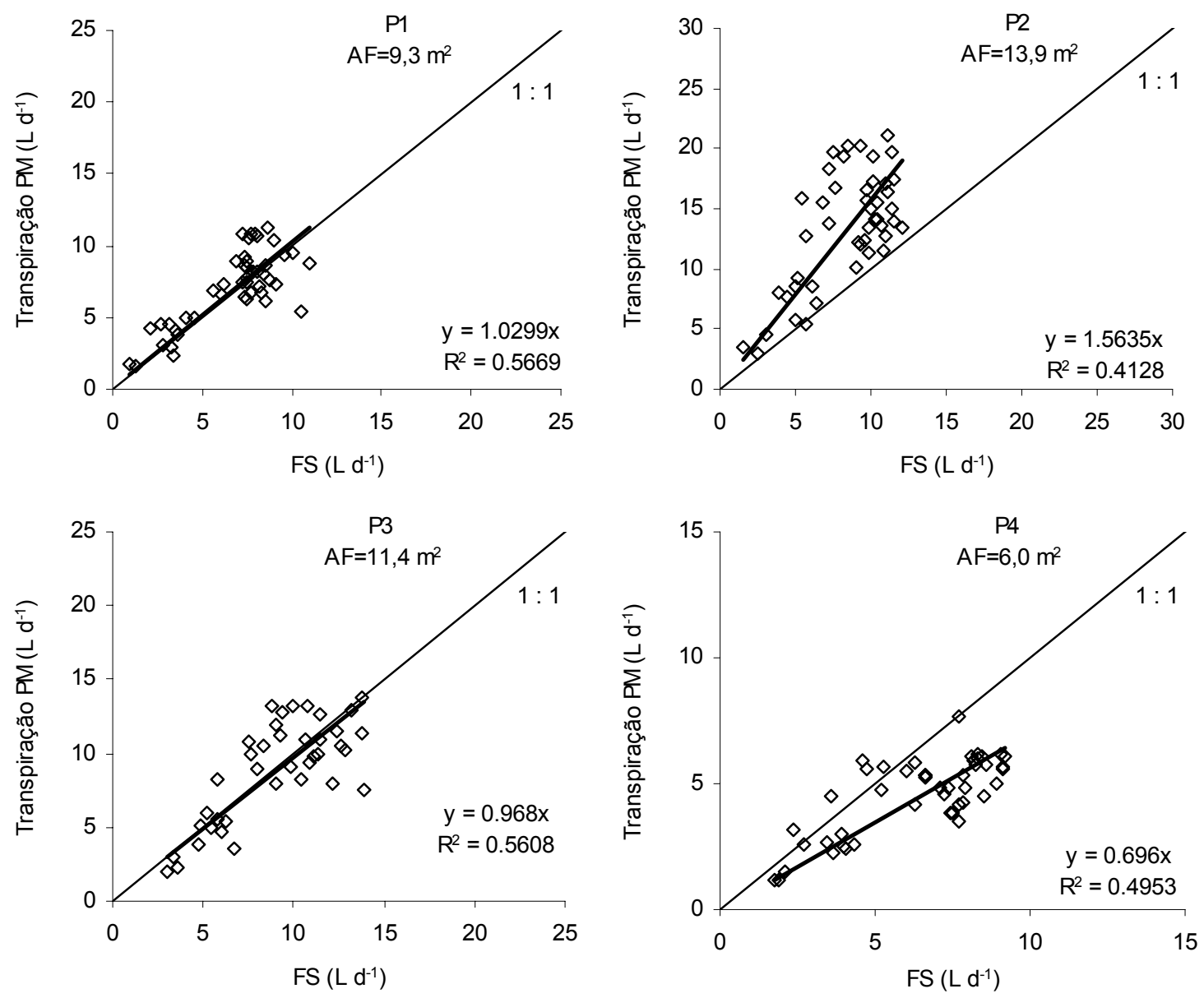

Figura 48 - Relação entre a transpiração máxima de quatro cafeeiros estimada com o modelo de Penman-Monteith (Transpiração PM) e as medidas de fluxo de seiva (FS). 
$\mathrm{O}$ fato dos valores de $\mathrm{b}$ das equações na Figura 48 guardarem relação decrescente com a AF das plantas é um indicativo de que as medidas de Rnf podem ter causado a grande parte das discrepâncias verificadas nas plantas 2 e 4. Como Rnf é variável de grande importância na composição das estimativas com o modelo P-M, erros na determinação de Rnf de 50\% resultam em erros no cômputo da transpiração de cerca de 30\% (Angelocci, 1996).

Pelo fato do sistema de medida de Rnf amostrar simultaneamente 4 plantas, tem-se aí uma premissa subentendida em que se admite que a absorção de energia radiante pelas copas das plantas tem relação linear positiva com a área foliar das mesmas, o que parece não ser correto em se tratando de cafezais adensados e em sua fase adulta. Os trabalhos de Hernandez et al., 1989 e Marin et al., 2003 mostraram que cafeeiros cultivados em espaçamentos reduzidos e com área foliar elevada apresentam uma certa limitação da absorção de energia pelas folhas ao longo da copa devido ao auto-sombreamento das folhas do interior da copa e dos extratos inferiores. Essa característica da cultura confere um caráter assintótico à relação entre a área foliar e a absorção de energia radiante pelas plantas, o que não é considerado no procedimento de medida estimativa da Rnf, tornando as estimativas do modelo P-M incoerentes quando os valores de $\mathrm{AF}$ estão acima (planta 2) ou abaixo (planta 4) do valor médio de AF das plantas amostradas. Confirmando essa hipótese, tem-se o bom nível de ajuste observado nas plantas 1 e 3, que tinham AF próxima do valor médio das quatro plantas.

O que se pode deduzir dessas considerações é que a planta 2, apesar de ter o maior valor de $\mathrm{AF}$, de cerca de 2,3 vezes a da planta 4, não teria transpiração proporcionalmente maior, devido ao efeito do auto-sombreamento. Assim, o modelo de Penman-Monteith na forma aqui considerada, que admite que a taxa de transpiração é diretamente proporcional à área foliar (equação 12) seria válido para cafeeiros cultivados em sistema adensado até determinados valores de área foliar das plantas e até um certo limite de transpiração, a partir do qual a relação deixaria de ser linear. Assim, deve-se aplicar no modelo algum tipo de fator de redução aos valores estimados de transpiração para considerar essa característica da espécie. Os dados das plantas 1 e 3 (Figura 48) subsidiam essas inferências, já que as estimativas mostraram-se em relativa concordância com as medidas de fluxo de seiva e a AF das plantas apresenta valores intermediários em relação às demais.

Uma forma de testar essa hipótese é a aplicação da equação de Penman-Monteith conjuntamente para as quatro plantas com medida do fluxo de seiva, adequando-se com isso a escala de determinação de Rnf, ou seja, para um renque de quatro plantas com AF de $40,6 \mathrm{~m}^{2}$, e não para plantas isoladas com $\mathrm{AF}$ variando entre $6,0 \mathrm{~m}^{2}$ e $13,9 \mathrm{~m}^{2}$. A Figura 49 mostra a 
correlação entre essas estimativas, utilizando-se os valores médios de ra e rf das quatro plantas, como representativos do renque, e o fluxo de seiva somado das quatro plantas como referência. $\mathrm{O}$ valor de $\mathrm{b}$ próximo da unidade é indicativo de que a forma de medida de Rnf foi o principal problema nas estimativas de transpiração máxima e que os cafeeiros estudados não apresentaram taxa de transpiração linearmente proporcional à área foliar, daí as discrepâncias verificadas nas plantas 2 e 4.

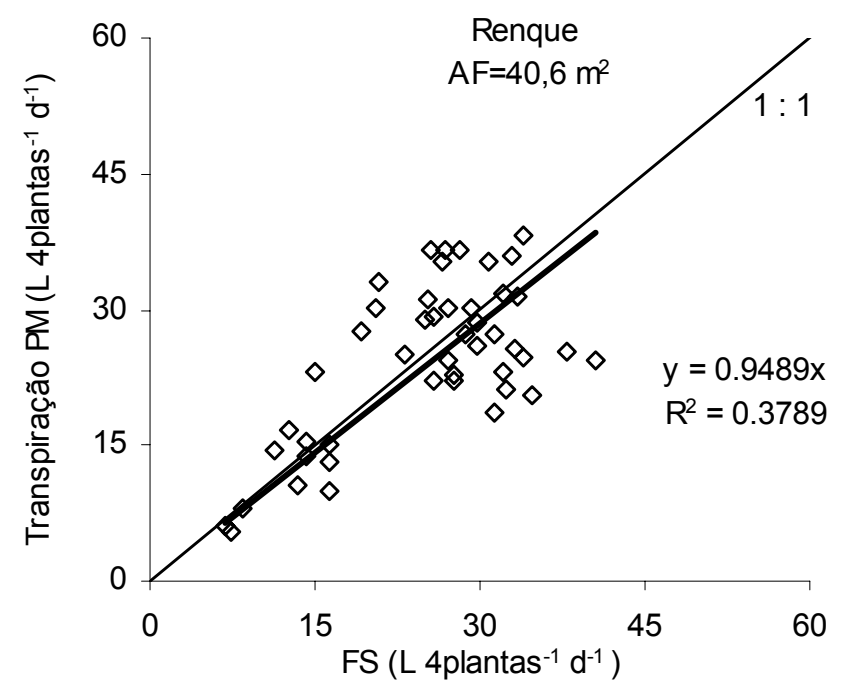

Figura 49 - Correlação entre a transpiração máxima estimada para um cafeeiro hipotético com área foliar igual à soma da área foliar dos quatro cafeeiros e a soma do fluxo de seiva medido nos quatro cafeeiros.

Aspecto que merece menção nessa discussão são possíveis erros introduzidos nas estimativas de $\mathrm{T}$ devidas aos desvios nas determinações de rf. Apesar da dificuldade em se testar a magitude desses erros, levando em conta as correlações entre medida e estimativa de rf (Figura 33), pode-se aceitar que parte dos desvios verificados nas estimativas de $\mathrm{T}$ para os quatro cafeeiros sejam devidas a rf. Diante das comparações entre os valores medidos e estimados de rf, infere-se, também, que os erros causados por essa variável tendam a ser aleatórios, diferentemente das tendências verificadas para Rnf.

Sobre a variável ra, diante dos dados disponíveis neste trabalho, é grande a dificuldade em se avaliar os possíveis efeitos de erros na sua determinação sobre a estimativa de T, pela falta de um método independente. A sensibilidade do modelo P-M aplicado à plantas isoladas de macieira dentro de um renque, foi menor em cerca de uma ordem de grandeza para ra do que 
para as outras variáveis de entrada. Além disso, verificou-se no item 4.3.1.2 a pequena amplitude de variação de ra entre as árvores e, também, para as diferentes velocidades do vento, levando à conclusão de que a discrepância entre a estimativa de T e a medida de FS não foram em maior grau decorrentes de erros na estimativa de ra.

Embora o déficit de pressão de vapor $(\Delta \mathrm{e})$ seja uma variável para a qual o modelo P-M tem grande sensibilidade, pode-se assumir que a sua determinação, quando feita com psicrômetros de boa precisão como os utilizados no presente estudo, não introduz erro apreciável na estimativa da transpiração P-M.

\subsection{RELAÇÃO ENTRE A TRANSPIRAÇÃO DOS CAFEEIROS E A EVAPOTRANSPIRAÇÃO DE REFERÊNCIA E DO CAFEZAL}

$\mathrm{Na}$ determinação dessas relações dividiu-se o conjunto de dados em dois períodos, baseando-se na fração da área da entrelinha ocupada pela vegetação rasteira. No início do experimento, o longo período sem chuvas na região de Piracicaba, resultou numa severa deficiência hídrica na faixa de solo não ocupada pelos cafeeiros, impossibilitou o desenvolvimento da vegetação da entrelinha, fazendo com que o solo dessa parte do cafezal permanecesse quase que totalmente exposto. Alguns dias após o início das medidas, as chuvas passaram a ocorrer com certa freqüência, estimulando o desenvolvimento da vegetação intercalar, que ganhou vigor expressivo cerca de 30 dias depois o início do experimento, quando já ocupava uma fração considerável da área exposta do cafezal.

Apesar de não terem sido feitas medidas do armazenamento hídrico do solo e da fração do solo ocupada pela vegetação, o acompanhamento diário do cafezal permitiu considerar os primeiros 30 dias de medidas como totalmente desprovidos de vegetação da entrelinha, e os dados de evapotranspiração do cafezal coletados posteriormente como sendo compostos pela evapotranspiração da vegetação rasteira e pela transpiração dos cafeeiros.

No primeiro período, a relação entre os dados de evapotranspiração determinados com o método da razão de Bowen $\left(\mathrm{ET}_{\text {total }}\right)$ e de transpiração dos cafeeiros $\left(\mathrm{T}_{\text {total }}\right)$, ambos convertidos para a área do cafezal esteve próxima de 0,91 (Figura 50), indicando que a transpiração dos cafeeiros representou cerca de $91 \%$ do total de água na forma de vapor perdida pelo cafezal. $\mathrm{Na}$ segunda fase, a quando o consumo hídrico da área elevou-se em relação à primeira fase, a relação caiu para 0,67 , indicando que a componente da evapotranspiração devida a vegetação da 
entrelinha ganhou em importância, chegando a representar $1 / 3$ do total de água consumida na área.

Esse valor é importante se considerado que a largura média dos renques de cafeeiros era de cerca de $1,8 \mathrm{~m}$, num espaçamento de entrelinha de $2,5 \mathrm{~m}$. Feita a razão entre área ocupada pelos renques e a área total do cafezal, encontra-se uma fração do terreno coberta pelos cafeeiros de 0,72 , valor esse próximo do coeficiente angular (b) da equação de regressão da Figura 45, na segunda fase, indicando similaridade entre a taxa de perda de água por unidade de área de terreno entre a vegetação da entrelinha e os cafeeiros.

Vale destacar que o desenvolvimento da vegetação da entrelinha ocorreu de forma gradual ao longo do experimento, de forma que a divisão em dois períodos visa apenas facilitar as análises e comparações entre as medidas, o que pode explicar a causa dos valores de b terem sido diferentes de 1,00 e 0,72 no primeiro e no segundo período, respectivamente. Além disso, levando-se em conta os possíveis erros de estimativa tanto do MRB como nas medidas de fluxo de seiva, é razoável considerar que as relações são coerentes em comparação com a área ocupada pelos cafeeiros e pela vegetação intercalar.

O efeito do crescimento gradual da vegetação intercalar pode ser observado na Figura 51 pela evolução das curvas de $\mathrm{ET}_{\text {total }}$ e $\mathrm{T}_{\text {total }}$ ao longo de todo o período. As falhas nos dados de $\mathrm{ET}_{\text {total }}$ apresentados nessa figura devem-se aos problemas com o método da razão de Bowen, especialmente com as medidas psicrométricas. Verifica-se o incremento gradual da curva de $\mathrm{ET}_{\text {total }}$ com o avanço do segundo período, ainda que a $\mathrm{T}_{\text {total }}$ tendesse a estabilizar-se, indicando o aumento proporcional da evapotranspiração da vegetação da entrelinha com seu crescimento. 

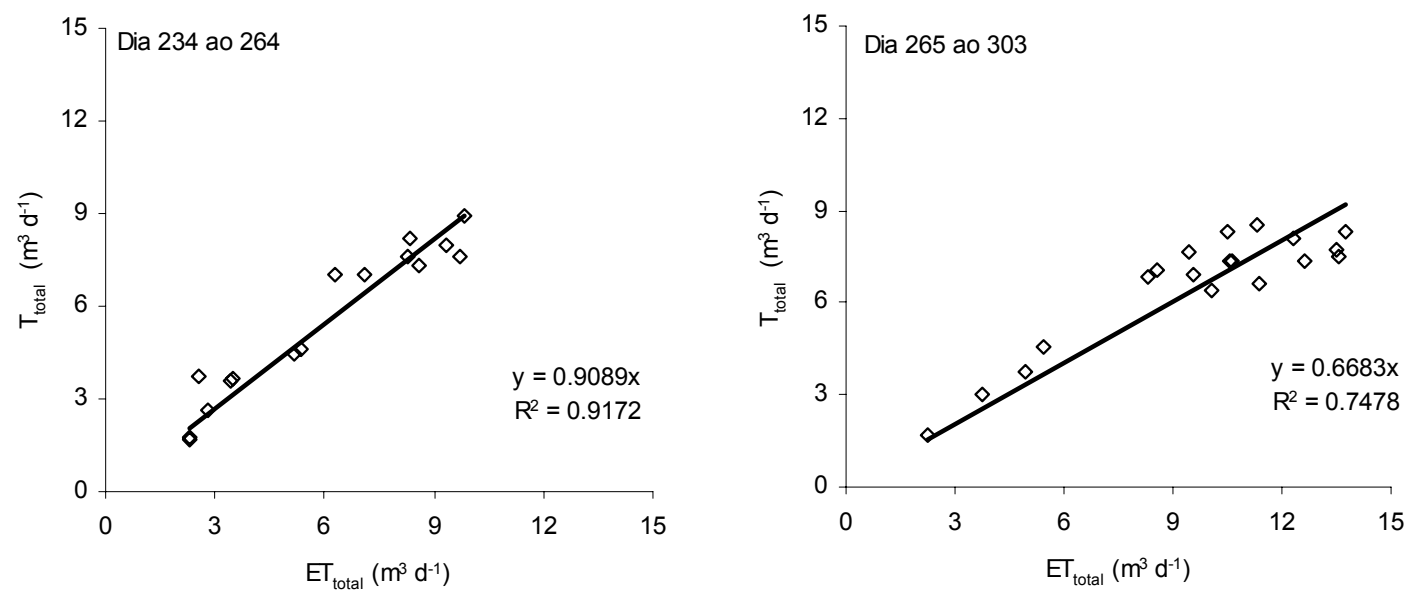

Figura 50 - Relação entre a transpiração dos cafeeiros $\left(T_{\text {total }}\right)$ e a evapotranspiração cafezal $\left(\mathrm{ET}_{\text {total }}\right)$, considerando toda a área do cafezal, em dois períodos subseqüentes. No segundo período a vegetação intercalar estava presente e ativa.

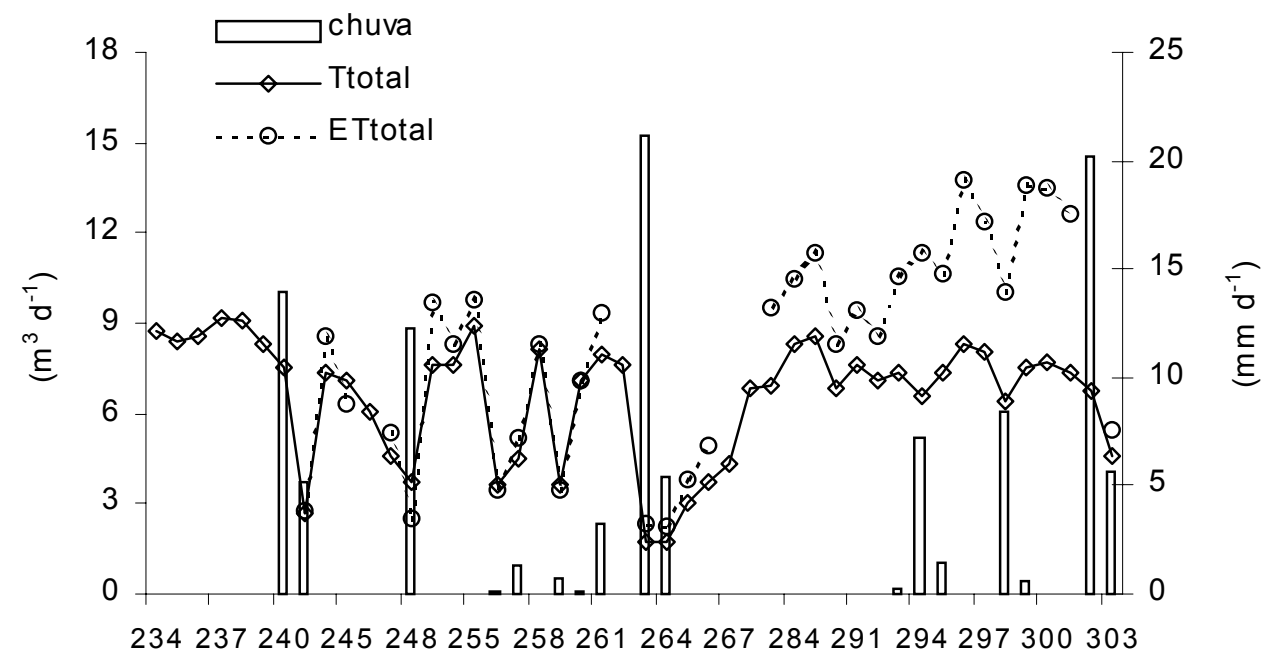

dia do ano

Figura 51 - Variação da evapotranspiração total do cafezal $\left(\mathrm{ET}_{\text {total }} \mathrm{l}\right)$ e da transpiração total $\left(\mathrm{T}_{\text {tota }} \mathrm{l}\right)$ ao longo do período experimental.

Análise semelhante à apresentada na Figura 50 foi feita comparando-se a evapotranspiração de referência $\left(\mathrm{ETo}_{\text {total }}\right)$ com a transpiração dos cafeeiros $\left(\mathrm{T}_{\text {total }}\right)$, ambas expressas em volume diário de água consumida na área total do cafezal (Figura 52). Esse 
procedimento representa a determinação do coeficiente de cultura $(\mathrm{Kc})$ para o cafezal estudado, largamente utilizado para a elaboração do balanço hídrico de culturas e no manejo da irrigação. O fato de se contar com medidas de fluxo de seiva permite, inclusive, determinar dois tipos de coeficientes de cultura, o basal $(\mathrm{Kcb})$, referente à transpiração dos cafeeiros, e o evaporativo (ou da evapotranspiração da entrelinha) (Kce), referente a evapotranspiração do restante da área, de acordo com a proposição de Allen et al. (1998).

A relação entre a $E T o_{\text {total }}$ e $T_{\text {total }}$, representada pelo valor de $b=0,79$ indica que, em média, a transpiração dos cafeeiros representou aproximadamente $80 \%$ da evapotranspiração de referência (Figura 52B). Já a relação com a evapotranspiração do cafezal foi próxima da unidade (Figura 52A), indicando que há similaridade entre o consumo hídrico do cafezal estudado e um gramado com índice de área foliar de 2,88. Pode-se admitir que o coeficiente angular da Figura $52 \mathrm{~A}$, igual a 1,03 corresponde ao valor de kc do cafezal como um todo, interessante nos casos em que a irrigação é feita em toda a área do cafezal, com sistema de aspersão convencional ou pivô central, por exemplo. O valor do coeficiente angular da Figura 52B, igual a 0,80, corresponde ao Kcb, útil na aplicação de água na forma localizada.

Gutiérrez \& Meinzer (1994a), utilizando o método da razão de Bowen para medida da evapotranspiração dos cafezais, encontraram valores de kc entre 0,68 e 0,82 para cafezais sem vegetação na entrelinha. Allen et al. (1998) citam valores de Kcb para cafezais entre 0,8 e 0,9, próximos aos apresentados na Figura 52B, apesar de Carr (2001) afirmar que os valores sugeridos por Allen et al. (1998) não tem embasamento experimental. 

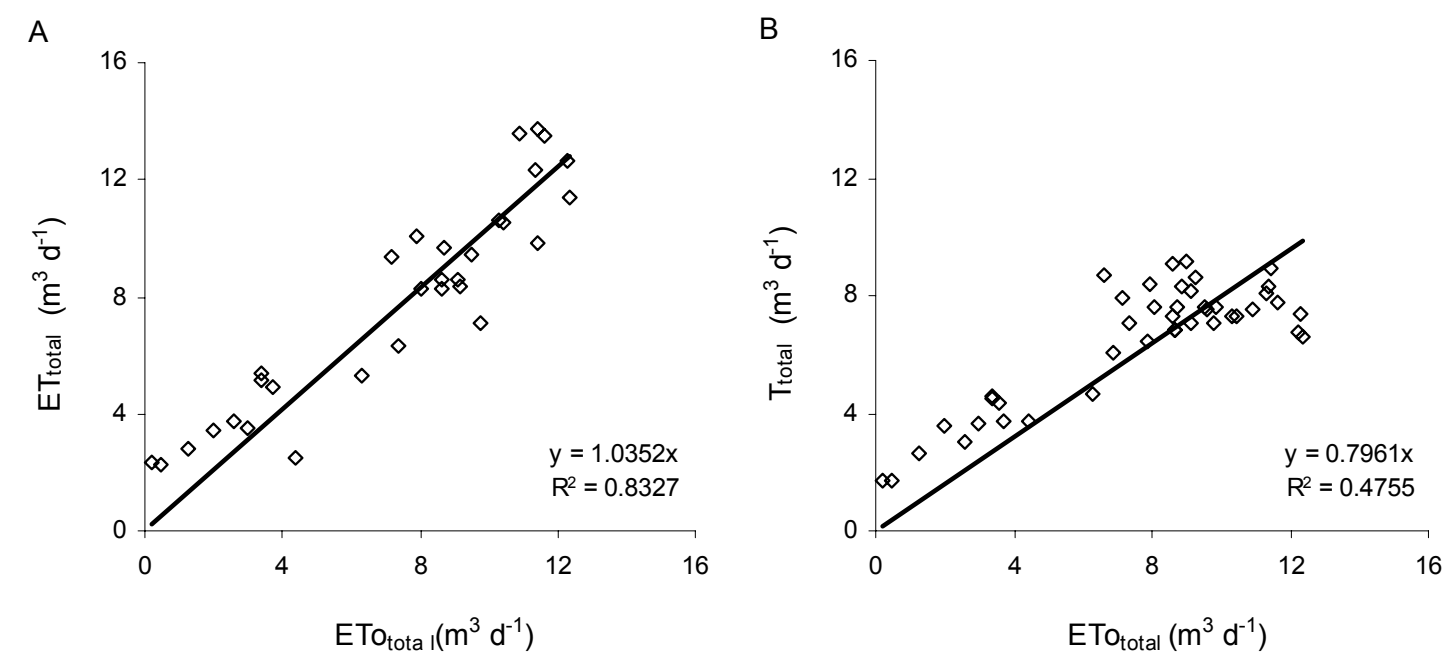

Figura 52 - Relação entre a transpiração total do cafezal (Ttotal) e a evapotranspiração total (ETtotal) com a evapotranspiração de referência extrapolada para a área total do cafezal $\left(\right.$ ETo $\left._{\text {total }}\right)$.

O valor de Kce pode ser determinado a partir do valor do coeficiente angular da Figura 52B, sendo próximo de 0,2. Novamente vale destacar a similaridade entre os valores de $\mathrm{Kc}$ obtidos e a fração da área total ocupada pelos renques de cafeeiros, sugerindo a possibilidade de se estimar o valor de Kc específicos para cada cafezal, a partir da área ocupada pelos renques, como também foi observado para lima ácida 'Tahiti' (Marin et al., 2002b).

Entretanto, tendo em vista que a transpiração é altamente dependente da área foliar, seria interessante que os valores de $\mathrm{Kcb}$ e Kce, bem como o valor de Kc global do cafezal, fossem relacionados com o índice de área foliar calculado por unidade de área de projeção da copa. Outra possibilidade é estimar a transpiração por unidade de área foliar dos cafeeiros que, nos casos em que a vegetação rasteira cobre totalmente a entrelinha, pode ser estimada por:

$$
T=\frac{E T A T}{N_{a} A F_{m}}
$$

em que $\mathrm{T}$ é a transpiração específica para um cafeeiro com AF igual ao valor médio do cafezal $\left(\mathrm{L} . \mathrm{m}^{-2}\right.$ de folha.d $\left.\mathrm{d}^{-1}\right)$; ET é a evapotranspiração total da área $\left(\mathrm{mm} . \mathrm{d}^{-1}\right)$, AT é a área total do cafezal $\left(\mathrm{m}^{2}\right) ; \mathrm{AF}_{\mathrm{m}}$ é a área foliar média das plantas $\left(\mathrm{m}^{2}\right.$ folha.árvore $\left.{ }^{-1}\right)$ e $\mathrm{N}_{\mathrm{a}}$ é o número de plantas do cafezal.

Para as situações em que o pomar não se encontrar com vegetação cobrindo a entrelinha, a transpiração média poderia ser estimada da seguinte forma: 


$$
T=\frac{E T}{I A F_{m}}
$$

em que $\mathrm{IAF}_{\mathrm{m}}$ é o índice de área foliar médio do cafezal, com base na área proejtada da copa.

A partir dessas relações poder-se-ia determinar a transpiração de cada uma das árvores do pomar, desde que se conhecesse sua área foliar, podendo-se, com isso, manejar a aplicação de água de modo a atender as necessidades de cada planta, apesar das técnicas atualmente disponíveis ainda não possibilitarem um controle da aplicação de água específica a tal ponto. Entretanto, esse enfoque tem aplicação prática para otimizar o manejo da irrigação em talhões relativamente homogêneos que tenham sistema de aplicação de água independente, sendo esse um importante avanço na racionalização do manejo da irrigação em áreas com cobertura descontínua do terreno. 


\section{CONCLUSÕES}

A estimativa da resistência foliar a difusão de vapor com o modelo proposto mostrou resultados razoáveis em comparação com dados porométricos, com os maiores desvios verificados principalmente nos horários iniciais e finais do período diurno.

A determinação da energia radiante absorvida pelo renque de cafeeiros com o sistema móvel mostrou-se uma técnica confiável e permitiu a obtenção de relações consistentes com valores de irradiância solar global e de saldo de radiação medido num plano horizontal acima do cafezal, o que demonstra a possibilidade de utilizar ambos para uma forma simples de estimativa do saldo de radiação da copa dos cafeeiros. Os valores de energia radiante da copa estimados com a adaptação da lei de Beer para a absorção de radiação pela folhagem apresentaram uma boa correlação com os valores medidos pelo sistema móvel, demonstrando ser, também, uma forma simples de estimativa da energia radiante absorvida pela copa do cafeeiro.

A resistência aerodinâmica determinada com o modelo de Landsberg \& Powell (1973) mostrou relação linear inversa com a área foliar dos cafeeiros, permitindo sua estimativa de forma mais simples.

As estimativas de transpiração máxima com o modelo adaptado de Penman-Monteith mostraram boa correlação com os valores integrados diários de fluxo de seiva para as plantas com área foliar entre 9,3 $\mathrm{m}^{2}$ e 11,4 $\mathrm{m}^{2}$, enquanto discrepâncias significativas foram verificadas para as plantas com área foliar de $6,0 \mathrm{~m}^{2} \mathrm{e} 13,9 \mathrm{~m}^{2}$. Esses desvios foram devidos, principalmente, à forma de determinação da energia radiante absorvida pelas plantas e a uma característica de auto-sombreamento dos cafeeiros, com redução na capacidade de captação de energia radiante pelas folhas dos extratos inferiores. Outra causa desses desvios foi a resistência foliar a difusão de vapor.

No período seco, a transpiração dos cafeeiros representou $91 \%$ da evapotranspiração do cafezal e, no período úmido, caiu para $69 \%$ da evapotranspiração total. O coeficiente de cultura basal para o cafezal foi de 0,8 , próxima da razão entre a área total do cafezal e a área ocupada 
pelos cafeeiros, enquanto o coeficiente evaporativo foi igual a 0,23 . O coeficiente de cultura global para as condições do cafezal em estudo foi muito próximo da unidade. 


\section{REFERÊNCIAS BIBLIOGRÁFICAS}

ALLEN, R.G.; PEREIRA, L.S.; RAES, D.; SMITH, M. Crop evapotranspiration: guidelines for computing crop water requirements. Rome: FAO, 1998. 300p. (FAO. Irrigation and Drainage Paper, 56).

ALVES. I.; PEREIRA, L.S. Modelling surface resistance from climatic variables? Agricultural Water Management, v.42, p.371-385, 2000.

ANGELOCCI, L.R. Estimativa da transpiração máxima de macieiras (Malus spp.) em pomares pelo modelo de Penman-Monteith. Piracicaba, 1996. 103p. Tese (Livre-Docência) - Escola Superior de Agricultura "Luiz de Queiroz", Universidade de São Paulo.

ANGELOCCI, L.R. Água na planta e trocas gasosas/energéticas com a atmosfera: introdução ao tratamento biofísico. Piracicaba: O autor, 2002. 268p.

ANGELOCCI, L.R.; VALANCOGNE, C. Leaf area and water flux in apple trees. Journal of Horticultural Science, v.68, n.2, p.299-307, 1993.

ANGELOCCI, L.R.; MARIN, F.R.; RIGHI, E.Z. Variação sazonal e ao longo do dia da condutância estomática e da transpiração de lima ácida 'Tahiti' em pomar irrigado em Piracicaba, SP. In: CONGRESSO DA SOCIEDADE BOTÂNICA DE SÃO PAULO, 11. Piracicaba, 1998. Resumos. Piracicaba: SBSP; ESALQ, 1998. p.110.

ANGELOCCI, L.R. VILLA NOVA, N.A.; SENTELHAS, P.C. Medidas do balanço de energia radiante na copa de lima ácida "Tahiti" em pomar na região de Piracicaba, SP, Brasil. In: CONGRESSO IBÉRICO DE ENERGIA SOLAR, 9., Córdoba, 2000. Acta. Córdoba: Sociedade Ibérica de Energia Solar. 2000. p.115-119.

ANGUS, D.E.; WATTS, P.J. Evapotranspiration - how good is the Bowen ratio method? Agricultural Water Management, v.8, p.133-150, 1984.

BAKER, J.M.; NIEBER, J.L. An analysis of the steady-state heat balance method for measuring sap flow in plants. Agricultural and Forest Meteorology, v.48, p.93-109, 1989.

BAKER, J.M.; VAN BAVEL, C.H.M. Measurements of mass flow of water in stems of herbaceous plants. Plant, Cell and Environment, v.10, p.777-782, 1987.

BARROS, R.S.; MOTTA, J.W.; MATTA, F.M.; MAESTRI, M. Decline of vegetative growth in Coffea arabica L. in relation to leaf temperature, water potential and stomatal conductance. Field Crops Research, v. 54, p. 65-72, 1997.

BATTEN, D.; LLOYD, J.J.; McCONCHIE, C. Seasonal variation in stomatal responses of two cultivars of lychee (Litchi chinensis Sonn.). Australian Journal of Plant Physiology. v.19, p.317-329, 1992. 
BOWEN, I.S. The ratio of heat losses by conduction and by evaporation from any water surface, Physical Review, v.27, p.779-787, 1926.

BOYER, J. Étude experimentale des effects du régime d'humidité du sol sur la croissance végétative, la floraison et la frutification du caféier Robusta. Café, Cacao, Thé, v.13, p.187200, 1969.

BRENNER, A.J.; JARVIS, P.G. A heated leaf replica technique for determination of leaf boundary layer conductance in the field. Agricultural and Forest Meteorology, v.72, p.261-275, 1995.

BUTTLER, D.R. Estimation of transpiration rate in an apple orchard from net radiation and vapour pressure deficit measurement. Agricultural Meteorology, v.16, p.277-289, 1976.

BUTLER, D.R. Coffee leaf temperatures in a tropical environment. Acta Botanica Neerlandica, v.26, p.129-140, 1977.

CAMARGO, A.P.; CAMARGO, M.B.P. Definição e esquematização das fases fenológicas do cafeeiro arábica nas condições tropicais do Brasil. Bragantia, v.60, n.1, p. 1-6, 2001.

CAMARGO, A.P.; PEREIRA, A.R. Agrometeorology of coffee crop. Geneva: WMO, 1994. 53p. (Bulletin, 58).

CAMPBELL, G.S.; NORMAN, J.M. An introduction to environmental biophysics. New York: Springler Verlag, 1998. 286p.

CANNEL, M.G.R. Physiology of coffee crop. In: CLIFFORD, N.M.; WILSON, K.C. Coffee:: botany, biochemistry and production beans and beverage. London: Croom Helm, 1985. p.108-134.

CARR, M.K.V. The water relations and irrigation requirements of coffee. Experimental Agriculture, v.37, n. 1, p.1-36, 2001.

CASPARI, H.W.; GREEN, S.R.; EDWARDS, W.R.N. Transpiration of well-watered and waterstressed Asian pear trees as determined by lysimetry, heat-pulse, and estimated by a Penman-Monteith model. Agricultural and Forest Meteorology, v.67, n.1, p. 13-27, 1993

CERMAK, J.; DEML, M.; PENKA, M. A new method of sap flow rate determination in trees. Biologia Plantarum, v.15, p.171-178, 1973.

CHARLES-EDWARDS, D.A.; THORPE, M.R. Interception of diffuse and direct-beam radiation by a hedgerow apple orchard. Annals of Botany, v.40, p.91-99, 1976.

CIENCIACALA, E.; LINDROTH, A.; CERMAK, J.; HALLGREN, J.E.; KUCERA, J. Assessment of transpiration estimates for Picea abies trees during a growing season. Trees, v.6, p.121-127, 1992.

COWAN, I.R. Mass, heat and momentum exchange between stands of and their atmospheric environment. Quarterly Journal of the Royal Meteorological Society, v.94, p.523-544, 1968.

DAAMEN, C.C.;DUGAS, W.A.; PRENDERGAST, P.T.; JUDD, M.J.; McNAUGHTON, K.G. Energy flux measurements in a sheltered lemon orchard. Agricultural and Forest Meteorology, v.93, p.171-183, 1999.

DAYAU, S. Realisation des capteurs pour la mesure du debit de seve dans des arbres (Methode du Bilan de Chaleur). Bordeaux: INRA, Laboratoire de Bioclimatologie, s.d.. 20p. 
DEVITT, D.A.; BERKOWITZ, M. SCHULTE, P.J.; MORRIS, R.L. Estimating transpiration for three woody ornamental tree species using stem-flow gauges and lysimetry. Hortscience, v.28, n.3, p.235-241, 1993.

FANJUL, L.; ARRCOLA-RODRIGUEZ, R.; MENDEZ-CASTREJOU, M.P. Stomatal responses to environmental variables in shade and sun grown coffee plants in Mexico. Experimental Agriculture, v.70, n.1, p. 25-34, 1985.

FISCHER, R.A. Aspects of potassium accumulation by stomata in vicia faba. Australian Journal Biological Sciences, v.25, p.1107-1123, 1972.

FRANCO, C.M.; INFORZATO, R. Quantidade de água transpirada pelo cafeeiro cultivado ao sol. Bragantia, v.10, n.9, p. 247-257, 1950.

FUCHS, M. TANNER, C.B. Error analysis of Bowen ratios measured by differential psychrometry. Agricultural Meteorology, v.7, p. 329-334, 1970.

GEIGER, R. Manual de micrometeorologia. Lisboa: Fundação Calouste Gulbenkian, 1980. $556 \mathrm{p}$.

GRANIER, A. Une nouvelle méthode pour la measure du flux de séve brute dans le tronc des arbres. Annales des Sciences Forestieres, v.42, n.2, p.81-88, 1985.

GRANIER, A. Mesure du flux de séve brute dans le tronc du Douglas par une nouvelle méthode thermique. Annales des Sciences Forestieres, v.44, n.1, p.1-14, 1987.

GRANTZ, D.A.; MEINZER, F.C. Regulation of transpiration in field-grown sugarcane: evaluation of the stomatal response to humidity with the Bowen ratio technique. Agricultural and Forest Meteorology, v. 53, p.169-183, 1991.

GREEN, S.R. Radiation balance, transpiration and photosynthesis of an isolated tree. Agricultural and Forest Meteorology, v.64, p.201-221, 1993.

GREEN S.R.; MCNAUGHTON, K.G. Modelling effective stomatal resistance for calculating transpiration from an apple tree. Agricultural and Forest Meteorology, v.83, n.1/2, p.1-26, 1997.

GREEN S.R.; MCNAUGHTON, K.G.; GREER, D.H.; MCLEOD, D.J. Measurement of increased PAR and net all-wave radiation absorption by an apple tree caused by applying a reflective ground covering. Agricultural and Forest Meteorology, v. 76, p.163-183, 1995.

GUTIÉRREZ, M.V.; MEINZER, F.C. Energy balance and latent heat flux in coffee hedgerows at different stages of canopy development. Agricultural and Forest Meteorology, v. 68, p.173-186, 1994a.

GUTIÉRREZ, M.V.; MEINZER, F.C. Estimating water use and irrigation requirements of coffee in Hawaii. Journal of the American Society for Horticultural Science, v. 119, n.3, p. $652-657,1994 b$.

GUTIÉRREZ, M.V.; HARRINGTON, R.A.; MEINZER, F.C.; FOWNES, J.C. The effect of environmentally induced stem temperature gradients on transpiration estimates from the heat balance method in two tropical woody species. Tree Physiology, v. 14, p.179-190, 1994.

HALL, A.E.; CAMACHO-B, S. E.; KAUFMANN, M. R. Regulation of water loss by citrus leaves. Physiologia Plantarum, v.33, p.62-65, 1975. 
HEILMAN, J.L.; BRITTIN, C.L. Fetch requirements for Bowen Ratio measurements of latent and sensible heat fluxes. Agricultural and Forest Meteorology, v.44, p.261-273, 1989.

HERNANDEZ, A.P.; COCK, J.H.; EL-SHARKAWY, M.A. The responses of leaf gas exchange and stomatal condutance to air humidity in shade-grown coffee, tea, and cacao plants as compared to sunflower. Revista Brasileira de Fisiologia Vegetal, v.1, n. 2, p. 155-161, 1989.

HERZOG, K.M.; THUM, R.; ZWEIFEL, R.; HÄSLER, R. Heat balance measurements - to quantify sap flow in the stems only? Agricultural and Forest Meteorology, v.83, n.1, p.7577, 1997.

JARAMILLO-ROBLEDO, A. Aspectos microclimáticos en plantaciones de café (Coffea arabica L.) con alta densidad de siembra. In: SIMPÓSIO INTERNACIONAL SOBRE CAFÉ ADENSADO, Londrina, 1994. Anais. Londrina: IAPAR, 1994. p.47-69.

JARVIS, P.G. Interpretation of the variation in the leaf water potential and stomatal condutance found in canopies in the field. Philosophical Transactions of the Royal Society of London, v. 273, p. 593-610, 1976.

JONES, H.G. Plants and microclimate: a quantitative approach to environmental plant physiology. New York : Cambridge University Press, 1992. 428p.

KALMA, J.D.; FUCHS, M. Vegetation and the atmosphere. New York: Academic Press, 1976. p. 309-328: Citrus orchards.

KHAIRI, M.M.A.; HALL, A.E. Temperature and humidity effects on the net photosynthesis and transpiration of citrus. Physiologia Plantarum, v.36, n.1, p. 29-34, 1976.

KRAMER, P.J.; BOYER, J.S. Water relations of plants and soils. New York: Academic Press, 1995. 200p.

LANDSBERG, J.J.; JAMES, G.B. Wind profiles in plant canopies: studies on an analytical model. Journal of Applied Ecology, v. 8, p.729-741, 1971.

LANDSBERG, J.J.; JONES, H.G. Apple orchards. In: KOSLOWSKI, T.T. (Ed.). Water deficits and plant growth: wood plants community. New York: Academic Press, 1981. v. 4, p.419469.

LANDSBERG, J.J.; POWELL, D.B.B. Surface exchange characteristics of leaves subject to mutual interference. Agricultural Meteorology, v.12, p.169-184, 1973.

LANDSBERG, J.J.; THOM, A.S. Aerodynamic properties of a plant of complex structure. Quarterly Journal of the Royal Meteorological Society, v.97, p.565-655, 1971.

LANDSBERG, J.J.; POWELL, D.B.B. BUTLER, D.R. Microclimate in an apple orchard. Journal of Applied Ecology, v.10, p.881-896, 1973.

LLOYD, J. J. Modelling stomatal responses to environment in Macadamia integrifolia. Australian Journal of Plant Physiology. v.18, p.649-60, 1991.

MALEK, E.; BINGHAM, G.E. Growing season evapotranspiration and crop coefficient. In: ALLEN, R.G.; VAN BAVEL, C.M.U. (Ed.). Management of irrigation and drainage systems: integrated perspectives. New York: ASCE, 1993. p.961-968.

MALEK, E.; BINGHAM, G.E.; McCurdy, G.D. Evapotranspiration from the margin and moist playa of a closed desert valley. Journal of Hydrology, v. 120, p. 15-34, 1990. 
MANSFIELD, T.A.; HETHRINGTON, A.M.; ATKINSON, C.J. Some current aspects of stomatal physiology. Annual Review of Plant Physiology and Plant Molecular Biology, v.41, p.55-75, 1990.

MARIN, F. R. Condutância à difusão de vapor e potencial da água de folhas de lima ácida (Citrus latifolia TANAKA) e suas relações com variáveis micrometeorológicas em um pomar. Piracicaba: ESALQ, 1998. 64p. (Relatório final da disciplina 011-601 Residência Agronômica. ESALQ/USP).

MARIN, F.R. Evapotranspiração, transpiração e balanço de energia em pomar de lima ácida "Tahiti". Piracicaba, 2000. 74p. Dissertação (Mestrado) - Escola Superior de Agricultura "Luiz de Queiroz", Universidade de São Paulo..

MARIN, F.R.; ANGELOCCI, L.R. Teste de um modelo para estimativa da condutância à difusão de vapor da cobertura vegetal em lima ácida "Tahiti" em pomar irrigado (compact disc). In: CONGRESSO BRASILEIRO DE AGROMETEOROLOGIA, Florianópolis, 1999. Anais. Florianópolis: SBA, 1999.

MARIN, F.R.; ANGELOCCI, L.R.; RIGHI, E.Z. Modelo simplificado para estimativa da resistência à difusão de vapor de árvores de lima ácida 'Tahiti'. Revista Brasileira de Agrometeorologia, v.9, n.2, p.227-233, 2001a.

MARIN, F.R.; ANGELOCCI, L.R.; SENTELHAS, P.C. Relações entre o saldo de radiação de pomar de lima ácida Tahiti, saldo de radiação de gramado e radiação solar global. Revista Argentina de Agrometeorologia. v.1, n.1, p.59-62, $2001 \mathrm{~b}$.

MARIN, F.R.; ANGELOCCI, L.R.; VILLA NOVA. N.A. Estimativa da transpiração máxima de lima ácida Tahiti com o modelo de Penman-Monteith. (compact disc) In: CONGRESSO BRASILEIRO DE METEOROLOGIA, Foz do Iguaçu, 2002. Anais. Foz do Iguaçu: SBMet, 2002a.

MARIN, F. R.; ANGELOCCI, L. R.; PEREIRA, A.R.; VILLA NOVA, N.A.; SENTELHAS, P.C. Sap flow and evapotranspiration in an irrigated citrus orchard. Revista Brasileira de Agrometeorologia, v.9, n.2, p.219-226, 2001c.

MARIN, F. R.; ANGELOCCI, L. R.; PEREIRA, A. R.; SENTELHAS, P. C.; VILLA NOVA, N. A. Balanço de energia e consumo hídrico em pomar de lima ácida 'Tahiti'. Revista Brasileira de Meteorologia. v.17, n.2, p.219 - 228, 2002b.

MARIN, F.R.; ANGELOCCI, L.R.; COELHO FILHO, M.A; VILLA NOVA, N.A. Construção e avaliação de psicrômetro aspirado de termopar. Scientia Agricola, v.58, n.4, p.839-844, 2001d.

MARIN, F.R.; RIGHI, E.Z.; SANTIAGO, A.W.; SENTELHAS, P.C.; PEREIRA, A.R. Estimativa da temperatura foliar e do balanço de energia de um gramado com um método iterativo. (compact disc) In: CONGRESSO BRASILEIRO DE METEOROLOGIA, v.11, Foz do Iguaçu, 2002. Anais. Foz do Iguaçu: SBMet, 2002c.

MARIN, F.R.; SANTIAGO, A.S.; RIGHI, E.Z.; SENTELHAS, P.C.; ANGELOCCI, L.R.; MAGGIOTTO, S.R.; PEZZOPANE, J.R.M. Solar radiation interception and its relation with transpiration in different coffee canopy layers. Revista Brasileira de Agrometeorologia, v. 11, n.1, 2003. /No prelo/.

MARSHAL, D.C. Measurement of sap flow in conifers by heat transport. Plant Physiology, v.33, n.6, p.385-396, 1958. 
MARUR, J.A.; ANDRIOCIOLI FILHO, A.; TSUKAHARA, R.Y.; MORAIS, H. Assimilação de $\mathrm{CO}_{2}$ em diferentes espaçamentos do cafeeiro IAPAR 59 (compact disc). In: SIMPÓSIO DE PESQUISA DOS CAFÉS DO BRASIL, 2., Vitória, 2001. Anais. Vitória: IAPAR: 2001.

MASSMAN, W.J. A surface energy balance for partitioning evapotranspiration data into plant and soil components for a surface with partial canopy cover. Water Resources Research, v.28, n.6, p.1723-1732, 1992.

MATIELlO, J.B. O Café: do cultivo ao consumo São Paulo: Globo, 1991. 320p.

MCNAUGHTON, K.G.; GREEN, S.R.; BLACK, T.A.; TYNAN, B.R.; EDWARDS, W.R.N. Direct measurement of net radiation and photosynthetically active radiation absorbed by a single tree. Agricultural Forest Meteorology, v.62, p.87-107, 1992.

MEIDNER, H.; MANSFIELD, T.A. Physiology of stomata. New York: MacGraw-Hill, 1968. $178 \mathrm{p}$.

MEYER, W.S.; GREEN, G.C. Comparison of stomatal action of orange, soybean and wheat under field conditions. Australian Journal of Plant Physiology, v.8, p.65-76, 1981.

MONTEITH, J.L. Evaporation and environment. Symposium of Society of Experimental Biology, v.19, p.205-234. 1965.

NAOR, A. Relations between leaf and stem water potentials and stomatal condutance in three field-grown woody. Journal of Horticultural Science \& Biotechnology, v.73, n.4, p.431436, 1998.

NOBEL, P.S. Physicochemical and environmental plant physiology. San Diego: Academic Press, 1999. 474 p.

NUTMAN, F.T. The root system of Coffea arabica. I. Root system in typical soils of British East Africa. Empire Journal of Experimental Agriculture, v.1, p. 271-284, 1933a.

NUTMAN, F.T. The root system of Coffea arabica. II. The effect of some soil conditions in modifying the 'normal' root system. Empire Journal of Experimental Agriculture, v.1, p. $285-296,1933$ b.

NUTMAN, F.T. The root system of Coffea arabica. III. The spatial distribution of the absorbing area of the root. Empire Journal of Experimental Agriculture, v.2, p. 293-302, 1934.

NUTMAN, F.T. Studies of the physiology of Coffea arabica: stomatal movements in relation to photosynthesis under natural conditions. Annals of Botany, v.1, n.4, p.681-693, 1937.

NUTMAN, F.J. Studies on the physiology of Coffea arabica L. III. Transpiration rates of whole trees in relation to natural environmental conditions. Annals of Botany, v.5, n.17, p.59-81, 1941.

OLIVEIRA, R.F. Water and energy flux in an urban landscape. Austin, 1994. 137p. Thesis (PhD.) - Texas A \& M University.

PALMER, J. Diurnal light interceptation and computer model of light interceptation by hedgerow-apple orcahrds. Journal of Applied Ecology, v.14, p.601-614, 1977.

PAULETTO, E.A. Determinação da condutividade hidráulica de solos a partir da curva de retenção de água. Piracicaba, 1986. 133p. Tese (Doutorado) - Escola Superior de Agricultura "Luiz de Queiroz", Universidade de São Paulo. 
PENMAN, H.L.; LONG, I.F. Weather in wheat: an essay in micro-meteorology. Quarterly Journal of the Royal Meteorological Society, v.86, p.17-50, 1960.

PEREIRA, A. B.; SENTELHAS, P. C.; VILLA NOVA, N. A. Estimativa do balanço de energia radiante em função de elementos climáticos. Revista Brasileira de Agrometeorologia. v.6, n.2, p.201-206, 1998.

PEREIRA, A.R.; VILLA NOVA, N.A.; SEDIYAMA, G.C. Evapo(transpi)ração. Piracicaba: FEALQ, 1997. 183p.

PEREIRA, A.R.; ANGELOCCI, L.R.; VILLA NOVA, N.A.; SENTELHAS, P.C. Estimating single tree net radiation using grass net radiation and tree leaf area. Revista Brasileira de Agrometeorologia, v.9, n.2, p.187-192, 2001.

PEREIRA, A.R.; MARIN, F.R.; ANGELOCCI, L.R.; VILLA NOVA, N.A.; SENTELHAS, P.C. Difficulties with micrometeorological methods in a small citrus orchards. Revista Brasileira de Meteorologia, v.18, n. 1, p. 13-20, 2003.

PEREIRA. L.S.; PERRIER, A.; ALLEN, R.G.; ALVES, I. Evapotranspiration: review of concepts and future trends. Journal of Irrigation and Drainage Engineering, v. 125, p.45$51,1999$.

PEREZ, P.J.; CASTELLVI, F; IBAÑEZ, M.; ROSELL, J.I. Assessment of reliability of Bowen ratio method for partitioning fluxes. Agricultural and Forest Meteorology, v.97, p.141$150,1999$.

PERRIER, A. Land surface processes: vegetation. In: EAGLESON, P.S. (Ed.). Land surface processes in atmospheric general circulation models. New York: Cambridge University Press, 1982. p. 395-448

PRUEGER, J.H.; HATFIELD, J.L.; SAUER, T.J. Surface energy balance partitioning over rye and oats cover crops in central Iowa. Journal of Soil and Water Conservation, v.53, n.3, p.263-268, 1998.

RAUPACH, M.R.; FINNIGAN, J. Single-layer models of evaporation form plant canopies are incorrect but useful, whereas multilayer models are correct but useless: discuss. Australian Journal of Plant Physiology, v.15, N.6, p. 705-716, 1988.

RENA, A.B.; MAESTRI, M. Ecofisiologia do cafeeiro. In: CASTRO, P.R.C.; FERREIRA, S.O.; YAMADA, T. Ecofisiologia da produção agrícola. Piracicaba: Potafos, 1987. p.119-145.

RIDER, N.E. Eddy diffusion of momentum, water vapour, and heat near the ground. Philosophical Transaction of Royal Society of London, v.246, p.481-492, 1954.

RIOU, C.; VALANCOGNE, C. PIERI, P. Une modèle simple d'interception du rayonnement solaire par la vigne - vérification expérimentale. Agronomie, v.9, p.441-450, 1989.

RITCHIE, J.E. Model for predicting evaporation from a row crop with incomplete cover. Water Resources Research, v.8, n.5, p.1204-1213, 1972.

SAKURATANI, T. A heat balance method for measuring water sap flow in the stem of intact plant. Journal of Agricultural Meteorology, v.39, n.1, p.9-17, 1981.

SCHMIDT, W. Radiation and evaporation from an open water surface, a contribution to the heat budget of the world oceans and to the water budget of the earth. Annals of Hydrological and Maritime Meteorology, v.43, p. 111-124, 1915. 
SENTELHAS, P.C.; NASCIMENTO, A.L.C. Saldo de radiação e sua relação com irradiância solar global, em Piracicaba, SP. In: CONGRESSO BRASILEIRO DE AGROMETEOROLOGIA, 12., Fortaleza, 2001. Anais. Fortaleza: SBA, 2001. p.255-256.

SHACKEL, K.A.; JOHNSON, R.S.; MEDAWAR, C.K. Substantial errors in estimates of sap flow using the heat balance technique on woody stems under field conditions. Journal of the American Society for Horticultural Science, v.117, n.2, p.351-356, 1992.

SHAW, R.H.; PEREIRA, A.R. Aerodynamic roughness of a plant canopy: a numerical experiment. Agricultural Meteorology, v.26, p.51-65, 1982.

SMITH, M. Report on expert consultation on procedures for revision of FAO methodologies for crop water requirements. Rome: FAO, 1991. 45p.

STEDUTO, P.; HSIAO, T.C. Maize under two soil water regimes. I. Diurnal patterns of energy balance, carbon dioxide flux, and canopy resistances. Agricultural and Forest Meteorology, v.89, n.3/4, p. 169-184, 1998.

STEINBERG, S.L.; McFARLAND, M.J.; WORTHINGTON, J.W. Comparison of trunk and branch sap flow with canopy transpiration in pecan. Journal of Experimental Botany, v. 41, n.227, p.653-659, 1990a.

STEINBERG, S.L.; VAN BAVEL, C.H.M.; McFARLAND, M.J. Improved sap flow gauge for woody and herbaceous plants. Agronomy Journal, v.82, p. 851-854, 1990 b.

STEWART, J.B. Modelling surface condutance of pine forest. Agricultural and Forest Meteorology, v.43, n.1, p. 19-35, 1988.

SYLVERSTEN, J.P.; LLOYD, J. J. Citrus. In: SCHAFFER, B.; ANDERSEN, P.C. Handbook of environmental physiology of fruit crops: sub-tropical and tropical crops. Boca Raton: CRC Press, 1994. v. 2, p.65-101.

TANNER, C.B. Energy balance approach to evapotranspiration from crops. Soil Science Society of America Proceedings, v.24, n.1, p.1-9, 1960.

THORNTHWAITE, C.W. An approach toward a rational classification of climate. Geographical Review, v. 38, p. 55-94, 1948.

THORPE, M.R. Net radiation and transpiration of apple trees in rows. Agricultural Meteorology, v.19, p.41-57, 1978b.

THORPE, M.R. Photosynthesis and transpiration of an isolated tree: model and validation. Plant, Cell and Environment, v.1, p.269-277, 1978a.

THORPE, M.R.; WARRIT, B.; LANDSBERG, J.J. Responses of apple leaf stomata: a model for single leaves and a whole tree. Plant, Cell and Environment, v.3, p. 23-27, 1980.

TREJO-CHANDRIA, J.E.; ANGELOCCI, L.R.; OLIVEIRA, R.F. Aplicação do método de balanço de calor na determinação da transpiração de mudas de limoeiro. Scientia Agricola, 54, n.3, p.221-231, 1997.

VALANCOGNE, C.; NASR, Z. A heat balance method for measuring sap flow in small trees. In: BORGHETTI, M.; GRACE, J.; RASCHI, A. (Ed.). Water transport in plants under climatic stress. Cambridge: Cambridge University Press, 1993. p. 166-173.

VAN BAVEL, C.H.M. Flow32 ${ }^{\text {TM }}$ Installation and operation manual. Houston: Dynamax Inc., 1999, 178p. 
VILLA NOVA, N.A. Estudos sobre o balanço de energia em cultura de arroz. Piracicaba, 1973. 78p. Tese (Livre-Docência) - Escola Superior de Agricultura "Luiz de Queiroz", Universidade de São Paulo.

WARRIT, B.; LANDSBERG, J.J.; THORPE, M.R. Responses of apple leaf stomata to environmental factors. Plant, Cell and Environment, v.3, n.1, p. 13-22, 1980.

WEIBEL, F.P.; de VOS, J.A. Transpiration measurements in apple trees: an improved stem balance heat method. Plant and Soil, v. 166, p.203-217, 1994.

WONG, W.C.; COWAN, I.R.; FARQUHAR, G.D. Stomatal condutance correlates with photosynthetic capacity. Nature, v. 282, p. 424-426, 1979.

YU, G.; NAKAYAMA, K.; MATSUOKA, N.; HISASHI, K. A combination model for estimating stomatal condutance of maize (Zea mays L.) leaves over a long term. Agricultural and Forest Meteorology, v.92, n.1, p.9-28, 1998.

ZHANG, H.; SIMMONDS, L.; MORISON, J.I.L.; PAYNE, D. Estimation of transpiration by single trees: comparison of sap flow measurements with a combination equation. Agricultural and Forest Meteorology, v.87, p.155-169, 1997. 
ANEXO 
Anexo 1. Programa utilizado no sistema automático de aquisição de dados para as medidas micrometeorológicas, de fluxo de seiva e para o cálculo da evapotranspiração pelo método da razão de Bowen.

$;$ CR7\}

;; programa utilizado para as medidas

; micrometeorológicas,

;; de fluxo de seiva e para o cálculo da

; evapotranspiração

; pela razão de Bowen. Marin, F.R. (2003).

*Table 1 Program

01: $1 \quad$ Execution Interval (seconds)

; temperatura do painel

1: Panel Temperature (P17)

1: 1 In Card

2: 2 Loc [ Tint ]

; vento baixo $(1.7 \mathrm{~m})$ com $014 \mathrm{~A}$

2: Pulse (P3)

1: 1 Reps

2: 1 In Card

3: 1 Pulse Input Channel

4: 22 Switch Closure, Output $\mathrm{Hz}$

5: 3 Loc [Vento_1_7]

6: .8 Mult

7: .447 Offset

; vento alto $(3.4 \mathrm{~m})$ com Wind Sentry

3: Pulse (P3)

1: 1 Reps

2: 1 In Card

3: 2 Pulse Input Channel

4: $11 \quad$ Low Level AC, Counts (Discard Bad Intervals)

5: 4 Loc [Vento_3_4]

6: .75 Mult

7:.2 Offset

; direcao do vento canal de exc. 1

4: Excite Delay Volt (SE) (P4)

1: 1 Reps

2: $185000 \mathrm{mV}$ Fast Range

3: 1 In Card

4: 1 SE Channel

5: 1 Ex Card

6: 1 Ex Channel

7: $1 \quad$ Meas/Ex

8: 2 Delay (units $0.01 \mathrm{sec}$ )

9: 5000 mV Excitation

10: 5 Loc [ Direcao ]

11: 071 Mult

12: 0 Offset

; radiacao global Li-Cor aferido

5: Volt (Diff) (P2)

1: 1 Reps

2: $3 \quad 15 \mathrm{mV}$ Slow Range

3: 1 In Card

4: 2 DIFF Channel

5: 6 Loc [RG ]

6: 107.3 Mult

7: 0.0 Offset

; saldo radiometro kipp zonen

6: Volt (Diff) (P2)

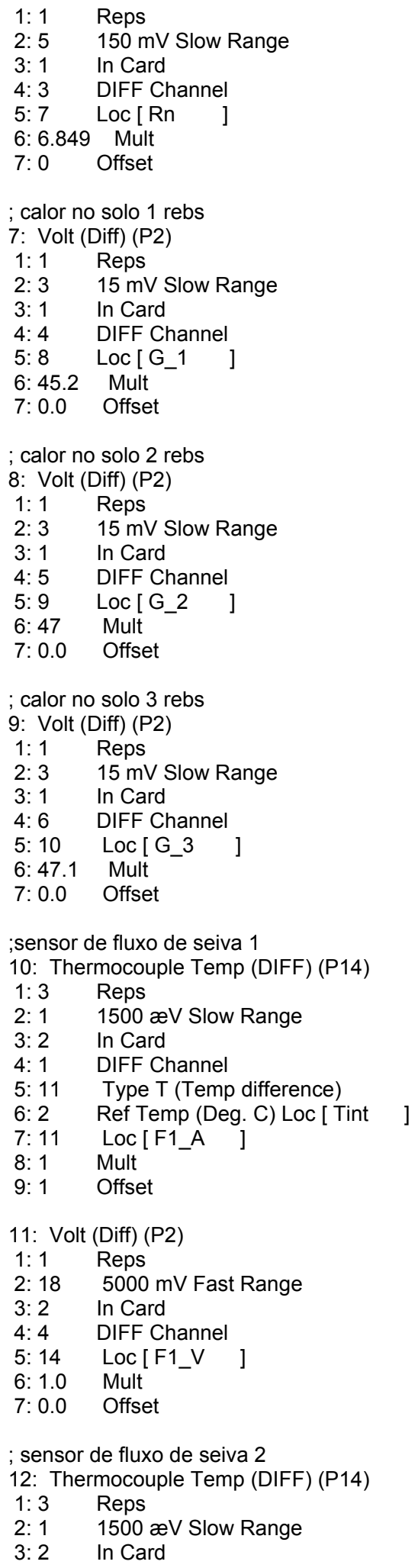




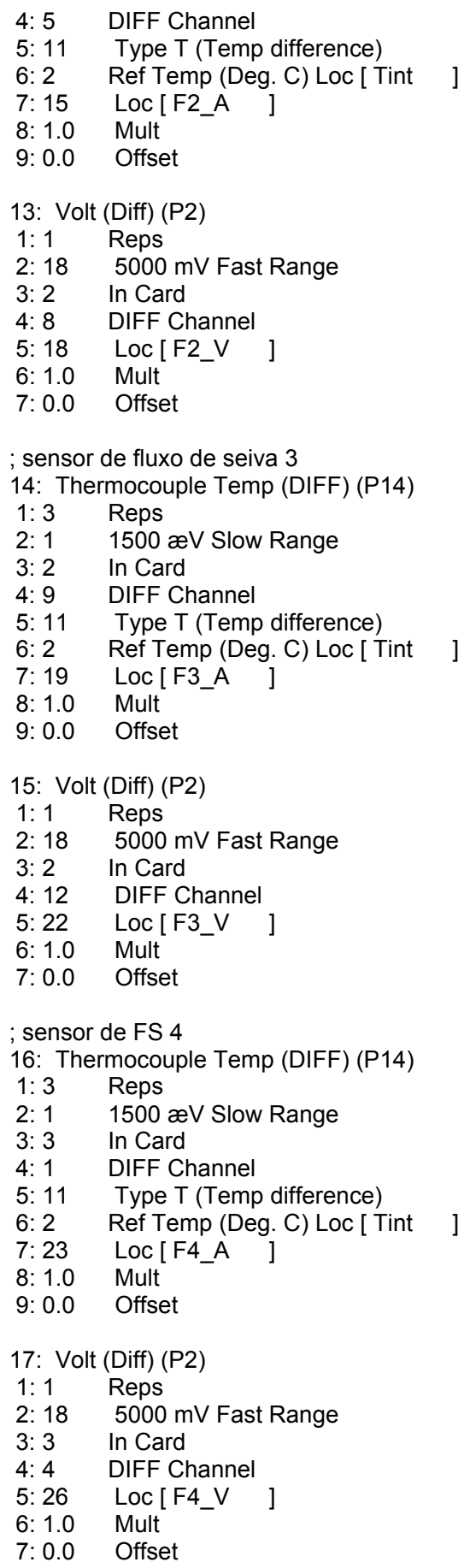

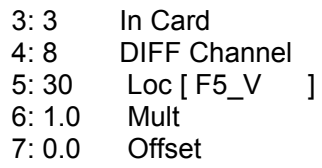

20: Thermocouple Temp (DIFF) (P14)

1: 4 Reps

2: $1 \quad 1500 æ V$ Slow Range

3: 4 In Card

4: 1 DIFF Channel

5: 1 Type T (Copper-Constantan)

6: 2 Ref Temp (Deg. C) Loc [ Tint

7: 31 Loc [Ts_34 ]

8: $1.0 \quad$ Mult

9: 0.0 Offset

21: Saturation Vapor Pressure (P56)

1: 31 Temperature Loc [ Ts_34]

2: 35 Loc [es_34 ]

22: Saturation Vapor Pressure (P56)

1: 33 Temperature Loc [ Ts_17 ]

2: 36 Loc [es_17 ]

23: $Z=F(P 30)$

1: $96 \quad F$

2: 42 Z LOC [ Patm ]

24: Wet/Dry Bulb Temp to VP (P57)

1: 42 Pressure Loc [ Patm ]

2: 31 Dry Bulb Loc [Ts_34]

3: 32 Wet Bulb Loc [ Tü_34]

4: 37 Loc [ea_34]

25: Wet/Dry Bulb Temp to VP (P57)

1: 42 Pressure Loc [ Patm ]

2: 33 Dry Bulb Loc [ Ts_17]

3: 34 Wet Bulb Loc [ Tü_17]

4: 38 Loc [ ea_17]

26: $Z=X / Y(P 38)$

1: $37 \quad X$ Loc [ ea_34]

2: 35 YLoc [es_34]

3: 39 Z LOC [ ur_34

27: $Z=X / Y(P 38)$

$\begin{array}{ll}\text { 1: } 38 & \text { X Loc [ ea_17 }] \\ \text { 2: } 36 & \text { Y Loc [ es_17 ] } \\ \text { 3: } 40 & \text { Z LOC [ ur 17 }\end{array}$

; razao de Bowen

28: $Z=X+Y(P 33)$

1: $32 \quad X$ Loc [Tu_34]

2: 34 Y Loc [Tu_17]

3: 41 Z LOC [ Tümed]

29: $Z=X * F(P 37)$

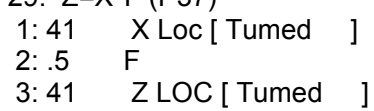

30: If $(X<=>F)(P 89)$

1: $41 \quad X$ Loc [ Tumed ]

2: $3 \quad>=$

3: $16.1 \quad \mathrm{~F}$

4: 30 Then Do

31: $Z=X^{*} F(P 37)$

1: $41 \quad X$ Loc [ Tumed ]

2: $0145 \mathrm{~F}$

3: 43 Z LOC [W ]
19: Volt (Diff) (P2)

2: $185000 \mathrm{mV}$ Fast Range 
32: $\mathrm{Z}=\mathrm{X}+\mathrm{F}(\mathrm{P} 34)$

1: 43 X Loc [W
2: 0.407 F
3: $43 \quad$ Z LOC [W

33: Else (P94)

$$
\begin{aligned}
& \text { 34: } Z=X^{*} F(P 37) \\
& \text { 1: } 41 \quad X \text { Loc [ Tumed ] } \\
& \text { 2: } 0.01 \quad F \\
& \text { 3: } 43 \text { Z LOC [W ] } \\
& \text { 35: } \mathrm{Z}=\mathrm{X}+\mathrm{F}(\mathrm{P} 34) \\
& \text { 1: } 43 \quad X \text { Loc [W] } \\
& \text { 2: } .483 \quad \mathrm{~F} \\
& \text { 3: } 43 \quad \text { Z LOC [W ] }
\end{aligned}
$$

36: End (P95)

37: Z=X-Y (P35)

$\begin{array}{ll}\text { 1: } 31 & \text { X Loc [Ts_34 ] } \\ \text { 2: } 33 & \text { Y Loc [Ts_17 ] } \\ \text { 3: } 44 & \text { Z LOC[DeltaTs }]\end{array}$

38: $Z=X-Y(P 35)$

1: $32 \quad X$ Loc [Tu_34 ]

3: 45 Z LOC [ DeltaTu ]

39: $\mathrm{Z}=\mathrm{X}+\mathrm{F}(\mathrm{P} 34)$

1: $43 \quad X$ Loc $[\mathrm{W}]$

2: $-1 \quad F$

3: 54 Z LOC [ Fator1]

40: $Z=X^{*} F(P 37)$

1: $54 \quad X$ Loc [ Fator1 ]

2: $-1 \quad F$

3: 54 Z LOC [ Fator1]

41: $Z=X^{*} Y(P 36)$

1: $54 \quad X$ Loc [ Fator1]

2: $44 \quad$ Y Loc [ DeltaTs ]

3: 55 Z LOC [ Fator2]

42: $Z=X / Y(P 38)$

1: $45 \quad X$ Loc [ DeltaTu ]

2: $55 \quad$ Y Loc [ Fator2 ]

3: 56 Z LOC [ Fator3]

43: $Z=X+F(P 34)$

1: $56 \quad X$ Loc [ Fator3 ]

2: $-1 \quad F$

3: 57 Z LOC [ Fator4 ]

44: $Z=1 / X(P 42)$

1: $57 \quad X$ Loc [ Fator4 ]

2: $46 \quad$ Z LOC [ Beta ]

; energia radiante disponivel

45: $Z=X+Y(P 33)$

1: $8 \quad X$ Loc [G_1 ]

2: 9 Y 4 Z LOC [ [ Gmedio

46: $Z=X+Y(P 33)$

1: $47 \quad X$ Loc [ Gmedio ]

2: 10 Y Loc [G_3 ]

3: $47 \quad$ Z LOC [ Gmedio ]

47: $Z=X^{*} F(P 37)$

1: $47 \quad X$ Loc [ Gmedio ]

2: $.33333 \mathrm{~F}$

3: 47 Z LOC [ Gmedio ]

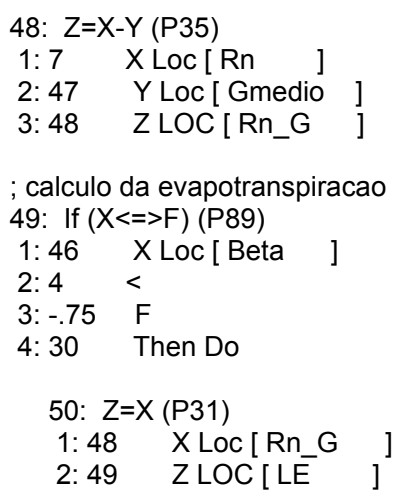

51: Else (P94)

52: $Z=X+F(P 34)$

1: $46 \quad X$ Loc [ Beta ]

2: $1 \quad F$

3: 58 Z LOC [ Fator5]

53: $Z=X / Y(P 38)$

1: 48 X Loc [Rn_G]

2: $58 \quad Y$ Loc [ Fator5]

3: 49 Z LOC [ LE ]

54: End (P95)

55: $\mathrm{Z}=\mathrm{F}(\mathrm{P} 30)$

1:.00001 $\mathrm{F}$

2: 59 Z LOC [ FatorMJ ]

56: $Z=X^{\star} F(P 37)$

1: $59 \quad X$ Loc [ FatorMJ ]

2: .1 F

3: 59 Z LOC [ FatorMJ ]

57: $Z=X / Y(P 38)$

1: $49 \quad X$ Loc [ LE ]

2: 59 Y Loc [ FatorMJ ]

3: $51 \quad$ Z LOC [ LEMJ ]

58: $Z=X / Y(P 38)$

$\begin{array}{ll}1: 7 & \text { X Loc [Rn ] } \\ 2: 59 & \text { Y Loc [ FatorMJ ] }\end{array}$

3: 50 Z LOC [RnMJ ]

59: $Z=X / Y(P 38)$

1: $47 \quad X$ Loc [ Gmedio ]

2: $59 \quad \mathrm{Y}$ Loc [ FatorMJ ]

3: $52 \quad$ Z LOC [ GmedioMJ ]

60: $Z=X / Y(P 38)$

$\begin{array}{ll}1: 6 & X \text { Loc [ RG ] } \\ \text { 2: } 59 & \text { Y Loc [ FatorMJ ] }\end{array}$

3: 53 Z LOC [RGMJ ]

61: Battery Voltage (P10)

1: 1 Loc [ Bateria ]

;gravacao dos dados a cada 15 minutos 62: If time is (P92)

1: $0 \quad$ Minutes into a

2: 15 Minute Interval

3: 10 Set Output Flag High

63: Real Time (P77)

1: 1110 Year,Day,Hour/Minute $($ midnight $=0000)$

64: Average (P71) 


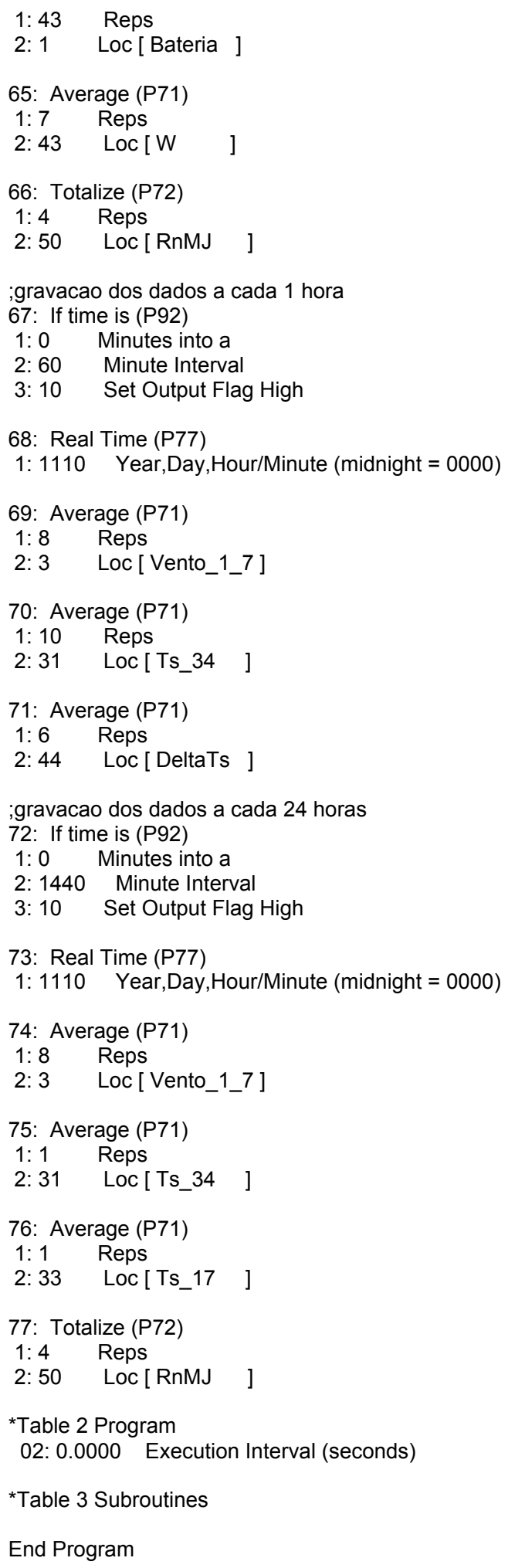

-Input Locations-

1 Bateria 111

2 Tint 171

3 Vento_1_7 131

4 Vento_3_4 131

5 Direcao 131

$6 \mathrm{RG} \quad 141$

$7 \mathrm{Rn} \quad 151$

8 G 1141

$9 \mathrm{G}^{-} 2 \quad 141$

$10 \mathrm{G} 3 \quad 141$

11F1_A 511

12F1 B 911

13 F1_C 1711

$14 \mathrm{~F} 1 \mathrm{~V} \quad 111$

15 F2_A 511

$16 \mathrm{~F} 2 \mathrm{~B} \quad 911$

17 F2_C 1711

$18 \mathrm{~F} 2 \mathrm{~V} \quad 111$

19 F3_A 511

20 F3_B 911

$21 \mathrm{~F} 3 \mathrm{C} \quad 1711$

$22 \mathrm{~F} 3 \mathrm{~V} \quad 111$

$23 \mathrm{~F} 4 \mathrm{~A} \quad 511$

$24 \mathrm{~F} 4 \mathrm{~B} \quad 911$

$25 \mathrm{~F} 4 \mathrm{C} \quad 1711$

$26 \mathrm{~F} 4$ _V 111

$27 \mathrm{~F} 5 \mathrm{~A} \quad 511$

28 F5 B 911

$29 \mathrm{~F} 5 \mathrm{C} \quad 1711$

$30 \mathrm{F5}$ - 111

31 Ts $34 \quad 561$

$32 \mathrm{Tu}^{-34} 951$

33 Ts $17 \quad 961$

$34 \mathrm{Tu}^{-17} 1751$

35 es $34 \quad 131$

36 es_17 131

37 ea_34 131

38 ea_17 131

39 ur_34 121

40 ur_17 121

41 Tumed 152

42 Patm 131

$43 \mathrm{~W} \quad 154$

44 DeltaTs 131

45 DeltaTu 131

46 Beta 141

47 Gmedio 163

$48 \mathrm{Rn} \mathrm{G} \quad 141$

49 LE 132

50 RnMJ 121

51 LEMJ 121

52 GmedioMJ 121

53 RGMJ 121

54 Fator1 122

55 Fator2 111

56 Fator3 111

57 Fator4 111

58 Fator5 111

59 FatorMJ 152

-Program Security-

0000

0000

0000 